\title{
ACCOUNT(ING)/(ABILITY): DEMOCRATISING THE ENVIRONMENTAL IMPACT ASSESSMENT IN MONGOLIAN MINING
}

\author{
BY \\ DANAASUREN VANDANGOMBO
}

\begin{abstract}
A thesis
submitted to the Victoria University of Wellington in fulfillment of the requirements for the degree of

Doctor of Philosophy in Accounting
\end{abstract}

Victoria University of Wellington (2012) 



\begin{abstract}
This study examines sustainable development in practice, particularly in the context of mining and environmental management in a less developed country (LDC). It argues for sustainable and participatory mining in LDCs, such as Mongolia, by encouraging democratisation of the environmental impact assessment (EIA) process.

The EIA, a major tool of environmental management, addresses the negative environmental and social impacts of development projects, such as mining, and has the capacity to mitigate such impacts by incorporating EIA recommendations into business practice. To ensure the inclusion of affected communities in the EIA process, public participation in EIAs is legislated in many countries. This is particularly important for mineral-rich LDCs, as they have experienced growing conflict among mining companies, local communities, and government authorities, due to a lack of dialogue among mining constituents and a lack of effective public policy and public engagement in the promotion of socially and environmentally accountable mining.

This study applies Brown's (2009) dialogic accounting framework in the exploration and evaluation of current EIA practices. By using Mongolian EIA practices for illustrative purposes, this study seeks to contribute to debate in EIA and SEA literature, and to support calls for more participatory EIAs that can embed sustainable development into business practice. Furthermore, the current and potential engagement of NGOs in the EIAs of Mongolia is examined in order to explore their potential to foster dialogic accounting.
\end{abstract}

Keywords: dialogic accounting, accountability, EIA, NGO, mining 
This doctoral thesis is dedicated to my father Professor Vandangombo Radnaasumberel 


\section{Acknowledgements}

First and foremost I wish to thank my supervisors, Professor Trevor Hopper and Professor Judy Brown. It has been a privilege to have them as supervisors. They have taught me through frequent discussions and advice how to think more critically, and how to conduct and deliver research. I have been particularly amazed by their patience when reading my numerous drafts, written in halting English, and their surprisingly prompt reviews and replies. My supervisors have guided me in a non-threatening, empathetic way on my research path, assisting me with compliance of administrative requirements, and offering timely words of encouragement and advice during the many ups and downs of this $\mathrm{PhD}$ study. I appreciate their belief in me, their time, advice, encouragement, and patience, which have been so motivational and inspiring. They have set an excellent example as supportive, knowledgeable professors.

I am also thankful to Professor Tony van Zijl and Professor Keitha Dunstan, my previous supervisors, who assisted me to explore the literature of many disciplines and to develop my research interest. I am very grateful to the New Zealand Development Scholarship, which provided the generous funding to help me pursue my PhD study. I am very thankful to the Victoria International Student Advisors, Ms Julia Harrison, Ms Inge De Leeuw and Ms Bridget Nankivell for their great understanding and support, enabling me to successfully complete this study.

During my study I have received much generous assistance and advice - notably from Professor Amanda Ball, Professor John Roberts, Professor Rob Gray, Professor Jesse Dillard, Professor Peter Söderbaum, Professor Ian Thomson, Professor Rosemary J. Coombe, Professor John Overton, Dr David Carter, Dr Michael Fraser, Dr Helen Tregidga, Dr Thu Phuong Truong, Mr Pala Molisa, Dr Jenny Alves, Ms Vanessa Borg, Dr Prae Keerasuntonpong, and many other professors and colleagues at the School of Accounting and Commercial Law at Victoria University of Wellington, and School of Economic Studies at Mongolian National University. I extend my warm and grateful thanks to them all.

I owe loving thanks to my family for all their care, encouragement, and support, particularly my parents, Professor Vandangombo Radnaasumberel and Gantogoo Suidaan, who by their examples, raised me to become a full scholar, and supported me in all my pursuits. I am also grateful to my brother, Undrakh-Erdem Vandangombo, my uncles, Professor Gonchigdorj Radnaasumberel and Professor Rinchinbazar Ravsal, and friends, Mr Enkhbayar Chimedkhorol and many others, who provided invaluable support and encouragement throughout my $\mathrm{PhD}$ study. I also thank my friends, Mr John Deverall and Ms Philippa Woodcock, for their patience and proofreading of my thesis. I owe sincere gratitude to my friend, Ms Nora Munkhuu, and her daughter, Duka, who have been so close to me from the beginning of my study in New Zealand. Ms Nora has always been helpful and encouraging, and showed much kindness during difficult moments in my study. 
This thesis is not only the outcome of my own passion and industry, but also the result of support and encouragement from my supervisors, professors, colleagues, friends, and family. 


\section{Table of Contents}

Acknowledgements

Chapter 2: A CALL FOR ECONOMICALLY SUSTAINABLE AND

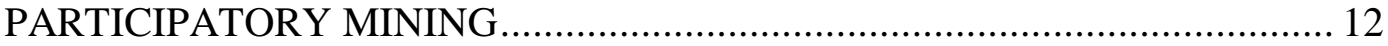

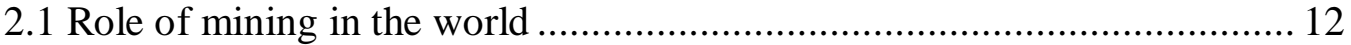

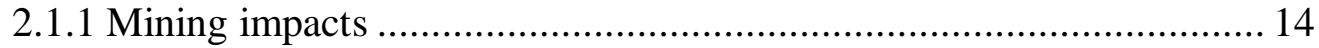

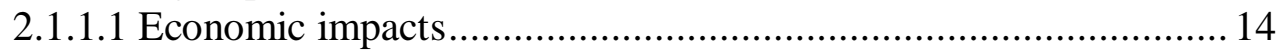

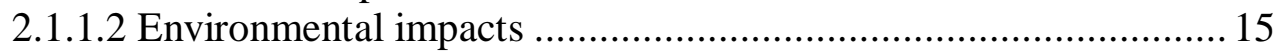

2.1.1.3 Social, cultural and political impacts ...................................... 18

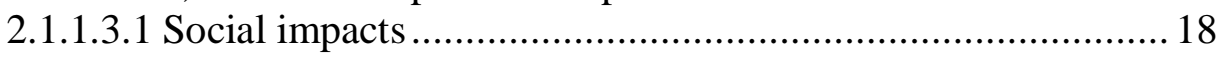

2.1.1.3.2 Cultural impacts ........................................................... 20

2.1.1.3.3 Political impacts ........................................................... 20

2.1.2 A call for economically sustainable mining .................................. 24

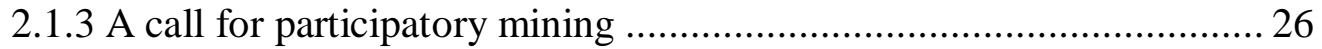

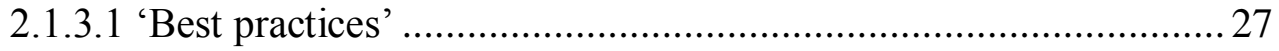

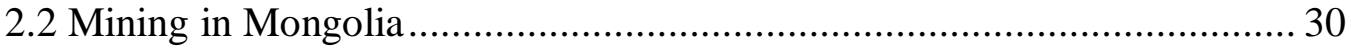

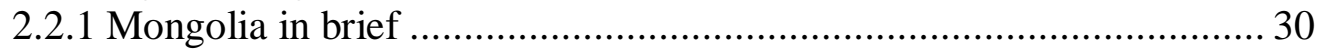

2.2.2 Economic, social, and political contexts ......................................... 30

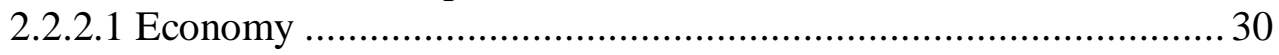

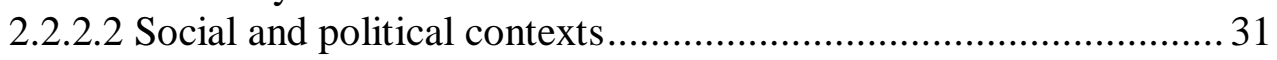

2.2.2.3 Social and political issues ...................................................... 34

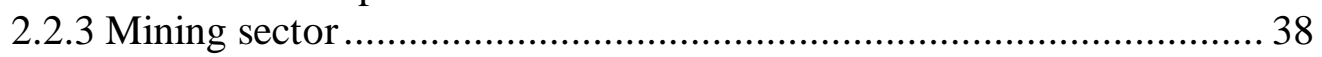

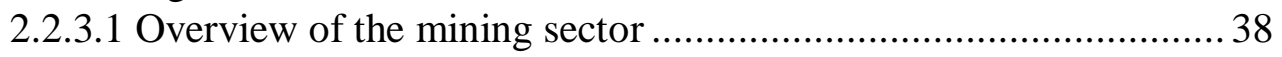

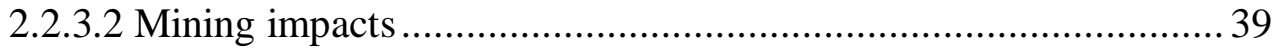

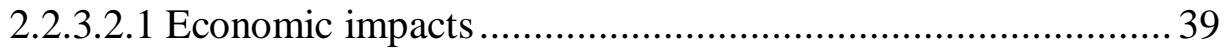

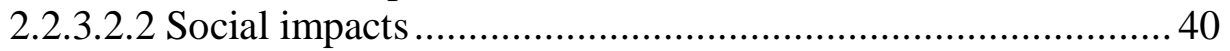

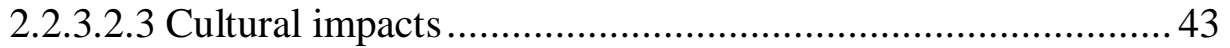

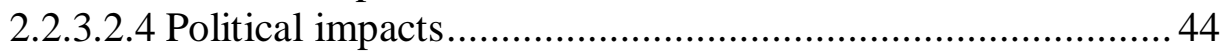

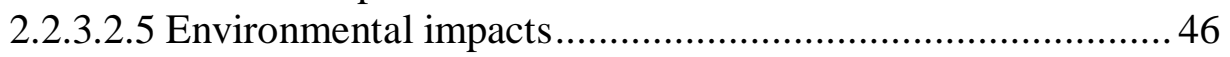

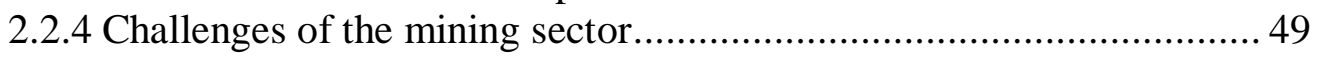

Chapter 3: AN ENVIRONMENTAL IMPACT ASSESSMENT AS A

POTENTIAL DIALOGIC ACCOUNTING TOOL ..................................... 53

3.1 Dialogic accounting for sustainability ................................................ 53

3.1.1 Introduction to social and environmental accounting .......................53

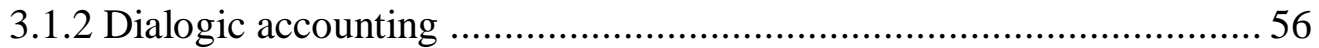




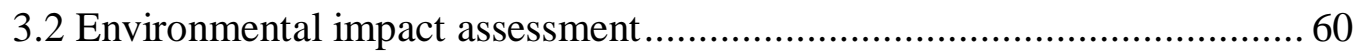

3.2.1 Literature on environmental impact assessment ................................. 60

3.2.1.1 Development of environmental impact assessment ......................60 60

3.2.1.2 Criticism of the EIA as a monologic tool and process..................63 63

3.2.1.3 The EIA as a participatory decision-making tool........................67

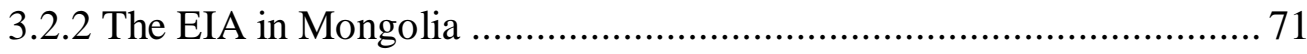

3.2.2.1 Overview of the environmental legislative framework ................ 71

3.2.2.2 EIA procedures ................................................................... 73

3.2.2.3 The state of the EIA in the mining sector .................................. 77

Chapter 4: NGOs AS PROMOTERS AND FACILITATORS OF

PARTICIPATORY DEMOCRACY AND DIALOGUE ................................ 81

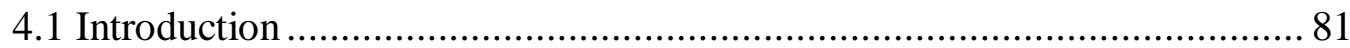

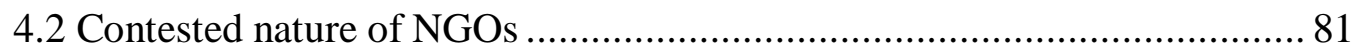

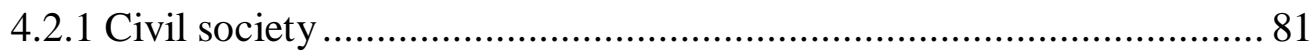

4.2.2 Definition and classification of NGOs ......................................... 83

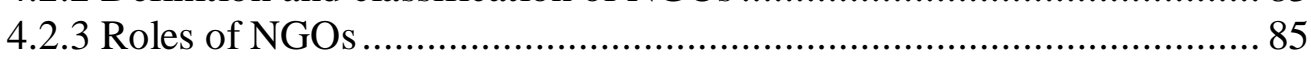

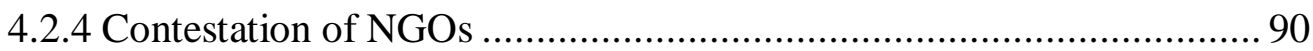

4.3 NGOs as promoters and facilitators of dialogue ..................................... 95

4.3.1 NGOs as 'agents' of democracy and participation ........................... 95

4.3.2 NGO engagement in environmental issues ....................................... 98

4.3.3 NGOs as promoters and facilitators of dialogue in mining ............... 101

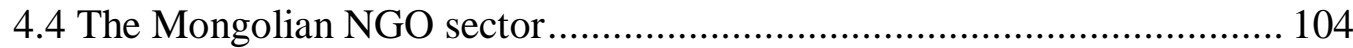

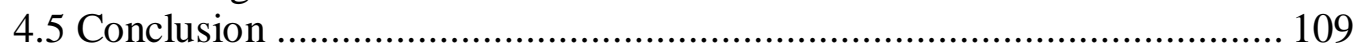

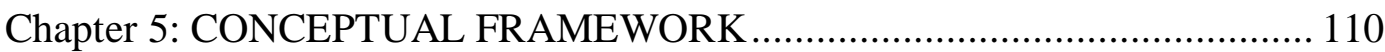

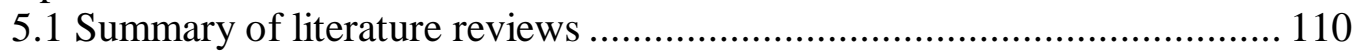

5.1.1 Importance of environmental concerns ........................................ 110

5.1.2 A call for participatory decision-making .................................... 112

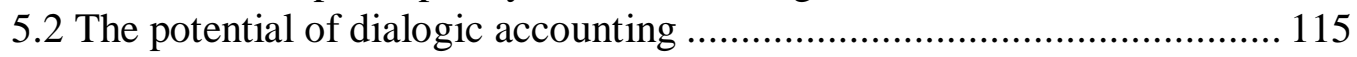

5.2.1 Challenges to technocracy ........................................................... 115

5.2.2 Participatory democracies as a means to participatory environmental decision-making .............................................................. 118

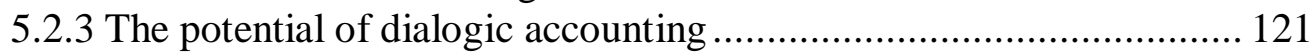

5.2.4 The EIA as a tool ....................................................................... 124

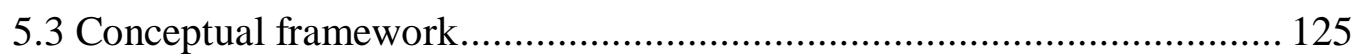

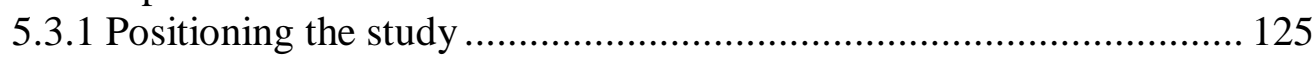

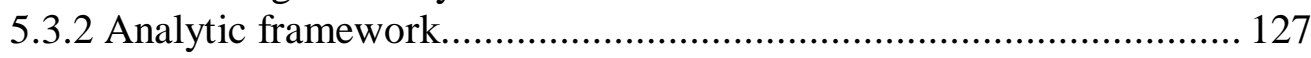

5.3.3 EIA constituents........................................................................... 138

5.3.4 NGOs as promoters and facilitators of a dialogic tool ...................... 141

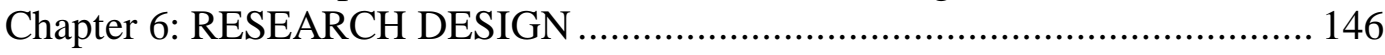

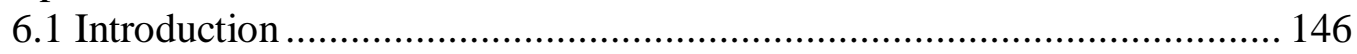

6.2 Research objectives and questions ................................................... 146

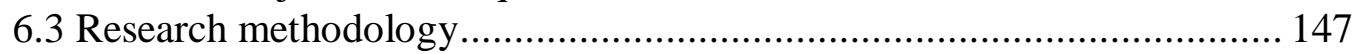

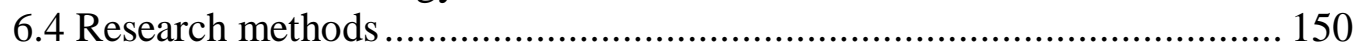

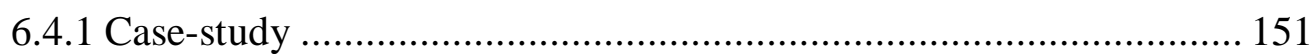

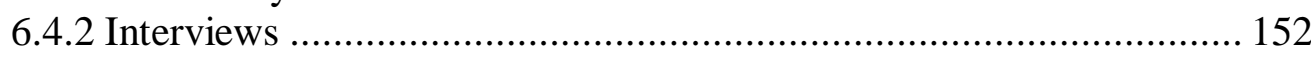

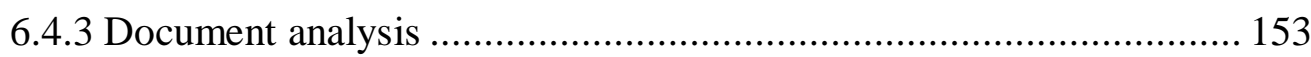

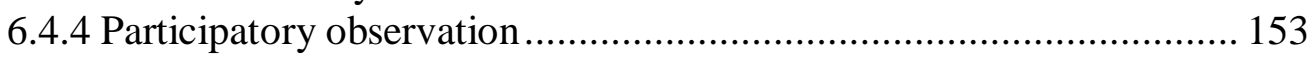




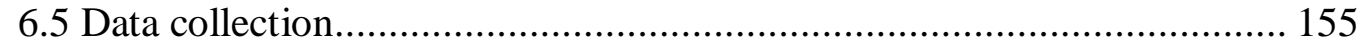

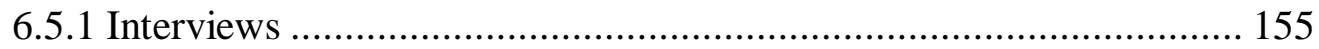

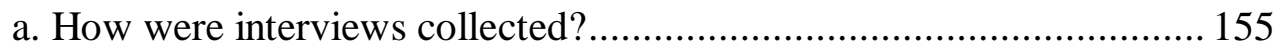

b. What was collected? ................................................................... 156

c. What difficulties were encountered? ............................................ 158

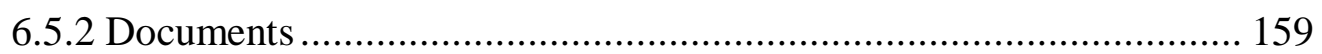

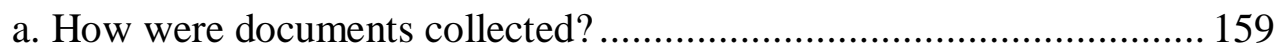

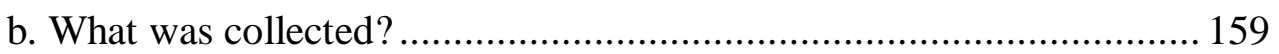

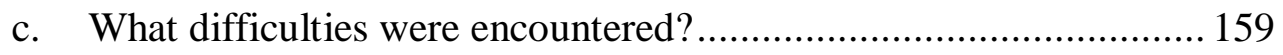

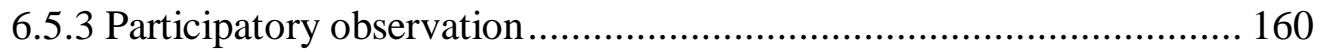

a. How was participatory observation conducted? .............................. 160

b. What difficulties were encountered? ................................................ 163

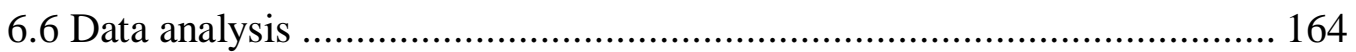

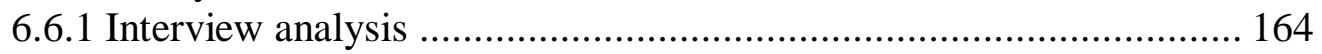

6.6.2 Document analysis .................................................................. 165

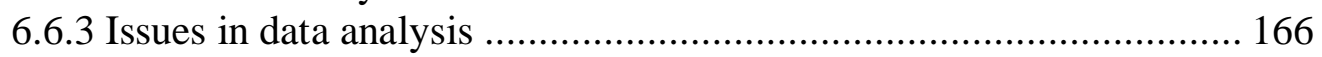

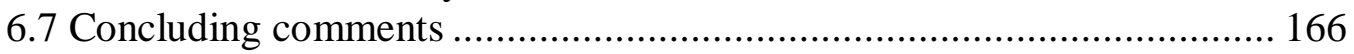

Chapter 7: MONGOLIAN EIA PRACTICE............................................... 168

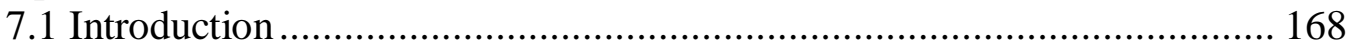

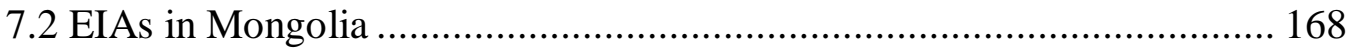

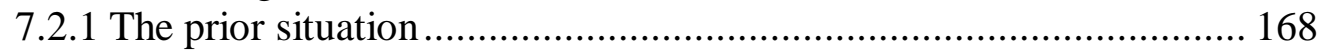

7.2.2 What has worked and what has not.............................................. 171

7.2.3 Different perspectives among constituents..................................... 173

7.3 The analytical framework analysis of Mongolian EIA practice .............. 180

7.4 The potential of dialogic EIAs ............................................................. 216

7.4.1 Deficiencies of monologic EIAs ................................................. 216

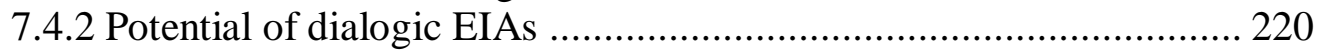

7.4.3 EIA as a space/tool/process ................................................... 221

7.5 How to transition from monologic to dialogic ..................................... 224

7.5.1 What to change, and by whom?..................................................... 224

7.5.2 How to transition from monologism towards dialogic EIAs? ........... 225

7.6 Limitations of dialogic EIAs and barriers to transformation ................... 231

7.6.1 Barriers for EIA constituents ......................................................... 231

7.6.2 Dangers of a new type of monologism......................................... 233

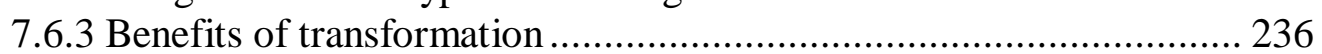

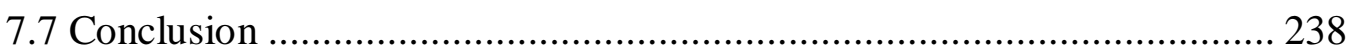

Chapter 8: MONGOLIAN ENVIRONMENTAL NGOs ............................... 240

8.1 Introduction ................................................................................. 240

8.2 Mongolian NGO practice ................................................................. 240

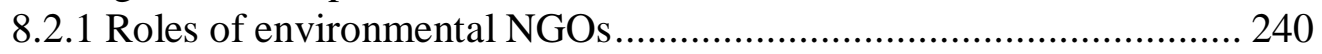

8.2.2 Two case-studies of environmental and mining NGOs ................... 243

8.2.2.1 A challenger NGO - Onggi River Movement........................... 243

8.2.2.2 A cooperative NGO - the Responsible Mining Initiative............ 253

8.2.3 Challenges for Mongolian NGOs ................................................... 259

8.3 The potential of NGOs to promote dialogic EIAs ................................. 269

8.3.1 Current NGO engagement in EIAs .............................................. 269

8.3.2 Potential roles of NGOs among EIA constituents ......................... 272 
8.3.3 Plurality of NGOs and promotion of the dialogic EIA ................... 274

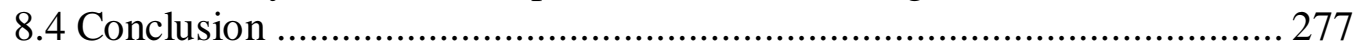

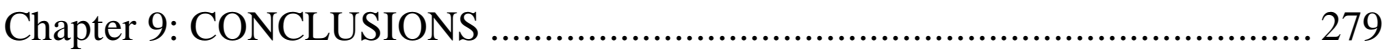

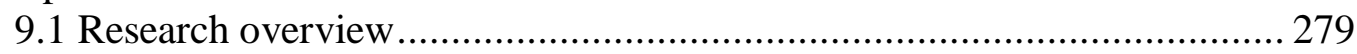

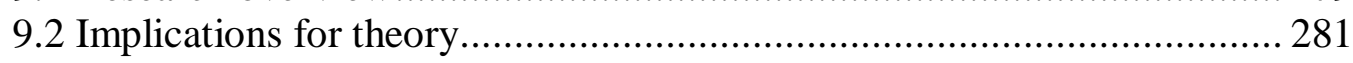

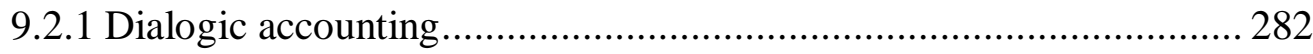

9.2.2 Environmental impact assessment ............................................. 283

9.3 Implications for Mongolian EIA practice ......................................... 286

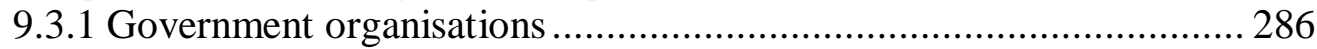

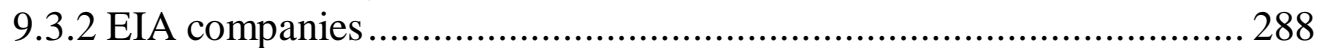

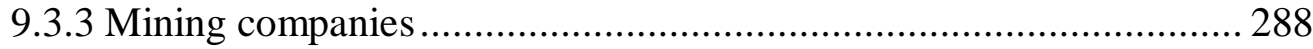

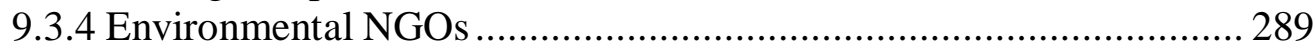

9.3.5 Affected communities .................................................................. 290

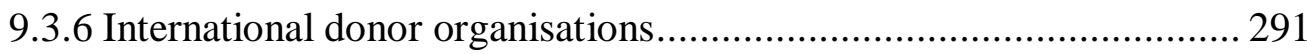

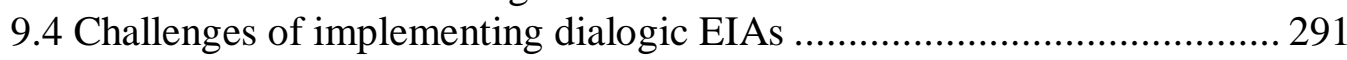

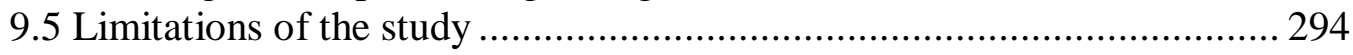

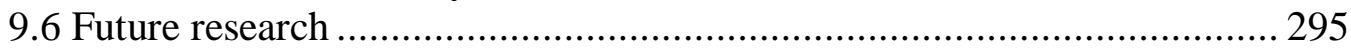

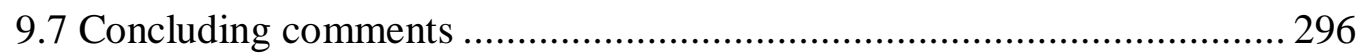

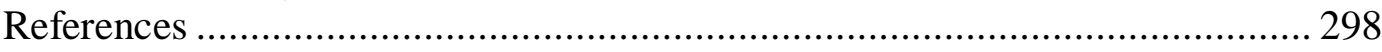

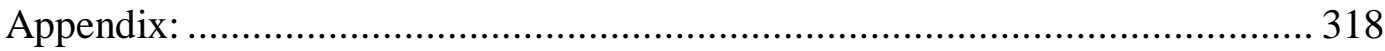




\section{List of Tables}

Table 1. Statistics on the Environmental Impact Assessment, 1998-2007 77

Table 2. Monologic and dialogic approaches to EIAs as a tool, and associated processes 130

Table 3. NGO strategies and implications for participatory democracy 144

Table 4. Demographic details of interviews 157

Table 5. Challenges of Mongolian NGOs 260

Table 6. Participatory democracies and the potential of NGOs to promote and facilitate dialogic EIAs. 276 


\section{List of Figures}

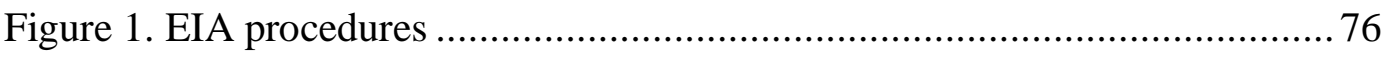

Figure 2. Numbers of Mongolian environmental NGOs by their functions in 2010

107

Figure 3. The EIA as a tool and process for participatory mining, environmental management and accounting 125

Figure 4. Relationship of EIA constituents with an engaged NGO ................... 140

Figure 5. Major operating mines and mineral deposits.................................. 170

Figure 6. Quality assurance of the EIA ...................................................... 189

Figure 7. Power relations and issues among EIA constituents..........................2204

Figure 8. Mongolian social and political context .......................................... 213

Figure 9. Engagement of NGOs with other EIA constituents ......................... 273 


\section{List of Abbreviations}

\begin{tabular}{ll} 
ADB & Asian Development Bank \\
CSR & Corporate social responsibility \\
EIA & Environmental impact assessment \\
HEC & Human Ethics Committee \\
IMF & International Monetary Fund \\
LDCs & Less developed countries \\
LRK & Local representative khural (or meeting) \\
MNET & Ministry of Nature, Environment and Tourism \\
MPs & Members of parliament \\
NGO & Non-governmental organisation \\
NIMBY & Not in my backyard \\
ORM & Onggi River Movement NGO \\
NGO & \\
RMI & Responsible Mining Initiative NGO \\
NGO & \\
SEA & Social and environmental accounting \\
SSIA & State Specialised Inspection Agency \\
TAF & The Asia Foundation \\
UMMRL & United Movements of Mongolian Rivers and Lakes \\
UN & United Nations \\
UNDP & United Nations Development Programme \\
VUW & Victoria University of Wellington \\
WWF & World Wildlife Fund \\
\hline
\end{tabular}




\section{Statement of Originality}

This is to certify that the work contained in this thesis has never previously been submitted for a degree or diploma in any university and that, to the best of my knowledge and belief, the thesis contains no material previously published or written by another person except where due reference is made in the thesis itself.

Danaasuren Vandangombo

24 January 2012 


\section{Chapter 1: INTRODUCTION}

This multi-disciplinary study examines environmental management, social and environmental accounting (SEA), mining, and non-governmental organisations (NGOs). It argues for sustainable and participatory mining in less developed countries (LDCs), such as Mongolia, by encouraging democratisation of the environmental impact assessment process. Dialogic accounting is explored as a potential accounting project for facilitating this process, given its critical pluralist roots and capacity to foster participatory democracy in relation to sustainable development (Bebbington, Brown, Frame, \& Thomson, 2007; Brown, 2009; Dillard \& Roslender, 2011).

This chapter explains my motivations for undertaking the study, briefly discusses the scope of the study, identifies the research aims and objectives, and outlines the organisation of the thesis.

\subsection{Research motivations}

I had several motivations for undertaking this study. Personally, I support initiatives that apply sustainable development in practice, believing that this can lead to changes in both social and business values. Being a Mongolian, I wish to make a contribution to my country, and I regard this $\mathrm{PhD}$ research as an opportunity to make such a contribution. Accordingly, I have explored ways of promoting sustainable development in the Mongolian mining sector. I also wished to combine the study of mining and sustainability issues with accounting, as I see accounting as an important tool in the endeavour to operationalise sustainabilityoriented changes in business.

Sustainable development - the idea of balancing economic and social development along with consideration for the state of the natural environment for future generations (UNWCED, 1987) - has been widely encouraged around the world. However, it is important to emphasise that this is not a totally new idea. In Mongolia, ideas of social equity, future generations, and the need to respect nature have influenced the social values and norms of Mongolians for centuries, as 
Mongolian nomadic culture is closely interrelated with the natural environment. By defining and conceptualising sustainable development, the United Nations has reintroduced or reminded countries about their traditional goals and values in this 'money-oriented' era that overemphasises economic growth. Thus, I welcomed sustainable development, and wished to conduct research that would help apply it to Mongolian business practice. The mining sector was chosen for this reason.

The study focuses on the environmental impact assessment (EIA) as an environmental management tool which aims to mitigate the negative environmental and social impacts of mining. In spite of enthusiasm by economists for mining as an income generator, mining-related social and environmental impacts have been increasingly questioned by communities around the world as well as in Mongolia.

Since Mongolia's democratic revolution of 1990, Mongolia has been in transition from an authoritarian communist regime, with a centrally-planned economy, to a democracy with an open-market economy. Political and institutional changes, and economic liberalisation have created a boom in mining. Mining has dramatically increased because of the introduction of mining legislation, intended to attract foreign investors by promising favourable mining conditions, such as a 'first come, first served' approach and tax-holiday incentives. As mineral deposits are distributed throughout Mongolia, many regions are affected by mining operations.

With the increase of mining activities, the negative impacts on society and the natural environment have become more evident. Traditionally, Mongolia's unique nomadic culture has been found throughout the vast steppes and has emphasised living in harmony with nature. Not surprisingly, poor mining practice and environmental degradation have antagonised local communities. In response, these communities have formed environmental and social NGOs to challenge the irresponsible behaviour of mining companies, and to seek better management of mining and greater accountability from government (Snow, 2010).

Globally, mining companies are also under increasing social pressure to consider their impacts and to operate in a socially responsible manner. There are various 
voluntary initiatives in the mining sector aimed at preserving their "social licence to operate". For LDCs with rich mineral resources it is particularly important to have rigorous planning and management of mining development. The mining practices of many LDCs show that poorly managed mining can result in serious environmental, social, and economic problems (MMSD, 2001). Once environmental degradation and other problems occur, it will be too late to reverse them. As the Mongolian proverb states, there is "no need to put on a raincoat after the rain". Therefore, I decided to pursue mining issues from the environmental management perspective in the hope it may have the potential to counter the adverse effects of mining.

Another reason for undertaking this study relates to the accounting discipline. As accounting is regarded as the language of business, it can both reflect and influence business values and ways of doing business. Arguably, accounting can and does play an important role in the 'greening' of business and in developing various applications that could promote sustainable development.

SEA researchers have actively initiated and engaged in discussions surrounding accountability, sustainability, and corporate social responsibility related initiatives and reporting practice. Dialogic accounting, an emerging SEA project, attracted my attention because of its promotion of multi-stakeholder dialogic engagement that could foster both accountability and sustainability. Thus I sought to conduct this study, which bridges SEA, mining, and the EIA, to address sustainability challenges.

All these personal values, love of my country, and research curiosity have motivated this study.

\subsection{Scope of the research}

This is a multi-disciplinary study relating to SEA, mining, environmental management, and civil society. The primary focus is on exploring potential ways of improving the accountability of mining practices in LDCs, such as Mongolia. 
Concepts of sustainable development have provided a major impetus for reflecting on and seeking to change organisational and societal values through various disciplines, such as accounting and environmental management. This is often referred to as a paradigm shift from economic-oriented development towards sustainable development ${ }^{1}$ (Thomas \& Mohan, 2007). Sustainable development has been enthusiastically supported in local and international circles in various disciplines and among many actors, such as practitioners, academics, politicians, international development agencies, and civil society organisations (Gray, 2006a; Nooteboom, 2007; Toth, 2010).

As sustainability concepts have evolved, the mining sector has come under increasing scrutiny, and is now expected to behave in a socially and environmentally accountable way to 'legitimate' its operations $\left(\mathrm{CSP}^{2}\right.$ and WRI, 2005; MMSD, 2002). It is argued that companies have moral obligations to take into account the social and environmental impacts of their activities (Millon, 1993; Molisa, Vandangombo, \& Brown, forthcoming). There are ongoing debates among researchers about how to internalise social and environmental impacts, previously regarded as 'externalities', so that sustainability can be taken seriously.

SEA and environmental management are promising tools with which to respond to this challenge. SEA is defined as an organisational communication process that accounts to stakeholders for the social and environmental effects of business (Gray, Owen, \& Mauders, 1987). The formation of sustainable development challenges the traditional instrumental approach, and requires a systematic rethink of accounting so that development can be studied in all its social complexity (Gray, Owen, \& Adams, 1996; Morgan, 1988; Unerman, Bebbington, \& O'Dwyer, 2007).

Unlike mainstream accounting, SEA explicitly acknowledges the importance of stakeholders, their engagement in accountability issues, and the urgency of social and environmental considerations in economic processes. It argues for public-

\footnotetext{
${ }^{1}$ However, sustainable development is a 'contested' concept that is interpreted differently by various actors (Söderbaum, 2011).
} 
interest oriented accounting as a potential proposal to address sustainability (Gray, 2006a; Lehman, 2005; Unerman, et al., 2007). Research is needed to explore possible ways to pursue SEA engagement, especially for LDCs that have not yet been closely investigated in SEA literature (Molisa, et al., forthcoming).

Dialogic accounting, an emerging SEA project, argues for dialogic engagement of different actors to open up discussion on contested issues, such as mining and its impacts (Bebbington, Brown, Frame, et al., 2007; Brown, 2009; Dillard \& Roslender, 2011). Dialogic accounting calls for more pluralistic and democratic accounting so as to humanise accounting and business with insights from sustainable development (Bebbington, Brown, Frame, et al., 2007). It argues the need for dialogic engagement of all actors in contested issues. Through dialogue, areas of agreement and disagreement and power dynamics among participants may be revealed (Brown, 2009). Dialogic accounting seeks to open up an arena for participation and debate on how to regard accountability from the perspectives of different actors, including what and how issues need to be addressed. This thesis explores its potential for enabling engagement among mining constituents to discuss social and environmental issues.

Another potential arena for addressing the sustainability challenges of mining is the EIA. This is an environmental management tool that addresses the negative environmental and social impacts of development projects such as mining, and attempts to mitigate such impacts by incorporating EIA recommendations into business practice. To ensure the inclusion of affected communities, public participation in EIAs is legislated in many countries (Glasson, Therivel, \& Chadwick, 2005).

In spite of its potential to promote sustainable development (Doberstein, 2003; Söderbaum, 2004; Wilkins, 2003), the EIA has been criticised for its technocracy and symbolic participation practice in developed countries and LDCs (Jay, Jones, Slinn, \& Wood, 2007; Morgan, 1998; Rockloff \& Lockie, 2006). At the same time, there are proposals in the EIA literature for meaningful public participation that can challenge existing technocratic EIAs and provide greater social learning for 
EIA constituents (Diduck, Sinclair, Pratar, \& Hostetler, 2007; Sinclair, Diduck, \& Fitzpatrick, 2008; Webler \& Tuler, 2006).

This is particularly important for mineral-rich LDCs as they have experienced growing conflicts (Szablowski, 2007) among mining companies, local communities and government authorities, due to a lack of dialogue among mining constituents and a lack of effective public policy and public engagement in the promotion of socially and environmentally accountable mining (CSP ${ }^{2}$ and WRI, 2005). There is a need for research to investigate EIA mining practices, and to examine its potential for, and the challenges of, fostering responsible mining.

Civil society actors, namely non-governmental organisations (NGOs), have performed crucial roles in promoting sustainability and accountability initiatives, by challenging mining, particularly in LDCs, and advocating for participatory environmental decision-making. NGOs are studied in literature concerning both the SEA and EIA. Especially in LDCs, local, national and international NGOs have actively raised public awareness of social and environmental issues, undertaken collective actions against local and multinational corporations, and challenged their socially and environmentally unfriendly business behaviours (Betsill \& Corell, 2008; Howell \& Pearce, 2001; Schlosberg, 2007). Thus, NGOs have been regarded as a leading actor, encouraging participation in contested issues surrounding mining and environmental management (Li, 2009; Schlosberg, 2007; Szablowski, 2007).

NGOs have also been criticised in many disciplines. In SEA, researchers have begun to address accounting and accountability issues relating to NGOs, particularly international advocacy NGOs (Gray, Bebbington, \& Collison, 2006; Lehman, 2007; O'Dwyer, 2007; O'Dwyer \& Unerman, 2008; Unerman \& O'Dwyer, 2006). In development studies and civil society literature, the accountability of NGOs is questioned, along with their representative powers, outreach to LDC beneficiaries, their over-reliance on donors, and opportunistic behaviours (Bano, 2008; Bebbington, 2005; Howell \& Pearce, 2001; Munck, 2006). However, the NGO sector is also seen as an under-researched area, and the 
potential of NGOs for promoting accountability, sustainability and participatory mining and environmental management has been recognised (Betsill \& Corell, 2008; Edwards \& Sen, 2000; Feher, Krikorian, \& McKee, 2007; Gray, et al., 2006).

This study explores the potential of dialogic accounting to address sustainability challenges that arise in LDCs. To this end, the EIA for mining projects can be regarded as a tool and a process, where environmental and social issues of mining projects are discussed and assessed, and alternatives for mitigation methods of these impacts are developed. Furthermore, the current and potential engagement of NGOs in the EIAs of an LDC is examined to explore their potential for fostering dialogic accounting.

\subsection{Research aims and objectives}

The principal goal of this study is to examine the use of the EIA in Mongolian mining and its potential as a dialogic accounting tool. The specific objectives are threefold:

1. to address global and local calls for sustainable and participatory mining.

2. to problematise symbolic participation practices evident in current EIA practice and to investigate ways of fostering more inclusive and meaningful EIA practices. To this end, the study focuses on the EIA as a potential dialogic tool for promoting sustainable and participatory mining, drawing on Brown's (2009) critical dialogic accounting framework to evaluate existing EIA practices and to suggest new ones.

3. to examine environmental and mining-related NGOs in Mongolia and to explore their potential for promoting dialogic EIAs that could 'democratise' environmental management and improve the performance of mining companies in relation to sustainable development.

Research questions are developed to understand the status quo of mining and EIAs, and to explore the potential for applying dialogic accounting to the EIA. If dialogic accounting has the potential to open up contestation of controversial issues and areas, such as mining and environmental decision-making, then it is 
important, first, to understand the complexity of these fields and their main actors. Issues, such as how the mining sector and the EIA framework have developed, what participants have been involved, and what challenges mining and EIAs encounter, need to be investigated. Further, theoretical questions are designed to examine whether existing EIA practice is monologic or dialogic, and to explore the potential application of dialogic accounting.

The key research question and sub-questions are as follows: Can the EIA provide a dialogic accounting tool to promote sustainable and participatory mining. This leads to four sub-questions:

1. Why do we need sustainable and participatory mining?

2. Are existing EIA practices primarily monologic or dialogic?

3. Can the EIA be a dialogic accounting tool to promote sustainable and participatory mining?

4. What role(s) might NGOs play in promoting dialogic EIA practices?

This study seeks to make theoretical and practical contributions and, to these ends, spans a number of fields of study.

This thesis seeks to contribute to literature on SEA, particularly dialogic accounting, and EIA. Dialogic accounting proposes dialogic engagement and pluralism to foster sustainability and accountability issues. This study applies the dialogic accounting framework to the EIA, endeavouring to link SEA with other disciplines so as to stimulate discussion of social and environmental mining concerns.

This study also draws NGOs into the application of dialogic accounting. The accountability of business can be addressed in a number of ways; stakeholders, including local communities and NGOs, have the potential to promote dialogic EIAs in different ways, depending on their perspectives and chosen strategies. This study proposes that a transformation towards dialogic EIAs may come from and be facilitated by a combination of insider and outsider NGO engagements.

By using Mongolian EIA practice for illustrative purposes, this study seeks to contribute to the ongoing debate in EIA literature. It supports calls within EIA 
research communities that seek more participatory approaches to EIA to apply notions of sustainable development in practice, and to enable social learning among EIA constituents.

The study aims to foster mining related debate, and proposes that sustainability challenges can be addressed through EIA and dialogic accounting. It suggests that sustainable and participatory mining may be encouraged through greater participation and dialogic engagement in EIAs that are conducted before mining projects begin. In this way the EIA - a well institutionalised environmental management tool around the world - has the potential to include sustainability and participatory aspects into the life cycle of mining projects.

This study also aims to provide practical benefits for the Mongolian EIA framework. There is a lack of research in Mongolia examining the EIA framework and public participation in the mining context, because both EIA and mining are relatively new to Mongolia. The emergence of environmental and mining NGOs is another new phenomenon in Mongolian society, which requires attention from research communities.

In short, the aim is to contribute to the development of SEA and related fields by exploring the potential application of the dialogic accounting framework to EIA mining practices in an LDC, and by exploring the potential role(s) of NGOs in promoting this practice. I hope this study can help foster debate on sustainability applications, and provide new avenues of thought and discussion for SEA and EIA researchers and mining constituents.

\subsection{Thesis organisation}

The nine chapters of this thesis are organised as follows:

Chapter 2 discusses the principal challenges of addressing sustainable development in the mining sector. It introduces the nature of mining and its impacts, and reviews mining issues raised by global and national communities. The historical context of Mongolia's mining sector is examined in terms of economic, social and political factors, providing an overview of the industry. 
Chapter 3 describes SEA in relation to dialogic accounting. It investigates the debates and calls for SEA, and explores dialogic accounting as a potential SEA project for promoting pluralistic and public-interest oriented accounting to foster sustainability. The chapter also introduces EIA, its application and ongoing debate among EIA research communities regarding the potential of EIA to address sustainability issues and for promoting participatory environmental decisionmaking.

Chapter 4 discusses NGOs and their roles in promoting participatory decisionmaking, sustainable development, and environmentally and socially accountable mining, globally and nationally. It also provides an overview of the Mongolian NGO sector and its development.

Chapter 5 briefly summarises the literature reviews on mining, SEA, EIA and NGO for the purposes of locating the study. It also introduces dialogic accounting in more detail, focusing on discussion of technocracy, monologism and participatory democracies. The chapter also proposes an analytical framework for this study, based on the dialogic accounting framework developed by Brown (2009).

Chapter 6 justifies the use of qualitative case-study methods to conduct this exploratory and multi-disciplinary study. It outlines the research process and explains the research methods used, and what and how data were collected, validated, and analysed.

Chapter 7 explores Mongolian EIA practice and public participation in EIAs. Development of the EIA, public participation, and contestation and power issues among EIA constituents are investigated, employing the analytical framework developed in Chapter 5. The chapter also discusses findings and possible ways to improve the existing EIA framework.

Chapter 8 examines the development of Mongolian NGOs with a particular focus on environmental and mining NGOs. The roles of NGOs are discussed and casestudies of two environmental and mining related NGOs are presented. The chapter 
discusses the potential of, and challenges facing, environmental NGOs for promoting sustainable and participatory mining, and discusses ways to foster dialogic EIAs.

Chapter 9 presents my conclusions, discusses the contributions and limitations of my study, and provides suggestions for future research. 


\section{Chapter 2: A CALL FOR ECONOMICALLY SUSTAINABLE AND PARTICIPATORY MINING}

\subsection{Role of mining in the world}

A growing world population creates an ever increasing demand for consumer products and thus demand for the mineral resources from which such products are made. Base metal minerals, such as copper, coal, gold, and iron ore are extensively used in energy, manufacturing, construction and heavy industries. Moreover, some emerging economies such as China and India are becoming rapidly industrialised, which increases even further global mineral demand (Australian Government: Corporate and Markets Advisory Committee, 2006, Article 5).

Mining has developed unevenly throughout the world. By 2004, the mining exports of 78 countries accounted for 2.6 percent of the world's annual GDP (Crowson, 2009). Fifty-three less developed countries (LDCs) are mineral dependent (Ross, 2008). Mining in these countries accounts for more than five percent of their annual GDP and plays a significant role in earning their export revenue. In 2000, 27 mineral dependent countries had mineral exports that accounted for more than 20 percent of GDP (Ross, 2008).

Compared with other economic sectors, mining is capital intensive, with high risks due to the inaccessibility and scarcity of mineral resources. The most easily accessible minerals have been extracted over the last few centuries, so today, companies must spend much time and money to extract minerals from deeper underground or from seashores (MMSD, 2001). Most mineral resources are spread unevenly throughout different regions and are becoming scarcer, as they are non-renewable and have been formed over millions of years in specific geological contexts. This quest to extract remaining deposits has resulted in more investment in many geographical regions, with no guarantee of finding economically viable mineral deposits. 
Even discoveries of large mineral deposits do not necessarily lead to extraction and processing as they require huge capital investment in extraction equipment, mining-site development, processing factories, technologies and more (MMSD, 2001, 2002). Therefore, risk sharing is common in mining, as a sole company often has insufficient capital and capacity to mine large deposits. Globalisation has allowed companies to operate anywhere in the world, so many smaller mining companies conduct exploration and then sell mining licences to larger mining companies once they have found economically viable mineral deposits and obtained mining licences (Ross, 2008). Large companies or consortiums can mine large deposits, given their capital and technical capacities. Consequently, the mining sector has seen considerable mergers and acquisitions (Humphreys, 2006). Today, only a few large mining conglomerates hold mining rights to the biggest deposits in the world, and their power and influence would exceed that of many nation-states (Global Witness, 2005).

Mining has increasingly spread to previously inaccessible regions or once economically unviable deposits, due to the economic liberalisation in many countries after the 'cold war era', technological advancements in mining and geology, globalisation, and the rapid development of information and communication systems (CSP ${ }^{2}$ and WRI, 2005; Humphreys, 2005).

With the end of communist authoritarian regimes and colonialism, countries in Eastern Europe, Asia and elsewhere have opened their economies to foreign trade and investment, and have undertaken rapid liberalisation involving privatisation of state-owned mining companies, lower rates of tax and royalties, and restructured mining laws to attract greater foreign direct investment (Bury, 2005; Szablowski, 2007). This neo-liberal development agenda, often supported by international donor organisations, has brought mining sector prosperity to many LDCs over the last few decades (Slack, 2009) as well as increasing concern about the benefits and costs. 


\subsubsection{Mining impacts}

Mining has both positive and negative economic, social, and environmental impacts.

\subsubsection{Economic impacts}

Mining has been received with hope and enthusiasm in many LDCs as it is perceived as a key determinant of development and economic growth. Economists, policy-makers and international policy advisors, influenced by neoclassical economics, have enthusiastically supported mining development, particularly in LDCs, in the belief that it will increase production, export income, tax revenue and reduce unemployment (Slack, 2009). The increased economic growth is claimed to reduce the inequalities of income distribution (Ross, 1997, 2004, 2008; Stevens, 2003).

However, in many LDCs mining has not led to economic prosperity. In spite of having rich mineral resources and high economic growth, poverty and inequality in such countries are worsening (Crowson, 2009; Ross, 2008). Terms such as 'Dutch disease', 'resource curse' or 'inequality trap', have been used to describe such results.

'Dutch disease' was termed after mineral-sector led economic development biased the Dutch economy during the 1970s. This relates to mineral-rich countries having a higher risk of becoming dependent on their mining sector, which is vulnerable to global price fluctuations of minerals. Excess concentration on mining can result in labour moving from other sectors to mining due to higher wages (Crowson, 2009). Consequently, sectors which cannot compete with mining wages, reduce their production or become bankrupt (Lahiridutt, 2006). Although mining may generate economic growth, the economy can become less diversified and more dependent on mining exports and volatile global mineral prices (Ross, 2008).

Some LDCs have experienced the so-called 'resource curse' or 'inequality trap'. Countries, such as Algeria, Angola, Colombia, the Democratic Republic of 
Congo, the Republic of Congo, and Nigeria show results that are contrary to neoclassical economic theory (Ross, 2008, p. 189). Instead of increased prosperity, mineral wealth has increased inequality, given rise to violent conflicts and corruption, increased country risk and decreased foreign investment, and limited diversification of the economy (Ross, 2004). Poor governance and control of politics and economies by elites has often resulted in mismanagement of mining sectors, and caused an increase in rent-seeking 'predatory state' behaviours (Stevens, 2003). Governments are encouraged to control mineral mining (Szablowski, 2007; World Bank \& International Finance Corporation, 2002), but some can become more bureaucratic and corrupt, which creates a mining inequality trap. It becomes difficult to break out of the trap, as considerable political will and effort are required to overcome entrenched economic, social and political practices (p. 193). Some countries, such as Bolivia and Chile, have used their resources well and enjoy economic prosperity (Ross, 2008), but most resource-rich LDCs are vulnerable to or suffer from the 'resource curse' (Crowson, 2009; Stevens, 2003).

In spite of increases in mining-led investment and economic growth, mining has often not brought benefits to LDCs, in terms of social well-being and the environment. Therefore, the economic contribution of mining must be treated cautiously because of its social and environmental impacts before, during, and after mining development.

\subsubsection{Environmental impacts}

Mining is 'digging, removing soil, and separating out ores and non-metal minerals' (World Bank \& International Finance Corporation, 2002, p. 1), hence it has negative impacts on the natural environment. Compared with other extractive resources such as oil and gas, hard-rock and coal mining have greater environmental impacts (Diamond, 2005), causing water and air pollution, land disturbance, tailings, and acid drainage.

Mining activities include digging the land's surface, using water sources, and piling waste rocks and ores in tailings, and dumps that carry the danger of acid 
drainage. Mining can cause water, soil, and air pollution that lasts for substantial periods (CSP ${ }^{2}$ and WRI, 2005; Diamond, 2005). If mining operates in a fragile and relatively closed ecosystem, such environmental disturbances affect the biodiversity and ecological systems of a region (Warner \& Sullivan, 2004, p. 9). Technological advancements have allowed mining to operate almost anywhere and it occurs more frequently in geographically isolated areas of LDCs, making biodiversity and ecosystems vulnerable to external or human activities $\left(\mathrm{CSP}^{2}\right.$ and WRI, 2005).

Land disturbance from mining without proper controls can be disastrous both during mining operations and after their closure. As mining commences with digging and removing top soil, the most fertile land and all vegetation with its biodiversity disappear (MMSD, 2001). Where there is low metal concentration in metal-bearing ores ${ }^{2}$, huge amounts of soil become waste. Therefore, mining needs careful planning and implementation of waste solutions and rehabilitation after mining closure (MMSD, 2002).

Mining generates various types of waste, including overburden, waste rock, tailings and heaps of leach-spent ore (MMSD, 2002, p. 234). Mounting tailings are created after separating the ore. Unfortunately, there is a worldwide lack of comprehensive legal requirements for the disposal of mining waste (Otto, 2009). Common solutions are dumping tailings into a river or ocean, piling them up on land, or (mostly) behind a dam (Diamond, 2005, p. 453). All cause water pollution and acid drainage problems (MMSD, 2002; Otto, 2009).

Disposal of mining waste into a river or ocean also causes water pollution. Chemicals, such as mercury and cyanide from gold or silver mining, and sulphuric acid from copper and uranium mining (MMSD, 2002, p. 235), are commonly used in ore separation processes. Mining companies should use chemicals to neutralise waste tailings, but they are often allowed to reach poisonous chemical

\footnotetext{
${ }^{2}$ The ratio of the earth to metal is $1: 400$ for a copper mine and 1:5,000,000 for a gold mine (Diamond, 2005, p. 460).
} 
concentrations $^{3}$ (MMSD, 2002, p. 235). Disposal of waste into water results in higher chemical concentrations of metals in water (UNEP GEMS/Water Programmes, 2006, p. 26). For instance, hard-rock mining is blamed for half of the reported industrial pollution in the USA, and nearly half of Western USA river headwaters are polluted by mining (Diamond, 2005, p. 452). Water pollution in LDCs threatens the life of local communities as it causes the loss of fish - the main food and source of living for locals. For example, the failure of the poorly constructed dam by BHP in the Ok Tedi copper mine of Papua New Guinea discharged 200,000 tonnes of mining tailings and waste into the Ok Tedi River in the late 1990s and destroyed its fishery, a source of living for 50,000 people (Diamond, 2005, p. 454).

Dumping mining waste as tailings has another serious negative impact on the natural environment - acid drainage (MMSD, 2002). Tailings and dams often hold high concentrations of metals and poisonous chemicals, even after neutralisation, so piled tailings have a high risk of causing acid drainage $\left(\mathrm{CSP}^{2}\right.$ and WRI, 2005). This is "characterized by depressed $\mathrm{pH}$ values and elevated concentrations of dissolved heavy metals; the sulphuric acid easily dissolves metals such as iron, copper, aluminium, and lead" (MMSD, 2002, p. 238). Such drainage can have a devastating impact on ecosystems and usually lasts a long time (Tarras-Wahlberg \& Nguyen, 2008).

Without proper regulation of accurate measurements, the clean-up costs ${ }^{4}$ of water, air and land pollution are often underestimated or avoided ${ }^{5}$ by mining companies (Diamond, 2005, p. 455). Consequently, the main victims of negative impacts of mining are ordinary people and governments due to the high cost of rehabilitation projects, using taxpayers' money. For instance, from 1980 the USA Superfund

\footnotetext{
${ }^{3}$ Neutralisation practices, in particular, in LDCs are poor as it is costly (Diamond, 2005; MMSD, 2002)

${ }^{4}$ Although there some initiatives, such as Integrated Environmental and Economic Accounting (UNEP, 2003) and Global Reporting Initiative (GRI, 2006), practical implications are critically weak.

${ }^{5}$ Becoming bankrupt is one way to avoid clean-up responsibilities. In the 1990s, after the bankruptcy of Pegasus Gold Inc., in Montana, and Galactic Resources' Summitville Mine in Colorado in USA, taxpayers paid US\$169,500 million to clean polluted rivers (Diamond, 2005, pp. 456-457).
} 
required companies to remedy environmental problems they created, but in 1990 Congress authorised US $\$ 15.2$ billion expenditure for clean-up operations when many companies responsible for the pollution had become bankrupt (Milne \& Patten, 2002). By 1990 there were 1,200 sites on the National Priorities List of the USA, and the average clean-up costs were US\$30 million (Milne \& Patten, 2002, p. 379).

Mining accidents often occur because of improper management and control of tailings and dumps. Anecdotal evidence suggests that every year there is one large accident from a tailing dam (Diamond, 2005; MMSD, 2002). The UNEP (2000) reports that failure of tailings storage facilities accounted for three-quarters of major mining-related environmental incidents since 1975 (MMSD, 2002, p. 240).

LDCs and their natural environments often become victims of poor mining practices. They often lack financial, professional and technical capacities to mitigate mining-related problems (Reed, 2002) and are often unaware of negative environmental consequences (MMSD, 2002; Tarras-Wahlberg, 2002; TarrasWahlberg \& Nguyen, 2008).

\subsubsection{Social, cultural and political impacts}

Researchers and practitioners have begun to address the negative social impacts of mining since the 1970s. However, these are controversial issues; given the complexity of social life and the effect of economics on the natural environment, the negative social impacts are difficult to measure (Mitchell, 2001). As most impacts occur gradually over a long period, they are often less noticeable. Social impacts can be classified as social, cultural, and political (MMSD, 2002). Mining development in LDCs needs careful consideration as it can have more serious direct and indirect social consequences than in developed countries where there is better governance, rule of law, and well-sustained social development.

\subsection{Social impacts}

In LDCs, the arrival of mining can result in the immigration of non-local people, as local people are often not employed due to their lack of training and 
professional skills in mining. Immigration creates social issues such as overpopulation, gender imbalance, and increased crime-rates near mining areas (MMSD, 2002). With the increased population, the local capacity and resources of social services, such as health, education, police, beverage and water, become inadequate for meeting the population's needs (Ross, 2004, 2008). Consequently, accessing facilities becomes challenging for local people, as they usually have lower incomes and less ability to access such facilities and services compared to miners (CSP ${ }^{2}$ and WRI, 2005).

Moreover, increases in gender imbalance, alcoholism, crime and prostitution are often associated with a growing number of male workers in mining areas (MMSD, 2001). Local women become more marginalised than before mining (CSP ${ }^{2}$ and WRI, 2005; ICMM, 2005). Immigration can also raise health issues for local people (World Bank, 1992). Previously uncommon diseases, such as HIV/AIDS, can occur as a result of overpopulation and prostitution (MMSD, 2001). Essential human rights of local people, such as the rights ${ }^{6}$ of women, children, and indigenous people, and rights to live in a safe and healthy environment and to be informed, are often violated in LDCs (CSP ${ }^{2}$ and WRI, 2005; Martin, 2006; MMSD, 2002). In addition, poorly managed mining companies, which infringe employees' rights and neglect health and safety issues, precipitate conflicts with their employees and accidents (Martin, 2006).

As mining companies receive formal consent from central government for their mining licensed areas, local communities are forced to move to other areas, which transfers migration and social problems elsewhere (CSP ${ }^{2}$ and WRI, 2005). Hence, local and indigenous people are often disadvantaged and marginalised following mining development in their areas (Haselip \& Hilson, 2005; Rockloff \& Lockie, 2006).

Additionally, mining-related water pollution can bring serious health problems for local people. One highly publicised environmental accident that occurred in the

\footnotetext{
${ }^{6}$ Human rights declared by the Universal Declaration of Human Rights; the UN Declaration on the Right to Development; the International Convention on Economic, Social and Cultural Rights; and the International Covenant on Civil and Political Rights (CSP ${ }^{2}$ and WRI, 2005, p. 7)
} 
Philippines in 1996 caused serious health and survival issues for local people. Following a burst concrete plug, which sealed a drainage tunnel, at the Marcopper mine, four million tonnes of mine tailings poured into the Boac River. After the accident, a UN assessment team declared the river to be biologically dead. The spill not only destroyed all aquatic life in the river but also affected more than 20,000 people living along the river (MMSD, 2002, p. 204).

\subsection{Cultural impacts}

Some researchers argue that the cultural impacts of mining should be considered alongside other social and environmental impacts (Söderbaum, 2007, p. 614). Mining has increasingly operated in isolated areas, where local and indigenous people have unique cultures, and traditions are often vulnerable to the imported ways of outsiders and other cultures.

Growing natural resource exploitation in LDCs cause, increasingly, local cultures to "resemble dominant modern cultures, with their individualistic and productive ethos and market orientation" (Escobar, 2006, p. 7). For example, Potosi, in Bolivia, has experienced great human, cultural and environmental damage after five centuries of mining (MMSD, 2002). Such cultural disturbances may replace local culture with cultural monologism, marginalise local people, and precipitate conflict between local communities and mining companies.

\subsection{Political impacts}

Consistent with the concept of 'resource curse', a growing number of studies argue that mining has direct and indirect impacts on the politics of LDCs. Due to poor governance and weak institutional capacities, a mining boom often creates a rent-seeking, predatory behaviour by government, as well as increased corruption, conflict and civil war (Ross, 2004, 2008; Stevens, 2003). Negative political impacts of mining are dangerous as they can weaken governance and accountability, and worsen injustice and inequality. This has attracted the attention of international donor and civil society organisations, researchers and practitioners (CSP ${ }^{2}$ and WRI, 2005; MMSD, 2002; Ross, 2004; World Bank \& International Finance Corporation, 2002). 
In many mineral-rich countries with poor governance and economic conditions, growing mining interests and foreign direct investment bring greater rent-seeking behaviours. Their governments become vulnerable to "predatory" behaviours, as mining can generate enormous revenues compared with other sectors. Common rent-seeking behaviour include creating or increasing windfall tax rates, demanding mandatory state shares, royalties, bribes, and lobbying (World Bank, 2007b). Furthermore, the strategic importance and income generated in individual countries makes mining a politicised sector: "large-scale resource revenues create a pot that is worth fighting for since whoever is in power is better able to plunder that pot" (Stevens, 2003, p. 8). Therefore, mining development in LDCs can increase political instability and country risk, which in turn negatively affects further mining investment and development (Auty, 2007).

Research in development studies and public policy suggests that mining contributes to corruption in many LDCs. Some mining companies bribe politicians, senior public officials, and public servants to facilitate access to licences for mining projects, or to obtain 'soft' contracts that provide favourable conditions for projects, or to avoid revenue sharing, and environmental and social obligations (Stevens, 2003; Szablowski, 2007). Some mining companies lobby and bribe public officials because it is a less costly way of doing business (World Bank \& International Finance Corporation, 2002) rather than adhering to very bureaucratic procedures in countries with high levels of corruption and nepotism (Stevens, 2003). In both cases, companies promote more corruption, including grand corruption ${ }^{7}$, in host countries (Hilson \& Maconachie, 2009).

Corruption affects every aspect of society, politics, and economics of countries, and threatens human rights, accountability and democracy. It results in unjust income distribution, increased inequality, improper use of investment, unproductive public and private sectors, and can lead to a 'shadow' economy and tax cheating (Lambsdorff, 2006). Combating corruption in countries with endemic

\footnotetext{
${ }^{7}$ There are two types of corruption: petty corruption and grand corruption. Grand corruption involves a large sum of money that is paid to political elites and higher-level public officials (World Bank, 1997, p. 34).
} 
corruption becomes a major challenge as it requires a greater political will and radical changes in the political and social environments of public institutions (Smith, 2010).

Many conflicts in LDCs have arisen due to the unfair distribution of wealth and ecological resources created by their mining sectors (Urkidi, 2010). Mineral-based conflicts can instigate serious conflicts among mining constituents, human-rights violations, and even civil wars in LDCs (Humphreys, 2005; Martin, 2006; Ross, 2008).

Unfair wealth distribution can cause conflicts between the government, the public and mining companies. Many LDCs cannot benefit from mining revenues due to their poor legislative frameworks, governance, and their limited human and institutional capacities (MMSD, 2001, 2002; Ross, 2008; World Bank \& International Finance Corporation, 2003). They receive an insufficient share of mining revenues and fail to distribute such income to promote development, alleviate poverty, and improve the well-being of locals (Martin, 2006).

Mining companies often fail significantly to share their revenues with governments of their host countries and especially with local people (Diamond, 2005). They favour tax holidays, a favourable investment environment, and the easy granting of mining licences in countries with weak governance, poor rule of law, and endemic corruption. Occasionally they provide ad hoc donations for local development which do not address local issues or improve living standards (CSP ${ }^{2}$ and WRI, 2005; MMSD, 2002). Moreover, the local population often have insufficient power and knowledge to influence mining decisions, to demand improved revenue sharing, or to protect their human rights (CSP${ }^{2}$ and WRI, 2005; Martin, 2006).

Given their lack of expertise and capacity to address mining issues and their high levels of politicisation, governments in many LDCs are incapable of making strong contracts with multinational mining companies to gain a better share of mining revenues (Mbaku, 1992). Even if they receive a proper share of mining revenues, many LCDs fail to provide effective and fair income distribution for 
their people (Martin, 2006). Predatory states often attempt to receive more income but not for the 'public interest'. Moreover, greater mineral resource income can increase social conflict. Poor governance and accountability, and politicisation lead bureaucrats to act in their political and individual interests as the "... bulk of rents created in these economies are channelled by bureaucrats, the majority of whom are members of the politically dominant group..." (Mbaku, 1992, p. 250). Instead of fulfilling their responsibility to act in the public interest, a few senior officials use mining-generated income illegally for personal or political interests or to fund political activities, civil war, and even for abuses of human rights, as in Sudan and Nigeria (Martin, 2006).

A growing number of conflicts among mining constituents are caused by negative environmental impacts of mining in LDCs. Local and indigenous people often become the most marginalised, as their lives depend on the natural environment. Polluted water sources, degraded land, and reduced animals and fish threaten the sustainable survival of their land. Mining companies often do not provide adequate compensation for their losses ( $\mathrm{CSP}^{2}$ and WRI, 2005). Dissatisfaction with mining by locals can lead to conflicts with mining companies (Martin, 2006; Szablowski, 2007).

In summary, the principal social and environmental impacts are closely interrelated with the economic, political and social life of LDCs. Mining affects local regions and ecosystems, but also seriously affects other regions and their public and private sectors. Therefore, it is simplistic to encourage mining only because of the assumed economic benefits (Slack, 2009; Szablowski, 2007). Rather, mining development should be seen as a complex development project with potentially negative impacts on the natural environment and society, politics and economy (MMSD, 2002). In this respect, the mining sector is increasingly under pressure from international and national states, donor organisations, civil society organisations, and the public. 


\subsubsection{A call for economically sustainable mining}

Global warming and more frequent, devastating environmental disasters have increased the urgency of paying greater attention to industries that impact directly on the natural environment. In particular, LDCs are vulnerable to economic and environmental shocks (Ingelson, Holden, \& Bravante, 2009), as their people become marginalised due to unequal income distribution, environmental damage, and the loss of biodiversity necessary to supply food and resources to local communities (CSP${ }^{2}$ and WRI, 2005; Diamond, 2005).

In a rapidly globalising world, the social, political and economic problems of individual countries have become part of regional and transnational issues. There is unprecedented close integration among countries, and even within a country, economic, social and environmental issues are often deeply interrelated. As mining uses non-renewable resources, sustainability issues must be properly addressed to ensure that mining does not jeopardise the lives of current and future generations of a country but, rather, benefits societies where it operates (Fitzpatricka, Fonsecab, \& McAllisterb, 2011; Waye, Young, Richards, \& Doucet, 2009). Therefore, mining impacts should be considered holistically without overlooking the particular benefits of specific mining projects (MMSD, 2002).

There are well-known initiatives among multilateral donor organisations, mining conglomerates, international and national NGOs and governments that encourage corporate social responsibility and sustainable development $\left(\mathrm{CSP}^{2}\right.$ and WRI, 2005; Fitzpatricka, et al., 2011; MMSD, 2002).

With growing concerns for sustainable development, international development agendas, public policies and public opinion on business have gradually changed over the last two decades. Sustainable development is a balanced way of development that considers economic, social, environmental and intergenerational equity issues (World Commission on Environment and Development, 1987). In spite of various interpretations, it proposes a new framework for development and calls for fundamental changes in ideologies, perspectives and values in development agendas, public policies, business goals and various disciplines in 
academia (Gray, 2006a; MMSD, 2002; Richards, 2009; Söderbaum, 2006; Wilkins, 2003).

Growing numbers of development agencies and practitioners have gradually revisited their development agenda for LDCs. The failure of widely advocated economic growth-oriented development (Stiglitz, 2006); destructive environmental and social practices of mining (Ross, 2008); growing conflicts among mining constituents (Barton, 2005; Ross, 2004); and worsening global and local environmental issues has brought reconsideration of fundamental developmental concepts (Richards, 2009; Söderbaum, 2006, 2007; Wilkins, 2003).

Corporate social responsibility (CSR) has been incorporated in the goals, policies and actions of numerous companies (Fitzpatricka, et al., 2011). With CSR, business entities must acknowledge they are a citizen of society and thereby recognise their social and environmental obligations to society (Gray, et al., 1996; Gray, et al., 1987). However, CSR is a controversial term, subject to on-going debate, reflecting ideological differences, which include the benefits of judicial versus voluntary CSR, its applications in developed and developing countries, the effectiveness and usefulness of its applications, and ways of further improvement (Australian Government: Corporate and Markets Advisory Committee, 2006; Collins, 2009; Fitzpatricka, et al., 2011; Imbun, 2007). In spite of initiatives to make CSR judicially binding, businesses are eager to keep it voluntary (Australian Government: Corporate and Markets Advisory Committee, 2006; Fitzpatricka, et al., 2011).

Today, sustainable development and CSR are extensively used in mining as it is a widely recognised polluter. Mining conglomerates have started to play a leading role to address this and to maintain their "social licence to operate" (BHP Billiton, 2007; Martin, 2006; MMSD, 2002). They have invested in local development programmes (Garvin, McGee, Smoyer-Tomic, \& Aubynn, 2009), cooperated with government agencies, research institutions and civil society organisations (Martin, 2006; Reed, 2002), produced sustainability reports (BHP Billiton, 2007; Shell, 
2007), and raised public awareness on sustainability (Hilson, 2000). However, some researchers and civil society organisations are sceptical about the motivation and effectiveness of voluntarism (Sethi, 2005) and criticise the lack of meaningful commitment by firms to sustainability (Imbun, 2007; Richards, 2009).

Sustainable development and corporate social responsibility have similar repercussions for business, in particular mining. Both involve complex issues and challenges that companies and managers cannot fully address on their own. Consequently, researchers and practitioners argue that multi-stakeholder participation can bring meaningful changes in practice.

\subsubsection{A call for participatory mining}

Multi-stakeholder engagement in mining is more inclusive and democratic as it enables participation of all organisations and communities affected by mining. More inclusive engagement of previously marginalised communities affected by social and environmental issues is crucial to ensure local societies benefit from mining and that their views on mining development are considered. Development practitioners and researchers suggest that participatory mining can promote CSR and sustainable development practices in the mining sector.

Agenda 21, developed during the United Nations Conference on Environment and Development, provides a solid foundation for public participation. It suggests that sustainable development requires new forms of participation. Its agenda encourages individuals, groups and organisations to participate in decisions, particularly those that "potentially affect communities in which they live and work", and to have "access to information relevant to environment and development ... [and] environmental protection matters" (United Nations, 1992, Chapter 23:2). After Agenda 21, many international donor organisations such as the UN, the World Bank, mining conglomerates, international NGOs, governments, and large mining consumers, established voluntary initiatives.

Sustainable and participatory mining is crucial in LDCs as they tend to be mineral dependent and vulnerable to the 'resource curse' and other negative effects 
(Crowson, 2009; Ross, 2008). Due to poor capacity and governance, governments often formulate inadequate mining policies that could otherwise favour development and the well-being of the populace (Diamond, 2005; Kapoor, 2008). This contributes to growing conflict in these countries (Lahiridutt, 2006; Stevens, 2003). The hope is that sustainable and participatory mining initiatives can promote sustainable development and democratic mindset in LDCs.

\subsubsection{1 'Best practices'}

Several initiatives and frameworks for proposed mining development have been developed by international developmental organisations. Depending on the interpretation of sustainable development, views on 'best practices' in mining can be situated between two extremes: sustainable economic growth in mining (Hilson, 2003) and 'deep green' opposition view of mining expansion (UNEP, 2000; Wackernagel \& Rees, 1996; WWF, 2002). However, the most influential recommendations lie between these two extremes.

The World Bank, a leading multilateral donor agency in LDCs, has published a series of papers with the International Finance Corporation on mining and development (Slack, 2009). The study, 'An Asset for Competitiveness: Sound Environmental Management in Mining Countries' (2002), examines environmental practices of mining and environmental regulatory frameworks of LDCs. The World Bank advocates vibrant mining in countries that can attract responsible private investment and create a foundation for economic and social well-being (World Bank \& International Finance Corporation, 2002). It acknowledges destructive mining practices in LDCs and considers environmental challenges of the mining sector, using economic cost-benefit and risk management analyses. It claims that irresponsible mining incurs substantial environmental and social costs, and thereby erodes the reputation of industry and social trust, which leads to social conflicts and political instability in countries where a mining company operates. Consequently, it becomes costly for the company to operate in countries with increased risk (World Bank \& International Finance Corporation, 2002, p. iv). The report suggests that governments should establish clear 
environmental frameworks, systems, and competent institutions to attract foreign direct investment which can promote sustainable economic growth (World Bank \& International Finance Corporation, 2002, pp. 4-5). The report shows that the World Bank recognises the responsibilities of the mining sector and encourages environmentally sound mining for sustainable growth that considers environmental issues. It calls on individual governments to create effective legislative frameworks and regulatory practices for environmental management.

Studies by the Mining, Minerals and Sustainable Development (MMSD) project of the International Institute for Environment and Development (IIED) are widely commended for their innovatory and comprehensive recommendations for mining best practice (Slack, 2009, p. 76). The first study, 'Mining and Economic Sustainability: National Economies and Local Communities' (2001), critically evaluates the lack of mining benefits to LDCs, and mining companies' approaches towards national and local community development. The study attempts to change the short-term interests of mining companies towards long-term sustained benefits of mining.

The report of the MMSD called 'Breaking New Ground' (2002) develops a comprehensive framework to extend sustainable development and CSR notions into practice. The report acknowledges the need for changes in mining perspectives, views and values to develop economically sustainable mining. It provides the first comprehensive framework for the mining sector that considers sustainable development (Danielson, 2006). The report examines the mining sector, its main actors, stakeholders and sectoral trends, its impact on economics, society and the natural environment, and governance of mining companies and national governments. The integrated approach has defined the meaning of sustainable development for the mining sector, defined necessary changes in values, visions, and approaches, determined key areas of actions and challenges, and addressed challenges of enforcing the framework. To make change meaningful, the report clarifies governance, and the roles and responsibilities of mining constituents, including mining companies, international donor organisations, national governments, financial stakeholders, customers, 
communities, and civil society organisations. It encourages effective stakeholder engagement and capacity building to promote economically sustainable mining.

Last but not least, the report, developed by an independent research team of the Centre for Science in Public Participation and the World Resource Institute, is another important publication that proposes a responsible mining framework consistent with sustainable development. The 'Framework for Responsible Mining: A Guide to Evolving Standards' (2005), outlines the need to recognise 'no-go' zones for mining; its environmental social impacts; and the importance of good governance. Building on existing norms and standards of responsible mining practice, the framework develops 'leading edge' or future standards for mining development. Furthermore, the framework highlights community participation at all stages of mining projects and emphasises the need for careful consideration of marginalised community groups, such as indigenous people and women (p. xiii). The framework encourages dialogue among mining constituents on social and environmental issues arising from mining projects.

In many mineral-rich countries, responsible or economically sustainable mining, which considers negative environmental and social issues as well as its economic benefits, has begun to be enthusiastically supported by international organisations, governments, mining conglomerates, and civil society organisations. The importance of the multi-stakeholder approach for promoting economically sustainable mining has also been acknowledged by international and local mining constituents (CSP ${ }^{2}$ and WRI, 2005; Guerin, 2009; MMSD, 2002; World Bank \& International Finance Corporation, 2002).

The next section will discuss mining practice in Mongolia - a newly democratic developing country in Asia, to illustrate the complexity and impact of mining in LDCs. 


\subsection{Mining in Mongolia}

\subsubsection{Mongolia in brief}

Mongolia is a large land-locked country, covering approximately 1.5 million square kilometres of land and bordering two of the world's largest nations, Russia and China. It has a diverse range of geological areas, found in high mountains in the west, wide steppes in the east, and the Gobi desert in the south. Mongolia has a dry continental climate, experiencing up to $+40^{\circ} \mathrm{C}$ in summer and down to $-40^{\circ} \mathrm{C}$ during winter in the hottest and coldest areas.

In spite of Mongolia's large land area, it has a relatively small population of 2.8 million people (Mongolian National Statistical Office, 2010). Of twenty ethnic groups, 82.4 percent of the population are Khalkhs (or Mongols), followed by 3.9 percent Kazaks, and 3.5 percent of other 20 ethnic groups and nationalities (Mongolian National Statistical Office, 2010). Mongolia has had a unique nomadic culture and shaman religion for many centuries. Such traditions have encouraged people to live in harmony with nature and to respect its biodiversity.

Mongolia is a relatively new democratic country. After 70 years of socialism under the former USSR, Mongolia had a peaceful democratic revolution in the spring of 1990. For the last two decades, Mongolia has undergone radical changes in its political, economic, and social arenas during the transition from rule under an authoritarian communist regime, with a centrally-planned economy, to a democracy with an open market economy.

\subsubsection{Economic, social, and political contexts}

\subsubsection{Economy}

In spite of a rapid increase in the tertiary sector over the last decade, the Mongolian economy is still based on the primary and secondary economic sectors of agriculture and industry. Full and semi-nomadic herding and mining accounted for 38 percent of GDP in 2010, of which mining and quarrying comprised 22 percent (Mongolian National Statistical Office, 2011). The main exports are 
cashmere products, meat, and minerals such as copper, molybdenum, gold and fluorite. As Mongolia has two giant economic neighbours, the majority of its exports ( 84 percent) go to China, while 31 percent and 33 percent of total imports come from China and Russia respectively (Mongolian National Statistical Office, 2011).

As a result of opening up the economy and creating a friendly legal environment, as advocated in a neo-liberal structural adjustment programme, foreign direct investment (FDI) has increased dramatically. Mining, construction, infrastructure, and communication have attracted the greatest FDI.

GDP, in terms of purchasing power parity per capita, has increased from US\$1,970 in 1996 (CIA, 1997) to US\$3,300 in 2010 (CIA, 2010). In terms of income distribution, Mongolia ranks 142nd out of 182 countries (International Monetary Fund, 2011). Although GDP per capita has almost doubled in the last 14 years, wealth distribution is uneven. There is an increasing gap between rich and poor; one-third of Mongolians live in poverty (UNDP, 2007).

\subsubsection{Social and political contexts}

In spite of its historic nomadic culture, Mongolia has experienced a mix of traditional and Western cultures after 70 years of the communist era in the twentieth century and globalisation since the 1990s. Today, more than half the population lives in the capital and two other large cities (World Bank, 2007b).

The communist period introduced industrialisation, agriculture, modern health and education systems, and Western or Russian style urbanisation. The influence of the USSR-educated, middle-class Mongolians and Russian supervisors has permeated almost every sector. Moreover, the change from a nomadic to a settled culture was accelerated by a political agenda which promoted a secular, Marxist country. In spite of many positive changes during the authoritarian political regime with its centrally-planned economy, political, economic, religious rights, and freedoms to express the voice of the people were limited (Cleary, 1995). A monopoly single party ruled the country and planned every aspect of political, economic, and social life. 
As in other former communist countries in Eastern Europe and the former USSR, Mongolia experienced conflict and protest against the authoritarian regime in the late 1980s. "Perestroika" (or 'reform' in English) in the USSR in 1989 contributed to this by giving hope to those who favoured the introduction of democracy. At the beginning of 1990, a few hundred mostly young people organised a protest march, requesting democratic changes, and declared a hunger strike in front of the parliament building (David, 2010). After several months of activism, the protest, which was supported by thousands, was successful. The ruling government officials resigned and agreed to stage the first election of a new multi-party parliament. It was a peaceful revolution for democracy without bloodshed, and it was a turning point for the country (Fritz, 2008).

Since 1990, Mongolia has experienced a rapid economic and political transition to a democracy with an open market economy. Many overnight radical changes were made to new political and economic systems. At the political level, the Mongolian Constitution created a semi-parliamentary system with a unicameral parliament and a prime minister-led government cabinet. The president has a symbolic status and plays an advisory role over legislation. The old tradition of one-party dominance was replaced by an elected parliament of multiple parties - the 'State Great Khural' (1992). To provide basic conditions for market-based economic development, the whole economic structure - strictly state regulated with fixed pricing systems, state-owned economic sectors and institutions - was changed under the supervision and support of international donor and developmental organisations, such as the International Monetary Fund (IMF), the World Bank and the UNDP. Following a neo-liberal structural adjustment programme, supervised mainly by the IMF and the World Bank, the government undertook fundamental economic reforms relating to pricing and trade liberalisation, and privatisation of state-owned entities and animal husbandry (Snow, 2010). Previously non-existent economic institutions, such as a stock market, commercial banks and commercial insurance, have been developed over the last two decades (Griffin, 1995). During this period, the State Great Khural has passed laws, regulations, acts and codes, influenced principally by the Romano-Germanic legal 
system (Odgerel \& Battsetseg, 2006), that have been crucial for the development of new political, social, and economic systems.

Seventeen political parties were registered on the Supreme Court registration list by 2010 (Supreme Court). However, only two major parties, the Mongolian People's Revolutionary Party (MPRP) ${ }^{8}$ and the Democratic Party have interchangeably ruled the country since 1996. In spite of obstacles, people are gradually learning to exercise their rights to freedom of speech and to vote. Today, demonstrations, hunger strikes, and other social and political activities are common phenomena, which were prohibited and unimaginable during the communist period.

Although democracy is welcomed by most Mongolians, its meaning and values are still not well understood. According to a survey on democratic governance indicators, only eight percent of respondents perceived "civil society, public participation", responsiveness, responsibility and consensus as major features of democracy, while "freedom, freedom of speech and expression" (34.3 percent), justice (19.5 percent), “open society, healthy political leaders" (13.1 percent), "private property, privatization" (10 percent), "respect of law, implementation of rights" (7.2 percent) and transparency (6.6 percent) were seen as crucial characteristics of democracy $^{9}$ (UNDP, 2006, p. 99). The survey found that half of respondents (52.9 percent) were "neither satisfied nor dissatisfied" with the development of democracy in Mongolia, while 14.3 percent of respondents were not satisfied (UNDP \& Government of Mongolia, 2006, p. 100). Given their partial understanding and appreciation of democracy, people are often unaware of their rights to express their voice, to be heard, and to actively engage in issues which affect them most.

In terms of human development, some social aspects of the country have been positive. Following a relatively well-developed education system during the

\footnotetext{
${ }^{8}$ It is the former communist party and was founded in 1921 and ruled Mongolia for over 70 years. The MPRP is still very powerful. It has won two parliamentary elections. Two presidents serving between 1996 and 2009 were elected from the MPRP.

912.7 percent of respondents said they did not know what democracy meant (UNDP \& Government of Mongolia, 2006).
} 
communist era, Mongolia today has a well-educated populace, reflected in a 98 percent literacy rate and the near absence of ethnic conflict, resulting in welldeveloped social capital (World Bank, 2007b). By 2006, the National Human Development Index attained its highest level at 0.718, making Mongolia a medium Human Development nation, with social indicators considerably more advanced than the average country with similar levels of GDP per capita (UNDP, 2007). In spite of these positive aspects of Mongolian society, the country faces many challenges, including the existence of an old communist mentality, nepotism, corruption, and power imbalances.

\subsubsection{Social and political issues}

Unlike the speed with which technical and institutional changes can be made, human mentality requires a longer period over which to change. Overnight reforms and radical institutional changes were made within a few years, and today the social and political institutions of Mongolia appear appropriate for the new democratic society. With its small population and adaptive nomadic characteristics, Mongolia has made a fast transition (World Bank, 2007b), but the most challenging task has been to change people's mentality and habits. The traditional mentality, a legacy of the communist past, including worship of the state, thereby being a 'passive recipient', still exists (UNDP \& Government of Mongolia, 2006, p. 10). Even after two decades of being a democratic country, fear of expressing opinions publically and the lack of trust between one person and the next are widespread social phenomena (USAID, 2005).

However, people are gradually learning new values and changing their attitudes. Time is necessary to learn new values, as people can become confused following massive changes in social ideologies and their associated values. Once prohibited items, such as freedom and money, now "represent" the principal aspirations of life. Once valued things, such as the communist ideology and its goals are no longer valued. Therefore, people and their mindsets during the transition between two very different social systems must be considered, in order to understand Mongolian society and its challenges (Griffin, 1995). 
Similar to other LDCs, nepotism and bureaucracy causes problems in society. As Mongolia has a family and locally oriented, small population, nepotism is common at social and political levels, and in business (USAID, 2005). People will often favour relatives or local tribal ties when voting in elections, making promotions and appointments in the public service, and providing public services (World Bank, 2004). Moreover, bureaucracy from the former regime still exists in the public service, due to the old mentality and a lack of understanding of the state's role in a democratic society with a liberal economy. Nepotism and bureaucracy contribute to the ineffectiveness of the public service and to increases in corruption (USAID, 2005).

Corruption ${ }^{10}$ has become one of the biggest social problems in Mongolia. According to Transparency International's Corruption Perceptions Rating, Mongolia moved from 43 in 1999 to rank 85 in 2004, and 116 in 2010, with a 2.7 score out of 10 (Transparency International, 2010). A survey conducted by a joint project of UNDP and the Mongolian Government reported that most respondents (88.9 percent) agreed that corruption had become widespread in the country (UNDP \& Government of Mongolia, 2006). The "ariin khaalga"11 or "backdoor" mentality from the previous period has also contributed to the endemic corruption (USAID, 2005). The danger of corruption is that it promotes more corruption at every level of society, sustains the "ill-belief" of people in giving bribes to succeed, causing deterioration of social trust, fairness and accountability.

Mongolia endeavours to combat corruption by the declaration of zero-tolerance in its National Millennium Development Goal 9 (UNDP, 2005). The main anticorruption policy documents are the National Program to Combat Corruption and the Anti-corruption Law (The State Great Khural of Mongolia, 2006a) among

\footnotetext{
${ }^{10}$ Corruption is regarded as the use of public office for illicit private gain (could involve bribe or self-interest). LaFree and Morris (2004) define it as "an abuse of public office that violates formal and informal norms, that brings direct or indirect gain to a public official and provides a third party with services or resources that would otherwise be more difficult or impossible to obtain" (cited in Fritz, 2007, p. 191).

11 "Ariin khaalga allowed Mongolians to cope under the Communist rule. It remains an efficient way to get things done in government-to-business and government-to-citizen interaction in Mongolia" ... "many Mongolians simply look for a friend, family member to circumnavigate the formal system of rules" (USAID, 2005, p. 19)
} 
others. To address corruption more effectively, the law was passed in 2006, establishing an authority to combat corruption that is independent of government. The authority aims to "educate and raise public awareness and prevent corruption" (The State Great Khural of Mongolia, 2006a, Provision 18.1).

Another social and political issue is the worsening of power imbalances. The democratic revolution decentralised political power and ended one-party domination. Liberal economic programmes enabled the establishment of private properties through privatisation in almost every economic sector. However, political and economic power gradually became concentrated in certain parties, groups, and people (UNDP, 2006). As noted above, political power and decisionmaking are mainly exercised by two dominant political parties in spite of the existence of seventeen other political parties.

The linkage between politics and business has gradually tightened (UNDP, 2006; UNDP \& Government of Mongolia, 2006, p. 30), which has resulted in political oligarchy and economic oligopoly, evidenced by the increased number of businessmen who are members of parliament; donations from businesses to political parties during elections; and political appointments for businessmen, who are large donors, to high ranking positions within ministries. This has resulted in a weak, corrupt public sector which is prone to political influence and favouritism. There is a lack of merit-based appointments, and increased instances of conflict of interest in the public service (Radnaasumberel, Baatartogtokh, Purev, \& Namkhai, 2006).

These issues have been detrimental to public confidence in democracy and democratic processes. According to the survey, following the Fifth International Conference of New or Restored Democracies, respondents ranked corruption (36.2 percent); "bureaucracy and red tape" (15.9 percent); "poverty, differences between rich and poor people" (11.5 percent); injustice (7 percent); and "old communist ideology, one party domination" (6.8 percent) as the main obstacles to Mongolian democracy (UNDP \& Government of Mongolia, 2006, pp. 100-101).

The more recent threat was the riot of 1 July 2008 in the capital city. The riot began with hundreds of people demonstrating in front of the MPRP headquarters, 
as they were annoyed with the alleged parliamentary election result. There were regrettable consequences, including deaths, arrests, and social chaos: five civilians were killed, 220 civilians and 108 service members were injured, and $731^{12}$ people were arrested, of whom 140, including 13 minors and 3 women, and sentenced from 2 to 7 years in prison as of 31 October 2008 (Wikipedia, 2008). The MPRP headquarters and the Cultural Palace were set on fire. Following the riot, the President declared the first state of emergency for four days. The country was in a state of shock. The riot "left a legacy of ill-treatment, impunity and injustice", and was "in sad contrast to progress that Mongolia has made in recent years in improving human rights" (Amnesty International, 2009, p. 23).

After the riot, the public, especially civil society organisations, feared that state suppression from the previous communist regime might re-occur. Therefore, people became silent and hopes for a stronger democracy were weakened. Perhaps, the public began "to worry that a self-interested elite is monopolising both political and economic power" (David, 2010, p. 255). However, a year after the riot the presidential election result revitalised hopes for democracy. The candidate of the Democratic Party, supported by other opposition parties, was elected in spite of a powerful competitor, the incumbent president from the MPRP who had held the position for 8 years. The new democratic president, campaigning on a theme of anti-corruption, was supported by 51.21 percent of voters (Mongolia-Web, 2009). He became the first president of the opposition Democratic Party (Bulag, 2010).

Given its economic, social and political background, Mongolia has experienced various challenges in its transition period. One emerging issue is the booming mining sector. Debate is growing in public arenas around the development of the mining sector, especially regarding its social and environmental impacts on local regions and the country as a whole.

\footnotetext{
${ }^{12}$ Most arrested people were freed after the new presidential pardon
} 


\subsubsection{Mining sector}

\subsubsection{Overview of the mining sector}

Mongolia's complex geology, which underlies diverse landforms of mountains, steppes and the Gobi desert, provides extensive mineral resources of about 800 deposits and 8,000 findings, comprising 80 different minerals identified to date, which cover 28 percent of the territory (Myagmarsuren, 2006; Unen sonin, 24.12.2007). The most economically significant minerals are base metals, most notably, copper, gold, zinc, silver, coal, fluorspar and uranium ${ }^{13}$.

In 2008, the mining sector accounted for 28.2 percent of the GDP, 64.3 percent of total industrial products and 80.7 percent of total exports (Mongolian National Statistical Office, 2009). The mineral dependency of Mongolia was 24th highest in the world in $2000^{14}$ and its mineral exports accounted for 25.45 percent of GDP (Ross, 2008, p. 195). This is due to its sizable deposits of copper, gold, coal and other minerals, and its relatively narrow economic base.

Since the mid 1990s, mineral exploration and mining has rapidly increased, following new laws and mineral discoveries. The cornerstones of mining regulations are the Constitution Law (1992), Law on Mineral Resources (1997), Foreign Investment Law (1993), Taxation Laws (1993 and 1998), Law of Environmental Protection (1995), Law of Environmental Impact Assessment (1998), Land Law (2002) and Law on Special Protected Area (1994). Consistent with the neo-liberal structural adjustment programme, these laws, particularly, concerning minerals, taxation, and foreign investment were intended to attract foreign investors by promising favourable mining conditions, such as a 'first come, first served' approach and tax holiday incentives.

\footnotetext{
${ }^{13}$ With growing international interests in uranium and an abundance of resources in Mongolia, uranium is likely to become a significant mineral in the near future.

${ }^{14}$ As the percentage of mineral exports to the GDP increased to 29 percent in 2008 (Mongolian National Statistical Office, 2011), mineral dependency can be higher than in 2000.
} 
Other important factors underpinning the mining boom are the increased world mineral demand ${ }^{15}$ and widely publicised discoveries of the Oyu Tolgoi copper/gold and Tavan Tolgoi coal deposits at the beginning of the new millennium ${ }^{16}$. After these discoveries, exploration licences and land held by licence-holders increased five-fold. By 2008, there were 4644 exploration licences and 1115 mining licences covering 44.4 percent of its territory (Shiirevdamba, 2009). Today, 500 mining companies operate, of which 127 are gold mining companies (Tsogtbaatar, 2009).

International mining companies and donor organisations have enthusiastically supported mining development as a source of Mongolian economic growth (World Bank, 2004, 2007b; World Growth, 2008). Today, the mining sector attracts considerable domestic and international interest and it plays an important role in the Mongolian economy. However, this sector has to be examined in terms of the complex economic, social, and environmental contexts in order to understand the impact of existing mining practices and to formulate appropriate action to ensure that mining can benefit the country.

\subsubsection{Mining impacts}

\subsection{Economic impacts}

With new mineral resource discoveries, favourable international market demand, and increased prices for minerals, the mining sector has developed rapidly over the last two decades. The sector has attracted increased domestic and international attention and investment because of supportive legislative and regulatory frameworks ${ }^{17}$, based on the neo-liberal economic view, which claims that increased foreign direct investment will result in GDP growth, and in turn will

\footnotetext{
${ }^{15} \mathrm{~A}$ big portion of this demand relates to China, due to its rapidly growing industries. Being a neighbour of China, Mongolia faces both international and domestic pressures to have more exploration and mining.

${ }^{16}$ These deposits are considered to be world-class deposits. According to information published by Ivanhoe Mines Limited, the mineral explorer and investor of Oyu Tolgoi copper and gold deposits, two mines are expected to produce an annual output of 500,000 tons of copper and 330,000 ounces of gold for at least 35 years (Ivanhoe Mines Mongolia Inc, 2005).

${ }_{17}$ Mongolia is ranked $15^{\text {th }}$ out of 64 countries for its favourable legal framework for mining (Fraser Insititute, 2007).
} 
help alleviate poverty and improve social well-being (World Bank, 2004; World Growth, 2008). Foreign direct investment increased five-fold ${ }^{18}$ between 2002 and 2006 (World Growth, 2008, p. 3), and GDP growth reached its highest points ${ }^{19}$ of 8.4 percent in 2006 and 10.2 percent in 2007 (Mongolian National Statistical Office, 2009).

However, mining-led economic growth does not necessarily reduce unemployment or alleviate poverty. Compared with other sectors, mining does not provide much employment. By 2009, it employed 49,000 people in Mongolia only 4.7 percent of the labour market (Tsogtbaatar, 2009). Moreover, GDP growth, created principally by development of the mining sector, has not had a positive effect on income inequality, a major problem in Mongolia, where 32.2 percent $^{20}$ of the total population live in poverty (UNDP, 2007, p. 11). The widely advocated economic benefits of the mining sector are questionable.

\subsection{Social impacts}

Mongolia has a relatively short mining history that can be traced back to the communist era ${ }^{21}$. State-owned companies had principally mined copper, molybdenum, and coal. Since the mid 1990s, mining has increased dramatically as a result of supportive policies, such as a government programme called 'Gold Programme, 22 and the investor friendly legislative framework. With growing economic interests and mining activities, people have expected much from the development of mining in their areas. However, mining has failed to meet public

\footnotetext{
${ }^{18}$ Mining sector received about $\$ 200$ million FDI in 2006, compared with $\$ 40$ million in 2002 (World Growth, 2008).

${ }^{19}$ Especially, after the Boroo Gold mining started its operation in 2004, the total mining production has nearly doubled (MRPAM, 2008).

${ }^{20}$ However various civil society organisations argue that the poverty rate in practice can be higher than 36 percent, as official statistics are often 'underestimates' of the status quo (UNDP, 2006).

${ }^{21}$ In the late 1970s, a joint venture of Mongolian and former USSR governments - called Erdenet was built. It is the only copper and molybdenum mining and processing company. Since then, the company has been the most significant income producer for the country. Erdenet city, the second biggest city of Mongolia, has established alongside the company development.

${ }^{22}$ In 1993, the government initiated the 'Gold Programme' to increase gold mining and thereby promote budget income and economic growth. However, economic benefits of mining outweighed proper consideration of environmental and social issues that might arise from mining (IUCN \& URM NGO, 2010). The programme is still in force.
} 
expectations of the benefits of development to local society and the lives of local people.

Mining legislation requires that mining companies hire 90 percent $^{23}$ of their total employees from the Mongolian population (The State Great Khural of Mongolia, 1997, Article 43). However, anecdotal evidence suggests that companies often breach this requirement and employ foreign mining engineers and workers ${ }^{24}$. This is related to the lack of trained, skilled, appropriately qualified local people (World Bank, 2006). Therefore, local areas often do not benefit from mining through employment.

As mining companies often do not hire local people, foreign and domestic migrants bring social problems to local areas. Social services and resources, such as education, health, and water sources, have become scarcer as the number of users has increased (World Bank, 2006). Migrants have also brought increased alcoholism, crime, prostitution and diseases in local areas, as miners are often male workers, away from their families (World Bank, 2006, 2007b).

Mining-related conflicts between local communities and mining companies are increasing as mining often occurs on state-owned pastoral land. According to the Constitution (1992), land is state property and can be used by local people for pasture. As in other LDCs, mineral rights belong to the state, while local communities can use only the land's surface (Szablowski, 2007, p. 34). Mongolian land has not been privatised because of the tradition of nomadic culture. Unlike farming, nomadic husbandry requires movement several times a year depending on the season. Therefore, herders live on relatively large areas all year round. Although local authorities register some pastoral areas for local use ${ }^{25}$,

\footnotetext{
${ }^{23}$ The Mineral Law allows mining companies to employ foreign employees but they must comprise no more than 10 percent of their total employees. Otherwise, companies must pay a penalty to the local administrative body that is ten times the minimum wage (The State Great Khural of Mongolia, 1997, Provision 43.2)

${ }^{24}$ Particularly, for Chinese invested or owned companies that are most likely to hire Chinese workers from China. This migration causes conflict as most Mongolians are not friendly to Chinese people.

${ }^{25}$ By law, mining licences should not be issued for areas registered as in local use. However, due to weak coordination and information sharing there are some cases in which licences are locally registered, but not registered in the Cadastral Agency information system.
} 
there are no other protection mechanisms for locals to save their pastoral land from mining (Suzuki, 2008). Therefore mining, which covers extensive landareas, forces herders to move without proper compensation (Snow, 2010). The migration of herders who have lost their pasture results in further conflict with herders in other local areas when they try to share pasture. Moreover, conflicts arise due to lands not being rehabilitated after mining and becoming infertile, thereby being unavailable for pasture and grazing.

Even if there are few conflicts over pastoral land, local people are often unhappy with mining in their regions because of its poor contribution to local development. Most taxes from mining go to the central government budget and only a few minor fees and payments are allocated to local budgets. However, mining companies usually provide ad hoc donations to local administrative bodies, particularly to governors on their request, but mining companies often do not widely inform the public about such donations (Crane White \& Accosiates, 2007). Most donations are either in cash for financing local anniversaries and festivals, or in-kind donations, such as vehicles, computers and renovations of local buildings and hospitals. However, there is no sustained comprehensive development programme for local areas (World Bank, 2006), which compounds the dissatisfaction of locals with mining. Moreover, the non-transparent contributions of mining companies promote corruption in the local public sector.

A serious issue for many regions during the last decade is artisanal mining, which began in Mongolia due to increased poverty ${ }^{26}$ and unemployment in the late 1990s (UNDP, 2007). This illegal mining appeared increasingly where gold/mineralbearing tailings were left from abandoned commercial mining (Dierkes \& Khushrushahi, 2006). Due to the 'cost-efficient' approach of businesses and lack of financial capacity, most small and medium mining companies use out-dated, cheap technologies and equipment that are incapable of efficiently processing extracted ore-bearing soils (World Bank, 2007a). Therefore, mining companies

\footnotetext{
${ }^{26}$ Particularly in the countryside, where the loss of livestock during 'dzud' disasters (extreme cold and excess snowing) that occurred in the late 1990s and early 2000s made many herders poor and desperate to find other sources of income.
} 
often focus on ores with a high concentration of gold, and leave tailings and dams containing minor parts of gold that are uneconomic to process (World Bank, 2006, 2007a).

This practice resulted in increased artisanal mining of abandoned tailings that remained from legal mining. It became the source of living for 30,000 to $100,000^{27}$ people, including men, women, children and older people (MRPAM, 2008). Today, ninja ${ }^{28}$ or artisanal miners work in 112 places of 83 soums of 16 $\operatorname{aimags}^{29}$ (Tsogtbaatar, 2009). Places with artisanal miners are often riddled with crime, prostitution, disease and loss of life (World Bank, 2006). In the absence of regulations concerning work safety, there are many accidents resulting in many deaths (World Bank, 2006). Currently, no effective legislation regulates artisanal $\operatorname{mining}^{30}$, and artisanal miners are excluded from mainstream society, with no access to health, education, and other public services.

\subsection{Cultural impacts}

Cultural impacts of mining should be taken into account, as the traditional Mongolian way of living is closely related to the natural environment. Mongolia has had a unique nomadic culture and shaman religion for centuries, which encouraged people to live in harmony with nature and to respect its biodiversity. Land was regarded as sacred and excavating it would have been taboo. As Jachid and Hyer (1979) illustrate, "Mongolian nomads have been psychologically conditioned for centuries to feel that toiling in the soil is not a proper way for humans to make a living" (p. 297 cited in Quah, 2003). Given this cultural background, mining, particularly large-scale mining, did not occur in Mongolia until the $1970 \mathrm{~s}^{31}$.

\footnotetext{
${ }^{27}$ Year round artisanal miners are about 30,000-40,000. This number increases during summer and reaches about 100,000 people or more (MRPAM, 2008).

${ }^{28}$ Another name for artisanal miners

29 'Aimag' is the biggest administrative unit in Mongolia. There are 21 aimags (Mongolian National Statistical Office, 2011).

${ }^{30}$ Bill for artisanal mining is on the Parliamentary discussion for recent years. The temporary regulation on artisanal mining came to force in 2007 , but it is not having impacts on the issue (World Bank, 2006).

${ }^{31}$ The Mongolian biggest mining company, Erdenet, was established in 1976. Erdenet is the biggest producer and exporter of copper and molybdenum.
} 
Since the mid 1990s, nomadic culture has been threatened by mining development in many aimags. Both legal and illegal mining have negatively affected nomadic culture. Large-scale migration of mining workers to local areas has caused rapid changes in culture (World Bank, 2007b). In artisanal mining, in particular, traditions and morality have been heavily violated (World Bank, 2006). For instance, the nomadic culture of respecting the land and water resources, and the tradition of respecting children and elders, are seriously ignored in localities with artisanal miners and foreigners.

Some heritage and culturally important places have been threatened by mining, as legislation and its enforcement have neglected the cultural impacts. Mining companies have failed to carefully respect heritage sites, sacred mountains, and water resources in their licensed areas. This has annoyed local people and created conflict with mining companies, giving rise to social movements and NGOs to address mining-related issues so as to protect the cultural heritage.

\subsection{Political impacts}

Another problem of mining in LDCs such as Mongolia is the political impact. In spite of an absence of in-depth studies, the current state of mining and politics in Mongolia demonstrates how mining can affect the politics of a country. As in other LDCs with rich mineral resources but poor economic conditions, Mongolia has a corrupt and politicised public sector which is vulnerable to rent-seeking activities, particularly in relation to extractive industry matters.

Typical rent-seeking behaviours in Mongolia include a windfall tax ${ }^{32}$, royalties, bribes, lobbying, and mandatory state shares ${ }^{33}$ in mining (World Bank, 2007b). The parliament passed the Windfall Tax Law in the spring of 2006, which caused

\footnotetext{
${ }^{32}$ Windfall tax on gold and copper mining was passed in 2006. By the law, during the favourable world mineral price situation, $68 \%$ of excess gold sale income (for gold, above US $\$ 500$ per ounce and for copper, above US $\$ 2800$ per tonne) is paid as windfall profit tax (The State Great Khural of Mongolia, 2006b). The law was disregarded in 2009.

${ }^{33}$ The Mineral Law amendment in 2009 states the Mongolian state should hold shares in a strategic mineral deposit: 34 percent if it is explored by private companies and 50 percent if the deposit is explored by state investment (The State Great Khural of Mongolia, 1997).
} 
a significant decrease in gold mining production ${ }^{34}$ (Portfolio Media Inc., 2007). Mining companies, investors and international donor agencies strongly criticised legislation on the windfall tax and the minerals law amendments in 2006, which require a mandatory state share in large deposits and identify 15 large deposits as strategic state deposits (World Bank, 2007b; World Growth, 2008). According to the Fraser Institute survey, Mongolia's mining legislation was an "unfortunate development" and the overnight legal changes resulted in the "collapse" of the favourable Mongolian legal environment for mining investors, evidenced by its reduced rank on the policy potential index, moving from 33 out of 64 in 2005/2006 to 62 out of 65 in 2006/2007 (Fraser Insititute, 2007).

Within Mongolia, these legislative changes caused enormous debate and conflict among political parties, NGOs, and the public. Anecdotal evidence suggests that mining becomes excessively politicised during elections. The most recent debate was on the government stability agreement with Ivanhoe Mining for its Oyu Tolgoi copper/gold mining project in the Southern Gobi. Several stability agreement proposals were discussed by governments and parliaments since 2004 and it was finally signed in September 2009. The process created huge social and political debate, protest, and conflict among politicians, governments, mining companies, international organisations, NGOs, academics, and the public in Mongolia.

Moreover, growing interests in mining have promoted corruption and red-tape in the country. Licence issuing and other mandatory legislative requirements are prone to corruption, as mining companies bribe public officials and servants "to obtain mining licences and avoid tax and customs payment” (USAID, 2005, p. 4). In general, the economic, social and political impacts of mining are deeply interrelated but are not easily observable.

\footnotetext{
${ }^{34}$ Anecdotal evidence suggests that although some small and medium mining companies stopped their operations, the law resulted in shadow exports of extracted gold without an intervention of the central bank which is in charge of buying all extracted gold and thereby monitors gold mining production.
} 


\subsection{Environmental impacts}

The impacts on the natural environment of increased mining activities have become more evident. Consequently, environmental concerns about mining development have increased significantly since the mid 2000s.

As suggested in the World Bank report (2006), Mongolia - A Review of Environmental and Social Impacts in the Mining Sector, the environmental record of the Mongolian mining sector is, at best, mixed. Its key environmental impacts are changes in hydrological regimes, deterioration of water and soil qualities, increases of mercury and cyanide pollution, and waste-rock piles and tailing repositories (World Bank, 2006, pp. 1-3).

Given that Mongolia is a land-locked country with scarce water resources, mining-related water pollution and the improper use of water are serious issues. Potential water resources of the country are estimated at about 36.4 square kilometres (Dorjgotov \& Purevsuren, 2006). As Mongolia consists of arid and semi-arid regions, there is a great risk of water scarcity (UN, 2007, p. 4).

By 2007 some 28 rivers ${ }^{35}$ had dried up and 56.2 ha land in 25 soums $^{36}$ of 10 aimags were poisoned by mercury and cyanide as the direct result of mining activities (2008). As gold deposits of open-pit mining often appear along river basins, many mining companies operate near rivers. Using their out-dated technologies such as dredges and "water guns ${ }^{37}$ to separate gold from ores by washing ore-bearing soils, some mining companies illegally redirect river flows and draw off substantial volumes of water (Grayson \& Baatar, 2009). This reduces water quantities down-stream in localities where water is a major resource for herding animals and for sustaining the biodiversity.

\footnotetext{
${ }^{35}$ Due to the lack of professional skills and technical capacities to measure water quality and pollution, the actual number of dried-up rivers may be greater.

36 'Soum' is an administrative unit after an aimag. Mongolia has 338 soums (Mongolian National Statistical Office, 2011).

37 'Water guns' are medium and large sized equipment commonly used by open-pit mining companies. They use gravitational force to separate gold concentration from ore-bearing material.
} 
Water ${ }^{38}$ quality is also affected by mining. Water pollution is caused by discharges of mining-processed water into nearby water ways to reduce costs, and the number of accidents are increasing due to the collapse of poorly constructed dams (World Bank, 2006). Government organisations have ineffectively regulated and monitored water quality, due to a lack of human, financial and technical capacities (ADB, 2005). The financial capacity of government organisations is limited as they must invest much to train specialists and acquire equipment to monitor water and soil qualities (MNPC, 2008). Anecdotal evidence suggests that more rivers and lakes are in danger of becoming polluted and drying up unless improvements are made to current mining practices, the regulatory framework and its implementation.

Another environmental problem caused by mining is cyanide and mercury pollution. Mercury and cyanide ${ }^{39}$ are commonly used chemicals in Mongolian mining. Since hard-rock mining began in 2000, and especially after a large project, Boroo Gold, by a Canadian mining company which began in 2004, cyanide use in mining has increased (Myagmarsuren, 2006). However, state controls on cyanide imports and usage are weak (MNPC, 2008). Moreover, improper use of mercury for gold washing by illegal miners has become a major cause of river and land pollution (World Bank, 2006). According to an extensive study by government authorities, sodium cyanide and mercury have been released in nine aimags in the Central and Gobi regions by 2007 and alleged incidents of mercury poisoning have increased (Mongolian River Resources, 2007a).

The most devastating mining-related scandal happened in Khongor soum near the third largest city Darkhan, 240km north of the capital city. There was a spillage of waste mercury and cyanide from an illegal gold washing operation in the factory owned by the governor of Khongor soum. Mercury and cyanide, which had been smuggled into Mongolia from China, were excessively used in the factory. Local

\footnotetext{
${ }^{38}$ In terms of annual water consumption, mining is the second largest user of water after the energy sector, accounting for 22 percent of total consumption (Batbayar, 2009).

${ }^{39}$ Gold ore is crushed with mercury first and as a result of amalgamation about 30 percent of the gold ore is extracted. The remaining 70 percent of gold ore is taken out from the waste by a solution of cyanide (World Bank, 2006).
} 
residents only became aware of this after the spillage in February 2007 (The HUB, 2007).

Some water supplies and soil in the area became contaminated by the spillage of mercury and cyanide. By the end of 2007, about 700 local people were poisoned and had suffered serious health problems; pregnant women suffered miscarriages, and animals died unusual deaths (Olloo.mn, 2007). Although environmental testing by the World Health Organisation (WHO) revealed that pollution in Khongor was at acceptable levels, locals and some NGOs made opposing claims (Sumyabazar, 13.03.2008). In November 2007, a public protest organised by human rights groups and other NGOs was held in the capital city after miscarriages of nine local women. Meanwhile, local people organised a small demonstration in Khongor soum on a main highway leading to Darkhan city (Batmonkh, 03.01.2008). However, the government and state organisations refused to acknowledge that cyanide and mercury poisoning was occurring in Khongor soum. In January 2008, the prime minister apologised to local residents for the government's provision of misleading information (Sumyabazar, 13.03.2008). The Khongor case demonstrated the potential environmental, health and social impacts of mining. In spite of contradictory views among state, public, and civil society organisations, the Khongor pollution made Mongolians recognise the environmental impacts of mining.

The lack of proper rehabilitation in affected areas is a serious issue. According to the Minerals law (1997) and the Environmental Protection law (1995), all mining companies must carry out technical and biological rehabilitations. Although mining companies claim they already do this, investigation shows that the amount of rehabilitated land, the quality of rehabilitation and the quality assurance of mining rehabilitation measures are deficient and poorly managed (Saran, 2009). In 2005, a ministerial inspection organised by the Ministry of Nature and Environment investigated the quality of rehabilitation undertaken by 107 mining companies operating in nine aimags. Only 40.24 percent of the total affected area of 2454 ha had undergone technical rehabilitation but not biological rehabilitation (Ministry of Nature and Environment, 2008). 
In summary, mining induced environmental impacts affect local people in various ways. Some have been affected both directly and indirectly by contaminated water and soil, and suffered health problems. Some have lost fertile pasture land and hence livestock - the main source of living for herders. This has caused growing conflict among local people, mining companies, illegal miners, and the state.

\subsubsection{Challenges of the mining sector}

The principal issues can be summarised as a lack of mining awareness, poor governance, non-transparent information, and increasing social conflict.

As mining in Mongolia has increased, the state and the public have gradually begun to understand its potential impact. Due to the relatively recent emergence of mining in Mongolia's economy, public awareness of mining is almost nonexistent. An informal survey conducted by the Asia Foundation ${ }^{40}$ among herders in some regions, revealed that many still have no understanding of mining, how it might affect their lives, and how they could engage in mining activities. Public officials and public servants at both central and local government levels are also unfamiliar with mining practices. Possible economic benefits of mining are overemphasized in decision-making without consideration of its other potential impacts.

In spite of legislative requirements, regulation and enforcement of environmental protection and rehabilitation was poor until 2006, and it received scant attention from government organisations. Due to growing environmental conflicts, protests and appeals organised by local environmental NGOs, and recommendations of international donors and NGOs, government organisations have begun to give more attention to environmental matters and are gradually improving the enforcement and monitoring of rehabilitation (ADB, 2005; MNPC, 2008; Myagmarsuren, 2006; World Bank, 2006).

However, more effective regulatory mechanisms, standards, policies and institutions are needed to improve the quality and quantity of rehabilitation. As

${ }^{40}$ A USA donor NGO operating in Mongolia 
Mongolia did not previously ${ }^{41}$ have the commercial mining sector practices, most legislation was merely 'copies' of legislation from developed countries, without proper integration between legislative frameworks and institutions, and without the appropriate consideration of Mongolian characteristics (ADB, 2005). Moreover, human and institutional capacity constraints and the need for effective resolution of bureaucracy and conflicts of interest in the public sector must be addressed, as weak governance and institutional structure cause weak compliance with legislation and poor transparency (UNDP, 2006; World Bank, 2007a, 2007b).

Mining-related information is often not transparent to the public or to government organisations. Individuals and civil society organisations encounter difficulties in obtaining reliable information on the investment and investors of mining companies, taxes and other contributions paid by mining companies, numbers and areas of issued mining licences, reports of environmental protection, rehabilitation and monitoring of mining, and decisions made by the government organisations on mining-related issues (Myagmarsuren, 2006; USAID, 2005). Additionally, government organisations have produced different statistics and reports about the mining sector and its impact due to a lack of coordination and cooperation between them as well as poor institutional and human capacities (World Bank, 2007a). Such secrecy and controversy increases public distrust of the state and mining companies, and creates corruption and conflicts of interest in the public sector (USAID, 2005).

These developments benefit no one. The government becomes less stable, more prone to corruption and comes under pressure from NGOs and the public. For mining companies, it becomes difficult to operate as mining becomes politicised and receives greater scrutiny from its stakeholders (World Growth, 2008). Given this distrust, it becomes riskier and unsustainable for mining companies to operate long-term (World Bank \& International Finance Corporation, 2002). The public therefore becomes the most disadvantaged party, due to unpaid or unfairly

\footnotetext{
${ }^{41}$ The state-owned Erdenet copper mining and some coal mining companies operated during the communist period from the 1970 s.
} 
distributed mining taxes, income and compensation, worsening environmental degradation, increasing health issues, endemic corruption, and loss of national wealth.

Thus, there are growing debates and initiatives among mining constituents for the promotion of socially and environmentally responsible mining in Mongolia. The increased recognition of sustainable and participatory mining is apparent in the responsible mining definition formulated by participants of the multi-stakeholder forum on mining in 2007. They defined responsible mining as 'a comprehensive and transparent minerals activity respecting the rights of all stakeholders, especially of local people; environmentally friendly and free of human health impacts; embracing the best international practices and upholding rule of law whilst generating a sustainable stream of benefits for Mongolia' (Mongolian River Resources, 2007b).

While the mining sector has been enthusiastically supported as the income generator for economic development (World Bank, 2004; World Growth, 2008), recent public debates and initiatives show an increased acknowledgement of the importance of economically sustainable mining that can benefit all Mongolians (Ivanhoe Mines Mongolia LLC, 2008; MNPC, 2008). International donor organisations and national NGOs have played crucial roles in this process (Dierkes \& Khushrushahi, 2006; Snow, 2010; World Bank, 2006). Domestic environmental and human rights NGOs have increased social awareness of the social and environmental impacts of mining, particularly in local regions; and international donor organisations and NGOs have introduced international best practice frameworks for mining by organising and encouraging multi-stakeholder forums, supervising government organisations, producing various reports and funding capacity building projects.

To summarise, there is tension both globally and nationally regarding mining development. The tension is between the income generation sector and mining which is economically sustainable and participatory. The current trend is shifting towards the latter, with varying degrees of voluntarism. Big multinational mining 
conglomerates and international donor and civil society organisations lead in the introduction of benchmarks and appropriate frameworks for mining development. Domestic civil society organisations have simultaneously contributed through various activities and initiatives. The mining sector has encountered a fundamental challenge to its business-as-usual practices, and 'the train has already started to move'.

The next chapter will introduce social environmental accounting and an environmental management tool known as the environmental impact assessment. Both concepts explicitly address environmental and social aspects of business and encourage putting sustainability ideas into practice. 


\section{Chapter 3: AN ENVIRONMENTAL IMPACT ASSESSMENT AS A POTENTIAL DIALOGIC ACCOUNTING TOOL}

\subsection{Dialogic accounting for sustainability}

\subsubsection{Introduction to social and environmental accounting}

The potential of accounting for reshaping society is controversial. A growing number of social constructionist researchers argue that accounting is not mere calculation and reporting but it (re)constructs social worlds. Through its language and methods of calculation, accounting shapes/creates meanings (Tinker \& Neimark, 1988) and "inscribe[s] its ... values on the world" (Hutchinson, 1989 cited in Brown, 2009). Accounting, therefore, affects people's lives "through its influence on economic and social exchanges and the mediation of conflicts" (Brown, 2009, p. 314). In this respect, it has the potential to promote sustainable development.

However, mainstream accounting has failed in practice to address sustainable development and corporate social responsibility, possibly because of its positivist roots and its monologism. Some researchers argue that accounting has become a technical authoritative tool which serves capitalism (Cooper \& Sherer, 1984; Gray, 2006a; Unerman \& Bennett, 2004). Its emphasis on profits and business interests are related to its positivist epistemology and neo-classical economic roots (Bebbington, Brown, Frame, et al., 2007; Brown, 2009). In the name of being objective and credible, accountants are expected to be value-neutral and apolitical professionals who produce "fair value" and assist users to make economically rational decisions (Gray, et al., 1996). However, researchers have increasingly argued that accounting is not value-neutral or apolitical (Cooper \& Sherer, 1984; Lehman, 2005; Lehman, 2001; Spence, 2009; Tinker \& Neimark, 1987). Rather, it is a subjective process by which means of power are exercised (Brown, 2009) and some unwanted issues, such as the environmental and social effects of businesses, are excluded by powerful groups under the name of 'externalities' (Gray, 1992), and do not recognised as real costs to economic actors (Jacobson, 1990). 
Since the 1970s, social and environmental accounting (SEA) has attempted to address the deficiencies of mainstream accounting, particularly on social and environmental matters. SEA is "the process of communicating the social and environmental effects of organisations' economic actions" to stakeholders (Gray, et al., 1987, p. ix). Researchers argue the need for public-interest oriented accounting (Cooper, 2005; Lehman, 2005; Sawabe, 2005), which can consider broader social influences and can "internalise" externalities into accounting and decisions (Gray, 1992; Mathews, 1997). In this respect, SEA is seen as "a vacant space of possibility" to reconsider "the relationship between forms of calculation and democracy" (Power, 1992, cited in Brown, 2009, 492-494).

Through applications of various perspectives, theories and approaches, SEA has burgeoned and attracted "almost unprecedented level[s] of interest" (Gray, Dey, Owen, Evans, \& Zadek, 1997). Much research covers a wide range of issues, such as social and environmental accounting, accountability, corporate social responsibility, sustainable development, accounting education, and accounting theories; research uses interdisciplinary approaches, and employs numerous theories not only from accounting but also from other disciplines. Today, SEA accommodates different perspectives and studies, ranging from the purely critical to those offering alternatives to conventional accounting.

This diversity challenges SEA itself. Some researchers are critical of some theories applied in SEA. They criticise their application for being companycentric, reflecting dominant neo-liberal economic models (Lehman, 1999), and for being constrained by instrumental reasoning and technical rationality (Cooper, 1992; Puxty, 1991; Tinker, Lehman, \& Neimark, 1991). They argue that existing cost-benefit analysis falls short of addressing sustainability (Bebbington, Brown, \& Frame, 2007) and that current voluntary social reporting initiatives lack commitment in practice (Gray, 2002; Lehman, 1995, 1999, 2001; Mathews, 1997).

Following corporate voluntary reporting, mainly in developed countries, studies have investigated the motivation, quality, and commitment to sustainable 
development by comparing reports with claims. In spite of evidence of changing business practice that incorporates the notion of being socially responsible, some researchers are sceptical of voluntary reporting practices. They criticise its selfpraising nature (Deegan \& Rankin, 1996, 1997; Guthrie \& Parker, 1990) and the tendency to 'green-wash' (using the term sustainable development in their reports while practices have actually been 'business-as-usual') (Cooper \& Sherer, 1984; Gray, 2006a; Gray, Walters, Bebbington, \& Thompson, 1995; Milne \& Gray, 2007). Consequently, more researchers have called for research which examines accountability not only from a corporate perspective but also from that of other stakeholders (Mathews, 1997; Milne \& Gray, 2007).

In this vein, some researchers have advocated pluralistic and democratic accounting (Bebbington, Brown, Frame, et al., 2007) that can 'humanise' business (Cooper, 1992; Gray, 1992) and promote sustainable development and democracy (Adams \& McNicholas, 2007; Brown, 2009; Gray, 2006a; Lehman, 2001; Saravanamuthu, 2004). This challenge requires a systems approach to accounting so issues can be studied in the context of their social complexities (Gray, et al., 1996; Morgan, 1988; Unerman, et al., 2007) and power relationships (Lehman, 1999; Spence, 2009; Tinker, et al., 1991).

A critical interdisciplinary approach is promising, as it embraces wider social, economic, and environmental considerations and recognises power inequalities (Bebbington, Brown, Frame, et al., 2007; Bebbington, Gray, Hibbit, \& Kirk, 2001; Cooper, 1992; Gray, 2006b; Mathews, 1997; Tinker, et al., 1991). Additionally, interdisciplinary research in SEA connects accounting with other disciplines, such as sociology, politics, and environmental, pedagogic, and development studies (Everett \& Neu, 2000; Hines, 1991; Thomson \& Bebbington, 2005; Tinker \& Neimark, 1988).

One emerging SEA area is dialogic accounting. Its pluralistic roots and encouragement of democracy provide the potential to address the SEA challenge of promoting pluralistic and public-interest oriented accounting. It is increasingly advocated for addressing accounting challenges regarding participation and 
sustainable development (Bebbington, Brown, Frame, et al., 2007; Brown, 2009; Gray, et al., 1997; Unerman, 2007). Dialogic accounting may enable SEA to contribute to "emancipatory social transformation" (Bebbington, Brown, Frame, et al., 2007, p. 357) by promoting participatory accounting which can acknowledge different perspectives and values, and challenge existing monologic accounting.

\subsubsection{Dialogic accounting}

Dialogic accounting is based on theories developed by Freire, Bakhtin, Habermas, Rawls and Mouffe (Bebbington, Brown, Frame, et al., 2007). Its central assumption is that "it is possible to resolve the contradictions in different worldviews, not by denying their differences but by denying the invasion of one worldview by the other and identifying the support and commonality each worldview offers to others" (Bebbington, Brown, Frame, et al., 2007, p. 364).

By "taking pluralism seriously", dialogic accounting challenges the monologic and technocratic nature of mainstream accounting (Brown, 2009; Dillard \& Roslender, 2011). The latter instrumental rationality reproduces a unitary view of the world which ignores social diversity and alternative perspectives. Its monetary reductionism emphasises economic factors while excluding their social and environmental impacts (Söderbaum \& Brown, 2010). Dialogic accounting, by contrast, rejects monologism and finding "one right answer" through economic rationalism and "value neutral" experts (Brown, 2009). Instead it favours a systemic approach which recognises different perspectives. The aspiration is to create a social reality which is presently excluded by the economic domination of monologic accounting (Brown, 2009; Söderbaum \& Brown, 2010).

Dialogic accounting particularly supports participatory projects, especially deliberative and agonistic democracies, formulated by Habermas and Mouffe (Bebbington, Brown, Frame, et al., 2007; Brown, 2009; Lehman, 1995; Lehman, 1996; Lehman, 1999; Power \& Laughlin, 1996; Unerman \& Bennett, 2004). Being pluralistic, they do not regard the different perspectives of opponents as problematic; rather, they are considered legitimate as long as they can accept valid 
dissent (Brown, 2009, p. 321). Differences among social actors and hegemonic struggles are not perceived as threats, but as "central to democratisation" (Brown, 2009, p. 320). Hence, the participation of stakeholders with differing views on development projects is widely advocated by dialogic accounting.

Thus, dialogue becomes a platform or space where participants with varying perspectives and values can discuss certain issues and "(re)construct their social realities" (Brown, 2009, p. 328). As Bebbington et al. (2007) state, dialogic accounting encourages "the heterogeneous interaction of multi-voiced dialogue" to expand meaning and understanding (Shields, 1996 cited in Bebbington, Brown, Frame, et al., 2007). Dialogue is particularly important for socially and environmentally sensitive issues that may arise from economic activities. However, full participation by stakeholders is problematic due to information asymmetries and existing power imbalances (Söderbaum \& Brown, 2010).

Dialogic accounting is critical by nature. It recognises that power inequalities among participants constrain effective engagement in dialogue. Power has negative repercussions when "used to exercise domination or oppression directly or indirectly" and to silence people. However, the exercise of power is always incomplete and is "the basis of all forms of behaviour in which people resist, struggle and fight for their image of a better world" (Freire, 1985). By its acknowledgment of power, critical dialogic accounting promotes the participation of marginalised people affected by economic activities although excluded from participating in them (Brown, 2009; Molisa, et al., forthcoming).

In most cases, affected communities or indigenous people do not have rights of participation and dialogue about development projects that have potential social and environmental impacts on them. However, a critical dialogic approach can promote dialogue that would provide "platforms for normally unheard voices to be heard" (Bebbington, Brown, Frame, et al., 2007, p. 366). Through fuller participation, it is argued that participants can better understand different perspectives, learn mutually from each other, and "create better outcomes" and accountability (Bebbington, Brown, Frame, et al., 2007). In this respect, social 
learning exercised through dialogue is "at the centre of ... the critical project" (Bebbington, Brown, Frame, et al., 2007; Brown, 2009).

However, dialogic accounting has attracted criticism, not least for the underdevelopment of its theories and practices (Bebbington, Brown, Frame, et al., 2007; Brown, 2009; Frame \& Brown, 2008; Thomson \& Bebbington, 2005). Its theoretical development is still in its infancy. Although it recognises the importance of pluralism and participatory democracy, dialogic accounting researchers have advocated different types of participatory democracies and their applications, especially in the context of sustainability (Bebbington, Brown, Frame, et al., 2007; Brown, 2009; Dillard \& Roslender, 2011; Frame \& Brown, 2008).

Dialogic researchers recognise the barriers and practical difficulties that any dialogic process might encounter, but its underdeveloped theory and practical application has inhibited its operationalisation. Current institutional arrangements lack the room and capacity for democratic participation (Söderbaum, 2007; Söderbaum \& Brown, 2010). Powerful decision-makers may be unwilling to promote effective dialogue among various stakeholders for fear that "dialogic approaches may cause difficulties for power elites and lead to heightened stakeholder demands" (Brown, 2009, p. 335). Others have criticised participatory approaches for being time-consuming and costly (Jones, 1997). Moreover, decision-makers trained in technocratic, positivist paradigms tend to resist dialogic approaches in the name of finding "right answers" on behalf of others (Brown, 2009, p. 336). They are often uncomfortable "with uncertainty associated with the absence of pre-specified foundations" and find dialogics too complex to operate (Brown, 2009). Moreover, dialogic approaches may be constrained by a lack of information access and by the ability of stakeholders to participate (Bebbington, Brown, Frame, et al., 2007).

Dialogic accounting lacks empirical studies of its application in LDCs, as it has been developed principally in developed countries. The latter usually have better institutional arrangements, more democratic participation, and better public and 
private sector accountability, due to relatively well-enforced legislative frameworks (Molisa, et al., forthcoming).

Much critical dialogic accounting research focuses on accounting democratisation by using a sustainability assessment model developed in the United Kingdom and New Zealand (Bebbington, Brown, Frame, et al., 2007; Brown, 2009; Frame \& Brown, 2008). However, there are not yet empirical studies or critical dialogic accounting proposals for LDCs (Molisa, et al., forthcoming). Less developed countries vary significantly from developed countries in terms of their social, political, economic and cultural contexts. The understanding of democracy and participation can differ in LDCs due to their "legacies of colonialism, the impact of socio-economic inequality on democratic politics, the democratic participation of the subaltern, and the pivotal role of the (Third World) state" in social arenas (Kapoor, 2008, p. 98). Therefore, critical dialogic accounting needs to recognise the differences between developed and developing countries, and may need to modify its proposals according to each LDC's context.

Researchers suggest using dialogue to operationalise critical dialogic accounting to resolve controversial issues, such as sustainability, accountability, and development projects with social and environmental impacts (Molisa, et al., forthcoming). In many LDCs, governments are less capable of handling social and environmental harms as they "often do not possess the material infrastructure or the technological resources and funding that enable them to cope with environmental crises compared to more materially well-off societies" (Molisa, et al., forthcoming, p. 2). Moreover, regulatory spaces have been reduced internationally by dominant neo-classical developmental agendas, such as structural adjustment programmes and decentralisation in the public sector (Hopper, Tsamanyi, Uddin, \& Wickramasinghe, 2007; Szablowski, 2007).

However, some argue that legislative frameworks could promote dialogic accounting if they were to legitimise and facilitate the institutionalisation of participation (Bebbington, Brown, Frame, et al., 2007; Brown, 2009). In this respect, the environmental impact assessment (EIA), a tool of environmental 
management, might be a tool which could operationalise critical dialogic accounting.

An EIA could provide space for dialogue and subjectivity. Because its multifaceted nature embraces a broad range of social, economic, and environmental issues and engagement with various stakeholders, the EIA could do this for SEA related issues.

\subsection{Environmental impact assessment}

\subsubsection{Literature on environmental impact assessment}

\subsubsection{Development of environmental impact assessment}

With its excessive emphasis on economic benefits, rapid industrialisation has caused increasingly negative environmental changes, such as global warming, environmental degradation, and more frequent disasters. The Intergovernmental Panel on Climate Change Report shows that human activities have increased greenhouse gas emissions by 80 percent between 1970 and 2004 and are a major contributor to global temperature increases (IPPC, 2007, p. 5).

Environmental ethics radically challenge the absence of environmental concerns in Western ethics. In contrast it acknowledges a human "duty to nature" (Gray, 1994, p. 57). Moreover, research has supported such ethics. Nature and its resources, once considered as "neutral stuff" (Mitchell, 2001, p. 6), are now receiving a great deal of attention. The commonly expressed idea that "natural resources are defined as resources if they satisfy human needs" (Zimmermann, 1933) has been criticised for its anthropocentric and utilitarian position (Mitchell, 2001). Now many researchers and practitioners argue that the economy is closely interrelated to society and the environment within a "closed system" (Daly \& Farley, 2004; Mitchell, 2001), and that there are limits to growth (Meadows, Meadows, Randers, \& Behrens III, 1972). In this respect, a systems approach which encourages careful consideration of economic, social, and environmental factors and their interrelations (Meadows, Randers, \& Meadows, 2004) is increasingly advocated by researchers in various disciplines, including economics, 
sociology, politics, development studies, accounting and management. Such an approach has also influenced environmental management studies.

Over the last few decades, the importance of environmental management has increased dramatically. Environmental management covers decisions and actions "concerning policy and practice regarding how resources and the environment are appraised, protected, allocated, developed, used, rehabilitated, remediated and restored, monitored and evaluated" (Mitchell, 2001, p. 6). It deals with an important dilemma - finding a balance between the rapid depletion of natural resources used to meet the needs of a growing world population and the worsening environmental degradation (Kapoor, 2001). Environmental management has been widely adopted in the legislative frameworks and public policies of most countries (Coenen, 2008; Mitchell, 2001).

The EIA is a major environmental management tool, which could directly address the environmental impacts of development projects that may negatively affect the natural environment. The origins of EIA legislation lie in the National Environmental Policy Act (NEPA) (1970) of the USA (Garb, Manon, \& Peters, 2007; International Association for Impact Assessment, 1999; Jay, et al., 2007; Mitchell, 2001). For the first time in environmental public policy, legislation proposed a systematic approach to assess and predict environmental impacts (Garb, et al., 2007, p. 482). Its drafters aimed to reform decision-making processes and mainstream development priorities "in a way that would be enforceable and subject to external review" (Caldwell, 1993).

According to the International Association for Impact Assessment (1999), an EIA is "the process of identifying, predicting, evaluating and mitigating the biophysical, social, and other relevant effects of development proposals prior to major decisions being taken and commitments made" (p. 1). In spite of possible variations, the principal stages of an EIA are screening, scoping, assessing impacts, reviewing, implementing and monitoring/auditing (Garb, et al., 2007, p. 483). 
The content of an EIA, and its institutionalisation, have gradually developed throughout the world from being a tool for measuring biophysical environmental impacts to being a decision-making tool which considers environmental, economic, and social aspects (Jay, et al., 2007). Over the last few decades, researchers have proposed various approaches and methods for its betterment, for example, adaptive environmental assessment (Holling, 1978), life-cycle assessment (Canadian Standards Association, 1994), and strategic impact assessment since the late 1990s (Fischer, 2003).

Since the introduction of the NEPA, EIAs have been incorporated in the environmental management frameworks of many countries either through legislation or by being integrated into planning procedures (Barrow, 1997). Today, more than 100 countries have EIA frameworks (Glasson, et al., 2005). The EIA is generally regarded as an anticipatory planning and decision-making tool which provides environmental information for decision-makers, thereby ensuring they consider environmental issues in decisions (Jay, et al., 2007, p. 288). The recognition of global environmental problems and the need to incorporate sustainability concerns into developmental agendas has significantly increased interest in EIAs among researchers and practitioners.

Many LDCs formed their EIA frameworks with help from international developmental and donor agencies, such as the United Nations Development Programme (UNDP), the World Bank, the European Bank of Reconstruction and Development (EBRD) and the Asian Development Bank (ADB) (Cherp, 2001; Glasson, et al., 2005; Jay, et al., 2007). To have an EIA framework represents an important achievement which can help LDCs to consider sustainability in their policies and development projects. Environmental issues are often at stake in these countries, where governments give priority to other urgent economic development needs, such as financial stability and poverty alleviation (Doberstein, 2003). Given this, EIAs have become the most common environmental policy tools in LDCs (Mitchell, 2001), including those countries in transition (Cherp, 2001, p. 335). 
By 2001, transition countries had more than one hundred new legal acts that adopted EIAs (Cherp, 2001, p. 336). These legislative measures aimed to improve environmental protection, encourage "more transparency, participatory and decentralized decision-making procedures" (Ziegler, 1991, cited in Cherp, 2001), and to comply with international norms, such as the Environmental Assessment Directives of the EU, the Espoo and Aarhus conventions (UNECE, 1991, 1998), and the environmental procedures of the World Bank and the EBRD (European Bank for Reconstruction and Development, 1996; World Bank, 1999). However, the evolution of EIAs in transition countries is strongly influenced by their societal contexts, in particular, the speed of transition processes, including reforms of political and economic regimes, consolidation of democracies, and progress towards integration into the European Union (Cherp, 2001; Kravchenko, 2002). Their EIAs focus mostly on the compliance of "proposed activities with sector- or media-specific technical standards" (Cherp, 2001, pp. 346-347).

Nevertheless, the EIA is a "fairly institutionalised" (Söderbaum, 2004, p. 3) and widely-employed environmental management tool, which can show the pros and cons of a development project (Mitchell, 2001; Morgan, 1998) and provide more comprehensive guidelines for decision-makers, project developers, and interested parties for resolving issues surrounding it. As mining proposals have potential negative impacts on the natural environment, they require an EIA in most countries (Biller, 2003). This not only helps decision-makers to approve or reject a project, but also to inform other constituents about possible methods for mitigating the potential impacts of a mining project.

\subsubsection{Criticism of the EIA as a monologic tool and process}

The EIA is an important managerial tool which can apply sustainability considerations at the project level. However, researchers and practitioners have increasingly criticised the effectiveness of EIAs, which has resulted in debate about the lack of work on the practical applications of EIAs and their theoretical bases. 
The theory and practice of EIA are dominated by positivism and technical rationality (Jay, et al., 2007, p. 288). The EIA process has to be based on "accepted scientific principles and procedures if it is to be perceived as credible" (Cashmore, 2004, p. 408). Hence, researchers tend to employ a positivist approach, which focuses on making models of an EIA, and predicting environmental impacts by pursuing quantified hypotheses that can, and should, be subjected to rigorous falsification (Richardson, 2005). They have the privilege of quantitative data obtained by 'objective' scientific methods. Environmental and social issues are often simplified and quantified where possible in order to develop an optimal model for prediction.

Objectivity and value-neutrality of an EIA are important claims of the dominant positivist perspective. Experts play an important role in identifying and measuring impacts, proposing mitigation methods, preparing EIA reports and making comments (Morgan, 1998). They are expected to be value-neutral and to make judgements based on "scientific rationality" and their expert knowledge (Petts \& Brooks, 2006; Wilkins, 2003). Value-neutrality also applies to EIA decisionmakers; they are regarded as value-neutral and apolitical individuals who make decisions rationally.

However, a growing number of researchers have criticised the techno-rationalist and simplistic ethos of EIAs. The multifaceted nature of EIAs and the broad range of environmental, social, political, cultural, and economic issues they cover render impossible the positivist assumption that they can perform an anticipatory role in planning and decision-making (Jay, et al., 2007). Indeed, in spite of their claims on "the likelihood of making an accurate prediction", technocratic researchers may make prediction less precise through simplification (Buckley, 1989, cited in Wilkins, 2003, p. 407). Over-emphasis on quantitative data generated through rational simplification ${ }^{42}$ has been questioned for most environmental and social impacts, and their boundaries are barely identifiable and quantifiable (Biller, 2003; Söderbaum \& Brown, 2010).

\footnotetext{
${ }^{42}$ Using models that simplify environmental systems by eliminating 'unimportant' variables leads to a structural error (Wilkins, 2003, p. 407).
} 
The 'value-neutrality' of the EIA has encountered criticism. Experts are valueladen individuals (re)shaped by their beliefs and institutional values (Petts \& Brooks, 2006). Similarly, decision-makers are influenced by their social and institutional values (Morgan, 1998; Richardson, 2005; Wilkins, 2003). Particularly in LDCs, decision-making often does not accord with a rational model. Rather decisions often depend on the interests, norms and values of decision-makers operating within a political arena (Jay, et al., 2007, p. 293). To acknowledge the politicisation of an EIA is not undesirable, for it may encourage recognition of plurality and help improve EIA practice (Cashmore, Richardson, Hilding-Ryedvik, \& Emmelin, 2010).

Critics of technocracy question EIA effectiveness. However, they differ on defining effectiveness: some look into "whether or not EIA is being carried out according to its own procedural requirements", while others suggest evaluating EIA "according to more substantive criteria, ... whether EIA is resulting in the kind of outcomes that are typically sought to identify the effectiveness" (Cashmore, 2004; Jay, et al., 2007). However, many agree that EIA effectiveness can be judged by evaluating its practical application against its initial objectives.

The EIA seeks to provide comprehensive environmental and social information about a project to decision-makers and other EIA constituents, and to incorporate environmental concerns into decisions (Jay, et al., 2007). Therefore, its effectiveness can be evaluated by its influence on planning and decision-making (Jay, et al., 2007). However, there is evidence that EIAs are not well integrated into the structures and procedures of decision-making institutions and their resultant decisions (Doberstein, 2003).

Technocracy often results in an expert-oriented EIA (Petts, 2004; Petts \& Brooks, 2006). The reports of experts use professional and technical language (Morgan, 1998) that can fail to provide useful and understandable information for decisionmakers and other EIA constituents (Mitchell, 2001). The size of reports is also problematic; they tend to have either too many pages or too few (Jay, et al., 2007). 
In addition, EIA practices in LDCs are ineffective for a number of reasons. The lack of rule of law, weak transparency and accountability, and endemic corruption leads to weak governance in LDCs (Cherp, 2001; Kakonge, 1998), and hence poor enforcement, low institutional and human capacity, and "overlapping jurisdiction", which creates conflict between agencies (Doberstein, 2003; Mitchell, 2001). Legislation usually requires proposed projects to bear all the EIA costs, but often provides 'flexibility' for proponents by allowing them to choose the assessor company ( $\mathrm{Li}, 2009)$. This increases conflict of interest among EIA companies and reduces the incentives for them to criticise projects (Biller, 2003; $\mathrm{Li}, 2009)$. It's often assumed these problems can be resolved by developing additional laws, regulations, and penalties for any damages, but these often have no effect (Biller, 2003, pp. 127-128), which can render the EIA to being a 'symbolic' reporting process for project approval (Branis \& Christopoulos, 2005).

The EIA will lose credibility among constituents if they believe it is a biased and inaccurate process. On the one hand, the public and environmentalists can distrust an EIA, as they believe it favours project developers (Essex Planning Officers Association, 1995). On the other hand, proponents of projects complain that an EIA is a costly and time-consuming 'bureaucratic hurdle' (Biller, 2003); hence claims that EIAs have become a tool for 'decision-aiding' rather than decisionmaking (Jay, et al., 2007, p. 293).

Following growing recognition of the importance of sustainable development, some researchers define EIA effectiveness by its sustainable development methods. However, EIAs are often politicised and decision-makers prioritise short-term individual gain over longer-term community goals (Wilkins, 2003, p. 410). Caldwell (1993) argues that EIAs are effective compared to the "past neglect and failings" of environmental management, but not if evaluated according to sustainable development criteria (cited in Cashmore, 2004, p. 2). However, the meaning of sustainable development and its application needs a better definition in EIA theory and practice (Akol, 2001; Cashmore, 2004; Nooteboom, 2007). 
EIAs involve "contested rationalities" and "inescapable relationships between power and value" (Richardson, 2005, p. 343). Consequently, researchers increasingly argue that the EIA cannot be "value neutral" and "apolitical" (Jay, et al., 2007; Richardson, 2005; Wilkins, 2003) and call for approaches that acknowledge its complexity and subjectivity (Cashmore, 2004; Cashmore, et al., 2010; Wilkins, 2003). Given the potential of the EIA to encourage preventive rather than corrective action, to gather considerable information about a project and its effects within the area where it will operate, and to build mitigation measures into contracts between the authority and a project proponent, the EIA could help reduce or resolve conflicts between the authority, the project proponent, and affected communities, and to increase public awareness of sustainability, thereby changing social values (Biller, 2003; Cherp, 2001; Garb, et al., 2007; Jay, et al., 2007; Mitchell, 2001; Nooteboom, 2007). Thus, the EIA becomes not merely a decision-making tool, but could also promote sustainable development (Söderbaum, 2004; Wilkins, 2003) and social learning (Diduck \& Mitchell, 2003; Diduck, et al., 2007; Sinclair \& Diduck, 2001; Wilkins, 2003). Thus the practice of the EIA needs guidelines for sustainability (LeBlanc \& Fisher, 1994), better coordination and commitment (Marsden, 1998) and better public participation (Glasson, et al., 2005).

\subsubsection{The EIA as a participatory decision-making tool}

Today, legislation in most countries requires public participation (EIA Centre, 1995a, 1995b), especially following the Aarhus Convention on "Access to Information and Public Participation in Decision-Making in Environmental Matters" (UNECE, 1998). The importance of public participation stems in part from the multidisciplinary nature of EIAs (Morgan, 1998). Stakeholder participation in an EIA increases its credibility and quality (Diduck, et al., 2007), and benefits participants, ranging from assessment experts to affected communities.

According to Mitchell (2001), participants or stakeholders are "a person and groups that are directly affected by or with an interest in a decision, or with legal responsibility and authority relative to a decision" (p. 189). Stakeholders can be 
classified as "active" and "passive" publics. The active public organise interest groups and are more committed to participation, where inactive sectors of the populace, usually the majority, are silent about environmental issues (Mitchell, 2001, pp. 189-190).

The most common methods of public participation are public hearings and consultations, usually organised to provide information about a project and to obtain comments from the public, once an EIA report has been prepared (Mitchell, 2001; Morgan, 1998; Sinclair, Diduck, \& Fitzpatrick, 2002). The effectiveness of participation in developed and developing countries has increasingly been questioned. In developed countries, such as Australia, Canada, UK, and USA, collaborative public engagement has largely been successful in raising understanding and shared capital, but has proven to be ineffective for translating such capital into action (Margerum, 1999). Research in Canada and the UK has criticised the trend for participation to become symbolic by relying on consultation rather than active public participation (Booth \& Skelton, in press; Kapoor, 2001; Lockie, Franetovich, Sharma, \& Rolfe, 2008; Marsden, 1998; Rockloff \& Lockie, 2006).

Such instrumental participation fails to address indigenous people's concerns about projects operating in their land. They are often incapable of participating in public consultation due to their lack of knowledge about an EIA and their inability to understand its professional language (Stewart \& Sinclair, 2007a). Even when they participate, their comments are often not included in final reports and decisions (Diduck \& Sinclair, 2002; Li, 2009). Thus, indigenous people are often excluded from decision-making even if they are involved in public hearings and consultations (Booth \& Skelton, in press; Hilson, 2003; Rockloff \& Lockie, 2006).

Often experts and decision-makers lack an appreciation and understanding of public participation, as their formal education and training tends to focus on environmental and economic issues, and instrumental rationalities (Doberstein, 2003; Petts, 2004; Petts \& Brooks, 2006). As Doberstein (2003) comments: 
The formal training of most development planning bureaucrats is in economic or technical/scientific disciplines, which reinforces the tendency to view impact assessment as a technical or scientific input to planning, rather than a participatory process of planning (p. 26).

The local knowledge and the ability of affected communities to participate in scientific decision-making tools such as EIAs are often underestimated by experts and decision-makers (Kwiatkowski \& Ooi, 2003; Mitchell, 2001), who can regard public participation as time-consuming and costly, with no direct benefits (Biller, 2003; Cherp, 2001).

It is important to recognise differences in cultural, political, governance and local knowledge systems of LDCs compared to Western countries. LDCs often uncritically import EIA legislation from Western countries or are recommended to do so by international donor organisations (Doberstein, 2003). Research on EIA practices in some South-East Asian countries, such as Thailand, Indonesia, and Malaysia, reveal that Western style public participation does not work due to the markedly different cultural and socio-political practices (Boyle, 1998). In these countries, public participation was absent, and decisions were often made without regard for public or national interests (Kolhoff, Runhaar, \& Driessen, 2009). The principal reasons for ineffective public participation include the common acceptance of paternalistic authority and social hierarchies, the desire to maintain 'face' in personal relations, the avoidance of conflict, and the inability of individuals, communities and public-interest groups to participate in an EIA (Boyle, 1998, p. 114).

Similarly, post-communist countries have also experienced ineffective public participation. In spite of claims to the contrary their democracies are still largely “on paper" and public participation in EIAs is very limited (Kravchenko, 2002, p. 502). The low participation rates emanate from poor public awareness of environmental matters, lack of a participatory tradition, and distrust of governmental bodies and the courts (Kravchenko, 2002, p. 467). This is compounded by state deficiencies, including a poor rule of law, weak institutions and human capacity, and no detailed regulatory frameworks for public 
participation (Cherp, 2001; Kravchenko, 2002). Moreover, many LDCs lack the political will to promote participatory decision-making as public participation is considered "unnecessary, inefficient, time-consuming or even politically dangerous" (Doberstein, 2003, p. 26).

Although researchers have criticised existing participation as being 'symbolic', its importance has not been undermined. Indeed, calls have grown for more interactive and meaningful public participation that could include affected communities and would challenge existing monologic EIA practices (Diduck, et al., 2007; Söderbaum, 2004; Stewart \& Sinclair, 2007b; Wilkins, 2003). It is argued that comprehensive assessment that can include local knowledge, values, and concerns of affected communities would be more effective (O'Faircheallaigh, 2010). Additionally, public engagement in EIA enforcement and monitoring may mitigate potentially negative impacts of a project and avoid future conflict among constituents (Furia \& Wallace-Jones, 2000; Mitchell, 2001; Morgan, 1998; Scottish Executive, 2006).

Importantly, a participatory approach would help to redistribute power from environmental assessment managers to the public (Arnstein, 1969), would improve accountability (O'Faircheallaigh, 2010), and could help make EIAs more plural, democratic, and better at incorporating sustainability considerations (Cashmore, et al., 2010; Jay, et al., 2007; Nooteboom, 2007). A participatory approach would improve public confidence in the EIA and encourage discourse and social learning among constituents (Diduck \& Mitchell, 2003; Sinclair \& Diduck, 2001; Webler, Kastenholz, \& Renn, 1995; Webler \& Tuler, 2006; Wilkins, 2003). In the absence of other forms of participation, the EIA could become "a crucial instrument of local democracy" (Cherp, 2001, p. 352). By granting space for the public to participate, the EIA could also encourage democracy in environmental decision-making (Petts, 2003; Petts \& Brooks, 2006; Rockloff \& Lockie, 2006; Sinclair, et al., 2002; Sinclair \& Diduck, 1995; Söderbaum, 2004).

Meaningful public involvement in all EIA stages, beginning with the identification of impacts to monitoring and auditing EIA compliance (Diduck, et 
al., 2007; Mitchell, 2001) would also put pressure on mining companies to become more environmentally and socially responsible (Ingelson, et al., 2009; Nooteboom, 2007).

In this regard, NGOs can "act as very powerful actors of monitoring and enforcing E[I]A provisions, provided they have such an opportunity" (Cherp, 2001, p. 352). National and international civil society organisations have been important for initiating participatory environmental management projects and for mobilising the involvement of local communities (Szablowski, 2007; Tarras-Wahlberg \& Nguyen, 2008), and for putting pressure on "reluctant governments or international agencies to at least begin making the necessary institutional changes" (Kapoor, 2001, p. 273).

NGOs have begun to engage in and activate public participation in EIAs. There is evidence that NGOs in post-communist countries have invoked EIA procedures "against legal and institutional odds" which have led to counter EIAs that demonstrate "public environmental expertise [in EIAs]" (Kravchenko, 2002, p. 490). Therefore, NGOs have the potential to promote participatory EIAs and to facilitate dialogue among EIA constituents, including affected communities (Whiteman \& Mamen, 2002).

\subsubsection{The EIA in Mongolia}

\subsubsection{Overview of the environmental legislative framework}

As in other countries that are in transition (Cherp, 2001), social context has influenced the Mongolian EIA framework. The transition period required radical changes to legislation that had been developed during the communist era. To balance environmental protection against dramatically increasing economic interests in the use of natural resources, Mongolia needed better legislation, stronger governance, and new institutions that could address the growing environmental and health concerns about the operations of mining.

Environmental legislation now consists of 30 laws and 150 associated documents that regulate environmental protection and use of natural resources, and define the 
scope of environmental management (ADB, 2005). The cornerstones of environmental legislation for mineral resource uses are: the Constitution Law (1992), the Environmental Protection Law (1995), the Law on Environmental Impact Assessment (1998), the Land Law (2002a), the Law on Special Protected Areas (1994), the Water Law (2004), the Law on Chemical Toxics (2006), the Air Law (1995), the Minerals Law (1997) and the Law to Prohibit Mineral Exploration and Mining Operation at Headwaters of the Rivers, Protected Zones of Water Reservoir and Forested Areas (2009). The Constitution (1992) guarantees the right of Mongolians to live in a safe and healthy environment and to be protected from adverse impacts. Therefore, the need for environmental management is addressed in legislation.

Environmental management has developed dramatically under the supervision of international development and donor organisations and advocacy NGOs. There are various inter-governmental projects on environmental governance and capacity building. The chief administrative bodies for environmental management are the Ministry of Natural Environment and Tourism (MNET), the State Specialized Inspection Agency, and local environmental units and inspectors (The State Great Khural of Mongolia 1995).

The EIA ${ }^{43}$ is the major environmental management tool in Mongolia. In 1998, the Law on Environmental Impact Assessment ${ }^{44}$ was passed after the introduction of the Environmental Protection Law (1995). The law regulates the coordination and control of activities relating to environmental protection and use of natural resources, and requires an EIA from the beginning of any project that has potential environmental impacts (The State Great Khural of Mongolia, 1998, Article 1). As mining has potential adverse impacts, the law states explicitly that a mining project requires an EIA at the Ministerial level (Annex).

\footnotetext{
${ }^{43}$ The EIA was first introduced by the Asian Development Bank in 1994 as an environmental management tool. Recognition of the importance of this tool led to the 1998 law (ADB, 2005).

${ }^{44}$ Amendments were made in November 2001
} 


\subsubsection{EIA procedures}

According to the Minerals Law (1997), all mining licence-holders should have an EIA, an environmental protection plan, and an environmental monitoring programme in order to operate (Article 30). The principal constituents of the EIA process are defined as mining companies, impact assessment companies, local administrative bodies, the Ministry of the Natural Environment and Tourism (MNET), and local people.

A legal entity with assessment specialists may apply to the MNET for a licence to conduct an EIA. The Technical Commission, appointed by the MNET, examines each application and provides its comments. If positive, the MNET decides whether to issue an EIA licence for two years, subject to renewal every two years. The Ministry can issue and revoke the licence of an EIA specialist if he/she were proved to have submitted a faulty EIA (Article 9.12).

Once a mining company is granted a licence for mining, it must then submit a project description, a technical and economic feasibility study, working drawings and other related documents to the MNET for screening (Article 4.4). Within 12 working days, a screening expert will make one of the following recommendations (Article 4.6):

- the project may be implemented without conducting a detailed EIA

- the project may be implemented pursuant to specific conditions

- a detailed EIA is required

- the project is rejected on the grounds of non-conformity with the relevant legislation, or adverse impacts of equipment and technology on the environment, or absence of the project in the land management plan.

Given their potential social and environmental impacts, all mining projects require a detailed EIA $^{45}$ which is subject to screening. To obtain an EIA, a mining company must find an authorised EIA company and pay all costs relating to the

\footnotetext{
${ }^{45}$ By the law, "new projects as well as the renovation and expansion of existing industrial, service and construction activities and project which use natural resources in different ways shall be subject for screening" (Article 4.1).
} 
EIA. The assessment company will develop a detailed EIA in accordance with set requirements by a screening expert in his/her recommendation (Article 5.1). An EIA report should include environmental baseline data and indices, appropriate project alternatives, recommendations for mitigating measures that can minimise or eliminate potential adverse impacts, a risk assessment, an environmental protection plan, an environmental monitoring programme, a rehabilitation project, and opinions of local residents and the Local Representative Khural (Article 5.4).

Following amendments in 2001, the opinions of residents from the area where a project proposes to operate became a requisite for the approval of an EIA report (The State Great Khural of Mongolia, 1998, Provision 5.4 and 7.3). Therefore, assessment companies require the comments of local people when conducting an EIA. They usually obtain these through a questionnaire and face-to-face meetings when preparing environmental baseline data in the local area (Johnova, 2004). The law states that the receiver of the EIA report should organise a public meeting to introduce the report (Article 7.5). However, a public meeting is not compulsory.

Once the EIA report is prepared, members of the Local Representative Khural or a local governor must approve it. Their signature of approval indicates that they have seen and commented on it. The report is also submitted to the mining company for review and comments (Article 5.5). The report and related documents are then sent to the screening organisation.

An expert (an impact assessor officer of the Ministry) must review the report and submit his/her conclusion/recommendation within 18 working days (Article 7.2). The EIA committee of the MNET then makes the final decision whether to approve the project (Article 7.3). The Committee consists of EIA specialists, the head of the Natural Resource Department of the Ministry, and academics.

After approval is granted, the EIA company will send two final copies of the EIA report, one to the MNET, the other to the mining company, and keep a further copy for itself. All copies are equally valid (Article 5.7), and all recipient organisations must ensure the public has access to the information when necessary 
(Article 7.5). The law also requires the Ministry to have an EIA database available for interested parties (Article 7.6).

Once the project is approved, the mining company must develop an environmental protection plan and an environmental monitoring programme. These should implement EIA recommendations and monitor and control mining performance accordingly (Article 6.1). An environmental protection plan includes "measures to minimize, mitigate and eliminate adverse impacts identified during the detailed EIA as well as indicates the timeline and estimated budget for implementation of these measures" (Article 6.1.1). The environmental monitoring programme should cover "the monitoring and study of changes in the environment as a result of project activity and reporting requirements, include monitoring schedule and methods as well as determine the timeline and estimated budget for implementation of those measures" (Article 6.1.2). These plans and estimated budgets need the approval of the MNET, and the mining company must deposit in a special MNET account fifty percent of its annual environmental protection budget as a guarantee. This is refunded when the environmental protection plan has been fully implemented (The State Great Khural of Mongolia, 1997, Article 30.11-12).

Figure 1 illustrates the entire process, beginning from the EIA request by a mining company through to developing an environmental protection plan following comments in the final EIA report: 
Figure 1. EIA procedures

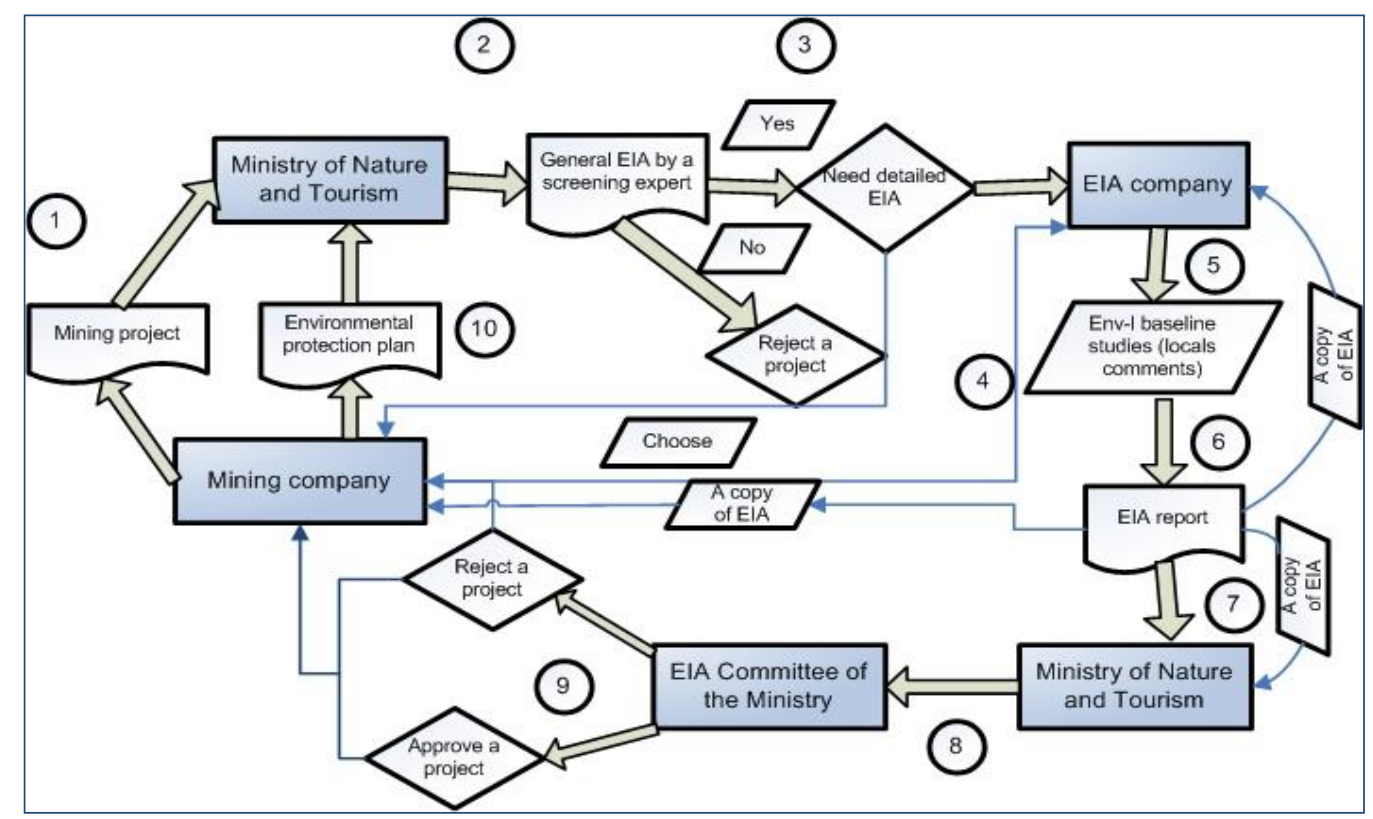

According to the EIA law (1998), if a mining company "caused or has caused damage to the health of the local population or the environment" the assessment should be reviewed (Article 8.1). The MNET would then appoint a review team and cover their expenses. Any guilty party must repay these costs. If the EIA was incorrectly prepared, the EIA company must conduct a reassessment to meet the MNET requirements, and the MNET may suspend the EIA company's right to conduct further EIAs (Article 8.6).

The EIA law establishes that violators of the law are subject to criminal or administrative liability, depending on the nature of the violation and the size of the damages. If the violation is not subject to criminal liability, administrative sanctions would be imposed by a judge or an environmental inspector (Article 12.2). If the project has been implemented without an EIA and an environmental plan and programme, or the means of implementation do not meet the requirements of the EIA and the environmental plan, the guilty official can be fined 25,000-50,000 tughriks ${ }^{46}$, and a guilty legal entity, 250,000 tughriks ${ }^{47}$. If a

\footnotetext{
${ }^{46}$ equals US $\$ 18-36$ at the current exchange rate (US $\$ 1=1400$ tughriks)

${ }^{47}$ equals US\$178 at the current exchange rate
} 
licensed EIA company is found guilty for making an incorrect EIA, it will be fined 150,000-250,000 ${ }^{48}$ tughriks (Article 12.2.2 - 12.2.4).

By law, the guilty party must eliminate or compensate for damage to human health, property, and environment caused by a project which has no EIA or has not complied with requirements of an EIA report. If an EIA company has prepared an incorrect EIA, it must pay all related costs of the EIA review process and compensate for environmental damages caused by the EIA (Article 13.2).

\subsubsection{The state of the EIA in the mining sector}

Over the last decade, the number of EIA reports and EIA companies has gradually increased, due partially to development of the mining sector. Mining accounted for 29 percent of EIA reports from 1998 to 2007 (MNET, 2008). About 70 EIA companies conduct EIAs (MNET, 2009a) (MNET, 2009b). Today, the EIA is a 'well-recognised' legislative process for mining companies wishing to commence operations. Table 1 details EIA reports from 1998 to 2007 by sectors.

Table 1. Statistics on the Environmental Impact Assessment, 1998-2007

\begin{tabular}{|r|r|r|r|r|r|r|r|r|r|r|r|}
\hline Name of projects & 1998 & 1999 & 2000 & 2001 & 2002 & 2003 & 2004 & 2005 & 2006 & 2007 & Total \\
\hline Gold deposit & 144 & 159 & 186 & 29 & 64 & 32 & 39 & 34 & 36 & 53 & 989 \\
\hline $\begin{array}{r}\text { Non-gold mineral } \\
\text { deposit }\end{array}$ & 74 & 82 & 98 & 27 & 57 & 32 & 25 & 48 & 44 & 125 & 715 \\
\hline Tourist camps & 119 & 138 & 154 & 37 & 85 & 57 & 125 & 101 & 54 & 129 & 1109 \\
\hline Industrial plants & 114 & 128 & 182 & 77 & 136 & 39 & 28 & 36 & 60 & 168 & 1109 \\
\hline $\begin{array}{r}\text { Gas stations and } \\
\text { fuel storing } \\
\text { facilities }\end{array}$ & & & & 103 & 178 & 39 & 61 & 87 & 100 & 167 & 735 \\
\hline Other projects & 50 & 60 & 133 & 100 & 285 & 187 & 155 & 119 & 117 & 160 & 1306 \\
\hline Total & 501 & 576 & 753 & 383 & 805 & 347 & 433 & 425 & 411 & 802 & 6043 \\
\hline
\end{tabular}

Resource: MNE (2008) "Report on the State of the Environment of Mongolia", Ulaanbaatar, p.103

However, EIA practice in Mongolia is still in its infancy and falls short of being an effective environmental institutional process that can address and prevent environmental and social damage from development projects (Netherlands Commission for Environmental Impact Assessment, 2002). Over its relatively short development, the EIA has become a technical procedure conducted among the authorities, EIA companies, and mining licence holders. As in other LDCs, the

${ }^{48}$ It equals to US $\$ 107-178$ by the current exchange rate. 
effectiveness of Mongolian EIAs is questionable (Johnova, 2004) for several reasons, including a poor legislative framework, a lack of capacity among the Ministry and EIA companies, weak implementation and compliance monitoring, and poor quality of the EIAs (ADB, 2005; Myagmarsuren, 2006).

Regulation to ensure implementation of EIA law remains inadequate. The framework is weak with respect to public participation, sanctions, funds for rehabilitation, informal mining, protected areas, and compensation for land-use (IIED \& WBCSD, 2002; World Bank, 2006). Moreover, there is poor implementation of EIA law because of a lack of coordination and cooperation between government organisations, poor human and institutional capacity, weak compliance monitoring, and inadequate penalties (Netherlands Commission for Environmental Impact Assessment, 2002; World Bank, 2006). Enforcement mechanisms and standards are still lacking in the current regulatory framework (World Bank, 2006).

The EIA may be a new policy tool in Mongolia, but the ministry lacks proper knowledge and expertise about it and is understaffed. The government has reduced the ministry budget and staff numbers, due to its policies of decentralisation, reducing bureaucracy, and for strengthening capacities (Ministry of Finance, 2007). Therefore, a few government officers cannot comprehensively review and assess EIAs given the limited time-frame and excessive workloads ${ }^{49}$ (Johnova, 2004). This is compounded by government organisations failing to make merit-based appointments due to political interventions, following each election (USAID, 2005). Constant changes in the ministerial structure have badly affected staff productivity and motivation to improve knowledge and skills (Radnaasumberel, et al., 2006), and conflicts of interest among public servants have also increased (Research team, 2006).

The number of EIA companies has grown rapidly in response to the dramatic increases in mining, infrastructure, construction and tourism sectors that require

\footnotetext{
${ }^{49}$ According to the law, the detailed EIA report should be reviewed within 18 working days. However, one officer has to review many EIAs at once as there are about 800 EIA reports reviewed annually and the number is expected to increase.
} 
EIAs. While EIAs have been a new business area for environmental and technical experts by EIA companies, their lack of expert knowledge and skills about EIAs has resulted in poor quality EIAs, and conflicts of interest (Netherlands Commission for Environmental Impact Assessment, 2002).

Weak compliance with the law and poorly managed EIAs are also linked to monitoring. In 2002, the government took the monitoring role from the MNET so as to separate the policy-making and controlling functions (ADB, 2005). Today, compliance monitoring of EIAs and associated environmental plans are inspected by the State Specialised Inspection Agency (SSIA) (Ministry of Nature and Environment, 2008). The intention was to centralise all monitoring functions of government organisations into the SSIA to improve coherence and effectiveness of state monitoring, but the situation has not improved due to poor coordination and cooperation among government organisations (World Bank, 2007a).

There are many problems with the accessibility of reports and public participation in EIAs. The process of preparing an EIA report and the decision-making leading to approval of a mining project are often "in-transparent" and not available for public review (World Bank, 2006). Public participation is lacking in an EIA and in the granting of a permit for a mining project, because legislation "fails to formalise public involvement" (World Bank, 2006, p. 3). Therefore, public participation is left to the discretion of the proponent and the government authority, in spite of the law saying that the ministry should consider public opinion when reaching a final decision (The State Great Khural of Mongolia, 1998, Provision 7.3). However, it does not specify how opinion should be gauged and included. Moreover, reports are inaccessible for the public as they are either not "effectively placed in the public domain" (World Bank, 2007b, p. 160) or "secretised" by the bureaucracy in spite of the legal requirement for public access to information.

As in other mineral-rich LDCs, Mongolians are gradually learning about the mining sector and its impacts on society and the natural environment. Although EIAs should be able to address the environmental impacts of mining, 
environmental destruction, and rehabilitation practices of mining, evidence suggests that EIA practice fails to do so (Saran, 2009). Weak compliance and monitoring of rehabilitation also compounds environmental degradation, water and soil pollution in local regions. Consequently, local people face more frequently serious issues concerning health and safety, dangers to biodiversity, and herding of animals, and the drying-up of local river resources (MNPC, 2008).

Environmentally destructive mining, which fails to contribute to local development, results in dissatisfaction, anger, and conflict among local people and NGOs. Consequently, they have formed local grass-root NGOs and movements (UNDP, 2006). They have begun to recognise the importance of environmental management for encouraging better environmental governance, and socially and environmentally responsible mining (MNPC, 2008). Participatory environmental and mining decision-making has the potential to address poor mining practice, which is gradually being acknowledged by government organisations, mining companies, environmental experts and international and domestic NGOs (ADB, 2005; RMI, 2009; World Bank, 2006). More local and international NGOs have begun to address environmental management and EIA practices. Some NGOs have been involved in preparing a bill that would make public participation in an EIA mandatory in law. This suggests there is a need and support for a democratic EIA which could allow public participation and consider the concerns and views of affected communities.

Chapter 4 will discuss in more detail the potential involvement of NGOs in mining and environmental management. 


\section{Chapter 4: NGOs AS PROMOTERS AND FACILITATORS OF PARTICIPATORY DEMOCRACY AND DIALOGUE}

\subsection{Introduction}

Within civil society, NGOs have been crucial in raising public awareness of mining issues and for promoting sustainability. As long-standing advocates for democracy and participation, NGOs promote transparent and inclusive public policy and decision-making that have a bearing on the lives of ordinary people.

This chapter will explore how NGOs promote sustainability and participatory decision-making in mining. First, notions of civil society are discussed, as NGOs are a part of and/or claim to represent civil society. Second, the classification, roles and the contested nature of NGOs are discussed, drawing from research in development studies, public policy, SEA, and environmental management. Third, the engagement of NGOs is examined, especially their promotion of democracy and participation, and the raising of environmental and mining issues. Lastly, this chapter discusses the development of the Mongolian NGO sector and its involvement in mining-related environmental issues.

\subsection{Contested nature of $N G O s$}

\subsubsection{Civil society}

The terms 'NGOs' and 'civil society' have been used interchangeably over the last three decades. This acknowledges the centrality and significance of NGOs within socio-political spheres compared with other civil society organisations. However, to understand NGOs it is important, first, to discuss civil society.

Since the late twentieth century, the term 'civil society' has been widely used across disciplines such as development studies and public policy (Howell \& Pearce, 2001). However, the concept and its meaning date back to at least Hobbes and Locke (Robertson, 1986) and other philosophers who have expressed divergent views on civil society and its relations with the state, family, and 
market. Hegel viewed civil society as "a social formation [that] intermediate[s] between the family and the state", whereas Marx and Engels distinguished civil society from the state (Gray, et al., 2006). An influential theorist, Antonio Gramsci, an Italian Marxist, argued that civil society constituted a separate arena from both the state and market (Robertson, 1986) that could disseminate the ideology of the dominant group or dispute it, especially through counterhegemonic actions, often influenced by organic intellectuals (Howell \& Pearce, 2001, p. 54). Although debate on civil society continues, its importance is now recognised both in theory and practice.

Civil society is defined as all aspects of society that are beyond the public and private sectors. It as "an arena of association and action independent of the state and market in which citizens can organise to pursue purposes that are important to them, individually and collectively" (Brown, Khagram, Moore, \& Frumkin, 2000, p. 275). Thus, a voluntary association in civil society - based on shared moral and intellectual sentiments - provides an opportunity to take collective action to achieve desirable ends that would be difficult to achieve individually (Teegan, Doh, \& Vachani, 2004). The London School of Economics Centre for Civil Society defines civil society as:

The arena of uncoerced collective action around shared interests, purposes and values. In theory, its institutional forms are distinct from those of the state, family and market, though in practice, the boundaries between state, civil society, family and market are often complex, blurred and negotiated. Civil society commonly embraces a diversity of spaces, actors and institutional forms, varying in their degree of formality, autonomy and power (Centre for Civil Society, 2004).

Collective action can originate from broad social concerns or the marginalisation or failure of social and political institutions to recognise the social identity of some groups of people and to support them appropriately (Putnam, 2002). Consequently, some civil society organisations pursue "political ends" outside the "state apparatus" (Salamon, 1994). "Shaping the larger political and social reality" (Schwartz \& Pharr, 2003) and "invoking public debate on common concerns" both influence and derive from collective actions (Teegan et al., 2004). 
One type of collective action is a social movement, which according to Teegan et al. (2004) occurs "when the collective action of a group of individuals is sustained over time in an identifiable way" and it "reflects an important emerging social change" (p. 465). When citizens lose trust in institutions that are supposed to protect their interests, a new "outward looking" and "bridging" mechanism which encourages social capital formation is needed (Putnam, 2002, p. 11). For this reason, social movements have become more organised, influential, and integrated into global political and economic systems, and have formed NGOs (Gray, et al., 2006). Although not all social movements become formalised NGOs, doing so can legitimate social movements, enable them to be eligible for fundraising, provide access to information, and help communities to be represented in decision-making, thereby pursuing their objectives in a sustained way (Korten, 1990; McIlwaine, 2009).

To define types of civil society organisations is difficult due to their diverse formality, size (in terms of membership), geographic scope, rationale (for formation/operation), and linkages to the market, state, and family (Gray, et al., 2006, p. 323). Nevertheless, civil society organisations continue to grow in size, vitality, and importance.

Civil society includes a wide range of organisations, such as registered charities, NGOs, community groups, women's and faith-based organisations, professional associations, trade unions, self-help groups, social movements, business associations, coalitions and advocacy groups (Centre for Civil Society, 2004). Given their roles and scope of operations, NGOs are now key elements of civil society and have significant influence in national and international social and public-policy arenas.

\subsubsection{Definition and classification of NGOs}

Any definition and classification of NGOs must carefully consider their multifaceted and diverse activities across sectors, their relationships with the state, market, public and international organisations, and their wide range of objectives (Gray, et al., 2006; Teegan, et al., 2004). Given this diversity it is unsurprising 
that there is little consensus on how to define and classify NGOs either theoretically or empirically (Vakil, 1997, p. 2057). Korten (1990) defines NGOs as being close to social movements, whereas Vakil (1997) identifies them as notfor-profit organisations for disadvantaged people. For the purposes of this study, NGOs are understood as movement-oriented, self-governing, non-profit organisations that have tended to focus attention on improving the quality of life of disadvantaged people and protecting the natural environment.

In developmental discourses, the term 'NGO' is used interchangeably with grassroot organisations. Some have attempted to distinguish NGOs from social movements. Mercer (2002) states:

NGOs are officially established, run by employed staff (often urban professionals or expatriates), well supported (by domestic or, as is more often the case international funding), and are often relatively large and well-resourced. Grass-root organisations are smaller, often membership-based organisations, operating without a paid staff but often reliant upon donor or NGO support, which tend to be (but are not always) issue-based and therefore ephemeral (Mercer, 2002, p. 6).

However, NGOs and social movements are not mutually exclusive or easily distinguished because the former sees "civil society as a collective of organisations, while the latter tends to encompass civil society as an arena for action" (McIlwaine, 2009, p. 136).

NGOs are commonly classified by their functions and geographic locations. Depending on their major activity, NGOs are classified as advocacy, operational or hybrid. Advocacy NGOs work on behalf of others who lack the voice or access to promote their interests and/or to exercise their rights. Operational NGOs provide critical goods and services to clients with unmet needs. NGOs involved in both activities, are called hybrid (Teegan, et al., 2004).

Thus NGOs play differing roles and adopt different strategies to achieve their goals. For instance, advocacy NGOs may be well positioned to give people a voice where markets are repressive, or weak, resource-strapped government 
regimes fail to meet their needs (Korten, 1990). They can advocate in various ways: lobby power-holders, serve as representatives and advisory experts in decision-making, conduct research, hold conferences, stage citizen tribunals, monitor and expose the actions (and inactions) of others, disseminate information to key constituencies, set/define agendas, develop and promote codes of conduct, and organise boycotts and demonstrations (Gunter, 2004).

Operational NGOs can also influence important values, but they are primarily involved in delivering public services to provide critical "safety nets" (Howell \& Pearce, 2001). They fill voids generated where markets fail or where politically challenged, indebted or corrupt states are unable or unwilling to provide unmet needs; and when global problems defy neatly defined nation-state responsibilities (Teegan et al., 2004).

NGOs can be classified by spheres and geographic locations, that is, local, national or international (or large international). As Mcllwaine (2009) states, NGOs range from "very small-scale community based organisations at the grassroots level to larger regional or nationally based organisations, to umbrella groups comprising several organisations, and to international NGOs" (p. 140). However, boundaries between classifications are becoming increasingly blurred. For example, the rapid development of internet use and globalisation enable NGOs to act nationally and globally (Feher, Krikorian, \& McKee, 2007). Attempts to classify and homogenise NGOs into a few categories may be detrimental and counter-productive to understanding their roles (Mercer, 2002). Rather, recognising NGOs' roles in contestation and the plurality within the social, political, economic, and cultural environments in which they operate may be more important (McIlwaine, 2009).

\subsubsection{Roles of NGOs}

The roles of NGOs in society and their relationship with the state and markets have changed in recent decades. Key roles now often include promoting and facilitating democracy; acting as a watchdog over states and businesses; representing and educating the public; mediating conflicts; advocacy in favour of 
poor/marginalised groups and environmentalists; providing public services and delivering aid; and participating in tri-sector partnerships (Howell \& Pearce, 2001; Teegan, et al., 2004).

As NGOs are civic organisations that aim to empower the public and make unheard voices heard, they are perceived as promoters of democracy (Howell \& Pearce, 2001). Their positive contributions in this capacity lie in fostering democratic transitions from authoritarian regimes and in consolidating democracy in the LDCs of Africa, Latin America, and Asia (Mercer, 2002). When the Cold War ended, liberal democracy and open-market economies were increasingly advocated by multilateral donor organisations; capitalism with liberal democracy became the "triumphant winner" in a long-lasting state/market-oriented development debate (Howell \& Pearce, 2001, p. 4). Many donor organisations turned to NGOs to further "good governance" in LDCs (McIlwaine, 2009; Mercer, 2002).

NGOs have also been public watchdogs over the state and business. Whether from a neo-liberal or human rights and justice perspective, local, national, and international NGOs have been independent 'auditors' of state and business performance. From the neo-liberal democratic perspective, NGOs help maintain accountability of the state to the public and help prevent state power from becoming too oppressive (McIlwaine, 2009). NGOs have promoted corporate social responsibility, human rights and environmental justice when addressing problems caused by the private sector (Howell \& Pearce, 2001; Schlosberg, 2007). International NGOs, such as Amnesty International, World Wildlife Fund, Greenpeace, Oxfam, and Mining Watch, as well as national NGOs, have monitored business activities around the world, particularly in LDCs, through their independent research on industries such as mining, and have challenged the 'business-as-usual' behaviour of multinational corporations and domestic businesses (Szablowski, 2007; Teegan, et al., 2004).

NGOs are commonly perceived as public or community educators, facilitators, representatives and mediators of conflicts among the public, state and business 
sectors (Teegan, et al., 2004). In spite of criticisms of their capacity to represent (see section 4.1.4), NGOs usually have closer connections with the public they serve because they are created and mobilised by individuals with similar interests (Korten, 1990). NGOs often try to increase people's awareness of their rights and participation in decision-making (Feher, et al., 2007), and they disseminate information on pertinent political, social, and environmental issues (Howell \& Pearce, 2001). NGOs in LDCs have introduced and implemented participatory approaches at community and national policy-making levels with the support of donor organisations (Jordan \& van Tuijl, 2006). Moreover, they have actively raised social, environmental, and human-rights issues at domestic and international forums and have acted as mediators and public representatives in conflict resolutions, not least in regard to social and environmental issues caused by mining (see sections 4.2.2 and 4.2.3 for more detail) (Humphreys, 2005; Li, 2009; Szablowski, 2007).

Throughout their history, NGOs have addressed issues that the state or market have neglected, often contrary to the expectations of the public. In spite of NGOs being present in many countries, it was not until the 1960s that NGOs became significant players in political and social arenas. Activists and social movements (or NGOs) propounded alternative views to the mainstream on the Vietnam War and human rights, such as race and gender inequalities, in the USA and Western Europe (Howell \& Pearce, 2001). At the time, NGOs were often regarded as critics and antagonists of the state and markets, and as representatives for suppressed voices, such as black people, women and environmental justice campaigners (Howell \& Pearce, 2001; Schlosberg, 2007). Since the 1980s, NGOs have frequently been cited as democracy promoters/facilitators in newly independent and post-communist countries (Kravchenko, 2002; Mercer, 2002), anti-globalisation activists, and campaigners against the environmental and social impacts of multinational companies in LDCs (Mittelman, 1998; Parker, 2003; Urkidi, 2010). Their mobilisation of local and international communities has endeavoured to promote democracy and empower people through greater public participation in policy and decision-making in the belief that this would improve 
public and private sector accountability and promote sustainable development (Hickey \& Mohan, 2004b; Schlosberg, 2007).

During the late 1970s, influential Keynesian economic theories were increasingly questioned; in many capitalist countries, burgeoning welfare states were deemed too expensive to sustain; and in newly independent LDCs the theories were perceived as having failed to generate development (Howell \& Pearce, 2001). By the 1980s, neo-liberal economic development policies, akin to the political economics of Margaret Thatcher and Ronald Reagan, spread across the world. Structural Adjustment Programmes (SAPs) were introduced in the North ${ }^{50}$ and the South. ${ }^{51}$ These incorporated aspects of new public sector management' (Kapoor, 2008), including decentralised government, privatisation of state-owned enterprises, and reduced social-welfare programmes (Reed, 2002; Szablowski, 2007). Multilateral donor organisations, such as the World Bank and the IMF, promoted SAPs in many LDCs to minimise state intervention and to promote freemarket economic development (Howell \& Pearce, 2001; Szablowski, 2007). Neoliberal development policies encouraged the provision of some public services by NGOs, and they began to be seen as 'substitutes' for some state agencies, particularly in providing social services such as health and education, and as social safety nets (Teegan, et al., 2004).

Hence, in cooperation with donor organisations, NGOs increasingly became aid deliverers in LDCs. Until the 1980s, development agencies and donor organisations had provided millions of dollars to the governments of newly independent countries in Africa, Latin America, and elsewhere. However, the failure of economic and social development in sub-Saharan countries, particularly, prompted a switch of strategy away from direct monetary aid to governments of LDCs (Howell \& Pearce, 2001). Often they had insufficient capacity and capability to use aid as effectively as expected (Bebbington, 2005). Such governments were criticised for their "militarism and authoritarianism, corruption

\footnotetext{
${ }^{50}$ The North is a commonly used expression in political studies to refer to welfare countries in North America and in Western Europe (Kapoor, 2008).

${ }^{51}$ The South refers to the remaining countries, mostly LDCs and newly independent countries (Kapoor, 2008).
} 
and venality, wasteful investment and expenditure, their distortion of market forces, protection of uncompetitive national industries, the creation of large-scale state monopolies" and for their lack of accountability and representation (Howell \& Pearce, 2001, p. 14). Governments of LDCs could be prone to corruption and nepotism, so donors turned increasingly to international and national NGOs to deliver development projects. NGOs were also favoured because of their less bureaucratic structures, closeness and willingness to help the public, and greater local knowledge (Feher, et al., 2007).

This created unprecedented new relationships between donor organisations, particularly regarding humanitarian and developmental agendas (Jordan \& Tuijl, 2006; Howell \& Pearce, 2001). Since the 1990s, NGOs have become regarded as partners of the state and business, reflecting the growing enthusiasm by development theorists and practitioners for "social capital" and tripartite partnership approaches (Teegan, et al., 2004). Nevertheless, neo-liberal development policies attracted criticism; their application was associated with a continuous decline of economic growth-rates in Africa and other regions, and with widening socio-economic disparities within LDCs and between LDCs and developed countries (Hall \& Trentmann, 2005). Some researchers argued that neither the state nor markets could fully deliver development policies and there was "a missing link" (Howell \& Pearce, 2001). In this vein some argued that "civil society and civic engagement produce an identifiable stock of norms, trust, and networks, an accumulation of social capital that enables development to take place" (Putnam, 2002). NGOs and other civil society organisations were deemed as crucial for building and strengthening "social capital" (Teegan, et al., 2004). Donor organisations welcomed this, and policies from international institutions, such as the World Bank ${ }^{52}$ and the UN, gradually changed (Howell \& Pearce, 2001). Over the last two decades they have strived to improve the capacity of NGOs and other civil society organisations to foster and deliver development (Toth, 2010).

\footnotetext{
${ }^{52}$ The World Bank changed its orientation in 1997 and encouraged more engagement with NGOs (Teegan, et al., 2004).
} 
Moreover, philosophies of sustainable development and building social capital encouraged more institutional collaboration to address the apparently complex social, economic, and environmental issues (Hall \& Trentmann, 2005; Korten, 1990). Donors introduced tri-sector partnerships, encouraging cooperation between the state, business, and civil society (Gunter, 2004). Consequently, NGOs became increasingly perceived as partners rather than as 'enemies' of the state and business (Teegan, et al., 2004).

In summary, the roles of NGOs have changed due to new development agendas that recognise the importance of civil society and its relationship with the state and business. Depending on their values and objectives, NGOs have assumed different roles. Thus, to attempt to make distinctions between NGOs according to their roles would be an ambitious exercise that could oversimplify their social contributions. NGOs are complex in their vitality, views, and objectives.

\subsubsection{Contestation of NGOs}

In spite of being 'non-governmental', 'non-profit' and 'apolitical' organisations, the NGO sector has attracted growing criticism from international donor organisations, academics and practitioners, particularly after the 1990s (Munck, 2006, p. 328), concerning its poor accountability, representation, credibility and/or co-option to dominant beliefs.

There are three main reasons for concern about the accountability of NGOs: rapid growth in their number and size; their increased funding; and their stronger voice in shaping public policy (Jordan \& Tuijl, 2006, p. 4). NGOs are accountable to fund-providers, members, and beneficiaries, but as the boundaries between each set of accountabilities has become blurred in practice, such distinctions are only useful for analytical purposes.

NGOs are non-profit, social organisations. Most depend on the funding of donors to provide benefits to the poor, marginalised communities, and beneficiaries. However, donors may focus on the efficiency of NGO accountability, rather than the effective use of funding (Howell \& Pearce, 2001). This has led some NGOs to 
concentrate on the donors' efficiency requirements, to the neglect of serving beneficiaries in areas such as participation and public empowerment, which has divided NGOs into followers and non-followers of donors' guidance (Bebbington, 2005; McIlwaine, 2009). Dependency on donor funding may divert NGOs from their initial objectives, lead to neglect of beneficiaries' needs by co-opting donors' perspectives, and encouraging opportunistic enterprises that seek to 'make money' under the name of 'NGOs' (Mercer, 2002). NGOs, particularly in LDCs, must go beyond securing aid if they are to attain their social goals and change society (Bebbington, 2005).

Some SEA researchers have examined the accounting and accountability issues of NGOs as non-profit organisations, and also in terms of both internal accountability and to society. Attention has been drawn to the poor institutional accounting and accountability of NGOs, particularly those in LDCs (Goddard \& Assad, 2006) and for Northern advocacy NGOs, such as Amnesty International (Unerman \& O'Dwyer, 2006). Others have criticised the unelected and 'profitcentred' nature of NGOs (Lehman, 2007), the loss of their legitimacy (O'Sullivan \& O'Dwyer, 2009), and the lack of willingness to apply accountability standards to themselves that they demand of others (O'Dwyer, 2007). Given the failure of mainstream accounting to provide effective accounting and accountability systems that are appropriate for the distinctive features and complexity of NGOs, some SEA researchers have called for more appropriate means (Lehman, 2007) and the development of new accounting systems for civil society organisations (Gray, et al., 2006).

NGOs have been criticised for being too distant from beneficiaries and for lacking accountability and outreach to them (Bebbington, 2005). Donors expect NGOs to bring benefits to marginalised communities (Howell \& Pearce, 2001) in the belief that they have 'greater capacity to reach the poor and promote local participation' (McIlwaine, 2009, p. 139). However, some NGOs fail to reach the poor, due to their dependence on development-aid, opportunistic, self-interested leaders, and an absence of skilled staff (Feher, et al., 2007). Operational NGOs in LDCs are mostly located in urban areas and staffed by middle-class professionals or (ex)- 
public servants (Weller, 2005). They are often formal, well-structured and wellstaffed to meet donors' requirements, but such NGOs can lack local knowledge and become geographically separated from rural areas and the intended beneficiaries of donor-funded projects (Jordan \& Tuijl, 2006; McIlwaine, 2009). Sometimes, especially in authoritarian and post-communist countries, (ex)political elites and (ex)-public servants use their contacts and information access to establish NGOs and obtain donors' funding (Weller, 2005). Low accountability to beneficiaries brings into question the power of NGOs to represent them (see later) as well as their ability to reach poor, marginalised people in LDCs (Bebbington, 2005; Gray, et al., 2006; Howell \& Pearce, 2001; McIlwaine, 2009).

Such criticisms may stem from the close relationships between the state and NGOs in LDCs and normative assumptions that NGOs are 'apolitical' and 'nonprofit' (Bebbington, 2005). NGOs are assumed to be separate from the state in LDCs, but in practice the boundaries between them can become blurred (McIlwaine, 2009; Mercer, 2002). Funding by the state or political entrepreneurs has brought unexpected 'fuzzy' relationships, particularly in non-Western countries where civil society is new and where no clear division exists between the state and civil society (Schwartz \& Pharr, 2003). In authoritarian regimes, this relationship can become symbiotic rather than antagonistic, as NGOs try to obtain better access to the state and to gain political benefits by working for it (Munck, 2006). Hence, NGOs can become both political and dependent on the state, albeit sometimes inadvertently (Feher, et al., 2007; McIlwaine, 2009).

Increased funding has precipitated a booming NGO sector and an increase in opportunistic NGOs. The neo-liberal ideology advocated by multilateral donor agencies, such as the World Bank and the IMF, and beliefs that NGOs can promote liberal democracy and economic liberalism has penetrated the development agendas of donors (McIlwaine, 2009), resulting in dramatic increases of donor funding to NGOs over the last three decades and increased numbers of NGOs in LDCs (Howell \& Pearce, 2001). Most funding has gone to the increased number of operational NGOs (Mercer, 2002, p. 14) rather than to advocacy NGOs that could contest issues such as human rights and environmental 
protection (McIlwaine, 2009, p. 139). Some operational NGOs have become regarded as money-making enterprises that have been established opportunistically, and some advocacy NGOs have changed their function accordingly (Howell \& Pearce, 2001). Some argue that opportunistic NGOs have acted as "supportive arms" of the neo-liberal economic perspective advocated by Western donors, and have become "semi-state entrepreneurs" (Feher, et al., 2007).

Donor funding is essential for the "survival" of many advocacy grass-root NGOs in LDCs (Howell \& Pearce, 2001). When they become operational, advocacy NGOs often lose their ability to provide critical voices against dominant hegemonies of the state and global governance (Mercer, 2002). Thus, the increased number of operational NGOs has fed criticisms about NGOs' accountability and claims to represent civil society. Given their dependence on donor funding, many operational NGOs are "too close for comfort" to donors and their independence has become threatened (McIlwaine, 2009). This calls into question whether donors can strengthen civil society through this route (Bebbington, 2005; McIlwaine, 2009). Moreover, distance from and a lack of transparency to beneficiaries and grass-roots organisations has weakened the legitimacy of NGOs in society (Mercer, 2002).

Some argue that donors' use of NGOs as a technocratic tool and service or as aid deliverers and facilitators to "strengthen civil society" in non-Western countries may undermine their representative abilities and may discourage NGOs from developing alternative politics (Bebbington, 2005; Howell \& Pearce, 2001; Mercer, 2002). Thus, a danger exists of non-Western NGOs co-opting the prevailing Western views on "development" (Hickey \& Mohan, 2004), and become 'missionaries of Western capitalism' (Munck, 2006, p. 329).

The above has created scepticism about the claims of NGOs as representing poor, marginalised people in LDCs (Mohan, 2002) and has served to undermine donors' neo-Tocquevillian goals for promoting liberal democracy and participation in LDCs (McIlwaine, 2009, p. 139). For example, some allege that donors' attempts to alleviate poverty and promote democracy in LDCs have failed because they 
have neglected the structural issues of poverty and socio-political inequalities (Bebbington, 2005; McIlwaine, 2009; Mohan, 2002).

In summary, there are criticisms concerning NGOs' accountability, the rise of opportunistic NGOs, and their ability to represent poor, marginalised people. However, the potential remains for NGOs to promote global and national democracy, participation, thereby improving the accountability of the state and markets to the public (Howell \& Pearce, 2001; Lehman, 2007; McIlwaine, 2009). Some critics advise paying attention to the complex political natures of NGOs and to avoid treating them as a unitary concept (Howell \& Pearce, 2001; Mohan, 2002). As noted, the term 'NGOs' covers a wide range of operational and advocacy NGOs, professional organisations, and grass-roots social movements and there is always scope for alternative thought and action (Mercer, 2002).

Conflict and antagonism should be expected in the NGO sector, if it seeks to create space for alternative views on issues such as "development", human rights, and environmental protection (Howell \& Pearce, 2001; McIlwaine, 2009; Schlosberg, 2007). In this respect, the neo-Gramscian view of civil society has been influential, especially during the democratisation of South America during the 1980s and of Eastern Europe during the 1990s (Munck, 2006, p. 330). There, civil society was both a supporter and challenger of the dominant hegemony; it became an arena where "people [could] associate in a myriad of forms and for a variety of purposes" (Howell \& Pearce, 2001, p. 34) and where "flexible, heterogeneous, and plural" discourses on justice and other issues abounded (Schlosberg, 2007, p. viii). In the capitalist era, this alternative space challenges "the mainstream's homogenisation of civil society" and "reflects a multiplicity of diverse and often diverging voices that share a wish to preserve a concern for a common humanity, to undo the negative aspects of capitalist development, and to promote forms of economic organisation that are environmentally and socially just" (Howell \& Pearce, 2001, pp. 35-37). Thus, it is misleading to treat NGOs as homogeneous; for instance, environmental, justice-oriented NGOs "employ multiple conceptions of justice simultaneously", ranging from fairer distributions 
of costs and benefits to ecological justice for animals and biodiversity (Schlosberg, 2007, p. 5).

Nevertheless, NGOs are consistently ranked among the most trusted organisations. According to the Edelman's Barometer Trust global surveys, between 2000 and 2005 they outranked corporations, governments, churches, the media, and other authorities (Edelman, 2005). The sixth survey showed that the public believed that NGOs most closely reproduced their own personal social networks, and offered more reliable information than leaders, experts, the media, governments or corporations (Jordan \& Tuijl, 2006, p. 13). They are undoubtedly powerful actors in national and global discourses on public policy, development, and other issues.

\subsection{NGOs as promoters and facilitators of dialogue}

\subsubsection{NGOs as 'agents' of democracy and participation}

The importance of NGOs is acknowledged in various fields. In particular, they are recognised as influential in fostering democracy and participation in LDCs. Democracy - "government by the people" - is argued to be a better social order than authoritarian regimes as it is more inclusive and not as oppressive (Lipset, 1995). It encourages empowerment of people whose voices often go unheard in authoritarian regimes (Korten, 1990). Public participation in socio-political and economic decisions has been widely commended in development discourses about poor and marginalised communities (Coenen, 2008).

As already noted, the neo-Tocquevillian liberal approach has influenced development discourses of donor organisations. Civil society is encouraged by the belief that it can provide a check to "potentially authoritarian elements of the state", while promoting democratisation through public participation (McIlwaine, 2009). NGOs have become an "integral dimension of the good governance agenda of donor organisations" and have attracted numerous international projects on strengthening the capacity building of NGOs, particularly in LDCs (Howell \& Pearce, 2001; McIlwaine, 2009; Mercer, 2002). 
Consistent with their claims of acting in the public interest, many NGOs have initiated, fostered and helped to maintain democracy - they have acted as a 'shepherd' for democracy. NGOs have pursued various strategies adapted to different stages of democratic evolution. They have organised antagonistic actions to raise social awareness of politically sensitive issues and demonstrations against oppressive states to foster democracy and social change (Li, 2009, Gunter, 2004). In countries undergoing democratic transition, NGOs have actively raised public awareness of democracy and citizens' rights, represented the voices of people who go unheard, and have mobilised public participation in socio-economic and political discourses (Howell \& Pearce, 2001; Teegan, et al., 2004). Moreover, they have checked "state power by challenging its autonomy at both national and local scales, pressing for change and developing an alternative set of perspectives and policies" (Mercer, 2002, p. 9). Hence, they have been leaders in mobilising pressure for political change and democratic transition in authoritarian regimes in Latin America, South-East Asia and in former communist countries (Howell \& Pearce, 2001; Mercer, 2002). However, this has been more difficult in countries where civil society is weak or underdeveloped: there, severe socio-economic constraints exist; corruption and ineffective legal systems abound, there is a lack of a "democratic culture"; and socio-economic inequalities among ethnic and regional communities exist (Kapoor, 2008; Reed, 2002).

From the neo-liberal viewpoint, development and democracy are positively correlated (Howell \& Pearce, 2001). As democracy is widely regarded as "humane" development, participation can empower citizens and marginalised people, and can aid the "transformation" to participatory democracy particularly in LDCs (Cooke \& Kothari, 2001). Participation - regarded as a prerequisite of democracy - has been supported and used "virtually unchecked from margins to the mainstream of development" since the mid-1980s (Hickey \& Mohan, 2004, p. 3). There is a normative consensus that civil society and NGOs are inherently "good things" and constitute "microcosms" of the (liberal) democratic process as they are separate and autonomous from the state, while acting as a "bulwark" against it (Korten, 1990; Mercer, 2002). International donor organisations have 
enthusiastically incorporated schemes such as participatory rural appraisal and rights-based approaches into funded projects and research executed by development practitioners, including NGOs (Cooke \& Kothari, 2001).

However, these participatory approaches are criticised for being technocratic tools and processes with little evidence of success. Accusations contend that participation represents a "new tyranny" used in the name of vulnerable people who are "coerced into activities". Thus, decisions become subject to a series of techniques that encourage people to express their experiences and views, but which rarely 'empower' them (Hickey \& Mohan, 2004); and such technocracy is "administered and planned by agents of development rather than negotiated with and contested by its subjects" (Hickey \& Mohan, 2004, p. 10). Arguably, technocratic participatory approaches fail to address power and politics and depoliticise "what should be an explicitly political process" (Hickey \& Mohan, 2004, p. 3). Decisions, concerning who should participate and how, and which issues and objectives should be prioritised, are political. Thus, participation in decision-making processes is inherently political and influenced by power relations.

International development NGOs facilitate/deliver development aid and projects of international donor organisations to LDCs and cooperate with domestic NGOs to implement these projects (Feher, et al., 2007); whereas, domestic NGOs act as facilitators and implementers of development projects in their own countries, and sometimes become beneficiaries of international NGOs (Howell \& Pearce, 2001). This relationship is increasingly criticised for being top-down, technocratic, and ultimately undemocratic. It is accused of being inattentive to local realities and power relations, and of ignoring empowerment goals and possible local inputs, such as local knowledge (Cooke \& Kothari, 2001).

However, that participation has entered mainstream views on development is "a sign of success" (Hickey \& Mohan, 2004, p. 12). It may have stimulated consideration of radical alternatives proposed by NGOs in LDCs and development study research (Mercer, 2002). Moreover, even critics acknowledge that civil 
actors can promote participation and strengthen democracy under certain conditions in LDCs with appropriate support from NGOs (McIlwaine, 2009; Mercer, 2002). Heller (2001) argues that 'transformatory' participation needs three enabling conditions:

$>$ a strong central state capacity

$>$ a well-developed civil society

$>$ an organised political force, such as a party, with strong social movement characteristics (Heller, 2001, pp. 138-139).

However, most LDCs lack these conditions. Thus it is important to focus on preconditions of participatory governance, such as awareness building on rights and citizenship; building civil associations and social movements engaged in governance issues; and strengthening institutions of governance, both at the local and central levels (Howell, 2001). NGO assistance in fostering these conditions is crucial for many LDCs, where state institutions are often neither responsive nor accountable to their people and have a lack of political will to support truly participatory governance (Mohan, 2002; Bebbington, 2005)

\subsubsection{NGO engagement in environmental issues}

Local, national and international NGOs, through public participation in decisions have raised public awareness of social and environmental issues associated with economic development - previously excluded as 'externalities'. In addition, they have organised collective actions against oppressive states, and they have exerted pressure on companies and multinational corporations to change their socially and environmentally unfriendly behaviours (Gray, et al., 2006; O'Dwyer \& Unerman, 2008; Schlosberg, 2007). Environmental protection and environmental degradation are two areas where NGOs have had a prolonged engagement expounding participatory development, with significant effects on global and national policies and decisions on environmental matters (Gunter, 2004; Howell \& Pearce, 2001).

Rachel Carson's book Silent Spring (1962) had a profound influence on Western thought. She combined consideration of the natural environment, its habitats and 
"the concern for human health and industrial impacts on individuals and communities" which had become disconnected from the dominant perspectives of the day (Schlosberg, 2007, p. 7). Inspired by Carson's work, numerous environmental movements and NGOs emerged in the North during the 1960s that were devoted to promoting environmental justice and human rights (Howell \& Pearce, 2001; Schlosberg, 2007). NGOs have raised social and global awareness of environmental issues and put pressure on responsible parties, for example, by organising demonstrations and consumer boycotts (Gunter, 2004; Howell \& Pearce, 2001). Alongside such activism, NGOs have cooperated with government organisations, international donors, companies, and research institutions over policies and decisions regarding environmental protection and preventing environmental destruction (Feher, et al., 2007). Thus, NGOs act as mediators or "border-crossers" among the state, business, academia and the public (Schlosberg, 2007; Teegan, et al., 2004). Depending on their ideologies, for example, whether they are anthropocentric or deep green, the views of NGOs and environmental movements on environmental issues can range from the just distribution of natural resources within local communities to complete environmental protection in favour of biodiversity (Schlosberg, 2007).

However, all NGOs recognise the importance of participation, and the inclusion of affected communities and ecological concerns in decision-making (Gunter, 2004). Given this, and their advocacy of environmental justice, NGOs believe that this can improve the credibility of decisions, prevent potential conflicts among constituents, and encourage democratisation in environmental management (Coenen, 2008; Kapoor, 2001). As discussed in Chapter 3, environmental management deals with "inherently political questions" by making decisions about "a shift of resources and opportunities from some groups to others" (Coenen, 2008, p. 6).

The importation of participatory approaches that are consistent with sustainable development and CSR has accelerated in both national and international policy agendas. International conventions, such as Agenda 21 and the Aarhus Convention “Access to Information, Public Participation in Decision-Making and 
Access to Justice in Environmental Matters", are outcomes of active collaboration with national and international NGOs on global policy-making (Coenen, 2008). These conventions provided fundamental international legislative documents for NGOs to promote participatory environmental decision-making in LDCs (Schlosberg, 2007; Toth, 2010). These documents declared that participation of affected communities in environmental and social matters is the pillar for achieving sustainable development (United Nations, 1992), which could provide the legal space for people and NGOs to participate in forms of environmental management that are less technocratic and more participatory (Kapoor, 2001; Toth, 2010).

NGOs, being legal entities with sufficient legitimacy and power to influence the state and business, have increased their mediating and facilitating roles among the state, business and the public (Feher, et al., 2007). Following greater enthusiasm for such tripartite partnerships, NGOs have engaged in national and global environmental policy-making and discourses, and capacity building schemes (Howell \& Pearce, 2001). They have endeavoured to incorporate local knowledge into the formal - often Western-style - environmental decision-making, and to cooperate with government organisations and academia to conduct research and policy analyses (Gunter, 2004). NGOs have also cooperated with the state and international organisations to raise public awareness of environmental matters, and to build and mobilise the public's ability to participate in environmental decisions (Li, 2009; Szablowski, 2007). Thus, NGOs have become wellrecognised, civil society organisations that are routinely given seats at major international meetings of the United Nations, and are systematically included in established networks concerning global and national policy arenas, the World Bank, and the decision-making processes of other multilateral donor organisations (Toth, 2010).

In the meantime, NGOs have retained the reputation for being watchdogs over the state and business, regarding social and environmental issues. As NGOs are heterogeneous, some work outside the state and business networks and act as social and ecological "auditors" (Schlosberg, 2007). Together with environmental 
advocates, national and international NGOs have strongly criticised multinational corporations, governments and international organisations by organising citizens' jury systems, and producing counter-assessments to formal EIAs ( $\mathrm{Li}, 2009$; Schlosberg, 2007; Szablowski, 2007). This is evidenced by successful transnational lawsuits, development of an ombudsman function by Oxfam/Community Aid Abroad, changes in World Bank policies following NGO criticisms about their negative impacts on LDCs, and creating "public independent expertise" in some post-communist countries (Kravchenko, 2002; Szablowski, 2007).

Globalisation and rapid technological advances in the Internet have given NGOs unprecedented power and influence across the world. Beside their traditional modes of operation, NGOs have used internet public domains, such as Facebook, Twitter, and their own websites and blogs to initiate public debate, organise "virtual" boycotts of multinational corporations, and help change social attitudes to social and environmental issues (Nelimarkka, 2010). Through a combination of their activist and watchdog roles, NGOs have encouraged greater accountability and democratisation in many countries (Feher, et al., 2007; Howell \& Pearce, 2001).

\subsubsection{NGOs as promoters and facilitators of dialogue in mining}

As noted in Chapter 2, mining can have severe environmental and social impacts in LDCs. This has fostered pursuit of various strategies and forms of activism by local, national, and international NGOs (Li, 2009; Szablowski, 2007). It is commonplace for local and international NGOs to work alongside affected local and indigenous peoples, protesting against poor mining practices and inequitable distributions of economic and social benefits, human rights' violations, land disputes and disastrous effects on the natural environment (Diamond, 2005; Martin, 2006; MMSD, 2002; Schlosberg, 2007). The sometimes "selective absence" of the state in LDCs in such matters, the power of multinational companies relative to individual states, and a lack of transnational legislation on 
environmental matters (Szablowski, 2007) have heightened the importance of NGO engagement in mining issues in LDCs.

A common tactic of local and international NGOs is to damage the reputations of target companies, thereby undermining their legitimacy (Szablowski, 2007). Methods to achieve this include "consumer boycotts, lobbying for legislative change, picketing retail outlets or corporate headquarters, lobbying large institutional investors, developing public awareness through media campaigns, raising issues in shareholder meetings", and organising local demonstrations (Szablowski, 2007, p. 68). International NGOs and their networks, such as Mining Watch, Greenpeace, Oxfam and the WWF, act as umbrella organisations to create globally influential media coverage, to support and mobilise national NGOs, and to monitor and exert pressure on multinational mining companies (Collins, 2009; Diamond, 2005). Sometimes, local NGOs have been involved in violent demonstrations and domestic conflicts in LDCs (Li, 2009; Martin, 2006).

Nevertheless, some NGOs have begun to cooperate and facilitate dialogue among mining constituents, with a growing emphasis on tripartite partnership and multistakeholder engagement to address sustainable development within the mining sector (MMSD, 2002). This has led some NGOs to initiate collaborations between the state and mining companies (Cornejo, Kells, Zuniga, Roen, \& Thompson, 2010). In such instances EIAs have increasingly become conduits for promoting democratic, environmental decision-making, deliberative engagement, collaborative social learning and for preventing conflict among mining constituents (Diduck \& Mitchell, 2003; Kakonge, 1998; Petts, 2004; Saarikoski, 2000). EIA legislation creates a legal public space "in which government is more prominently involved in an administrative capacity", and requires EIA companies to assess their social and environmental impacts and to ensure public participation in EIA decisions (Szablowski, 2007, p. 49).

NGOs have begun to consider EIAs as potential spheres where affected people can actively participate, have a voice, and thereby prevent negative environmental impacts. Stronger environmental NGOs have managed to increase their 
involvement in EIA procedures against legal and institutional odds (Cherp, 2001, p. 346). In both developed countries and LDCs, NGOs have begun to play a crucial role in improving public participation in EIAs (Diduck \& Mitchell, 2003; Mitchell, 2001; Richardson, 2005). This, coupled with a dialogic approach, may challenge the current technocracy of EIAs and their neglect of sustainable development (Kapoor, 2001; Söderbaum, 2004).

The Peruvian case of the Tintaya copper mine shows how an EIA can promote participation and dialogue among all mining constituents, including domestic and international NGOs and their coalitions (Barton, 2005). In this space, mining constituents not only "may deliberate the facts and issues" regarding mining projects, but can also engage in social mediation (Szablowski, 2007, pp. 49-51). Previously, paternalistic CSR models used by mining companies were ineffective as they "reinforced a cycle of dependency and rendered the local communities unorganised, voiceless and weak", thus multi-stakeholder dialogue is "a fundamental element in promoting sustainability" (Cornejo et al, 2010, p. 1).

As noted in Chapter 3, public participation in EIAs is still weak internationally (Cherp, 2001; Sinclair, et al., 2008; Jay, et al., 2007; Mitchell, 2001). Nevertheless, given their long-standing support for participatory environmental decision-making and engagement in EIA practices, NGOs can or do have a role in educating, mobilising and organising the public and affected communities, giving voices to marginalised people, involving and monitoring EIA processes (Barton, 2005; CSP $^{2}$ and WRI, 2005; Kapoor, 2001), building alliances nationally and internationally, and in identifying partnerships that can move beyond “partisanship" (Cornejo, et al., 2010, p. 41).

However, not all NGOs are enthusiastic about contributing to formal EIA procedures. Some prefer to produce counter-assessments of EIAs (Kravchenko, 2002) in the belief that formal EIAs play only a symbolic role in mining practice (Szablowski, 2007). For example, when there was an official public hearing on an EIA for the Minera Yanacocha project, a foreign mining venture in Peru, some 
social movements (NGOs) and affected communities refused to participate, claiming that:

Nothing they could say would prevent the EIA from being approved. Not only would their intervention in the meeting be futile, but the company would use their attendance to legitimate the EIA with the claim that it was democratically accepted. They decided that their best course of action was to step outside the [EIA] document (Li, 2009, p. 230).

However, NGOs can use EIAs to construct scientific counter-arguments against mining companies, rather than only engaging in activism (Li, 2009, pp. 229-230).

Thus, NGOs have used collaborative and activist strategies to force the state and mining companies to improve their accountability of environmental management and mining ( $\mathrm{Li}, 2009$ ). Participatory EIAs could help advance economically sustainable mining.

\subsection{The Mongolian NGO sector}

The emergence of NGOs in Mongolia is closely related to growing public demand for strengthening democracy, respecting human rights, combating corruption, and improving inadequate state management of social and environmental issues. NGOs and other civil society organisations have increasingly contested mining problems and unfair income distribution. The involvement ${ }^{53}$ of NGOs in such issues has been late compared to other countries. Since the 1990s, following the end of communism, Mongolian civil society has grown dramatically. The notion of civil society, or 'citizens society' in Mongolian terminology, appears in the 1992 Constitution. Its preamble states that the supreme objective of Mongolia is to build "a humane, civil, and democratic society in the country" (The State Great Khural of Mongolia 1992, Article 1).

Currently, Mongolian civil society covers a wide range of organisations, including NGOs, trade unions, chambers of commerce, saving and credit cooperatives,

\footnotetext{
${ }^{53}$ Although there were trade unions and associations for women, youth and the elderly during the communist era, they were not voluntarily established and not separate from the state. Rather, they were a part of the dominant communist party (UNDP, 2006). 
political parties, religious organisations, apartment owners' unions, non-profit media, informal self-help and leisure groups, and community groups (UNDP, 2006, p. 1). Among these, NGOs are the most influential and active.

The democratic Constitution and the law on NGOs opened up legitimate grounds for NGOs. The law defines a NGO as:

An organisation which is independent from the state, self-governing, not-for-profit and established voluntarily by citizens or by legal persons other than State bodies (that exercise legislative, executive and judicial powers) on the basis of their individual or social interests and opinions (The State Great Khural of Mongolia, 1997, Article, 4.1).

Thus, it guarantees the right of Mongolian citizens to freely establish a NGO to further their interests and opinions without intervention by the state or other parties. The law defines two types of NGOs: public benefit, and mutual benefit. Public benefit NGOs are non-member NGOs that operate for the public benefit "in the fields of culture, art, education, science, health, sport, nature and environment, community development, human rights, protection of the interests of specific subsets of the population, charity and other such fields" (The State Great Khural of Mongolia, 1997, Article 4.2). Mutual benefit NGOs are member-based and operate "primarily to serve the legitimate interests of its members" (The State Great Khural of Mongolia, 1997, Article 4.3). The law indicates that NGOs may be involved in drafting and implementing decisions by state organisations and have a right to access information about activities of state organisations unless they are classified as state secrets (The State Great Khural of Mongolia, 1997, Article, 9.4 - 9.5).

Since the Law on NGOs (1997), the number of NGOs registered with the Ministry of Justice and Home Affairs has boomed, reaching more than 5000 by 2005 (Open Society Forum, 2005). However, the Mongolian NGO sector is still in its infancy. It faces numerous challenges ranging from the internal problems of NGOs to their broader impact on society in their endeavours to pursue democratisation. In spite of their relatively large number, only about one-fifth of NGOs operate on a 
regular basis (UNDP, 2006). The Civil Society Index 2005, developed by the International Civil Society Forum for Democracy, indicates that major obstacles for the development of NGOs emanate from the weak political, economic and social environments of Mongolia, the underdeveloped internal capacities of NGOs and their poor external cooperation (UNDP, 2006, p. 3). There is a need for powerful umbrella organisations, more active intra- and cross-sector cooperation and effective engagement with grass-root organisations and communities (Open Society Forum, 2005; UNDP, 2006).

Almost eighty percent of the registered NGOs are located in the capital city (Open Society Forum, 2005) where Mongolian economic, political and social resources are located. Urbanisation of NGOs jeopardises their ability both to represent and to be accountable to the public, given that NGOs claim to serve the interests of ordinary citizens and local communities. Most NGOs are not well-structured and staffed, which weaken their strength and reputation in society (UNDP, 2006). Financial resources of NGOs come mainly from abroad rather than donations from the public ${ }^{54}$ and other organisations. Ninety percent of NGO activities are financed by international donor organisations (Asian Development Bank, 2005). Consequently, NGOs are at risk of becoming opportunistic and of losing their initial social objectives, as well as their independence and internal democracy.

Environmental concerns expressed by environmental NGOs are becoming more frequent and influential as increased economic activity consumes more natural resources and worsens global warming. An article in the Environmental Protection Law (1995), defining the roles of NGOs, helped to legitimise environmental NGOs. It permits them to supervise and inspect the implementation of environmental protection legislation, demand rectification of breaches, submit matters to authorised organisations for decision, organise ecological training and education, and develop proposals, recommendations and methodologies for environmental protection and restoration to submit to the relevant organisation for a decision (The State Great Khural of Mongolia 1995, Article 32.1).

\footnotetext{
${ }^{54}$ Due to low income and social problems, people are often not financially able to support NGOs. A lack of donations from the public is also related to the near absence of philanthropy in society. 
The law also defines the scope of cooperation between the state and environmental NGOs. The ministry responsible for the natural environment may cooperate with NGOs on a contractual basis to delegate special functions (Article 32.2). Consequently, the MNET has increasingly cooperated with environmental NGOs on environmental protection and on raising public awareness (Gansukh, 2010). Since 2009, it has organised an annual environmental conference for NGOs. The first conference in 2009 established the Citizens Representative Committee from representatives of environmental NGOs so as to facilitate cooperation between environmental NGOs and the ministry (Bakei, 2010).

In 2010, 549 environmental NGOs accounted for ten percent of all NGOs (Gansukh, 2010). Figure 2 details the number of NGO's according to their main functions.

Figure 2. Numbers of Mongolian environmental NGOs by their functions in 2010

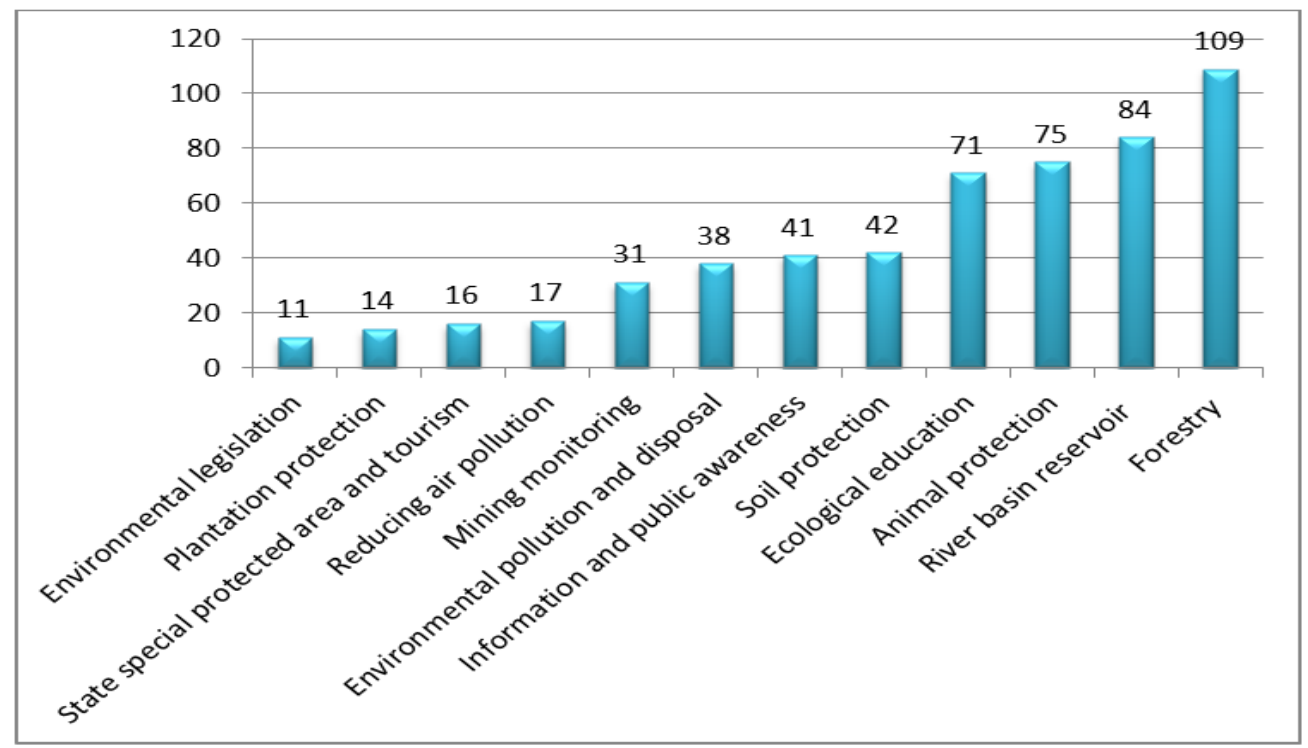

Source: Adapted from Bakei, A (2010) “The status quo of the natural environment: Roles of NGOs”, UB

Fifty-nine percent of NGOs work on environmental protection of the main ecosystem elements (such as water and soil) and biodiversity, 22.4 percent increase public awareness of environmental protection and ecological education, 10 percent seek to reduce either air or soil pollution, and 5.6 percent act as mining watchdogs. 
In spite of international and domestic enthusiasm for the development of Mongolian mining, its potentially adverse impacts on society and the natural environment have increasingly attracted the attention of NGOs. Since the early 2000s, local communities in some regions have organised social movements and demonstrations against poor mining practices in their regions. They argue that mining has not brought beneficial local economic and social development and has left a legacy of disturbed pasture land and dried-up rivers (Snow, 2010).

Consequently, various NGOs have been established to protect the constitutional rights of Mongolians to live in a safe and healthy environment. Figure 2 shows that 35.5 percent of environmental NGOs are directly concerned with mining issues. NGOs in areas which suffer from water, soil, and environmental pollution often focus on poor local mining practices. However, the remaining NGOs and other social NGOs have also addressed and participated in public debate on related issues, such as the large mining projects of Oyu Tolgoi and Tavan Tolgoi.

NGOs often complain about poor mining practices in local regions and request that the mining companies responsible should consider their social and environmental impacts (Munkhbayar, 2005). Local NGOs have pressured local and central government to address issues such as environmental degradation, contributions to local development, licence trading, and rehabilitation (Snow, 2010). The most significant contributions of environmental NGOs have been to raise societal awareness, mobilise the public, protest against poor mining practices, and to act as public representatives in negotiations and mediation (Snow, 2010).

In sum, development of the Mongolian NGO sector is still its infancy. Nevertheless, NGOs, particularly environmental NGOs, have played important roles in recent years to address social and environmental issues that have arisen from Mongolia’s booming mining sector. 


\subsection{Conclusion}

Being active, influential players of civil society, NGOs have long-standing interests and engagement in social and environmental issues that concern democracy, participation, environmental protection and mining. However, NGOs have diverse perspectives, objectives, adopted societal roles, strategies, operations, and national and global influence. They are invariably not 'good actors' - opportunistic NGOs exist which seek to exploit increased donor funding in their enthusiasm for new societal roles. Thus, the NGO sector is contested and variegated. Some parts promote the dominant development agendas, whereas others challenge and propose alternative viewpoints. Nevertheless, NGOs are crucial for promoting participatory environmental decision-making and sustainable mining, particularly in LDCs. Mongolian NGO practices illustrate this. Chapter 8 introduces the empirical analysis and will discuss the roles of Mongolian NGOs in more detail. 


\section{Chapter 5: CONCEPTUAL FRAMEWORK}

\subsection{Summary of literature reviews}

Drawing from the literature on mining, discussed earlier in relation to SEA, EIA, development studies, and civil society, this chapter develops an analytical framework for examining the empirical data in later chapters. First, the principal arguments raised by the literature review will be summarised to explain how and why the theoretical framework was chosen.

\subsubsection{Importance of environmental concerns}

The rapidly growing world population has increased the exploitation of natural resources. Neo-classical economic theories have encouraged mining development around the world, particularly in mineral-rich developing countries. This enthusiasm for mining assumes that mining sector growth will increase GDP and, thereby, development of a country (MMSD, 2001); that mining development will reduce unemployment; and that it will increase tax revenue (Ross, 2008). However, the mining sector is increasingly being questioned by its broader stakeholders because of its environmental, social, and cultural impacts, and whether the economic benefits to mineral-rich LDCs actually accrue and how they are distributed across different sections of society.

As the concepts of sustainable development and corporate social responsibility (CSR) have developed, the mining sector has increasingly been criticised for its negative impacts on the natural environment, society, particularly in LDCs. Evidence from mining development in Africa, Latin America, the Asian and Pacific regions show that mining has worsened environmental degradation and the social divisions, evidenced by the widening gap between rich and poor, corruption, increased incidences of local conflict and crime-rates, as opposed to creating economic and social prosperity (Diamond, 2005; Slack, 2009; Szablowski, 2007).

Consequently, mining has come under increased pressure and scrutiny from international and local communities, donor organisations, academics, and civil 
society organisations. If mining is to be compatible with sustainable development aims it is expected to meet the societal expectations of being socially and environmentally sound while generating economic benefits (CSP${ }^{2}$ and WRI, 2005; MMSD, 2002). Sustainability requires that the mining sector should consider its broader stakeholders and include local communities in decisions that may significantly affect them (CSP${ }^{2}$ and WRI, 2005).

Therefore, sustainable and participatory mining is increasingly advocated by international developmental organisations, donors, civil society organisations and governments around the world ( $\mathrm{CSP}^{2}$ and WRI, 2005; MMSD, 2002). Following this growing awareness, international communities have established various initiatives: international declarations, conventions and agreements among member countries of international developmental organisations, and the formation of voluntary standards for business, such as the ISO $14000^{55}$ (International Standards Organisation), 'AccountAbility and the GRI (Global Reporting Initiative) Sustainability Reporting Guide' for business entities (Reed, 2002), which address environmental issues and sustainable development in practice.

Social and environmental accounting endorses sustainable development and CSR initiatives in business communities and in other disciplines. Accounting that primarily serves 'business interests' has increasingly been questioned and its potential to re(de)construct realities and values has begun to be recognised (Molisa, et al., forthcoming). Alongside calls for democratising accounting, in the public interest, a growing number of researchers argue that environmental, social, political and cultural issues, which are viewed as externalities or neutral factors in the mainstream economic paradigm, should be internalised in managerial decisions and accounting practice so as to incorporate sustainable development and CSR into practice (Gray, 1992; Mathews, 1997). However, researchers approach these challenges differently, depending on their ideologies, perspectives, and values.

\footnotetext{
${ }^{55}$ The ISO 14000 family addresses various aspects of environmental management and provides "a framework for a holistic, strategic approach to the organisation's environmental policy, plans and actions" (ISO, 2005).
} 
Critical dialogic accounting, which openly acknowledges and engages with plurality, provides a promising SEA approach to this. By supporting pluralism, it supports the democratisation process in accounting. It argues that participatory accounting would encourage dialogue among stakeholders with differing ideologies, values, and views on social and environmental issues involving business (Bebbington, et al., 2007) and would help counter narrower "managerial" approaches to SEA. Given the lack of business concern about social, environmental, and intergenerational issues, sustainable development initiatives from international communities will require fundamental changes in their prevailing economic ideologies, values, and views if such initiatives are to be effective (Brown, 2009; Söderbaum, 2007). In this respect, dialogic accounting may be useful, as it would outline dialogic processes that could enhance social learning and re(de)shape the ideologies and values among various actors, thereby promoting social change (Brown, 2009; Söderbaum \& Brown, 2010).

Participatory decision-making on environmental and mining issues has begun to be encouraged in public policy and mining research, in the belief that it has the potential to improve sustainability and reduce conflict among mining constituents, including stakeholders, mining companies, and the state; and that it will increase the credibility of decisions among international developmental and donor organisations, civil society actors, academics, and local and national governments (Akol, 2001; $\mathrm{CSP}^{2}$ and WRI, 2005).

\subsubsection{A call for participatory decision-making}

Following calls for participatory environmental decision-making, international communities have produced several quasi-legal documents that provide frameworks for fostering greater inclusiveness in environmental decision-making and for promoting sustainable development. Agenda 21 and the Aarhus Convention are notable examples. These influential documents provide legitimacy for public participation in environmental and social issues that stem from development projects. They encourage countries to guarantee participants access 
to information and justice, and to grant the public, particularly affected people, the right to participate (Toth, 2010). As Zillman et al. (2005) point out:

Public participation means, at least, that members of the public have a right to gather information about major developments from government and from the developer, that they have a right to participate in the legislative and administrative and proceedings that consider the propriety of the project, and that they have an "access to justice" that reflects an ability to bring questions about the project to an independent judiciary (Zillman, Lukas, \& Pring, 2002, p. 2).

Consequently, participatory approaches have been widely advocated and applied in environmental decision- and policy-making. However, it is important to understand how such participation is actually viewed and used. Public participation can be used normatively and technically, depending on the premises and motivations of policy-makers and proponents of participation. Table 2 developed in Coenen (2008) summarises these arguments:

Table 2: Arguments and motives for public participation

\begin{tabular}{|c|c|c|c|}
\hline \multicolumn{2}{|c|}{ Normative arguments } & \multicolumn{2}{|c|}{ Instrumental arguments } \\
\hline For government & For participants & For government & For participants \\
\hline $\begin{array}{l}\text { Functioning of } \\
\text { democracy } \\
\text { Creating 'shared } \\
\text { responsibility' in, and } \\
\text { legitimacy of, } \\
\text { environment - related } \\
\text { decisions }\end{array}$ & $\begin{array}{l}\text { Emancipation, } \\
\text { particularly of certain } \\
\text { groups } \\
\text { Empowerment and } \\
\text { learning about the } \\
\text { environmental } \\
\text { problems facing } \\
\text { society }\end{array}$ & $\begin{array}{l}\text { Additional source of } \\
\text { ideas and information } \\
\text { Monitoring and } \\
\text { appraisal by } \\
\text { participants } \\
\text { Broadening of public } \\
\text { support for } \\
\text { environment - related } \\
\text { decisions } \\
\text { Reducing the level of } \\
\text { conflict }\end{array}$ & $\begin{array}{l}\text { Protection of } \\
\text { stakeholders' interests }\end{array}$ \\
\hline
\end{tabular}

Source: adapted from (Akol, 2001, p. 8)

Normative arguments for participation emphasise the democratisation process in environmental decision-making and the empowerment of affected communities. In contrast, instrumental arguments suggest that participation makes more data available to government organisations and may reduce conflict among participants and government organisations. Whether normative or instrumental, participatory environmental policy has been promoted globally (Coenen, 2008) and adopted widely within environmental frameworks of LDCs under the supervision of 
international developmental and donor organisations (Kapoor, 2004). Using environmental management tools, such as the EIA and strategic impact assessment, researchers and policy-makers have encouraged the participation of affected people when addressing environmental issues, and have recognised the need to take sustainability more seriously (Jay, et al., 2007; Wilkins, 2003).

Since the 1970s, the EIA - an environmental management decision-making tool has been developed and standardised in legislation. More than 100 countries now mandate that the EIA should be conducted before proceeding with development projects, such as mining, that may impact the natural environment (Glasson, et al., 2005). However, researchers have increasingly criticised EIAs for being little more than symbolic tools, having only minor consequences on practice (Jay, et al., 2007; Richardson, 2005; Wilkins, 2003). Critics argue that EIAs have become expert-oriented technocratic tools, distant from the social and environmental realities they are expected to address (Wood, 2008). Others claim that EIAs have failed to achieve the initial goal of being a preventive decision-making tool that can mitigate the negative environmental consequences of a given project (Jay, et al., 2007).

Although public participation in an EIA is mandated in most countries (EIA Centre, 1995; Mitchell, 2001), there is growing criticism that it is becoming a symbolic process that serves principally the interests of elite groups (Diduck, et al., 2007; Whiteman \& Mamen, 2002), rather than helping to facilitate inclusive and realistic decisions that consider local knowledge and opinions of affected communities (Diduck \& Sinclair, 2002; Petts \& Brooks, 2006; Rockloff \& Lockie, 2006). Moreover, EIAs are not regarded as tools that encourage social learning among stakeholders with differing ideologies and views (Diduck, et al., 2007; Söderbaum, 2004; Wilkins, 2003), or necessarily help to prevent conflict among mining constituents (Li, 2009; Richardson, 2005). Therefore, some researchers argue that for EIAs to address sustainability effectively they need to adopt a more "subjective" approach to knowledge (Richardson, 2005; Wilkins, 2003) if they are to encourage more meaningful participation (Cashmore, 2004; Diduck, et al., 2007; Sinclair, Diduck, \& Fitzpatrick, 2002; Söderbaum, 2004). 
Nevertheless, the potential of EIAs is still widely recognised among researchers and practitioners. They infer that EIAs can: facilitate preventive rather than corrective actions; gather considerable information about a project and the area in which it will operate; facilitate contracts that detail mitigation measures between authorities and project proponents; help prevent or resolve conflicts among different constituents; and can promote social learning and increased awareness, leading ultimately to changed social values on sustainable development (Biller, 2003; Cherp, 2001; Jay, et al., 2007; Mitchell, 2001; Nooteboom, 2007; Sinclair, et al., 2002).

In sum, there are many significant calls for sustainable and participatory mining, and more democratic and inclusive EIAs. As this study attempts to incorporate dialogic accounting principles into an EIA to these ends, it is important at this point to introduce dialogic accounting and its underlying concepts.

\subsection{The potential of dialogic accounting}

Dialogic accounting in SEA attempts to respond to calls for public-interest oriented accounting that could enable greater participation and help to address social and environmental concerns in business and society. Dialogic accounting, with its critical roots, recognises power inequalities, the limitations of instrumentalist approaches, and the value-laden nature of accounting (Bebbington, et al., 2007). Therefore, it challenges the mainstream monologic approach of accounting and seeks "to take pluralism seriously" as a way of promoting dialogue, participation, and participatory democracy (Brown, 2009; Söderbaum \& Brown, 2010). Before introducing dialogic accounting in detail, it is important first to discuss technocracy in accounting and environmental management, and the types of participatory democracies to which dialogic accounting relates.

\subsubsection{Challenges to technocracy}

Dominant neo-classical economic theories are frequently criticised for their technocratic rationalities and instrumentalism in creating information and making decisions (Brown, 2009; Gray, 2006; Söderbaum \& Brown, 2010). Their 
'objective' technocratic assumptions fail to meaningfully embrace global calls for sustainable development, due to their simplification and homogenisation of economic actors, and the exclusion of social and environmental factors from decisions, labelling them as externalities (Lehman, 2001; Molisa, et al, forthcoming).

Critics challenge the basic premises of neo-classical economics, such as the possibility of an economically-rational person, value-free experts, optimal solutions, and politically neutral decision-making (Brown, 2009; Gray, 2006; Söderbaum \& Brown, 2010). They argue that identifying/reducing individuals to being merely consumers who make rational decisions within constrained budgets is too simplistic and unrealistic (Söderbaum, 2006). People are both economic and political individuals, influenced by their social, political, cultural and economic contexts (Söderbaum, 2004). It is also difficult to separate the roles of individuals because they are not only consumers but also employees, stakeholders, academics, citizens, voters, or members of various political and civil society organisations (Söderbaum, 1994). Individuals, therefore, are not constrained by simple economic, rational choices. Similarly, decision-makers and politicians are not value-neutral and apolitical, and they do not make decisions based solely on instrumental rationality, as neo-classical economists typically assume (O'Neill, 1998).

As well as criticisms of the fundamental values and assumptions of neo-classical economics, its analytic methods, including cost benefit analysis, are also challenged (Söderbaum, 2006). Cost benefit analysis, which has deeply penetrated economics, accounting, and environmental management decision-making is accused of being an instrumental and technocratic approach that relies on "narrow forms of expertise" (Söderbaum \& Brown, 2010, p. 190). The dominant economic view portrays experts who conduct research and analyses as value-neutral individuals, free from any ideology, values and politics. However, others argue that experts are individuals with beliefs and are usually members of professional bodies, which would influence their ideologies and perspectives (Brown, 2009; Söderbaum, 2004). 
The dominant positivist philosophy of science, favoured by neo-classical practitioners, is privileged with a "hard scientific approach" or economic rationalism and its derivative disciplines (Söderbaum, 2004, 2006; Wilkins, 2003). One-dimensional monetary, quantitative analysis recognises only economically countable or priceable impacts, and claims to identify one optimal solution for an issue or decision; but non-monetary impacts, such as social and environmental issues are excluded (Molisa, et al., forthcoming).

Following sustainable development and related initiatives, solely economic, rationality-based assumptions and views are challenged for their inability to address contested areas, such as environmental management and mining (Cashmore, et al., 2010; CSP $^{2}$ and WRI, 2005; Wilkins, 2003). Some argue that existing neo-classical economics and positivist paradigms in many disciplines are incapable of addressing sustainability, as their basic assumptions leave little room for the democratic participation of different stakeholders (Söderbaum, 2006, 2007; Wilkins, 2003).

In environmental economics, a democratic approach is suggested as a potential alternative to the technocratic, mainstream economics paradigm. Peter Söderbaum, a long-standing academic advocate of pluralism and democracy, argues that a democratic approach to decision-making creates space for participation by various actors and stakeholders on issues in which they have differing views (Söderbaum, 2006; Söderbaum \& Brown, 2010). Although the importance of experts is recognised, they are seen as value-laden and having their own particular ideological orientations (Brown, 2009).

The objective of a pluralist approach is to discuss the complexities of issues with an open recognition of the ideological differences among actors, "rather than providing a solution assumed optimal for all actors" (McLean \& McMillan, 2003, p. 191). This approach is echoed in environmental management literature, which calls for EIAs to acknowledge the subjectivity of experts (Cashmore, 2004; Petts \& Brooks, 2006) and to allow greater participation by affected people when addressing sustainability (Jay, et al., 2007; Wilkins, 2003). 
Similarly, others challenge the technocratic nature of conventional accounting and call for democracy and pluralism in accounting to address sustainability, environmental, and social issues. Technocratic and monologic accounting is criticised for its inability to fully illustrate and reflect the complexities of social and environmental realities (Power, 1992). A growing number of researchers advocate the incorporation of pluralism and democratic norms into accounting and for a shift from monologic to dialogic accounting (Bebbington, et al., 2007; Brown, 2009; Dillard \& Roslender, 2011). As the basic assumptions of dialogic accounting are based on participatory democracy and pluralism, different types of participatory democracies are considered below.

\subsubsection{Participatory democracies as a means to participatory environmental decision-making}

There are three types of participatory democracies: aggregative, deliberative and agonistic. Deliberative and agonistic democracies are increasingly recognised as more participatory than the former type (Brown, 2009; Kapoor, 2008). Although aggregative democracy is favoured in current politics and neo-classical economics, it falls short on the promotion of broader participation (Dillard \& Roslender, 2011). In an aggregative democracy, citizens elect politicians who are recognised as legitimate representatives and are expected to make decisions on behalf of citizens (Brown, 2009). However, this does not provide an arena for the broader participation of stakeholders and affected communities in decisions (Kapoor, 2008).

Proponents of both deliberative and agonistic democracies are critical of existing liberal democratic institutions as they not only "fail to adequately deliver on such liberal goals as participation and freedom, but sometimes they can even foreclose avenues for public contestation and redress" (Kapoor, 2008, p. 105). Deliberative and agonistic democracies both call for deeper or more extensive democracy that can incorporate the participation of marginalised or affected communities (Brown, 2009). However, each is based on different theoretical perspectives and makes differing arguments for participation. 
Deliberative democracy, influenced by the works of John Rawls and Jürgen Habermas, attempts to deliberately create situations that enable participation. It employs a normative communicative rationality model, based on the assumption that it is "possible to reach a consensus that would be deeper than a mere agreement on procedures, a consensus that could qualify as moral" (Mouffe, 2000). Moreover, deliberative democrats try to position authority and legitimacy in public reasoning (Brooke, 1998). Politics is regarded as being associated "with the exchange of arguments among reasonable persons guided by the principle of impartiality" (Mouffe, 2000, p. 4), according to the "original position" of Rawls and "the ideal speech situation" of Habermas (Brown, 2009, p. 320).

However, deliberative democracy is criticised for its own form of technical rationality in seeking to achieve "a fully inclusive rational consensus" (Mouffe, 2000 , p. i). It is argued that such democracy is difficult if not impossible to achieve in practice, due to complex realities and participants who are influenced by different social, political, and economic contexts, differing ideologies, and unequal abilities to express their voices (Kapoor, 2008). Mouffe (2002) describes deliberative democracy as "the dream of a perfect harmony or transparency" (cited in Brown, 2009, p. 320).

In contrast, an agonistic approach denies instrumental and what is regarded as overly consensual normative rationalities and, instead, favours pluralism. Agonistic democracy rejects the possibility of an optimal or fully inclusive consensus advocated by deliberative democracy. It argues that there is no sole right answer, but only provisional solutions (partially or mostly) that are agreed to by most actors through extensive debate and dialogue (Mouffe, 2000). The central points of the agonistic approach are the recognition and acceptance of a plurality of ideologies and values of different actors, the acknowledgement of the complexity of situations, the acceptance that hegemonic political struggles are central to democratisation, the recognition of alternatives as legitimate rather than hostile, and the need for negotiation and compromise in reaching a "conflictual consensus" or a "temporary respite in an ongoing confrontation" (Mouffe, 2000, p. 16). Some researchers suggest that agonistic democracy has great potential to 
promote pluralism and democratisation in economics, accounting, and other areas (Dillard \& Roslender, 2011; Kapoor, 2008; Söderbaum \& Brown, 2010).

Moreover, agonistic democracy encourages more extensive democracy that is operationalised by civil society organisations. Mouffe, an agonistic theorist, considers it "being concretised in the rise of new social movements and their politicization of sociocultural spaces heretofore ignored or excluded by mainstream democratic regimes" (Kapoor, 2008, p. 102). In this respect, civil society organisations have the potential to address democratisation and participation as they are often established by people who are ignored by or are unhappy with the existing dominant systems and institutions (Teegan, et al., 2004).

In sum, Mouffe recognises the importance of democratic demands/movements that "grow out of a particular sociohistorical context", while Habermas tries "artificially engineering participation" from the outside (Kapoor, 2008, p. 104). Both types of democracy have their advantages and critics. Deliberative democracy has the potential to establish democratisation processes in a shorter period, but may fail to recognise adequately the complexities, political struggles, and characteristics of different participants (Kapoor, 2008). In contrast, agonistic democracy provides greater learning opportunities for participants with differing ideologies, values, and backgrounds. It also acknowledges the plurality and politicisation of issues and respects those with alternative views as legitimate actors (Mouffe, 1999). Therefore, it enables broader social learning and promotes social change agendas (Brown, 2009). However, agonistic democracy requires more resources and time to have meaningful dialogue, as well as the passion and commitment of participants to understand pluralism (Kapoor, 2008).

For both types of democracies, power inequalities and political influence/manipulation are great threats. Although participatory democracies, particularly deliberative democracy, are romanticised in various disciplines and areas relating to development, practice shows that power asymmetries among participants and political influences on individuals and groups affect enormously the application of participatory proposals and their outcomes (Kapoor, 2002). 
Therefore, any attempts to import or establish democracies in a certain context would need to be wary of power inequalities and political manipulation (Kapoor, 2008). This is particularly relevant to LDCs, which usually have different sociopolitical contexts from 'Western democratic' practices.

As both theories have been developed and applied mostly in developed country contexts, they often fail to address LDCs. Kapoor (2008) argues that both theories have paid insufficient attention to "materiality, [and show] inadequate appreciation of the discursive barriers between elite and subaltern, and the lack of importance given to the state" (p. 113). Differences between LDCs and Western developed countries lie in their economic, social, political and cultural aspects. For instance, Reed (2002) identifies the following as key factors that make it difficult for citizens of LDCs to participate in decision-making:

(a) less secure guarantees of civil and political rights,

(b) less practical opportunity to exercise such rights (due to illiteracy, poverty, etc.),

(c) less than fully democratic institutions (for example, endemic corruption in administration; slow, ineffective legal systems; electoral systems dominated by a single party; influence over the electoral system by the military; business; etc.), and

(d) weaker or less dense civil society organisations (Reed, 2002, p. 194).

Therefore, any application of participatory democracy in LDCs would need to consider such features and complexities. It may need modification, depending on a LDC's culture, socio-political characteristics and power dynamics (Kapoor, 2008; Molisa, et al., forthcoming). This study takes up this challenge by examining the importance and potential of participatory democracy in LDCs, and whether it is currently being applied or could be applied to environmental management practices in Mongolia.

\subsubsection{The potential of dialogic accounting}

As noted, dialogic accounting endeavours to take pluralism seriously by challenging monologic accounting practices and by promoting democracy, 
participation, and dialogue. It criticises conventional accounting for being instrumental and monologic and too heavily based on dominant neo-classical economics (Bebbington, et al., 2007). Although mainstream accountants claim to be objective by providing apolitical and value-free accounts (that is, "taking a view from nowhere" - (Brown, 2009, p. 316), they have arguably been co-opted by business and power holders and become trusted 'gate-keeper[s]' of capitalist domination (Tinker, et al., 1991). Monologic accounting treats certain issues as "off-limits" and excludes social and environmental issues from decision-making by labelling them as externalities (Brown, 2009). Therefore, it is criticised for its inability to act in the public interest, to address sustainability issues seriously, to promote democracy and participation, and to make decisions more inclusive and socially efficient that can reflect social and environmental realities (Gray, 1992, 2006).

In contrast, dialogic accounting in SEA supports a call for pluralistic and democratic accounting that can serve public interests. In this respect, accounting may be seen as a "dialogic machine" (Lehman, 1999) with the potential to facilitate democratisation at organisational and societal levels, as well as to improve accountability (Dillard \& Roslender, 2011). Dialogic accounting aims to provide flexibility and space for stakeholders with differing views to discuss and debate issues and to (de)(re)construct their ideologies, values, and views (Brown, 2009). This would promote greater awareness of social and environmental factors and could improve the accountability of participants.

Based on a social constructionist epistemology, dialogic accounting can incorporate agonistic democracy as a potential participatory democratic approach. Along with the recognition of things 'out there', social constructionists argue that calculations labelled as costs and benefits are an outcome of our constructed values and views on what and how to include in accounting (Brown, 2009, p. 325). Accounting is value-laden, rather than value-free (Tinker, et al., 1991). Therefore, dialogic accounting argues that different ideological orientations can be exercised in accounting that would create the potential to (re)construct values of individuals and groups in more inclusive and realistic decision-making (Molisa, et al., 
forthcoming). With its agonistic roots, dialogic accounting supports pluralism and recognises the plurality of issues, the conflicting or differing perspectives of individuals and groups, and the complexity of power dynamics (Söderbaum \& Brown, 2010). It suggests dialogue as a potential way to explore and recognise plurality and to promote participatory democracy for addressing sustainability issues (Dillard \& Roslender, 2011).

However, "the power dimension of social relations" is explicitly acknowledged (Brown, 2009, p. 319) and discussed with strong cautions about applying the dialogic approach in practice. Dialogic accounting recognises that power inequalities among stakeholders affect or restrict some from participating and influencing decision-making (Brown, 2009; Kapoor, 2008). It argues that the monologic accounting claim of finding a 'right' answer ignores power issues that inherently exist among participants, and compresses differing views of participants into one 'optimal' solution by excluding alternative views (Dillard \& Roslender, 2011). Critical dialogic accounting, by contrast, aims for wide-ranging debate and dialogue that can "facilitate genuine and informed citizen participation in decision-making processes" (Boyce, 2000, p. 55). Through dialogue, participants could, potentially, better understand different perspectives, learn from each other, and problematise the existing 'taken for granted' knowledge of monologic accounting. Importantly, with due care for the voicing of alternative perspectives, dialogue also provides "platforms for normally unheard voices to be heard" (Bebbington, et al., 2007, p. 366) and helps to "make power relations more transparent" (Brown, 2009, p. 318) by presenting the dominant voices in decisionmaking. Thus, dialogic accounting is able to challenge the technocracy and monologism of existing accounting and can recognise power issues in practice. It has the potential to recognise diverse perspectives and to foster participation when addressing sustainability and participatory decision-making. It can also incorporate the social and environmental impacts of business into accounting considerations. Multistakeholder engagement in dialogue could play a crucial role in recognising the plurality of different stakeholder perspectives and help to re(de)conceptualise social, economic, and environmental realities. 


\subsubsection{The EIA as a tool}

The EIA can be regarded as both a tool and process for operationalising the dialogic accounting framework. Some argue that the EIA is not only a well-known managerial tool providing environmental information, but also a process that can incorporate environmental considerations into decision-making and practice (Glasson, et al., 2005; Jay, et al., 2007). In spite of criticisms that the EIA is a technocratic tool used to support decision-making about mining projects, many have long recognised its potential to be a participatory, preventive tool that would promote sustainability (Cashmore, et al., 2010; Jay, et al., 2007; Nooteboom, 2007). In this respect, public participation could help transform the EIA from being monologic to being dialogic.

As public participation is mandated in most EIA legislation, the EIA contains legal space for stakeholder dialogue. The contested political nature of mining and environmental issues requires multistakeholder dialogue, if the plurality of participants is to be acknowledged. This would entail conflicting values and views being openly discussed to define the social and environmental impacts of mining and to negotiate mitigation methods. Public participation in the EIA would enable communities to make not only better informed and credible decisions but also to promote a social learning process among participants with contested views and differing knowledge (Diduck \& Mitchell, 2003; Sinclair \& Diduck, 2001).

In the absence of other forms of participation, the EIA would become 'a crucial instrument of local democracy' (Cherp, 2001, p. 352). By granting space for the public to participate, the EIA could also encourage democratisation of environmental decision-making (Petts, 2003; Petts \& Brooks, 2006; Rockloff \& Lockie, 2006; Sinclair, et al., 2002; Söderbaum, 2004), as it has the potential to make visible the subjective and political nature of environmental decisions and to consider plural perspectives and alternative solutions that participants develop and recommend (Cashmore, et al., 2010; Wilkins, 2003). Therefore, the EIA should be considered as a tool which can provide a 'space' for dialogue among stakeholders that have differing views on mining and its social and environmental impacts. 


\subsection{Conceptual framework}

\subsubsection{Positioning the study}

Figure 3 summarises the issues raised by calls for participatory environmental decision-making, economically sustainable mining, and democratisation in accounting that could foster sustainable development.

Figure 3. The EIA as a tool and process for participatory mining, environmental management and accounting

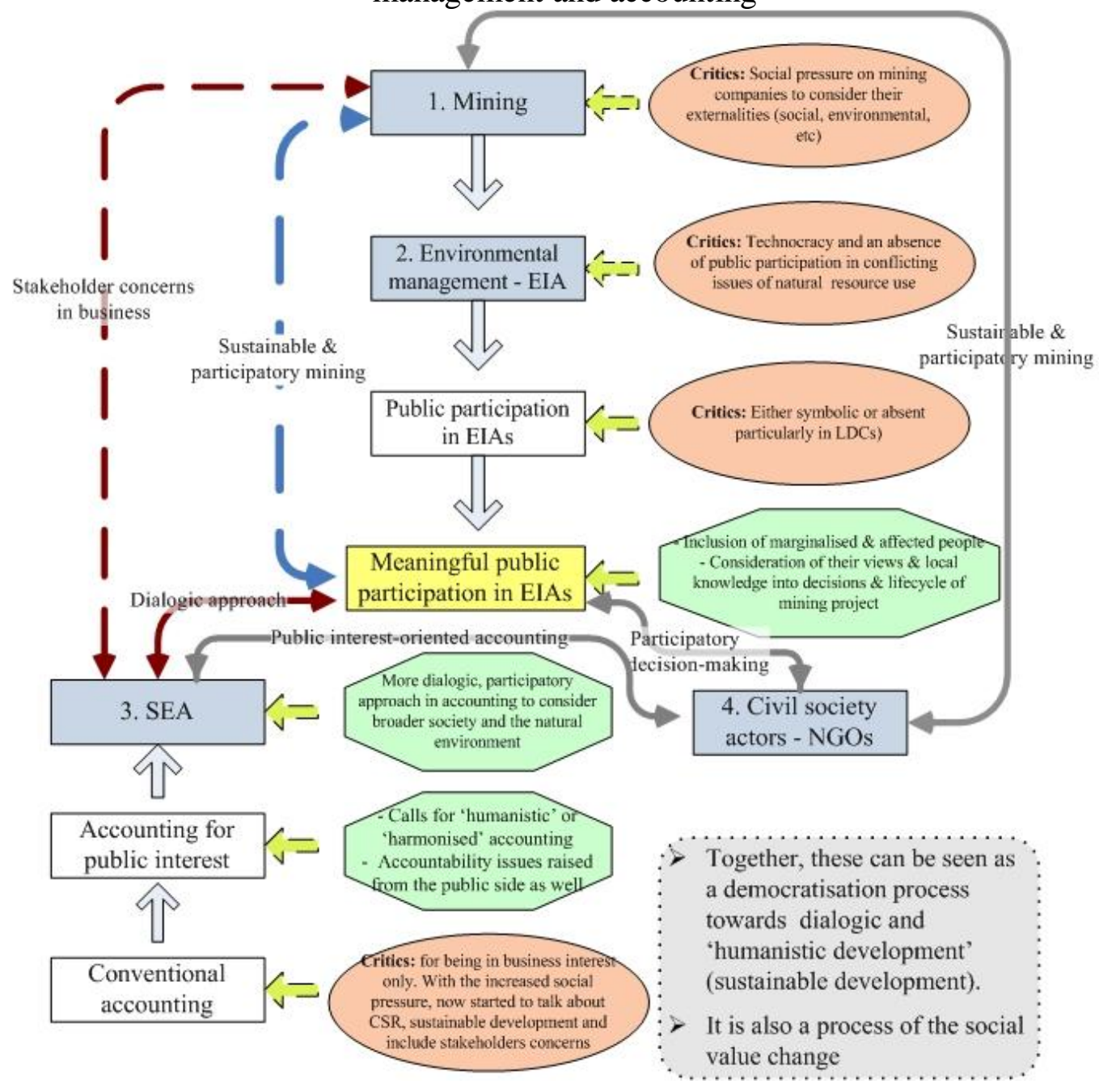

Figure 3 describes criticisms raised in each area of literature (bright brown oval shapes), arguments (bright green diamond shapes), and calls (or challenges), which are alongside arrows, depending on which disciplines and areas they refer. 
Four different areas are illustrated in light-blue rectangles in the following $\operatorname{order}^{56}$ : mining, environmental management, SEA, and NGOs.

Firstly, the mining sector has been criticised for its negative impacts on the natural environment and societies, particularly in LDCs. There is mounting social pressure on mining companies to be concerned about their impact. Secondly, the roles of environmental management tools, particularly the EIA, have become more crucial. Figure 3 illustrates that the EIA, order 2, is criticised for having become a technocratic tool with an absence of inputs from affected people. Researchers therefore argue that public participation in an EIA is important in order to address negative mining impacts and concern about sustainability. This is illustrated by the arrow that indicates a call for meaningful public participation in EIAs. Thirdly, SEA literature also challenges conventional accounting with criticisms that accounting favours business interests and fails to consider multistakeholder engagement. With this omission, current accounting practice falls short of addressing the challenges of sustainability and CSR. Social and environmental accounting calls for more dialogic approaches and public-interest oriented accounting. These concurrent arguments of SEA, as well as those of mining and environmental management, demonstrate the calls for sustainable and participatory mining (or business), and are shown in Figure 3 by red and green arrows. Fourthly, civil society actors, particularly $\mathrm{NGOs}^{57}$, are recognised as potential actors in promoting participatory decision-making that would enable democratisation in environmental management and sustainable and participatory mining. The engagement of NGOs in these issues is denoted in the figure by grey arrows. All these challenges and dynamics of development can be considered as a gradual, social-value change process, especially in a LDC context such as Mongolia (Molisa, et al., forthcoming).

This study argues that the EIA can provide a space for dialogue and participation in the promotion of sustainable and participatory mining. By challenging the

\footnotetext{
${ }^{56}$ Note that the order is not significant, and serves only to organise discussion

${ }^{57}$ Despite potential roles of other constituents, the potentials of NGOs in addressing democracy, environmental protection, participatory decision-making and economically sustainable mining are discussed in Chapter 4.
} 
symbolic participation practices of the EIA, this study regards the EIA as an arena where various mining constituents can come together to discuss the potential negative and positive impacts of a project. Stakeholders may have conflicting values and views on social, environmental, economic, and cultural impacts of mining, and they may propose different evaluation methods and alternatives to mitigate the impacts.

Through dialogue, stakeholders can identify their similarities and differences and develop a shared understanding of "sustainable development". Or, equally, where deep differences exist among people, some may decide not to cooperate in the formal dialogic process but prefer to problematise and critique from "outside" (for example, as "challenger" NGOs). Whatever decisions are made, dialogic participation can enable all stakeholders to be informed about an EIA, to learn to talk with each other, and to recognise and engage with different perspectives on environmental decisions. Importantly, a dialogic approach may encourage use of the EIA as a more inclusive and participatory decision-making tool and process. The following section introduces the analytic framework which this study employs for its empirical analysis.

\subsubsection{Analytic framework}

This study argues for a dialogic EIA which can promote sustainable and participatory mining practices. It takes critical dialogic accounting as its analytic framework and focuses on the EIA for illustrative purposes. The critical dialogic accounting framework developed by Brown (2009) - previously used to assess sustainability assessment models $(\mathrm{SAMs})^{58}$ - will be employed in this respect.

The EIA is complex and contestable as it incorporates social, environmental, economic and cultural concerns regarding developmental projects. The EIA is

\footnotetext{
${ }^{58}$ The SAM is an accounting tool designed to assist organisations to perform sustainability evaluations by communicating information on the broad impacts of organisational activities. It was designed by the BP (UK), in conjunction with the University of Aberdeen and Genesis Oil and Gas Consultations and has been applied in several case-studies in the United Kingdom and New Zealand (Bebbington, 2007). EIAs were considered more relevant for this study as they are currently used in Mongolia and are less reliant on monetisation and neo-classical economic valuation methodologies and, thus, arguably less vulnerable to charges of "monetary reductionism" (see Brown, 2009, p. 332).
} 
normally conducted before a mining project commences. It is a multi-dimensional tool that recognises there may be various stakeholders with conflicting views on the potential impacts of mining. This study argues that the EIA can be a dialogic accounting tool. With guaranteed legislative rights to information and participation, the EIA can provide a formal space for dialogue where stakeholders with differing views can come together and debate the potential positive and negative impacts of a mining project. Through dialogue, participants can (de)(re)construct their values and views on the identification, categorisation, and evaluation of impacts, and their mitigation methods and processes (Cashmore, et al., 2010).

A more dialogic EIA could promote democracy through participation of local communities, civil society groups and other interested parties. In doing so, the EIA would encourage non-expert accessibility to environmental management decision-making processes, and generate additional quantitative and qualitative data and criteria about the social, environmental, economic and cultural impacts of a mining project.

Unlike previous studies which use dialogic accounting in the contexts of developed countries (see Bebbington, 2007 for an overview), this study employs the framework in a LDC context. Specifically, it applies the key principles of critical dialogic accounting to analyse the dialogic potential of EIAs in Mongolia, as a newly democratic LDC. Findings and the proposed application of the dialogic framework in LDCs may differ from developed countries, given their different socio-political-cultural contexts (Belal, 2007; Molisa, et al., forthcoming). Thus, this study may advance debate on critical dialogic accounting within LDC contexts and thereby contribute to the development of the critical dialogic accounting framework.

The following section discusses the analytical framework for this study. It derives from Brown's (2009) conceptual framework for critical dialogic accounting, which is compatible with pluralism and agonistic democracy. There are eight key principles: 
1. Recognise multiple ideological orientations

2. Avoid monetary reductionism

3. Be open about the subjective and contestable nature of calculations

4. Enable accessibility for non-experts

5. Ensure effective participatory processes

6. Be attentive to power relations

7. Recognise the transformative potential of dialogic accounting

8. Resist new forms of monologism.

This study uses these principles to examine EIA practices in Mongolia. The empirical data will be analysed according to the extent to which existing EIA methods and associated participation practices are monologic or dialogic. The framework of Table 2, which illustrates differences between monologic and dialogic EIA approaches, will be used. However, it is important to recognise that the definition of each type of EIA and its categories are "ideal types", which are constructed as a heuristic for analytic purposes, rather than as a checklist for providing mutually exclusive and definitive "yes" or "no" answers. Bessire and Onnée (2010) adopt a similar approach and note that "to achieve this aim, we have elaborated ideal types of strategy and ideal types of ideology. It must be kept in mind that these ideal types are used as analytical tools: reality is obviously more complex and strategies of legitimation oscillate along a continuum" (Bessire \& Onnée, 2010, p. 446). 
Table 2. Monologic and dialogic approaches to EIAs as a tool, and associated processes

\begin{tabular}{|c|c|c|}
\hline $\begin{array}{l}\text { Key critical dialogic } \\
\text { principles }\end{array}$ & Monologic EIAs & Dialogic EIAs \\
\hline $\begin{array}{l}\text { Recognise multiple ideological } \\
\text { orientations }\end{array}$ & $\begin{array}{l}\text { A "pure" EIA science is possible. } \\
\text { Little or no acknowledgement, of } \\
\text { stakeholders with different socio- } \\
\text { political perspectives. } \\
\text { The relevance of ideological } \\
\text { orientation is either denied or a } \\
\text { particular perspective (e.g. neo- } \\
\text { liberalism) is regarded as axiomatic. } \\
\text { Consensus about values (e.g. } \\
\text { economic growth) assumed. EIA } \\
\text { seen as a neutral, value-free } \\
\text { technical tool. }\end{array}$ & $\begin{array}{l}\text { EIA can never be a purely neutral, } \\
\text { value-free technical tool. The scope of } \\
\text { an EIA analysis, and measurement } \\
\text { techniques, depend on underlying } \\
\text { values and socio-political perspectives } \\
\text { (e.g. how the "environment" is } \\
\text { defined, the value placed on economic } \\
\text { development, the appropriateness of } \\
\text { expressing issues in monetary terms). } \\
\text { Dialogic EIAs require recognition of, } \\
\text { and engagement with, a diverse range } \\
\text { of stakeholders and socio-political } \\
\text { perspectives. }\end{array}$ \\
\hline Avoid monetary reductionism & $\begin{array}{l}\text { Dominated by scientific "hard" data } \\
\text { - scientific calculations, geographic } \\
\text { maps and monetary data. }\end{array}$ & $\begin{array}{l}\text { Includes both monetary and non- } \\
\text { monetary data - scientific and } \\
\text { monetary calculations and other } \\
\text { "hard" data along with visual data } \\
\text { (photographs, videos, etc.) and other } \\
\text { non-monetary information and } \\
\text { explanations for a diverse range of } \\
\text { stakeholders. }\end{array}$ \\
\hline $\begin{array}{l}\text { Be open about the subjective and } \\
\text { contestable nature of calculations }\end{array}$ & $\begin{array}{l}\text { Singular and dominating within a } \\
\text { given knowledge-power structure - } \\
\text { typically positivism with resulting } \\
\text { knowledge viewed as "objective } \\
\text { and value-free". } \\
\text { Ideologically closed models (e.g. } \\
\text { cost-benefit analysis) - typically } \\
\text { approached in scientific and } \\
\text { mathematical terms - fixed } \\
\text { valuation rules. } \\
\text { One (optimal) alternative } \\
\text { recommended. }\end{array}$ & $\begin{array}{l}\text { Recognises the contestability of } \\
\text { knowledge and calculations - what is } \\
\text { included in EIAs, how items are } \\
\text { included and the decision rules as to } \\
\text { what constitute impacts and mitigation } \\
\text { methods. Greater transparency around } \\
\text { value judgements, assumptions and } \\
\text { calculation methods. } \\
\text { Ideologically open - recognises the } \\
\text { value of scientific information but only } \\
\text { one input and involves its own value } \\
\text { judgements and uncertainties. No } \\
\text { single "best solution" - responsive to } \\
\text { perspectives/evaluative criteria of all } \\
\text { stakeholders. Recognises the validity } \\
\text { of, and need to include, "local } \\
\text { knowledge". } \\
\text { Conclusions conditional in relation to } \\
\text { the ideological orientations considered } \\
\text { and inputs into wider democratic } \\
\text { processes. }\end{array}$ \\
\hline
\end{tabular}




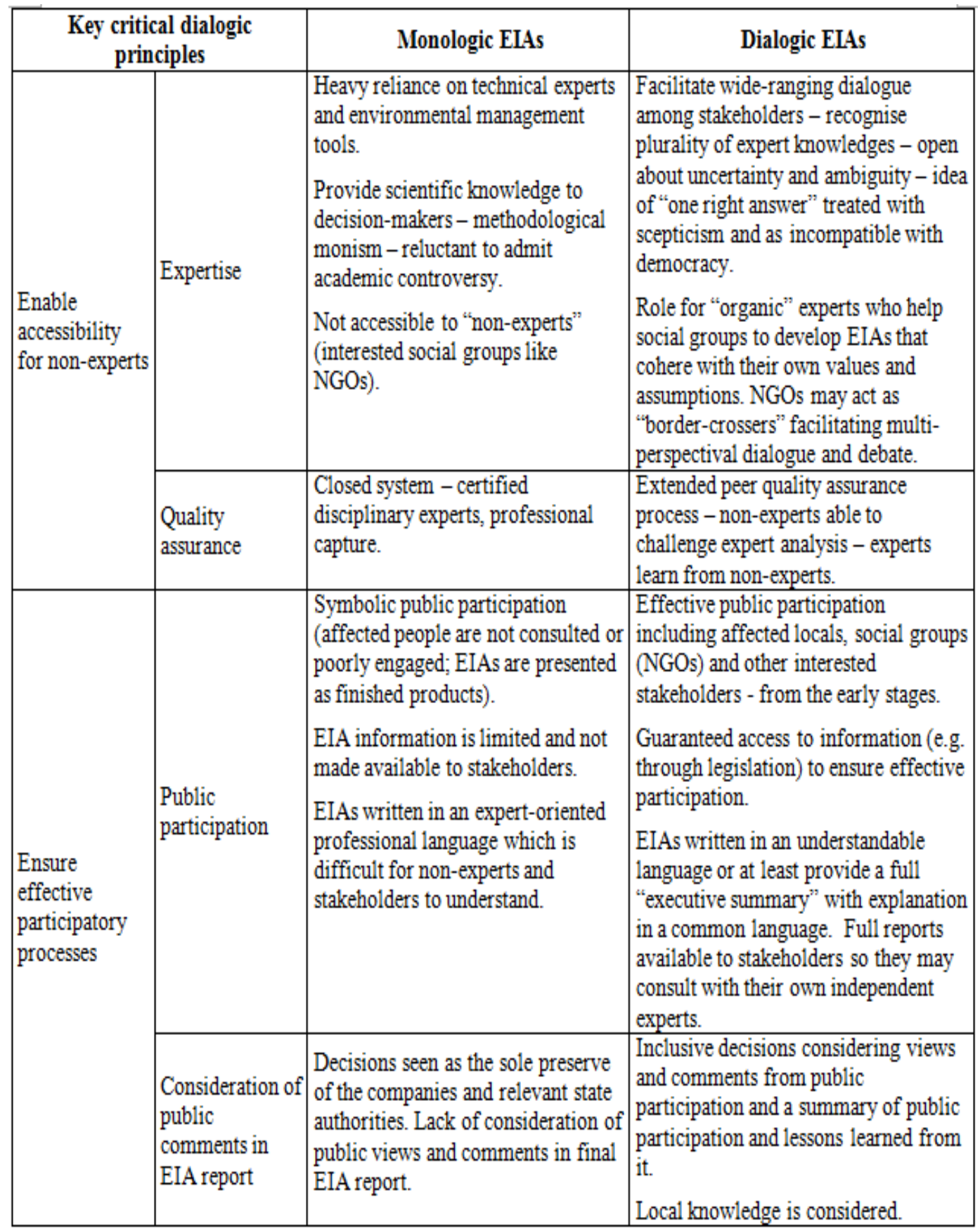




\begin{tabular}{|c|c|c|}
\hline $\begin{array}{c}\text { Key critical dialogic } \\
\text { principles }\end{array}$ & Monologic EIAs & Dialogic EIAs \\
\hline Be attentive to power relations & $\begin{array}{l}\text { No consideration of the complexity } \\
\text { of knowledge-power relations (e.g. } \\
\text { in terms of who gets recognised as a } \\
\text { legitimate 'expert'). } \\
\text { No consideration of capacity } \\
\text { building for stakeholders (or at the } \\
\text { individual EIA company or } \\
\text { government authority levels). } \\
\text { No recognition of the potential for } \\
\text { undue political and business } \\
\text { influence on EIA report preparation } \\
\text { and decision-making. }\end{array}$ & $\begin{array}{l}\text { Recognises the complex nature of the } \\
\text { relationship between knowledge, } \\
\text { expertise and power. Interested in the } \\
\text { ways in which social, political, and } \\
\text { institutional contexts (e.g. legal } \\
\text { requirements, social norms, knowledge } \\
\text { of alternatives) mediate values, beliefs, } \\
\text { interests and preferences. } \\
\text { Use EIA to challenge power elites } \\
\text { (e.g. to expose the frames dominating } \\
\text { specific decision outcomes and their } \\
\text { distributional impacts). } \\
\text { Recognise a need for capacity building } \\
\text { for effective stakeholder participation. } \\
\text { Both stakeholders and those in power } \\
\text { learn from each other. } \\
\text { Marginalised groups retain the right } \\
\text { "not to participate" in EIA unless/until } \\
\text { they are able to participate in their own } \\
\text { ways and with their own voices. } \\
\text { Minimise the potential for undue } \\
\text { political and business influences } \\
\text { and/or manipulation by politicians, } \\
\text { senior public officials, mining } \\
\text { companies and others through } \\
\text { transparent and effective public } \\
\text { participation. }\end{array}$ \\
\hline $\begin{array}{l}\text { Recognise the transformative } \\
\text { potential of dialogic accounting }\end{array}$ & $\begin{array}{l}\text { A closed technical and expert-laden } \\
\text { tool. Used by dominant groups to } \\
\text { transmit knowledge in a one-way } \\
\text { fashion (e.g. to legitimate activity, } \\
\text { manage stakeholders, silence } \\
\text { dissent or alternative voices). }\end{array}$ & $\begin{array}{l}\text { Use EIA as a tool for dialogic learning } \\
\text { - discussion and debate which can } \\
\text { lead to critical reflection, } \\
\text { problematisation and transformative } \\
\text { change (e.g. providing knowledge of } \\
\text { feasible and desirable alternatives). }\end{array}$ \\
\hline $\begin{array}{l}\text { Resist new forms of } \\
\text { monologism }\end{array}$ & $\begin{array}{l}\text { Technical-instrumental - } \\
\text { emphasises successful prediction } \\
\text { and agreement over ends. } \\
\text { Monitoring - done by a state } \\
\text { organization. }\end{array}$ & $\begin{array}{l}\text { Resist temptation to use EIA to guide } \\
\text { actors to pre-defined "right answers". } \\
\text { Use competing EIAs as a basis for } \\
\text { ongoing monitoring (e.g. comparison } \\
\text { of actual and expected outcomes) as } \\
\text { way of keeping discussions alive. } \\
\text { Ensure ongoing contestability of EIA } \\
\text { methodologies. }\end{array}$ \\
\hline
\end{tabular}

Adapted and modified from (Brown, 2009, pp. 329-333) and (Söderbaum \& Brown, 2010, pp. 184-191)

Each principle in Table 2 is explained below:

1. Recognise multiple ideological orientations

Dialogic accounting's recognition of different perspectives, values and assumptions, encourages a broader stakeholder arena where participants, including previously marginalised communities, can express their views and claims. It is particularly relevant to mining, where social, environmental, 
economic and cultural factors are often incorporated into "closed" decisionmaking that excludes the concerns of affected local communities $\left(\mathrm{CSP}^{2}\right.$ and WRI, 2005).

A pluralistic approach challenges technocratic EIA practice, which has traditionally ignored socio-political differences among stakeholders and has perceived participants as homogeneous (Wilkins, 2003). In a dialogic EIA, participants are recognised as having differing perspectives and values; but critical dialogics does not "embrace total pluralism" and difference is valued "only insofar as it does not support domination and inequality" (Brown, 2009, p. 324).

\section{Avoid monetary reductionism}

The dialogic approach opposes monetary reductionism; rather it encourages the production of quantitative and qualitative data to help individuals and groups discuss and judge the potentials and trade-offs of monetisation. An attraction of the EIA is that it is less epistemologically restrictive than positivistic techniques, such as traditional cost benefit analysis, which relies heavily on monetisation and neo-classical economic valuation methodologies. A monologic EIA, based solely on scientific "hard" data, mathematical calculation, and geographical mapping (Cashmore, 2004), would be challenged by a dialogic approach to EIA.

In contrast, dialogic EIAs would usually use scientific 'hard' data and monetary calculations as well as non-monetary data and visual information to help stakeholders understand an EIA, or to provide photographic or similar evidence to support their arguments (Brown, 2010). This combination is important for an EIA, where many environmental, social and cultural impacts are denied consideration, or cannot be realistically assessed in monetary forms due to the underdevelopment of existing EIA evaluation methods.

3. Be open about the subjective and contestable nature of calculations The monologic EIA is based on positivism and the notion that knowledge and calculation is/should be "objective and value-free" to predict the impact of a given project (Jay, et al., 2007). Ideologically closed models, such as a cost benefit 
analysis and scientific calculations with fixed valuation rules, are widely used in monologic approaches (Wilkins, 2003).

However, subjectivity should be seen as a positive aspect of the EIA, endeavouring to promote "more environmentally sustainable assessment decisions" (Wilkins, 2003, p. 402). Consistent with a social constructionist epistemology, the dialogic approach recognises the subjectivity and the uncertainty surrounding contested issues (Brown, 2009, p. 325), such as natural-resource use and mining. Therefore, the dialogic EIA acknowledges the subjectivity and contestation of definitions of impacts and calculations, that is, those identified and included, how impacts are measured, how mitigation alternatives are developed and assessed, and which decision rules apply in judgements on a selection of mitigation methods.

\section{Enable accessibility for non-experts}

The expert-laden monologic EIA is further challenged by the dialogic EIA, as it neglects the contested nature of EIAs, and calls for participatory decision-making to promote sustainability (Jay, et al., 2007; Nooteboom, 2007). The dialogic EIA asks experts not only to be aware of their underpinning values and perspectives, but also to be self-reflective and recognise subjectivity and plurality (Wilkins, 2003); it rejects any attempt to find "one right answer", with its pluralistic roots, as this is incompatible with democracy (Mouffe, 2000). In contrast, the dialogic approach encourages dialogue and involvement of non-experts. A combination of monetary and non-monetary data gives both experts and non-experts access to dialogue. NGOs can act as "border-crossers" to facilitate this multi-perspective dialogue (Brown, 2009, p. 333) given their capability to raise and address issues that surround EIAs ( $\mathrm{Li}, 2009$ ); for example, they are more likely than lay people to have access to independent experts.

Another area of non-expert involvement in the EIA is quality assurance. Whereas the quality assurance of monologic EIAs is executed by experts from relevant state organisations, the dialogic approach recognises the importance of nonexperts in this process (Bebbington, et al., 2007). The latter may challenge experts 
by developing their own quality assurance tests, as evidenced in some postcommunist developing countries (Kravchenko, 2002). Both experts and nonexperts can learn from each other from such engagement (Petts, 2007). More importantly, the extensive peer quality assurance process would improve the quality of EIAs (Petts \& Brooks, 2006).

\section{Ensure effective participatory processes}

Although public participation may be mandated by legislation, it can become symbolic in monologic EIA practices, for example, by being treated as one component of an EIA check-list (Biller, 2003). Symbolic participation often excludes the engagement of affected communities and other stakeholders with significant concerns about proposed projects (Mitchell, 2001; Rockloff \& Lockie, 2006). A lack of access to information and the "professionalised language" of a monologic EIA can contribute to symbolic participation (Petts, 2004). Moreover in monologic forms of EIA, public comments are rarely considered in final reports, and decisions are made solely by bureaucrats (Jay, et al., 2007; Li, 2009).

In contrast, the dialogic EIA encourages more effective participation that helps people to (re)construct their values and views and to identify issues in their own way (Anderson, 1988, p.65 cited in Brown, 2009, p.326). Effective participation should have "legislative rights to information and participation", procedural rules for ensuring "a more even playing field", and early engagement of stakeholders in the process (Söderbaum \& Brown, 2010). The dialogic approach requires the EIA to be written in an understandable common language, with an executive summary that can provide basic information and knowledge to stakeholders. Participants have a right to oppose policies if they are perceived as conflicting with their interests.

An inclusive EIA represents an important attribute of effective participation. Therefore, a final EIA report should consider public views and comments regarding mining projects and should include local knowledge when necessary (Diduck, et al., 2007). To ensure further meaningful participation, the EIA report 
should have a summary, clarifying the main points drawn from participation, and publically disseminate them.

6. Be attentive to power relations

The monologic and technocratic EIA does not recognise the complexity of power relationships surrounding an EIA. In spite of its claim to be objective, powerful groups influence EIA preparations and decision-making - thus it is political by nature (Cashmore, et al., 2010). This is particularly relevant to LDCs, where close linkages between bureaucrats and businesses, and endemic corruption may exist (Belal \& Owen, 2007; Webler \& Tuler, 2006). Capacity building among EIA constituents is rarely considered in the monologic approach because the EIA is perceived primarily to be an instrumental decision-making tool (Doberstein, 2003).

The dialogic approach, in contrast, is attentive to the complexity of knowledge, expertise, and power (Dillard \& Roslender, 2011). It regards the EIA as a learning process, whereby the capacity building of all parties is encouraged. Moreover, by proposing or enabling a more participatory and inclusive EIA, it would challenge power elites.

Critical dialogic accounting recognises power inequalities that can influence decisions and restrict participation of some people and groups. The collective actions of NGOs are important because they have the capacity to challenge technical scientific discourse (Lehman, 1995), develop counter-reports (Spence, 2007), and to provide "resistance from outside established institutional channels" (Brown, 2009). Hence, critical dialogic accounting would encourage insider and outsider engagement (Brown, 2009) of NGOs, which would promote pluralism and open the EIAs to contestation.

7. Recognise the transformative potential of dialogic accounting The perception of an EIA as a purely technical and expert-laden tool is further challenged by the dialogic approach, which acknowledges the (re)constructive potential of discussion and debate. Dialogic accounting promotes horizontal dialogue to make social actors more aware of differences and similarities of their perspectives (Bebbington, et al., 2007). Hence, it supports “discussion, debate and 
dialectic learning in pluralistic environments" (Brown, 2009, p. 327). It views an EIA as "a system for producing knowledge, not only as a means to make informed planning decisions, but also as a source of directing the development of social values" (Wilkins, 2003, p. 402). Thus, the dialogic framework may have important transformative potential (Dillard \& Roslender, 2011), that is, to transform monologic EIAs into dialogic ones. The desire to foster a transformative dialogue that could promote social learning and sustainable and participatory mining is a major reason to adopt a critical dialogic framework.

8. Resist new forms of monologism

Dialogic tools are not merely viewed as technical innovations, rather critical dialogic accounting views them as a means of revealing conflict and for maintaining democratic contestation (Bebbington, et al., 2007). The aim is for all participants to appreciate the complexity of issues rather than necessarily achieving agreement (Söderbaum \& Brown, 2010). Through the dialogic process, social change could gradually occur. Social change in dialogic accounting is considered to be "dependent on social interaction and learning - discussing and debating one's own and other peoples' interests and values" (Brown, 2009, p. $327)$.

Thus, the dialogic EIA is an on-going learning process that should include comments, recommendations, and lessons learned from public participation and EIA contestation. This could enable EIA constituents to constantly improve EIAs, exercise more democratic and effective participation, undergo social learning, and to improve mining practices with respect to sustainable development. Engagement outside the formal EIA institutions is welcomed as it may discourage elite-groups from co-opting EIA participants who favour their interests, and prevent the EIA from reverting to monologism.

Each constituent plays an important role in the transformation process within the dialogic EIA. 


\subsubsection{EIA constituents}

EIA constituents can be classified as experts and non-experts. 'EIA experts' refers to officials in state organisations and EIA companies. EIA legislation in most countries requires professional assessment companies to use a specific methodology and framework, and then submit their EIAs to state organisations, which have considerable influence as they finalise EIA approvals (Cashmore, et al., 2010). Consequently, experts from both state organisations and EIA companies exercise significant power over how to conduct EIAs, whom to include as participants, and whether to approve or reject EIA reports.

Mining companies, affected local communities, international donor organisations, and civil society actors, such as NGOs, can be categorised as 'non-experts'. Mining companies choose the companies which prepare EIAs, pay all EIA related costs, implement EIA recommendations when EIA reports are approved by state organisations, and establish internal systems to monitor compliance with EIAs. Therefore, mining companies are customers of EIA companies that are responsible for implementing state regulations for EIAs. In many LDCs, international donor organisations are directly and indirectly engaged in EIAs through their supervisory and advisory roles to state organisations. In most cases, international donor organisations introduce EIA frameworks to LDCs (Cherp, 2001; Doberstein, 2003).

The main players in EIA public participation are local communities that are likely to be affected or already affected by a mining project. State organisations, mining companies, and EIA companies are, or should be, accountable to the public ( $\mathrm{Li}$, 2009; Lockie, Franetovich, Sharma, \& Rolfe, 2008). However, local communities are often marginalised and excluded from EIA decision-making processes in spite of their legal rights to participate (Kakonge, 1998; Rockloff \& Lockie, 2006). Local and international NGOs have engaged in EIAs to varying degrees, claiming to act as representatives of the public and professionals, and as activists for environmental protection and human rights. They have actively raised public awareness by promoting participation, being participants, developing alternative 
EIAs, and using formal EIAs to support their arguments against poor mining practices (Kravchenko, 2002; Li, 2009).

In advocating dialogue among EIA constituents and engagement of non-experts in EIAs, the dialogic approach emphasises the role of both experts and non-experts. Both are crucial to promote the transformation process within the dialogic EIA. Various problems for each constituent can arise, due to a lack of public and private sector accountability, and weak governance in LDCs. EIA companies can prepare EIAs of poor quality, ignore public participation, and favour their customers - mining companies (Annandale \& Taplin, 2003). State organisations can be bureaucratic and corrupt, and often do not provide access to EIAs or make inclusive, realistic decisions (Kolhoff, et al., 2009). The citizens of LCDs are often unaware of environmental issues and their right to participate, or are excluded from participation due to power imbalances, a lack of understanding of the professional language and jargon used, inadequate financial resources, and time-frames in which to participate (Doberstein, 2003; Kolhoff, et al., 2009; Li, 2009).

Thus, it is often argued that NGOs have the greatest potential for encouraging dialogue and acting as border-crossers among EIA constituents with differing views and interests (Brown, 2009; Söderbaum \& Brown, 2010). They may be able to challenge the bureaucratic and unaccountable structures of EIA companies and exert pressure on mining companies, and state organisations. Figure 4 illustrates the relationship of each EIA constituent with engaged an NGO. 
Figure 4. Relationship of EIA constituents with an engaged NGO

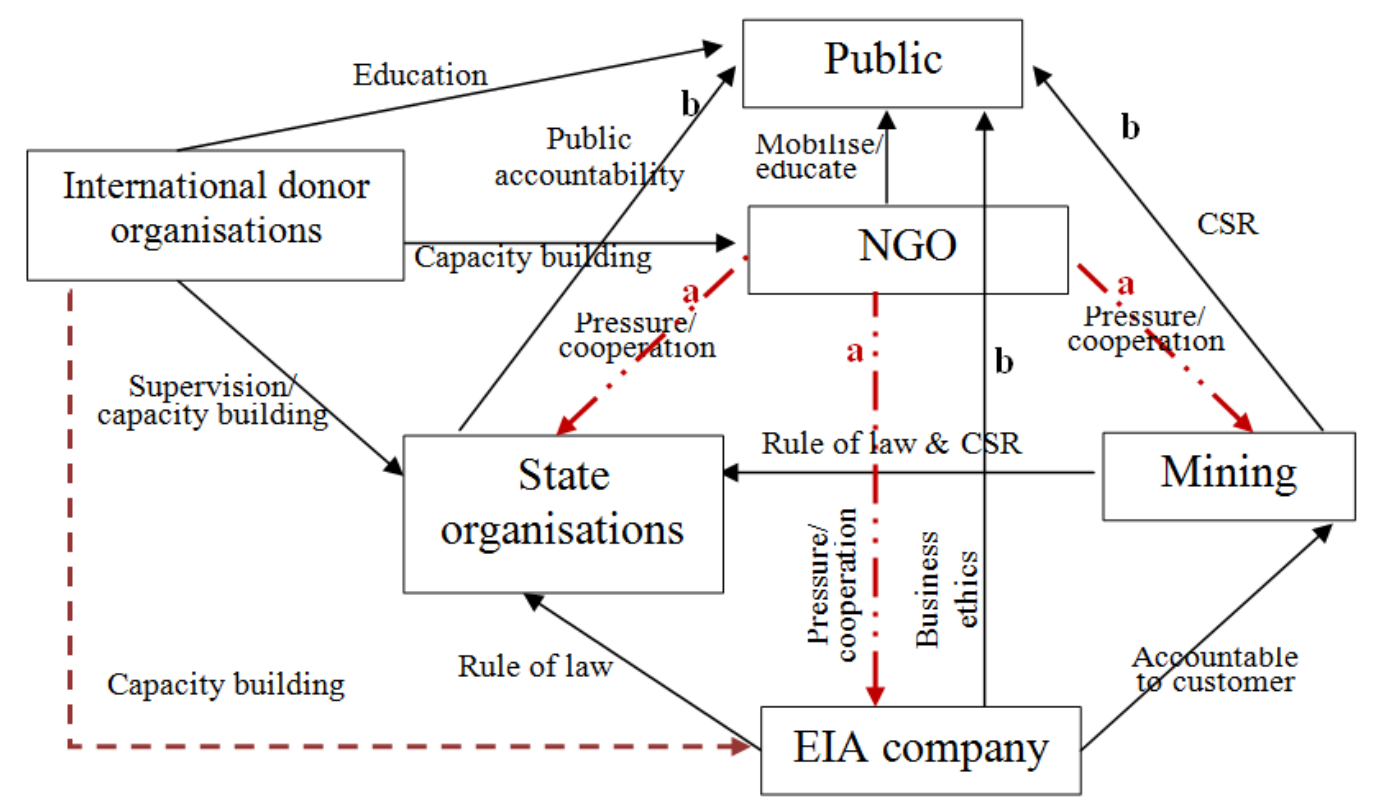

LDCs with a poor rule of law, weak public sector accountability, and a lack of concern with CSR tend to lack participatory EIAs, and economically sustainable mining due to power imbalances among constituents. These countries are also more vulnerable to external shocks of global markets, price fluctuations of minerals, and environmental destruction caused by poor business practices (Molisa, et al., forthcoming; Toth, 2010), such as mining.

These countries often lack the political will and institutional capacity to foster democracy and participation (Kapoor, 2008). Doberstein (2003) argues that decisions in LDCS are often manipulated by powerful individuals and that environmental decisions are often 'corrected' to reflect the preferred opinion. Moreover, corruption and bribery are important factors, and the approval of development projects is often influenced "by political, rather than environmental considerations" (p. 26). EIA companies and experts are often not supportive of more input from the public, claiming that the public lack appropriate training and knowledge, and that participation is costly and time-consuming (Annandale \& Taplin, 2003; Biller, 2003; Jay, et al., 2007). International donor organisations are also criticised for a lack of local knowledge and for pursuing "essentially neocolonial development agenda[s]" (Cashmore, et al., 2010, p. 374). 
Given the lack of political will and capacity of other EIA constituents, particularly experts, civil society actors, especially NGOs, can play crucial roles in transforming this situation. Mining and environmental issues are controversial and political, given their impact on broader stakeholders and non-human species, so NGOs need to be constantly engaged in these issues and to mobilise interestgroups and individuals to express their views, if they are to influence decisions and policies (Akol, 2001; Schlosberg, 2007; Szablowski, 2007). As Figure 4 illustrates, an NGO interacts differently with EIA constituents according to the arrows labelled (a), and constituents react to the pressures and mobilisation of an NGO according to the arrows labelled (b). Through this engagement, the accountability of both public and private sectors can improve, and the rule of law and public participation in decisions may gradually strengthen.

Thus, this study argues that local NGOs in LDCs have the potential to mobilise and educate local communities, regarding mining and EIAs, and to encourage both public and private sectors to be more accountable for their decisions and actions. Through such pressure and mobilisation of local communities, the mindsets in LDCs can be challenged, and the accountability of state organisations and private companies and the rule of law can gradually be improved. Importantly, NGOs can help operationalise transformations to dialogic EIAs and thereby promote sustainable and participatory mining.

\subsubsection{NGOs as promoters and facilitators of a dialogic tool}

NGOs have considerable potential to promote dialogue and participatory decisionmaking. Throughout their history, NGOs have played various roles in society, ranging from being activists to partners of state and business in the tri-sector approach (Gray, et al., 2006; Howell \& Pearce, 2001). With their strong advocacy for participatory democracy, human rights, social justice, and environmental protection (Howell \& Pearce, 2001; Li, 2009; Lockie, et al., 2008; Teegan, et al., 2004), NGOs have enthusiastically supported and strived for participatory decision-making in public policy and environmental management (Akol, 2001; Lockie, et al., 2008). Some dialogue practices among mining and EIA constituents 
illustrate how NGOs can initiate and facilitate multi-stakeholder dialogue in mineral-rich LDCs (Cornejo, Kells, Zuniga, Roen, \& Thompson, 2010).

Although the complexity and contested nature of NGOs are widely acknowledged, previous studies have not clearly addressed how NGOs are heterogeneous and consist of actors with different perspectives, views, and strategies (Howell \& Pearce, 2001), particularly in mining and environmental decision-making ( $\mathrm{Li}$, 2009; Szablowski, 2007). Instead of being perceived as a homogeneous entity, civil society can be perceived as an 'intellectual space' for the development of discourses (Lockie, et al., 2008), thus reconciling Western assumptions with 'subalterns' views and perspectives (Kapoor, 2008). The monologic approach to NGOs, which homogenises them as a single-actor group, ought to be challenged, particularly in LDCs. NGOs in these countries are diverse in their perspectives, strategies, and actions, and experience internal conflict and constant struggle over issues, ranging from survival and opportunistic behaviours to counter-hegemonic actions against dominant groups and Western capitalism (Feher, et al., 2007; McIlwaine, 2009).

However, this study recognises the plural and contested nature of NGOs in its application of critical dialogic accounting. It does not attempt to homogenise NGOs as a unitary whole, but rather, recognises that they have legitimate differences of viewpoint and, relatedly, adopt different social-change strategies. This study views the plurality and the constant struggle within the NGO sector as "neither disturbances that unfortunately cannot be eliminated, nor empirical impediments that frustrate the realisation of an 'ideal' harmony"; instead, it considers them as "central to democratisation" (Brown, 2009, p. 320).

Hence, this study explores the different roles, perspectives, and strategies of NGOs for promoting dialogic EIAs and greater accountability of EIA constituents. NGOs are seen as 'border-crossers' among different stakeholders. Given their diversity and potential influence, many prefer to work for social change, either from inside or outside mainstream institutions. As Brown (2009) states: 
Some combination of insider and outsider forms of engagement arguably provides the most effective form of praxis for those with social change agendas. This entails some social actors working for change from the "inside" (e.g. working with business and policymakers to reform institutions from within) and others working more combatively from "outside" mainstream institutions (p. 327)

Thus, some NGOs cooperate with business and state, while others prefer to work outside mainstream institutions and to challenge them by developing alternative perspectives through counter-arguments or counter-reports (Howell \& Pearce, 2001). Particularly in LDCs, socio-political contexts and power dynamics should be considered (Kapoor, 2008); neither solely Western democratic concepts imported by NGOs nor local activism by a few local NGOs can effectively address the complex and contested nature of EIAs and mining issues.

This study argues that NGOs can promote the key principles of the critical dialogic accounting framework. Although they share similar goals, such as participation, democracy, and sustainability, the engagement of insider and outsider NGOs can be distinguished by their perspectives. Some may prefer (implicitly or explicitly) more deliberative approaches to democracy, while others may promote a more agonistic stance. Mohan (2002) argues that both strategies of NGOs could make a difference in LDCs. Mohan (2002) argues:

Crucially, greater and more critical engagement with the state is required although this is incredibly difficult where states, donors and other aid organisations delimit the political space open to civil society. One route for this is more accomodatory via the recent emphasis on citizenship and rights which seek to generate greater 'synergy' between state and society through the promotion of social capital and civic engagement. A second route is more radical and involves civil society actors opposing the dominant development discourse and challenging local, national and global structures (p. 151).

\footnotetext{
${ }^{59}$ Some researchers on civil society make a similar argument from the neo-Gramscian perspective. They suggest that civil society is 'simultaneously the arena in which capitalist hegemony is secured but also where the subaltern classes forge social alliances and articulate alternative hegemonic projects' (Howell \& Pearce, 2001; Munck, 2006).
} 
Whereas Mohan (2002) concentrates on human rights and social capital issues, this study argues that a similar combination of NGO strategies could promote public participation in EIAs. Based on critical dialogic accounting roots, this study explores differing strategies and engagements of NGOs in promoting a transformation to dialogic EIAs. Table 3 illustrates the differences between the two types of participatory democracy advocated in dialogic accounting research.

Table 3. NGO strategies and implications for participatory democracy

\begin{tabular}{|c|c|c|}
\hline $\begin{array}{l}\text { Types of participatory } \\
\text { democracy }\end{array}$ & Deliberative democracy & Agonistic democracy \\
\hline Positions of NGOs & $\begin{array}{l}\text { Insider within the mainstream } \\
\text { institutions }\end{array}$ & $\begin{array}{l}\text { Outsider to the mainstream } \\
\text { institutions }\end{array}$ \\
\hline NGO strategies & Cooperative/collaborative & Challenger \\
\hline Engagement in dialogue & $\begin{array}{l}\text { Initiates and facilitates dialogue } \\
\text { in a deliberative sense }\end{array}$ & $\begin{array}{l}\text { Initiates and facilitates dialogue } \\
\text { Or opposes the formal dialogue }\end{array}$ \\
\hline Danger & Being co-opted & $\begin{array}{l}\text { Being excluded from the } \\
\text { mainstream institutions }\end{array}$ \\
\hline \multirow{4}{*}{$\begin{array}{l}\text { Advantages of co- } \\
\text { existence }\end{array}$} & $\begin{array}{l}\text { Prevents challenger NGOs } \\
\text { being excluded from the } \\
\text { mainstream institutions (by } \\
\text { including their arguments and } \\
\text { proposals in the mainstream } \\
\text { agenda and developmental } \\
\text { discourses) }\end{array}$ & $\begin{array}{l}\text { Prevents cooperative NGOs } \\
\text { being co-opted by the } \\
\text { mainstream institutions (by } \\
\text { criticising cooperative NGOs, } \\
\text { putting pressure on them to } \\
\text { "keep them in public interest") }\end{array}$ \\
\hline & $\begin{array}{l}\text { discourses) } \\
\text { Performs a connective function } \\
\text { between insider and outsider } \\
\text { participants }\end{array}$ & $\begin{array}{l}\text { Performs a monitoring function } \\
\text { over cooperative NGOs, } \\
\text { experts, donors and mining } \\
\text { companies }\end{array}$ \\
\hline & \multirow[t]{2}{*}{$\begin{array}{l}\text { Facilitates dialogue in a } \\
\text { deliberative sense }\end{array}$} & $\begin{array}{l}\text { Participates in the dialogic EIA } \\
\text { to express their views and } \\
\text { propose their agenda }\end{array}$ \\
\hline & & $\begin{array}{l}\text { Produce their own counter- } \\
\text { assessments and arguments }\end{array}$ \\
\hline
\end{tabular}

This table shows that both types of NGO may choose different positions and strategies for promoting participatory EIA decision-making and economically sustainable mining. Being either a cooperative or challenger NGO has advantages and disadvantages. However, both cooperative and challenging strategies can encourage pluralistic engagement within formal and informal EIA arenas.

A cooperative NGO can mobilise EIA participants and facilitate dialogic EIAs in a deliberative sense, whereas a challenger NGO can work outside the formal dialogic EIA, acting as an independent watchdog or making 'counter-EIAs' that challenge formal EIAs, addressing power issues associated with EIAs, and 
stymieing the formation of new types of monologism. However, this carries the danger of cooperative NGOs being co-opted and of challenger NGOs being excluded from the EIA arena. Therefore, the co-existence of both types of NGOs may be necessary for encouraging dialogic EIAs, and thence agonistic democracy and ongoing dialogue.

The NGO framework, illustrated in Table 3, is used in this study to analyse the empirical data and discussion on whether transformation to a dialogic EIA for promoting sustainable and participatory mining is feasible. The next chapter will describe the research methodology and methods adopted to analyse the Mongolian empirical data. 


\section{Chapter 6: RESEARCH DESIGN}

\subsection{Introduction}

This chapter introduces the research objectives and design. It bridges the conceptual framework and the analysis of empirical data by demonstrating how and why the research methodology and methods are suitable for the theoretical framework adopted.

The chapter is organised as follows. The first section introduces the research objectives and the research questions, formulated from the literature review and the conceptual framework chapter. These guide the analyses and discussion of the two empirical chapters. The consistency of research methodology with the proposed conceptual framework is then discussed, followed by discussion of the appropriateness of the research methods (including case-studies, interviews, document analysis and participatory observation) with the research aims and research methodology. Details of the data collection follow, including explanation of how and which data were collected, and the difficulties encountered. Finally, the data analysis of interviews and documents are described, as well as issues that arose during the analysis.

\subsection{Research objectives and questions}

This study examines sustainable development in practice, particularly in the context of a LDC. Sustainable development for business can be defined as economically profitable activities that include consideration of social and environmental issues (MMSD, 2002) - the latter being a crucial consideration for the mining sector of mineral-rich LDCs. As discussed, researchers across disciplines argue that sustainability requires the public participation of affected communities in social and environmental decisions. Allied to this, several authors promote ideas about the 'democratisation' of decision-making. In recognition of these issues, the objectives of this study are three-fold:

1. to address global and local calls for sustainable and participatory mining; 
2. to problematise symbolic participation practices of EIAs and investigate whether they could foster more inclusive and meaningful EIA practices; the study focuses on the EIA as a potential dialogic tool for promoting sustainable and participatory mining; it draws on Brown's (2009) critical dialogic accounting framework to evaluate existing EIA practices and to suggest new ones;

3. to examine environmental and mining-related NGOs in Mongolia and to explore their potential for promoting dialogic EIAs. This could 'democratise' environmental management and improve the performance of mining companies regarding sustainable development.

To address these objectives, the key research question and sub-questions are as follows: Can the EIA provide a dialogic accounting tool to promote sustainable and participatory mining?; arising from this, are four sub-questions:

1. Why do we need sustainable and participatory mining?

2. Are existing EIA practices primarily monologic or dialogic?

3. Can the EIA be a dialogic accounting tool to promote sustainable and participatory mining?

4. What role(s) might NGOs play in promoting dialogic EIA practices?

Chapters 2, 3 and 4 have examined these questions, drawing from the relevant literature both within and outside the accounting discipline. The next two chapters address the questions in the specific context of Mongolia and the empirical findings from my fieldwork.

To address the research questions, a qualitative research methodology and methods were used to collect, analyse, and write up the empirical data. The next sections discuss the methodology and methods used, the data collected, and how they were analysed.

\subsection{Research methodology}

This multi-disciplinary study examines environmental management, SEA, mining, and NGOs. Each area provokes distinct, controversial views on sustainability and participatory decision-making, but attempts to address all areas simultaneously, 
making the study a more complex process. Therefore, it is important to trace interactions and connection points between areas to focus the study. Although some points and areas may be lost during this 'particularisation' process (May, 2001), a search for intersections helps narrow the research and enables a deeper understanding and exploration of specific issues, notably sustainability and participatory environmental decision-making - key areas for this research.

This study uses normative arguments to examine why and if a critical dialogic accounting framework in an EIA could positively influence mining practices in LDCs, by creating sustainability and empowering affected communities. In this respect, the study explores the potential for promoting dialogic and participatory environmental decision-making for sustainable and participatory mining in LDCs, with a focus on the engagement of NGOs.

Qualitative research (in an interpretive and critical rather than a "positivistic" sense which views it as an open-ended way of discovering new "variables") ${ }^{60}$ is deemed suitable for these ends, as it is compatible with the dialogic accounting framework employed. Qualitative research promotes multiple perspectives with which to understand research issues better. It is open to subjectivity and does not purport to find one "correct" answer, unlike positivist viewpoints (Willis, 2007, p. 194). Qualitative researchers believe that people have their own interpretations of reality, so they choose methods that encompass this worldview (Mason, 2002). Bearing this in mind, dialogic accounting researchers use qualitative research to explore the potential of pluralistic approaches in SEA (Bebbington, et al., 2007; Dillard \& Roslender, 2011).

Given its multi-disciplinary and exploratory nature, this study draws on qualitative social research, which is by its nature "an interdisciplinary, transdisciplinary, and sometimes counterdisciplinary field ... and inherently political" (Denzin \& Lincoln, 2005, p. 7). It is open-ended and accommodates

\footnotetext{
${ }^{60}$ In the remainder of this chapter, the term "qualitative research" is used in this sense, and the literature drawn on comes from writers who adopt interpretive and/or critical stances. For further discussion on different approaches to "qualitative research" see Crotty (1998). As explained in Chapter 5, dialogic accounting involves both an interpretive dimension (understanding multiple perspectives) and a critical dimension (concerned with power relations).
} 
many interpretive and critical research viewpoints, and various research methods (Patton, 2002).

Qualitative researchers acknowledge the value-laden nature of inquiry and emphasise "the socially constructed nature of reality". Thus they try to understand "how social experience is created and given meaning" (Denzin \& Lincoln, 2005, p. 10). This is important for this study as public participation in EIA practices is viewed as socially constructed, and has different meanings to different EIA constituents. This study also focuses on NGOs, but does not attempt to homogenise this sector as a unitary whole; rather, NGOs are perceived as contested and plural. Differences and similarities emerge for particular issues, and the power dimension among different NGOs, and between NGOs and other social actors, should be taken into account.

Qualitative methodology provides flexibility for researchers to investigate contested issues while recognising their complexity. It is also attentive to subjectivity and power issues (Crotty, 1998), which is appropriate for this study because it addresses those issues in relation to mining, EIA practice, and NGOs, and examines them in the complex context of a developing country. By understanding these issues, it is hoped that the potential for bridging these areas and promoting sustainability and participatory democratic change can be encouraged.

Given its critical roots in dialogic accounting, this study recognises power issues, particularly those in LDCs. Like other critical researchers, I endeavour to "expose the forces that prevent individuals and groups from shaping the decisions that crucially affect their lives" (Denzin \& Lincoln, 2005, p. 308). Recognition of power inequalities among EIA and mining constituents provides not only an opportunity to be attentive to the contestation of actors and issues, but also to the possibilities and limitations of dialogic accounting in practice.

Given this study's orientation to a dialogic accounting research framework, qualitative research methods are deemed more appropriate, not least because they "facilitate study of issues in depth and detail" (Patton, 2002, p. 14) and help 
researchers to understand the complexities of social phenomena (Denzin \& Lincoln, 2005). Hence, the study employs a case-study methodology involving interviews, document analysis, and participatory observation. Mongolian EIA practices and two NGOs are used as case-studies to explore the nature and potential of EIAs and NGOs for promoting sustainable and participatory mining.

\subsection{Research methods}

Studies that promote pluralism are often interdisciplinary because they seek to explore differing interpretations of various stakeholders across a range of issues in order to understand the complexity of issues (Bebbington, et al., 2007). Researchers apply multiple methods to identify stakeholders' perspectives and views, to explore competing/collaborating relationships among them, to examine existing conflicts of interest, and to investigate power relations (Reed, 2002; Rockloff \& Lockie, 2006).

A multi-methods approach or methodological triangulation is commonly used in qualitative research to gain greater understanding and clarification of meaning (Fontana \& Frey, 2005, p. 722). Triangulation contributes to the "validity" of qualitative research (Denzin \& Lincoln, 2005) and "involves confirmation across different data collection methods" (Willis, 2007, p. 219). Multiple methods can give a "simultaneous display of multiple, refracted realities" (Denzin \& Lincoln, 2005, p. 3). The strengths of one method can compensate for weaknesses of another and increase the credibility of findings through cross-checking (Patton, 2002).

The case-studies used focuses on Mongolian EIA practices for mining projects and NGO involvement in promoting 'responsible mining' initiatives. It uses interviews, document analysis, and participatory observation to gather rich data, which is then analysed to explore the potential contribution of EIAs and NGOs in these regards. My personal experience was also useful. As I am Mongolian, there was no language barrier to interviewing people, conducting participatory observation, or analysing documents. Furthermore, it was important to be familiar with the Mongolian social, political, economic, and cultural contexts, to 
understand local traditions, and to have witnessed democratisation in Mongolia since the 1990 democratic revolution.

The following section discusses the research methods and explains how they are appropriate.

\subsubsection{Case-study}

The advantages of the case-study, which is commonly used in qualitative research, are that it allows researchers to collect rich, detailed data; it is more holistic and helps to understand issues in specific social contexts; and it can also be done without overly predetermined, detailed plans (Willis, 2007, p. 240).

These features are important, given the exploratory nature of this study. It was necessary to gather rich data that were not readily available because of the absence of prior studies on environmental management, mining, and NGOs in Mongolia. Therefore, I collected all the data personally by interviewing different EIA constituents, undertaking participatory observation, and collecting documents.

Case-studies provided a holistic approach. Six-month' fieldwork was conducted in Mongolia. The various methods for data gathering, and personal experience of Mongolian mining and NGOs helped me to understand more fully EIA practices and the engagement of NGOs in mining issues. Rich data and personal observation were supported by documents and media coverage of related issues. Case-studies enabled me to place issues within their social and political contexts and to uncover power dynamics among EIA constituents and NGOs. This is important for this study - as dialogic accounting encourages interdisciplinary and interpretive study that is open to subjective interpretations of issues (Brown, 2009; Söderbaum \& Brown, 2010).

The study did not commence with a clear predetermined plan for conducting the research and analysing data. Rather it attempted to explore issues as they unfolded. I had ideas about how to collect data, which groups of stakeholders to interview, and how to analyse initial data according to the dialogic accounting framework, but these were not specified in detail in advance. Accordingly, interviews were 
mostly unstructured, and participatory observation evolved during the fieldwork in Mongolia.

\subsubsection{Interviews}

Interviews were the main resource for data collection. They are widely used in qualitative studies as they enable researchers "to learn about social life through the perspective, experience, and language of those living it" (Boeije, 2010, p. 62).

This study attempts to understand different views and interests of various stakeholders and to explore the potential of EIAs and NGOs, so it is interested in both the "whats" and "hows" of meaning production (Holstein \& Gubrium, 2004). Interviews helped to explore different stakeholders' views on the roles and potential of EIAs for sustainable and participatory mining in Mongolia. They revealed stakeholders' differing understandings of public participation in EIAs.

The format of interviews differed depending on the research objectives and interviewees' background. A combination of semi-structured and focused interviews was used. This provided flexibility and active engagement between the interviewer and interviewees (Fontana \& Frey, 2005). Flexibility proved to be a major advantage (May, 2001), as it allowed me to "explore incompletely articulated aspects of experience, encouraging respondents to develop topics in ways relevant to their own experience" (Holstein \& Gubrium, 2004). It also allowed me to modify interview questions and clarify interviewees' meaning by using "reflecting back" methods that permitted "interviewees not only to elaborate, but also to correct and/or modify their account" (May, 2001, p. 133).

Semi-structured interviews were used for government officials, EIA specialists, mining company managers and project managers of international organisations. These helped my understanding of current EIA practices and different EIA constituents' views on their potential for improving public participation. To use a semi-standardised format of topics, such as mining and EIAs in Mongolia, was an advantage, as it ensured every interviewee provided answers to the principal 
questions. It also enabled me "to have more latitude to probe beyond the answers and thus enter into a dialogue with the interviewee" (May, 2001, p. 123).

A focused interview was used for NGO members. Its open-ended character provided flexibility, permitted the discovery of meaning, and provided "qualitative depth by allowing interviewees to talk about the subject within their own frames of reference", thereby supplying "a greater understanding of the subject's point of view" (May, 2001, pp. 124-125). Hence, focused interviews helped to establish an understanding of the values and views of selected NGO members, regarding mining practices and public participation in EIAs.

\subsubsection{Document analysis}

Various documents were collected during the fieldwork. Document analysis was used because it helped me compare my understanding of events and topics with those recorded in documents, and it "situate[d] contemporary accounts within an historical context" (May, 2001, p. 175).

As this study covers a wide range of disciplines and issues, I needed various documents from different sources. The main documents related to mining and environmental issues, EIA processes and reports, and the activities of NGOs on mining-related environmental and social matters.

\subsubsection{Participatory observation}

In order to understand interviewees' views and gain an understanding of mining, EIAs, and NGOs, participatory observation was employed as well as interviews. Researchers often use interview and observation methods together as "observation guides us to some of the important questions we want to ask the respondent, and interviewing helps us to interpret the significance of what we are observing" (Whyte, 1984, cited in May, 2001, p. 159). The observations noted "body language and other gestural cues that lend meaning to the words of the persons being interviewed", and to "learn things that people would be unwilling to talk about" during interviews (Patton, 2002, p. 263). Direct observation during 
interviews helped reveal interviewees' intentions, feelings and attitudes towards issues of concern.

Participatory observation also helped to understand the politics and competing interests that surround mining and EIAs. Observation is commonly used in social research to gain a deeper understanding of social life. Due to time ${ }^{61}$ and funding constraints, I could not conduct more in-depth participatory research in certain organisations, such as the MNET in the EIA study and the two NGO case-studies. Rather, I acted as a participant-as-observer as defined by Gold (1969). This role emphasises the researcher's "desire to know and understand more from people within the setting", rather than attempting to act "as one of the group studied" (May, 2001, p. 156). Observations supplemented evidence from interviews and documents, especially about the context of issues and relations between EIA constituents.

Fieldnotes were constantly taken during fieldwork. They helped to highlight particular events and my reflections on them; provided analytic notes regarding rules, roles, and relationships between participants; helped formulate further questions and events for further in-depth investigation (May, 2001, pp. 160-161); and they were helpful for tracing "a chronological overview of the decisions made and how they guided future actions" of the research (Boeije, 2010, p. 70).

In addition to fieldnotes, research-generated visual data were also gathered. 'Visual data' refers to "the recording, analysis and communication of social life through photographs, film and video" (Harper, 2007). Using such data to promote a pluralist dialogic accounting is encouraged by researchers, as visual data provide material to develop research arguments (Brown, 2010; Söderbaum \& Brown, 2010).

Memos on theory and methodology were written during the entire $\mathrm{PhD}$ study. Theory memos illustrate how findings are derived from the data, and "form an intermediate step between analysing the data - in particular coding - and the

\footnotetext{
${ }^{61}$ According to my PhD scholarship terms and conditions, I was allowed to visit to Mongolia only once, for up to 6 months, to conduct fieldwork.
} 
reporting phase" (Boeije, 2010, p. 70). Methodology memos helped me to reflect on my methods. They were useful during data analysis and for writing up the thesis, as they traced the constant evolvement of the methodological framework and my reflections on theory and practice.

The next section discusses how these methods were used, what was collected and from where, and difficulties encountered during the fieldwork.

\subsection{Data collection}

\subsubsection{Interviews}

\section{a. How were interviews collected?}

Before going to Mongolia, I made a list of potential interviewees from key government institutions, international organisations, mining companies, EIA companies and domestic environmental NGOs. The list considered their relevance to the research questions and their accessibility. Consent forms, proposed interview questions, and an information sheet in English were approved by the Human Ethics Committee (HEC) of Victoria University of Wellington. The information sheets and consent forms were then translated into Mongolian.

Once in Mongolia, I met each interviewee twice. During the first meeting, I introduced the study, provided an information sheet and consent form, and explained my research and how the interview would be conducted. On receiving the interviewee's approval, an appointment for the second meeting was made. No potential interviewee refused to be interviewed, possibly because of their interest ${ }^{62}$ in the study and the ethical assurances in the information sheet and consent form. Interviewees had an option to be anonymous. Most interviewees, except for a few local environmental NGOs, preferred this.

During the second meeting, interviewees were asked to complete and sign the consent form. I digitally recorded all interviews. At the end of each interview,

\footnotetext{
${ }^{62}$ Issues related to mining, its impacts and environmental NGOs are current 'hot' topics in Mongolia.
} 
each interviewee was asked for suggestions of other potential interviewees with a direct interest in and/or experience of the topics under scrutiny; some made recommendations and introduced other interviewees. As a result of this 'snow-ball' method, more interviewees from different groups of stakeholders emerged during the fieldwork, most of whom were met.

Although NGO interviewees had unstructured interviews, I initiated conversation and gently nudged them towards issues of special interest. During all interviews, I endeavoured to be attentive and interactive to gain a more comprehensive understanding of the interviewees' perspectives, views, and interpretations. As Boeije (2010) puts it, "during the interview it is paramount that the interviewer to some degree accommodates the participant's need to spend more time on certain issues, listens with interest, and does not interrupt the flow" (p. 63). During the semi-structured interview of experts, mining companies, and international organisations, the principal questions approved by the HEC were asked, but with sufficient flexibility to allow interviewees to discuss other related issues they considered relevant.

\section{b. What was collected?}

The main determinants of the number of interviews were time, cost, and accessibility of interviewees. Initially, 24 interviews were planned, given my limited time, availability, and uncertainty of accessibility. Also transcribing, translating and analysing interviews are time-consuming and costly processes (Holstein \& Gubrium, 2004), and gaining consents from interviewees was uncertain before the fieldwork began. However, during the fieldwork the number of interviews increased to 43 , due to more potential interviewees being identified; all were willing to give interviews. I actively sought additional interviews in the belief that more could provide richer and more informed data.

In total, 43 interviews were made from seven different groups of EIA constituents: EIA companies; government organisations, such as the MNET and the SSIA; international organisations or projects with a focus on mining and the natural environment; mining companies; local herders; domestic environmental NGOs; 
and researchers with interests in mining and local development. Following the classification in 5.3.3 of Chapter 5, these groups were categorised as experts or non-experts.

Interviews lasted, on average, about 50 minutes. The duration depended on an interviewee's time, willingness to talk, understanding or experience of the research-related issues, and personal characteristics ${ }^{63}$. The following table gives demographic details of interviewees.

Table 4. Demographic details of interviews

\begin{tabular}{|c|c|}
\hline Stakeholder groups & Number \\
\hline a. $\quad$ Experts & 13 \\
\hline 1. EIA companies & 6 \\
\hline 2. Government organisations including & 7 \\
\hline $\begin{array}{l}\text { Ministry of Nature Environment and Tourism } \\
\text { (MNET) }\end{array}$ & 4 \\
\hline State Specialised Inspection Agency (SSIA) & 2 \\
\hline Ministry of Energy and Minerals & 1 \\
\hline b. Non-experts & $\underline{30}$ \\
\hline 3. Mining companies including & 3 \\
\hline Mongolian domestic mining companies & 2 \\
\hline Foreign mining company & 1 \\
\hline 4. International organisations and projects & 8 \\
\hline 5. Local herders & 3 \\
\hline Local herders & 3 \\
\hline 6. NGOs & 14 \\
\hline Local people initiated environmental NGOs & 6 \\
\hline $\begin{array}{l}\text { Domestic NGOs (responsible mining, human } \\
\text { right and other social issues) }\end{array}$ & 5 \\
\hline NGO coalitions & 2 \\
\hline Business interest-oriented NGO & 1 \\
\hline 7. Researchers & 2 \\
\hline Legal researcher & 1 \\
\hline Australian PhD student in Mongolia & 1 \\
\hline Total number of interviews & 43 \\
\hline Total hours of interviews & 34 hours 31 minutes 38 seconds \\
\hline Average duration of interview (min) & 48 minutes 27 seconds \\
\hline Number of interviews lasted up to 35 minutes & 13 \\
\hline $\begin{array}{l}\text { Number of interviews lasted more than } 35 \\
\text { minutes }\end{array}$ & 30 \\
\hline
\end{tabular}

${ }^{63}$ For example, I noticed that male interviewees of government organisations, mining and EIA companies were less talkative and more formal. This might relate to the hierarchical cultural tradition and a Mongolian male stereotype of being less talkative. 
All interviews were digitally recorded and stored in a file format of Windows Media Audio.

\section{c. What difficulties were encountered?}

Although all interviewees were supportive, I was aware of some scepticism and suspicion among interviewees, possibly because mining and environmental issues are controversial and stakeholders have differing views and interests. Some interviewees were careful when giving interviews, and I was concerned that they may have viewed me as a 'spy' from mining companies (for NGO interviewees) or from NGOs (for interviewees from mining companies). However, this was understandable and expected, given the lack of trust among mining constituents and the political sensitivity of mining-related environmental issues. I endeavoured to overcome such mistrust by being honest about the study and by actively engaging in their activities when necessary ${ }^{64}$.

In five instances this suspicion resulted in delayed interview meetings. In these cases, I explained my research interests more fully and issued gentle reminders to them. Ultimately, all gave interviews; the longest waiting period was five months.

Difficulties occurred during interviewing; sometimes interviewees provided too much irrelevant information or very brief answers. Some NGO interviewees, mostly female, appeared more relaxed about discussing issues and would digress to fresh issues ${ }^{65}$; a gentle reminder about the initial question was necessary for them return to it. Other interviewees, mostly from government organisations, mining companies and EIA companies, tended to answer briefly or give a 'fuzzy' answer; they were then asked to provide more precise information and evidence, or were asked more questions for clarification, or the question was returned to later. Some interviewees may have provided brief answers because mining and environmental issues in Mongolia are politically sensitive, and officials tend to be careful when expressing views on them.

\footnotetext{
${ }^{64}$ See part B of 6.5.3 Participatory observation for an example.

${ }^{65}$ For example, if the question was about mining in local regions, some talked more about city issues and the debate about education and mining projects debated in the capital city.
} 


\subsubsection{Documents}

\section{a. How were documents collected?}

Although some reports and legislation were downloaded from the Internet before the fieldwork began, many documents were not available through the Internet as e-governance is still in its infancy in Mongolia; however, most government organisations have their own websites. To obtain updated information and documents, I gained access to the parliamentary library, the Mongolian Central Library, the library of the National Legal Institution, the library of the National Scientific Park, and the library of the Open Society Forum.

Visits were also made to the MNET, the Ministry of Energy and Resources, the SSIA, and some international NGOs, international projects, and television studios, to obtain documents and video materials on mining and environmental issues.

\section{b. What was collected?}

About 200 documents were collected, including reports from government institutions, international donor organisations and various projects; legislative documents; publications of NGOs and other institutions; video materials produced by television channels in cooperation with international projects and NGOs; and organisational documents of the Onggi River Movement NGO. These were obtained from libraries, the Internet, the press, NGOs, and personal contacts.

\section{c. What difficulties were encountered?}

Finding relevant documents and reports was not easy. In some cases, personal contacts were necessary to access sources. Bureaucracy of government organisations and librarians posed the main difficulties. Also, many documents were unavailable because EIAs, mining-related environmental issues, and environmental NGOs are relatively new phenomena in Mongolia. 
Access to the parliamentary library was difficult - I waited three weeks to obtain the one-week access permission ${ }^{66}$. The objective was to obtain EIA related legislation and archival materials on parliamentary debates during 1998 and 2001, when the EIA law and amendments were passed. However, few archival documents on parliamentary debates existed. Taking notes and photocopying relevant materials was difficult due to limited time ${ }^{67}$, place $^{68}$ and photocopy restrictions.

It was extremely difficult to access EIA reports and related official documents, although the law permits access to information (The State Great Khural of Mongolia 1995, Section 7). I attempted to see EIA reports and had submitted a written request to the Ministry, describing the research interest and desire to view these reports. I also attempted to set up an appointment with a government officer in charge of EIA reports. A week after the written request was made, the head of the EIA related department advised me to meet with an officer in charge of EIAs, but she had a strict, bureaucratic approach and denied me the opportunity to view the EIA reports.

In sum, finding useful documents and statistics for this study was difficult due to the unavailability of such information, bureaucracy, and the state secrecy mindset held by government organisation employees.

\subsubsection{Participatory observation}

\section{a. How was participatory observation conducted?}

Given my limited time-frame and funding, I conducted participatory observation, rather than participatory action research in specific organisations. This fieldwork had a participatory aspect but was not in-depth. However, I was open to

\footnotetext{
${ }^{66}$ I needed another permission for specific archival materials from the parliamentary archive. I waited a week for the signature of the Secretary of the Parliament for my written request, identifying the documents I wished to see from the archive office.

${ }^{67}$ Mostly, I visited the parliamentary building for only 2-3 hours during workdays of one week. An applicant to the parliamentary library is allowed to visit one week only and archival materials related to research interests were available only between $2-5 \mathrm{pm}$ on weekdays.

${ }^{68}$ Archival materials were only allowed to be viewed in front of the head of archive department, who shared his office with another staff member. The workspace was small and inconvenient, due to constant interruption by the frequent visits of parliamentary staff to the archive office.
} 
participating in any mining-related forum, conference, and event for the purpose of meeting mining constituents and to gather information about mining development and environmental issues. I also endeavoured to make close contact with some NGOs and other organisations so as to learn about their activities and understand their views on mining and the environment.

I participated in various meetings, conferences, and gatherings organised by mining constituents, including: two conferences on mining investment and the South Gobi mining development, organised by the Mining Association and the World Bank respectively; the annual "Mining and Rehabilitation" seminar, organised by the "Mining and the Environment" project ${ }^{69}$; several visits to the Onggi River Movement NGO; three attendances at monthly board meetings of the United Movements of Mongolian Rivers and Lakes (UMMRL) NGO; some press conferences and discussions organised by domestic NGOs on Oyu Tolgoi mining project $^{70}$; and a hunger strike ${ }^{71}$ organised by the UMMRL NGO to accelerate parliamentary debate on a new law prohibiting mining and exploration at the beginning of river resources and forest reservoirs.

To observe mining practices first-hand, I briefly visited three local areas, each lasting one day or more. They included the Erdenet mining company in Orkhon aimag, Zaamar soum in Tuv aimag and Uyanga soum in Uvurhangai aimag ${ }^{72}$. These two areas are 'infamous' places where unrehabilitated land and dried-up large rivers have occurred due to both legal and illegal gold mining operations. I interviewed two herders from each soum. The herder families who lived in or near mining sites were randomly chosen. During the short interviews with herders, it became evident that their families had lived in each soum for about ten years or

\footnotetext{
${ }^{69}$ This is a joint project of the Mongolian and German governments. The project focuses on the SSIA.

${ }^{70}$ Oyu Tolgoi copper mining project has been one of the 'hottest' topics since 2004. Ivanhoe Mining (Canadian gold mining company), which owns the licence, spent five years negotiating a stability agreement with the Mongolian government. The agreement was signed in September 2009. Domestic NGOs often protested against the agreement as they see the agreement and its process as contrary to the best interests of the Mongolian public.

${ }^{71}$ I had brief interviews with hunger strikers, including three herders from Khentii aimag - the most recent local area to have mining activities and protests against mining.

${ }^{72}$ The Erdenet mining company is located $373 \mathrm{~km}$ from the capital city. Zaamar and Uyanga soums are $230 \mathrm{~km}$ and $500 \mathrm{~km}$ from the capital city.
} 
more and had experienced the mining boom from its outset. I gained greater personal insights from these visits, which helped me to confirm or reject some views and arguments circulated by the press and mining constituents, based in the capital.

I had the opportunity to observe the rehabilitation processes of two mining companies during the fourth "Mining and Rehabilitation" seminar organised among mining constituents, which included domestic and international NGOs interested in mining. This was organised by the SSIA and the German government-funded project called "Mining and Environment". The seminar was semi-formal and held outside the city. During the first two days, senior-ranking government officials, academics, mining company managers, and international experts made fifteen presentations. These covered a wide range of issues, including mining development, implementation of mining laws, and water and rehabilitation related issues faced by the Mongolian mining sector. Each presentation was followed by an open-microphone session, which allowed the 50 participants to ask questions and discuss practical issues. On the third day, all participants visited Baganuur and Nalaikh coal mining companies and were shown the rehabilitation practices on mining sites. During this seminar, I was able to discuss informally my research with some academics and mining managers.

Regular visits to the UMMRL NGO formed a major part of the participatory observation. The NGO was chosen because of its interest in recent years in mining-related environmental issues, and the plurality of its organisational structure. The UMMRL is a coalition NGO of local environmental movements, including the Onggi River Movement NGO - a major focus of this study. During informal visits to the NGO, I spent days talking with members to familiarise myself with their activities and to study their archival materials. Sometimes NGO staff contacted me when there was a meeting or activity that might be of interest.

Besides fieldnotes and memos, I collected some visual data, including miningrelated brochures, posters, NGO newspapers, e-newspapers of the UMMRL NGO, and photos. Photographs were taken during the hunger-strike of the UMMRL 
$\mathrm{NGO}^{73}$, fieldtrips to Erdenet, Zaamar and Uyanga soums, and participation in the fourth "Mining and Rehabilitation" seminar, as visual evidence for this study.

\section{b. What difficulties were encountered?}

Although it was not difficult to access the UMMRL NGO, initially there was suspicion from its staff and members. This was understandable given the highly political and controversial nature of their activities, which focus on negative mining-related environmental and social impacts. There had been fear among local NGOs since the riot of 1 July 2008. To gain access and build trust, I visited the UMMRL NGO weekly or fortnightly, depending on my availability. I had informal discussions with NGO staff and members, helped them to translate some materials, acted as an interpreter during their meetings with some voluntary international researchers and interested parties, took photos during their hungerstrike for their archival use, and expressed sympathy for occasions such as the hunger-strike.

Fieldtrips to mining regions presented difficulties, such as financing them, finding reliable drivers who knew local roads, and safety considerations. Due to my safety concerns as a female researcher with limited funding, I visited the three mining regions one day for each. Such short visits were insufficient to gain an in-depth understanding or for interviewing enough local people, but each visit nonetheless provided valuable local insights on mining practices.

I also managed to overcome difficulties for participating in the three-day fourth "Mining and Rehabilitation" seminar. Participation proved challenging due to the limited number and expensive invitations for participants. However, I helped project managers to prepare and organise the seminar, and in return they allowed me to participate as an organiser. The seminar provided an excellent opportunity

\footnotetext{
${ }^{73}$ Six NGO members declared a hunger-strike on 4 July 2009. Three of the strikers were interviewees of this study and one was the leader of the Onggi River Movement NGO. The purpose of the strike was to put pressure on parliamentary members to pass the law 'To prohibit mineral exploration and mining operation at headwaters of rivers, protected zones and water reservoir and forested areas', which was circulated among MPs for one year. The hunger strike was supported by a further 20 environmental NGOs and ended on 9 July with success. The law was passed on 16 July 2009.
} 
to experience mining rehabilitation practices on mining sites, to meet various people, such as mining managers, academics, and officials, and to gather up-todate information on mining issues.

\subsection{Data analysis}

\subsubsection{Interview analysis}

Analysis of interviews occurred in several steps, namely preparing interviews in an analysable manner, then organising, coding, and analysing them. First, I personally transcribed all interviews, so as to avoid losing the meaning of interviewees' gestures, expressing their intentions and perspectives, which would otherwise have been lost in a verbatim transcription by another person. Five interviews were in English, so did not need translation, and were therefore only transcribed. Thirty-eight interviewees in Mongolian were transcribed in Mongolian, making it easier for me to refer to original transcripts when necessary.

Second, a three-to-five page summary of each interview was written after careful reading of interviews. These endeavoured not to exclude any points and examples raised in the original interviews. However, if there were repetitions of ideas, they were summarised as one. All interviews also had memos, recalling my reflections on each interviewee. These included the main points raised in each interview, and gestures and intentions of interviewees noted during direct observation. Third, all summaries were translated into English, which was important and helpful for later data analysis and writing-up of findings.

Fourth, a Word document of 197 pages was created combining all summaries. This enabled me to examine all summaries without accessing individual summary files.

Fifth, another Word file, titled Coded interview summaries", was created to put documents in a manageable classification form, as the first step of analysis (Patton, 2002). This file was one version of the combined file, but all sentences and paragraphs were organised and grouped according to codes. I endeavoured to be flexible with coding, using two general types of coding. One group consisted of 
ten codes, according to eight principles of the analytical framework, described in Chapter 5. The second group consisted of sixteen general themes, based on those most frequently mentioned by interviewees. These free codes were titled as follows: Mongolian specific features, cultural framework of Mongolians, mining practice (including positive and negative impacts), responsible mining ${ }^{74}$ (interviewees' interpretations of this term), other EIA related issues (main points not included in the first group of codes), rehabilitation practice, rehabilitation cost, ecological destruction assessment, legislative environment, politicisation, corruption, ministerial liaison, NGO sector (including the status quo, and appraisal and criticism of NGOs), democracy, foreign influence, and accountability. To assist with tracing back to original interviews, each sentence or extracted part was associated with the name of interviewees and its time indicated in minutes and seconds.

Sixth, the empirical chapters were prepared from the coded file, memos of observations, and documents collected during the fieldwork. To prepare data analysis of parts with specific codes in the empirical chapters, I read all pages relating to that code. All the main points were then placed in logical order to create a story. This was like rearranging the elements of a puzzle to form a picture.

\subsubsection{Document analysis}

A qualitative content analysis enabled me to critically analyse documents and the political, social and economic contexts of meaning production (Willis, 2007). All documents, including reports, publications, newspaper articles, posters and enewspapers were organised into file folders according to their context. This analysis provided flexibility and allowed me to consider how meanings were constructed, developed, and employed (May, 2001, p. 193).

Interviews and documents were similarly coded according to the analytical framework and free codes. If arguments and views did not match interview codes,

\footnotetext{
${ }^{74}$ The term 'responsible mining' started to be widely used in 2006. This term is compatible with the term of 'sustainable and participatory mining' in this study, because responsible mining covers both sustainable development and participatory decision-making in mining (RMI, 2009)
} 
then new codes were created. However, not many extra codes were needed. After coding, all the main documents were entered into the EndNote X3 referencing programme. This was useful for citations while writing the thesis and helped to filter searches for related documents. All useful documents were entered with keywords and notes. A research note on each document briefly described its main points, indicated useful sentences or evidence for citation, and provided suggestions for which chapters and arguments might apply.

As the notes included page numbers of useful citations and the main arguments, I could easily trace them back to documents and use them during the writing process. When carrying out the data analysis, documents were mainly used as supporting evidence for interview analyses. Documents helped provide evidence and statistics not obtainable in interviews.

\subsubsection{Issues in data analysis}

Initially, the NVivo 8 software was used to organise all interviews. After two months using the software, I decided it was better to code manually, due to the inconvenience of the software. It needed many files for data analysis, making it difficult to examine all simultaneously. Also, coding was problematic, as one sentence could cover many different areas and codes. I therefore decided it was preferable to use a Microsoft Word document to code manually in order to gain a fuller picture.

It was very time-consuming to transcribe all the interviews myself. Consequently, transcription took longer than expected. As there were 38 interviews in Mongolian, lasting in total 30 hours and 25 minutes, it was not feasible to translate all into English. The time restriction of my $\mathrm{PhD}$ scholarship allowed only six months for transcribing and translating interviews (while also having to attend to other aspects of the study).

\subsection{Concluding comments}

This chapter has outlined the research design used. The research objectives and questions were developed from the literature review chapters and the conceptual 
framework. The qualitative case-studies, using interviews, document analysis, and participatory observation, has been justified with regards to its relevance and usefulness for this study. The results inform the following two empirical chapters on EIA practices in Mongolia and the potential of dialogic EIAs and NGOs for promoting a dialogic approach to sustainable and participatory mining. 


\section{Chapter 7: MONGOLIAN EIA PRACTICE}

\subsection{Introduction}

This chapter analyses the empirical data on Mongolian EIA practice and is organised as follows: first, the nature and context of existing EIAs are discussed, including the situation prior to the introduction of EIAs, how the EIA process operates, and constituent perspectives on it; second, the empirical data are analysed, using the framework developed in Chapter 5 regarding whether EIA practices are monologic or dialogic; third, the potential of dialogic EIAs to address the deficiencies of monologic EIAs is discussed; fourth, how to make the transition from monologic to dialogic EIAs is examined; and lastly, the limitations of a dialogic transformation are discussed, as well as the danger of creating a new type of monologism and how EIA constituents could benefit from such an EIA transformation.

\subsection{EIAs in Mongolia}

\subsubsection{The prior situation}

Large-scale mining in Mongolia was not developed until the late 1960s, due to Mongolia's nomadic culture, its isolation from the rest of the world, its lack of mining knowledge and demand for a mining industry, and the absence of industrialisation.

Environmental protection and a sustainable way of living had been core values of nomadic life for centuries. Given that the main source of living for nomads is herding animals ${ }^{75}$, nomads are dependent on the natural environment. Thus, environmental protection has been reflected in Mongolian legislation, tradition, culture, religion and social norms. The Secret History of the Mongols ${ }^{76}$ recorded

\footnotetext{
${ }^{75}$ Mongolia has five types of herding animals: sheep, goats, cows, horses and two-hump camels in the South Gobi.

${ }^{76}$ An unknown author wrote The Secret History of the Mongols in 1228. The book introduced the genealogy of Genghis Khan (or Chinggis Khaan in Mongolian) and the rise to prosperity of the Mongolian Empire. Although it contains folklore and poetry, it remains the principal historical source on Mongolia at that period.
} 
in the thirteenth century that Genghis Khan had promulgated rules for environmental and animal protection that prohibited Mongolians from polluting water resources, digging land, and hunting animals during their reproductive periods (Unknown, 1228). Such practices reflected the nomad philosophy of "father sky and mother earth" and shaman belief in the existence of spirits for every natural element, such as rivers, lakes, mountains, steppes, trees and land, and to this day Mongolians perform a special ritual to obtain the permission of 'mother earth' if they wish to dig land for special purposes, such as for buildings or for burial. Nomadic life has necessitated that herders be self-sufficient; they still minimise the waste of any natural resource. Mongolians claim there is no waste from animals: they use the milk for milk products, skin for clothes, bones for home utensils, toys and buttons, and faeces are used for fuel, for building animal shelters, and natural incense is used to protect herded animals against mosquitoes and flies; and all meat and organs are eaten. That no mining occurred in Mongolia until the twentieth-century ${ }^{77}$ was partly because digging land was taboo, and the self-sufficient life style, nomadic culture and philosophy of Mongolians did not encourage large-scale mining. As well, Mongolia is isolated from other countries and sandwiched between Russia and China, neither of which became industrialised until the twentieth-century.

However, the communist period from 1921 brought fundamental social, economic and cultural changes. The state promoted industrialisation, especially through heavy industries including the mining of coal, copper and building materials to accelerate communist development, and provide exports of energy, minerals and construction materials to meet the ever increasing demands of the USSR and other communist countries (Griffin, 1995). The establishment of state-owned mining companies during the 1960s and 1970s brought a growing number of miningbased cities and towns, such as Erdenet ${ }^{78}$ and Nalaikh. At the time, religion and

\footnotetext{
${ }^{77}$ Anecdotal evidence suggests that in the 19th century during the Qing Dynasty domination in Mongolia, there were a few small-scale illegal mines operated by Chinese immigrants. Mongolians had also conducted some small-scale mining of silver, gold and other precious stones for jewellery and home utensils.

${ }^{78}$ Erdenet is the third largest city in Mongolia. Its main income generator and employer is the Erdenet copper mining company.
} 
nomadic culture was considered old-fashioned and anti-communist, and thus strictly prohibited.

The state encouraged rapid development of agriculture and mining, but environmental protection and mining rehabilitation were not carefully considered. Mongolians remained silent about their tradition of environmental protection for fear of accusation of being labelled enemies of communism and for being oldfashioned. Thus, people were "blind" to mining-related environmental issues during the communist period; at the time, mining companies were state-owned and no-one could protest against them (Interview D1) ${ }^{79}$.

Since the mid-1990s, especially after the government 'Gold Programme' and the 1997 Mineral Law, mining has boomed in Mongolia. As section 2.2.3 in Chapter 2 discussed, mining attracted huge international and domestic interest and has been regarded as a major determinant of Mongolian economic development, resulting in widespread mining exploration and operations in almost every region. Figure 5 shows a map of exploration and mining licences issued by the mining authority.

Figure 5. Major operating mines and mineral deposits

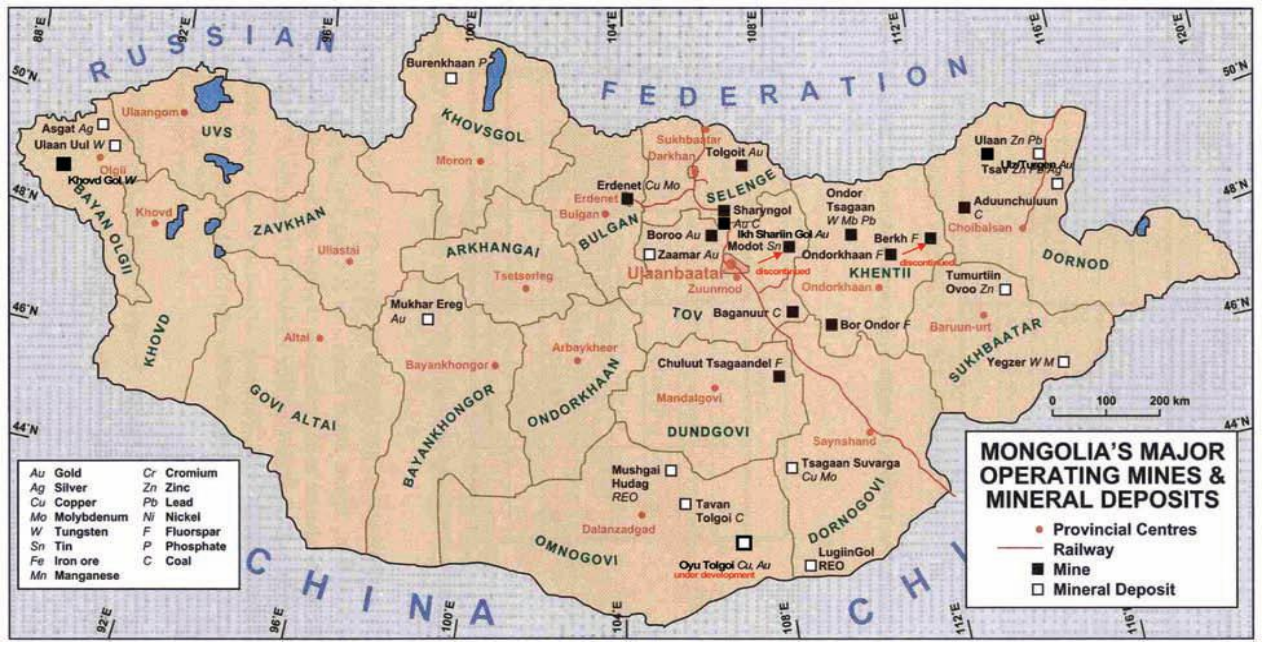

Source: Rheinbraun Engineering und Wasser GMBH (2003) "Review of the Environmental and Social Policies and Practices for Mining in Mongolia" (World Bank, 2006, p. 8)

\footnotetext{
${ }^{79}$ See Appendix on page 343 for an explanation of interviewee codes.
} 
However, this Figure is controversial as other sources suggest different numbers of licences and mining operations ${ }^{80}$. There are no officially agreed statistics and maps regarding mining licences, mineral deposits, and mines: the collection of such statistics is an on-going process.

Environmental protection legislation was passed at the time of mining growth and development. Parliament established an environmental management system and associated tools, such as the EIA, but it was not until 2006 that the environmental and social consequences of mining became widely discussed in society, which gradually increased public awareness and public debate. Today, the EIA and its associated environmental protection and monitoring plans are the main management tools for regulating mineral exploration and operations, and for preventing or reducing their negative environmental and social impacts.

\subsubsection{What has worked and what has not}

The Mongolian EIA framework has been gradually developed since 1998, and EIAs are today conducted for major development projects concerning infrastructure, construction, mining, and tourism. The framework clearly identifies EIA constituents as: the Ministry in charge of EIAs, private assessment companies, project developers (mining companies for mining projects), local authorities, the government inspection organisation, and local communities (see section 3.2.2 of Chapter 3 for details of the environmental legislative framework, EIA procedures and an overview of the EIA for mining).

The EIA, as a new environmental management tool in Mongolia, required new institutional arrangements and capacity building for training EIA professionals. With supervision from the ADB, the EIA was introduced to the MNET in 1994 and the Ministry then prepared the first EIA (ADB, 2005). Given the booming mining industry and other sectors with potential environmental impacts, it became evident that the Ministry did not have the financial and human capacity to conduct EIAs (Interview B1). The EIA law (1998) separated roles and responsibilities

\footnotetext{
${ }^{80}$ For example, maps provided by the government organisations sometimes differ from maps produced by NGOs. This is discussed more in Chapter 8 .
} 
(Interview B2), so as to ensure the independence of an EIA assessor, approver and controller. The law states that a legal business entity with an EIA licence should conduct EIAs, while the MNET should make the final decision concerning approval or rejection (Article 4 and 9). Today, 83 EIA companies conduct EIAs for mining and other projects. Mining projects account for 30 percent of total EIAs (MNET, 2009a, 2009b). The law was amended in 2001 to incorporate public participation $^{81}$ in EIAs (The State Great Khural of Mongolia, 1998).

The EIA framework has had both successes and challenges. EIA law is acknowledged as being is relatively good (Interview A2, B5, F8); most interviewees, even NGO interviewees who had not been engaged in EIAs, knew about the EIA and when it should be conducted. The EIA has become a wellknown environmental management tool. An EIA expert claimed that the chief achievement of the last decade was that everyone understood that EIAs should be undertaken before relevant projects and that they "provided some understanding for people on how to protect and use natural resources effectively with consideration for the mitigation of negative impacts" (Interview A5, 00:17:28-2). However, the absence of a clear regulatory mechanism hinders the practical application of legislation (Interview D5) which has led to poor implementation of the EIA and mining laws (Interview D1).

Many difficulties are caused by the lack of professional knowledge, expertise, and institutions. Study of documents and interviews reveal that the quality and implementation of EIAs for mining are problematic. Often considered technical issues, such as how they are conducted, what is included, and how they are implemented, the quality and inclusiveness of EIAs also reflect conflicting perspectives on mining and environmental issues by EIA constituents. Arguably, these differences ought to be brought into the open and discussed, as they influence ways of thinking, behaving and arguing about EIAs and mining. Although different perspectives are invariably not explicit, they were implied during interviews and in documents, and were apparent from personal observation.

\footnotetext{
${ }^{81}$ Detailed discussion on public participation of EIA practice will be introduced in section 7.3.
} 


\subsubsection{Different perspectives among constituents}

Four different sets of opinions in this study are relevant to mining development, its benefits, mining-related environmental issues, and mining rehabilitation. Each is discussed below:

$>$ Mining development: 'source of growth' versus 'fear of mining':

Proponents of mining claim that the chief source of growth for mineral-rich LDCs is mining development (World Bank, 2004; World Growth, 2008) as well as a favourable mining environment that attracts greater foreign direct investment to mining and related sectors such as infrastructure, which will generate increased income, tax revenue, and lower unemployment (World Bank, 2007). Given such a viewpoint, Mongolia should begin to mine its large mineral deposits, as China one of the world's largest mineral consumers - has a huge demand for coal, copper and other minerals due to its rapid growth (World Growth, 2008); as well, state intervention for a liberal economy should be minimal, with regulation of mining development based on the global and national market demand and supply for minerals (Fraser Insititute, 2007). Most international organisations, members of parliament, government officials, economists, mining companies and EIA companies support such mining development. Some interviewees said "it is difficult to see a Mongolian future without mining, and we need to live by using our land and its deposits" (Interview A6, B7, D1).

However, some mining constituents, particularly environmental and social NGOs and some local communities, oppose mining, believing that it is not "the right way" for Mongolian development (Interview F3, 00:11:49-0). An NGO interviewee expressed his deep-green view against mining by quoting a Mongolian proverb "Gold is dangerous and can take over people's lives" (Interview F1). Between these two extreme viewpoints lies a third view on mining development: four interviewees argued that it would be better to mine only a few large deposits and not allow the spread of small and medium mining enterprises throughout the country, as currently occurs. An NGO interviewee stated that "we need only a few large mining projects to promote the export of final products (processed metals)" 
to add more value to the economy (Interview F11). "Once we have a few large mining companies there would be service and other small industries based in mining areas" (Interview F8, 00:10:39-5). These views opposing a booming mining industry relate not only to the fear of being left without mineral resources in the near future, but also to the violation of traditional nomadic, cultural beliefs that to dig land is not acceptable (Jachid \& Hyer, 1979).

These conflicting views are evident in public debate in the press and television programmes. However, the concept of "responsible mining", developed since 2007, endeavours to incorporate sustainability and cultural aspects into mining practice. Discussion among mining constituents confirms a "consensus" that mining is important to Mongolian development and its future (Interview D6, F9). Given Mongolia's lack of mining tradition and experience, unlike many countries in Latin America, the chief question is "how can we use this non-renewable resource to develop sustainably by creating renewable [economic] resources" (Interview F9, 00:14:43). Arguably, Mongolians are on the cusp of mutiny (Interview D6, 00:02:12-08) and must decide how to develop mining in a sustainable way.

\section{Mining benefits:}

The distribution of mining benefits is a major issue of contention. Supporters of mining argue that mining can benefit the economy through increased tax revenue, employment, local development and social welfare of local regions (through investment to hospitals, local secondary schools etc.). However, opponents argue that mining benefits can neither benefit the national economy nor local development. They claim instead that mining companies enjoy tax holidays, avoid taxes, and because they employ mostly foreign personnel - often Chinese workers - few employment benefits flow to local regions and Mongolians in general (Interview A2, D5, F1, F3, G1). Moreover, they argue that the benefits of mining investment flow mainly abroad. One NGO interviewee claimed that the only benefit to the Mongolian economy from mining was from the petrol consumption of mining companies (Interview F8). Even if mining companies employ local people, they pay the lowest wage and use temporary contracts that allow 
employees to be dismissed without justification (Interview F7, 00:18:59-4). Thus, foreign investors "take our capital, rather than invest in us" (Interview F8, 00:16:52-2). Another NGO interviewee confirmed this, citing an example from her local region where a Chinese mining company had a licence to operate for 27 years; in the first four years of operation it had not built roads, paid full royalty taxes, or provided benefits to local communities as promised in contracts (Interview F4, 00:02:11-4 P2).

However, the lack of economic benefits from mining relates to weak governance and legislation that fails to take account of the advantages and disadvantages of mining development. Poor governance in mining has precipitated social and environmental issues that, although not yet fully apparent or scientifically proven, have provoked debate among mining constituents.

\section{Environmental issues:}

Due to both legal and illegal mining, the natural environment in many regions has deteriorated, and water and soil have been polluted. Until 2006, the environmental effects of mining were not visible and hence not addressed by mining constituents. An overemphasis on the economic benefits of the 1993 'Gold Programme' and the Mineral Law 1997 contributed to poorly managed mining in Mongolia (Interview D5, F7, F8). These regulations failed to consider the environment or to define clear mechanisms for reaping mining benefits with less environmental harm (Interview F7, F9). Consequently, local communities and the natural environment have become "victims of poor mining" (Interview A1, F8). The photos below show environmental destruction in two mining regions.
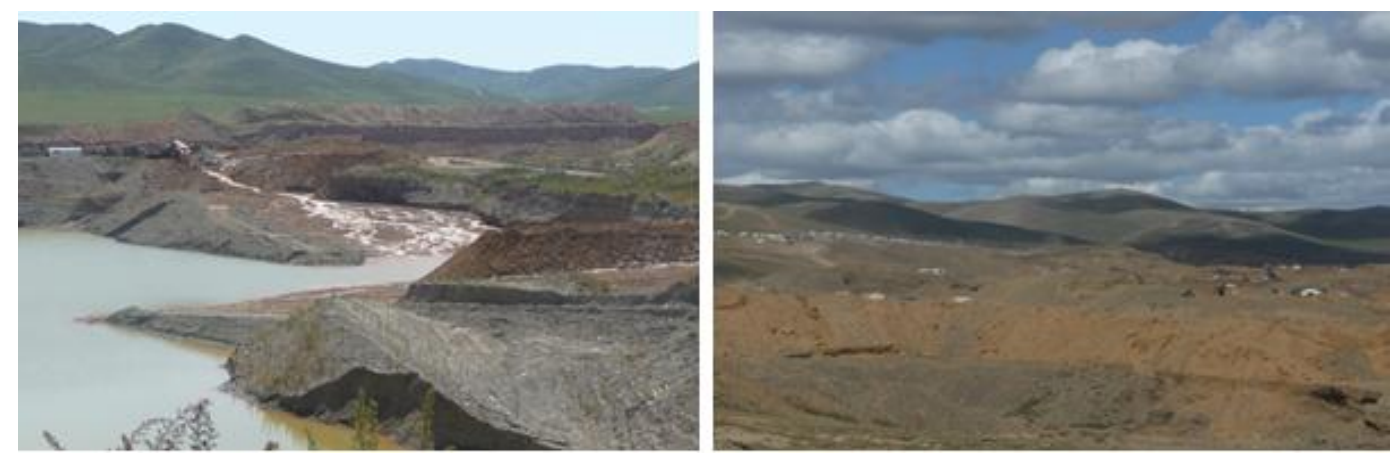
These photos were taken in the Zaamar and Uyanga soums: the left photo shows mining tailings and water usage; the right photo shows the environmental degradation caused by legal and illegal mining.

In the left photo, a mining company had diverted the river flow to its mining site and then discharged processed water back into the river. In the right photo, the once beautiful, fertile pasture of Uyanga soum has become a "borderless" site for legal and illegal miners. Illegal miners came to live near small and medium mining companies, and local residents claimed the area was no longer available for local use as pasture land for herders (Interview E2, F6).

Mining constituents present conflicting views on the causes of environmental degradation. Supporters of mining argue that it is not caused by mining, operations but is the result of global warming and overgrazing in local regions (Interview A6, C1, C2, D2). They identify illegal miners as the guilty party with respect to digging, not rehabilitating land, and polluting the water and soil, as they use mercury to wash out gold from ore-bearing soil (Interview D1, D5, C2).
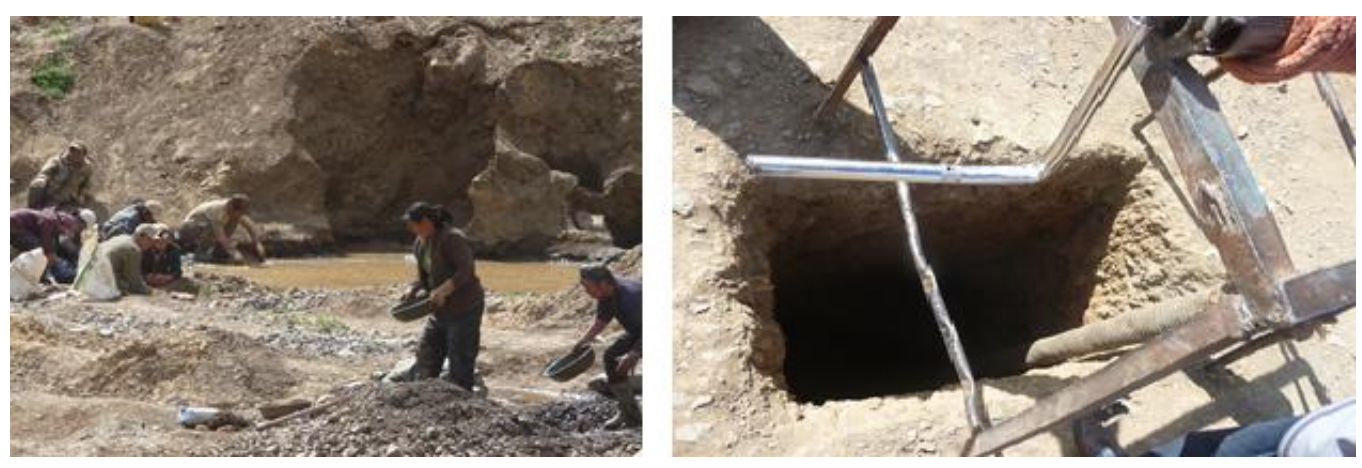

The above photos, taken in Uyanga soum, show illegal mining operations. Mongolia has more than 100,000 illegal miners, ranging from small children to 70 year old men. The right-hand photo shows a hole dug by an illegal miner; orebearing soil is excavated from 20 to 40 metre deep holes and fine gold fragments are then washed out, using gravity and mercury (World Bank, 2006).

On the other hand, critics of mining argue that both the poor state of the economy and mining companies have created this situation. Most mining companies use out-dated equipment to cut their costs, with the result that 30 to 40 percent of gold-bearing tailings remains unprocessed in legal mining (Interview A4); this 
attracts illegal miners who do not rehabilitate the land (Interview B7, C1, D5). Gold mining is also heavily criticised for its environmental impacts. As gold deposits are mostly located along rivers, mining operations "pollute water, cut trees and dig pasture land" and thus "threaten the essence of local communities" (Interview F2, 00:07:47-2). Local environmental NGOs such as the Onggi River Community claim that water resources in many regions are dried up and polluted due to poor mining practices (Snow, 2010). Opponents of these groups, in turn, claim that such assertions are not based on scientific proof and therefore lack credibility (Interview C2, D6, D1).

The role(s) of scientists is thus crucial to this debate. Depending on their perspectives, most scientists support the argument that global warming and overgrazing are important factors in environmental degradation, rather than mining (Interview A2, A6, B1, D1). However, some scientists do criticise mining for the pollution and degradation of the local environment (Suzuki, 2008) and work voluntarily with environmental NGOs on EIA matters (Interview F5). Thus, scientists, too, are divided about environmental issues.

The important aspect of debate for this thesis is that accountability issues are raised and blurred, depending on the alleged causes of environmental degradation. In the case of global warming, the need for accountability of poor mining and governance issues is silenced by the assumption that individual companies and countries can do little to change the situation. With "no one responsible for the situation", accountability issues are downplayed if not ignored. This is an outcome of the current social context which lacks accountability mechanisms at all levels of society (Interview F4, D8). However, there are signs of change. Environmental and social NGOs have become increasingly active in mining debates and provide various arguments and visual evidence. Social awareness of environmental matters has improved since 2006 and local communities have begun to engage in mining issues (Interview F2, F7, D5, C3). One of the main issues raised around mining-related environmental impacts is mining rehabilitation. 


\section{$>$ Rehabilitation:}

Rehabilitation $^{82}$ of mining land is compulsory for all mining companies (The State Great Khural of Mongolia 1995, Article 25). In gold mining and some other minerals, rehabilitation can be done during operations once gold-bearing ore is processed, while for coal and fluorspar mining rehabilitation is only possible after mine closure (Interview A4, B1).

There are differing opinions among EIA constituents regarding rehabilitation practices. Interviewees of mining companies, some government officials, EIA companies and professional NGOs reported that relatively high quality rehabilitation was carried out (Interview A6, B2, C1). They also noted that mining companies engaged professional rehabilitation companies, thus providing reassurance that the quality of rehabilitation was adequate (Interview C2, B1, B2, A6). Mining interviewees noted further that illegal miners would dig rehabilitated mining sites after companies had left (Interview C1, C2); un-rehabilitated land was not the responsibility of only mining companies (Interview D5).

By way of contrast, most NGO interviewees and some government organisations and EIA companies were concerned at the absence or poor quality of rehabilitation. They maintained that mining companies have a window-dressing attitude, pretending to comply with legislation (Interview A1, B3, F2, F3). They also contested the figures for rehabilitation costs and argued that a deposit of 50 percent of annual rehabilitation costs was not sufficient when companies disappeared without undertaking rehabilitation (Interview F8, F10). Some argued that rehabilitation companies themselves were problematic, as they were not operated professionally and owned mostly by previous or current public officials who had only limited influence in the quality monitoring of rehabilitation projects (Interview F3, F6). Other commentators claimed that if mining companies used modern equipment and fully processed gold-bearing ores, there would be no illegal mining (Interview A4, B3). The following photos show the rehabilitated

\footnotetext{
${ }^{82}$ There are two types of rehabilitation: technical and biological. Technical rehabilitation means to cover mined areas with soil, whereas 'biological' refers to restoring vegetation with appropriate planting (MNET, 2006b).
} 
land of a Mongolian mining company which was recognised as one of the best practice companies for good rehabilitation.
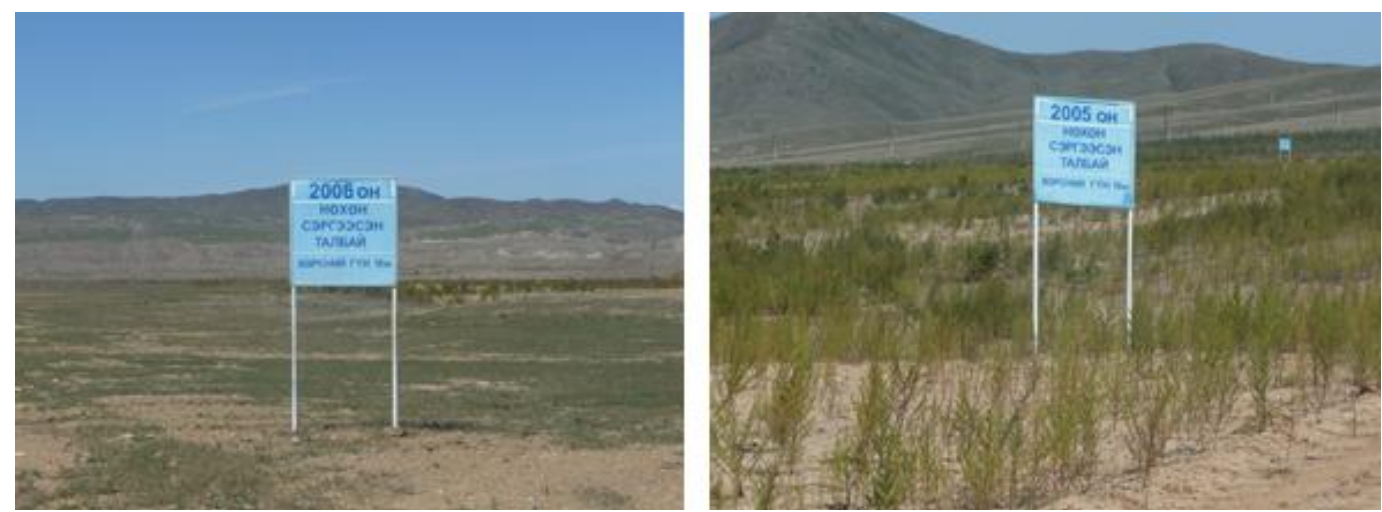

Photos taken in July 2009, showing land of a Mongolian gold mining company in Zaamar soum, which was rehabilitated in 2005 and 2006.

Although some argued that rehabilitation was properly carried out, it was evident when I compared areas with surrounding ones that had no mining, that most rehabilitated land was not restored to its original state prior to mining. In spite of the ongoing debate about rehabilitation quality, interviewees agreed that rehabilitation needs to be substantially improved (Interview D7, F9, B3, C3). Some suggested that public monitoring of rehabilitation after mining closure was important, as some inspectors were limited in their ability to influence the conduct of companies $^{83}$ (Interview A5, B5).

To summarise, there are different views on mining and its environmental impacts. Controversy about mining is also evident in the social issues and political debate on the ownership and usage of large strategic deposits. For the purposes of this study these views have been briefly outlined to illustrate the contestation of mining issues and various perspectives held by mining constituents. As the EIA is a legal management tool which can address mining-related environmental impacts, differing views on mining and environmental issues are also relevant when considering its application. Such views influence the behaviour and understanding of mining constituents regarding EIAs and their implementation during the mining life cycle. To illustrate this, the analytical framework, developed in Chapter 5, is used to analyse interviews, documents and field notes.

\footnotetext{
${ }^{83}$ Public participation in the quality assurance of EIAs will be discussed in next section.
} 


\subsection{The analytical framework analysis of Mongolian EIA practice}

The principal purpose of this section is to analyse Mongolian EIA practice and to examine whether it is monologic or dialogic, based on the principles of the framework outlined by Brown (2009). However, the order of principles has been changed slightly, and some principles have been merged, depending on their relevance to Mongolian practice and data availability ${ }^{84}$.

1. Avoid monetary reductionism and be open about the subjective and contestable nature of calculations:

Currently, there is neither clear recognition nor avoidance of monetary reductionism. In practice, the EIA is a relatively technical environmental assessment for determining the impacts on soil, air, and water pollution (MNET, 2006). EIA assessors, who are mostly environmentalists, must assess these impacts according to the EIA legislation and methodology (MNET, 2006; The State Great Khural of Mongolia, 1998). Currently, EIA companies use the 2002 EIA methodology, a few standards on mining and rehabilitation of gold and coal mining, and an ecological destruction assessment that was used as a trial during 2008-09.

However interviewees, particularly NGOs, criticise the lack of a comprehensive methodology and standards that should include assessments of mining impacts on biodiversity, local society, culture, and heritage sites. They argue that the EIA should consider all components of the ecological system and not be limited to only soil, air and water impacts of a given project (Interview A5). As well, animals and plants that surround mining affected areas should be considered in terms of potential adverse impacts on them and potential mitigation methods (Interview D4, F3).

\footnotetext{
${ }^{84}$ Some concepts, such as monetary reductionism and dialogic potential, are either not developed or recognised, due to the social background and transition phase of Mongolia. As the dialogic framework has been formulated, based on the context of a developed country, it ought to be modified for the Mongolian context.
} 
Currently, no comprehensive guidance and database exist on the animals and biodiversity of different regions. Interviewees of EIA companies acknowledged that many EIA companies copy and use only general textbooks or research on the major geographic regions, rather than conducting actual field studies in the proposed mining area for each EIA (Interview A1, A5). This situation relates, arguably, to interests of EIA companies, which endeavour to cut costs (Interview A3, F2). As there is no clear mechanism for evaluating the impacts on biodiversity and for ensuring the quality of an EIA assessment, companies tend to comply only minimally with EIA regulations and to avoid expensive field-based assessments (Interview A5). To address the lack of a general database, the World Bank is cooperating with MNET to develop an online tool that will provide information on all animals and vertebrates of each region (Interview D2). It is hoped the database will help improve the quality and inclusiveness of EIAs (Interview D4).

Some NGO interviewees complained that environmental experts often ignored the social and cultural impacts of a mining project. There is no evaluation method and guidance regarding what should be considered social and cultural impacts, how to determine them, and what potential mitigation methods are available to avoid or minimise these impacts (Interview F7). Interviewees pointed to impacts due to mining operations in culturally significant areas that upset local communities (Interviews F4, F5, F9). A television programme, "Detective Derrick", alleged that some mining companies hide archaeological findings at their sites to avoid termination of their licences ${ }^{85}$, and that illegal miners later dug them up, selling them to foreigners at very low prices.

To address these issues, a bill for EIA law amendments was drafted in 2008, using input from various EIA constituents, including social and environmental NGOs (Interview A5). The bill proposed consideration of the social aspects of mining projects and the inclusion of local communities in EIAs (The State Great Khural of Mongolia, 2008). The Human Rights and Development Centre and other NGOs

\footnotetext{
${ }^{85}$ By law, mining should not occur if a licenced area is archaeologically significant (The State Great Khural of Mongolia, 1997).
} 
are also evaluating the quality of EIAs and proposing a social impact assessment as well as the EIA (Interview F7). However, the need for a social and cultural impact assessment will lead to the issue of how to evaluate compensation for affected people, which is a very political issue, given the many years of delay to pass legislation on compensation in other areas (Interview A5).

As no clear calculation method on environmental and social impacts currently exists, the issue is not about monetary reductionism at present (compared with a developed country context, as discussed by Söderbaum, 2004, 2011; Brown, 2009; Bebbington, et al., 2007 and others). Rather, most EIA constituents are eager first to have a comprehensive methodology and calculation. Perhaps then, there can be debate on whether the calculation is sufficiently inclusive and accurate, and whether it reduces intangible values to monetary ones. On the other hand, the lack of a calculation methodology may provide the opportunity for EIA constituents to debate what and how to include and assess the social and cultural impacts of mining, by drawing on debate in developing country contexts. They might then learn from those who warn of the limitations of trying to "commodify" impacts through monetisation (Bebbington et al. 2007, p. 221). It should also be emphasised that the EIA is not as vulnerable to claims of monetary reductionism as, for example, the Sustainability Assessment Model, which aims to translate as many impacts as possible into monetary terms (Bebbington et al. 2007).

In terms of the subjectivity of EIAs, what and how to calculate is subjective, although this is not widely recognised by EIA constituents. One factor, reflecting the cultural and social backgrounds of Mongolians, is that people do not question decisions and methodology developed by state organisations; EIA methodology and calculations are taken for granted, which is evident in interviewee responses. An interviewee of an EIA company said he was unsure of the accuracy of the EIA methodology and on what perspective it was based, but he considered that EIA companies had to "merely obey regulations" and that the accuracy of the methodology was not an "EIA company matter" (Interview A3, 00:22:12-3). Interviewees of government organisations also did not question the methodology, stating that "costs are calculated by experts according to the methodology, so it is 
not possible to say whether it is realistic" (Interview B2, 00:02:06-5 P2). However, some acknowledged that the methodology was out-dated, as it was developed in 2002 (Interview B3, B5).

In spite of the silence on subjectivity, views on rehabilitation costs demonstrate that the subjective nature of calculation is implicitly 'acknowledged'. Fifteen interviewees agreed that the rehabilitation costs calculated were very low. Some interviewees from EIA companies and NGOs were more critical about the methodology and the unrealistic calculation of rehabilitation costs. Due to conflicts of interest by EIA companies, rehabilitation costs were regarded as being "unrealistically" determined (Interview F8, 00:36:03-6) and calculated "roughly" (Interview A3). Low rehabilitation costs were also produced by "non-specialised" experts of EIA companies, who were often "corrupt" (Interview A4, part 7). An NGO interviewee provided an example of rehabilitation costs, calculated at 60,000 tughriks (about $64 \mathrm{NZD}^{86}$ ) per hector of land (Interview F5, 00:36:33-8). However, NGO criticism of poor rehabilitation was often dismissed by other EIA constituents, given that NGOs were labelled as "noise makers", providing "no scientific evidence" (Interview D1, D6).

Another concern regarding subjectivity relates to public participation. A public official interviewee acknowledged the subjectivity of surveys used as the principal tool for collecting public comments on a mining project. He argued that when EIA companies prepared and conducted surveys in local areas, there was the possibility of a sociologist's view biasing the information presented to local people. As he explained:

If he [the sociologist] included mainly positive aspects of a project and praised it during his survey, then comments from local people would be in favour of a mining project, in the absence of unbiased information. But, it may result in further conflict once the project begins (Interview B1, 00:32:30-7).

In summary, there is no recognition of either monetary reductionism or the subjectivity of EIAs. However, interviewees were critical of the calculations of

\footnotetext{
86 By April 2011, the currency exchange rate was 942 Mongolian Tughriks = NZ\$1
} http://www.xe.com 
low rehabilitation costs, and out-dated EIA methodology. To some degree, this relates to these two principles of the dialogic accounting framework. Thus, there are some aspects that EIA constituents must begin to question and debate.

\section{Enable accessibility of non-experts:}

In terms of the accessibility of non-experts, practice shows that EIAs do not have to engage non-EIA expert stakeholders. The following section demonstrates how formal EIAs are based heavily on the input of experts and the various associated problems that are created for EIAs: first, expertise in EIAs is considered at the time of engaging EIA experts and non-experts; second, the processes and problems of quality assurance in EIAs are introduced, based on interviews and documents.

\section{a. Expertise}

According to the law, EIAs should be conducted and prepared by licensed, professional EIA companies (The State Great Khural of Mongolia, 1998, Article 5). Experts of EIA companies usually come from various natural and social science disciplines, including biology, hydrobiology, geology, hydrogeology, mining, environmental studies, engineering, sociology, and others. Interviews suggest there is a lack of EIA expertise at both the administrative level ministerial and operational - and at the EIA companies' level.

At the ministerial level, seven specialists are in charge of conducting general assessments, and read and comment on EIA reports (MNET, 2009b). However, all mainly have biological backgrounds (Interview B3). As an EIA covers a wide range of issues relating to the ecological system in general and its components ${ }^{87}$, a lack of appropriate expertise has become one of the chief causes of poor quality EIAs. As one interviewee described it, ministerial experts do not have "universal" understanding (that is, capable of doing anything from any field) (Interview A6). Moreover, they are overwhelmed with work, given the continual increase in the number of EIA reports prepared each year (Interview B2, D4). Since the mid-

\footnotetext{
${ }^{87}$ Components of the ecological system are soil, landscape, water and biodiversity (The State Great Khural of Mongolia 1995, Article 3.1).
} 
2000s, the number dramatically increased, due to the rapid development of mining, infrastructure, tourism, and construction (MNET, 2008). The number of experts has not increased, but has remained constant or has been decreased due to tightened ministerial budgets (Interview B2, B3). Decentralisation policies, supported by the IMF and the World Bank, resulted in the government tightening ministerial budgets. The Public Sector Management and Finance Law (2002) required restructuring of the public sector, and the introduction of contractualbased financing, which aimed to improve the efficiency of public-sector organisations, cut unnecessary costs, and enhance effective public services (The State Great Khural of Mongolia, 2002b). However, the law is criticised for actually promoting budget centralisation, given that all budgets must be allocated through the State Fund (ADB, 2008). Due to a continually tightened budget, the MNET has undergone restructuring, budget cuts, and staff reductions (Interview B3). Thus, the few experts who are employed are overwhelmed (Johnova, 2004), which compromises potentially the quality of EIAs (Interview A5, B2).

The lack of expertise in EIA companies also contributes to poor quality EIAs. Nine interviewees agreed that EIA companies do not have experts who are proficient in EIAs and mining (Interview A4). As both EIAs and mining are new fields in Mongolia, specialised training is almost absent from degree programmes at universities (Interview F8). However, some experienced companies have better expertise and can conduct good quality EIAs (Interview A3, A4, A6). Some interviewees were critical that new EIA companies often have conflicts of interest and are under the "cover" of current/previous ministerial officials (Interview B7, F8). Such companies have been established to use the EIA as a money-making activity (Interview A2, A6, F10).

Another expertise related issue, raised by interviewees, is that EIA companies 'share' a few well-known scientists to satisfy legislative requirements. The law requires the use of experts in relevant fields, and a few popular academics are simultaneously hired by different EIA companies as permanent or contractual experts (Interview A5). By 2009, there were thirteen experts who worked for three to seven EIA companies (MNET, 2009a). Combining academic responsibilities 
with work commitments for many EIA companies by academics raises further questions about the quality of some EIA reports.

Some academics were criticised by NGO interviewees for being corrupt and for favouring mining companies. One observed that an EIA report prepared by a wellknown environmental science professor had devastating effects ${ }^{88}$ on the natural environment of one soum in Khentii aimag. NGO members met the professor and criticised his report. He acknowledged he was wrong and reported that fees promised by a mining company had motivated him to prepare a flawed EIA (Interview F5).

In spite of these problems relating to expertise, experts are considered the only valid party for EIAs. As EIAs are regarded as a scientific, technical tool and process, EIA reports are accepted as finished technical documents, rather than as outputs of scientific calculation and of stakeholder engagement. This can be found in the views of some interviewees: a public servant stated that "EIAs are conducted by experts of professional companies, so they should be correct" (Interview B2). Another interviewee stated that a general assessment clarified whether the impacts of a mining project were acceptable; if it recommended an EIA, it merely followed the recommendation; thus the EIA was correct and consistent with the general assessment (Interview B1). Mining companies pay experts to conduct EIAs and to follow EIA reports and monitoring plans once mining commences (Interview C1, C2). NGOs also assume that EIAs are conducted according to the law, and do not pay close attention, as they consider EIAs objective because they have been conducted by experts (Interview F8).

However, EIA constituents have begun to recognise that EIAs are not objective and correct. Most interviewees agreed that EIAs are poorly prepared or copied from each other and that their implementation and monitoring is not satisfactory. In particular, environmental NGOs understand that EIAs are important documents that affect mining operations (Interview F2, F5, F8). Thus, there are varying

\footnotetext{
${ }^{88}$ The EIA report was prepared for a gold mining project and concluded that there would be no negative impact by allowing mining along a river that has supported a surrounding fragile ecosystem for thousands of years.
} 
degrees of acceptance that EIA practice is problematic and ought to be problematised and closely scrutinised. This leads to the issue of the accessibility of non-experts in EIAs.

Currently, the engagement of non-experts is limited. According to the law, local governors and heads of Local Representative Khurals (LRK) should receive EIA reports and sign them if they approve (The State Great Khural of Mongolia, 1998). Some interviewees raised their poor performance, attributing it to the lack of expertise by local officials in EIAs. An NGO interviewee said that for local governors, EIAs were scientific documents and would be difficult to comprehend (Interview F2). They also lack professional support from the central government and related government organisations to perform their function well (Interview D6). Thus, poor quality EIAs can receive approval by local authorities without much scrutiny.

Interviewees acknowledged that it is important to consider local knowledge in EIAs. They argued that local people know their surrounding environment better than EIA experts based in the capital city, often substantial distances from local areas (Interview F3). Local people are also familiar with nomadic culture and knowledge, regarding environmental protection, from oral history traditions (Interview A2). Thus, their knowledge could serve as a valuable resource during EIA preparation and impact mitigation processes (Interview A5, B5). However, local input in EIAs is almost non-existent at present and will be discussed later under the fourth principle - public participation practice.

Most scientists work for EIA companies and make arguments based on a neoliberal view of supporting mining. However, there are also scientists, who voluntarily engage in NGO activities and help to prepare counter-arguments, using scientific research. An NGO interviewee provided an example when he made an argument opposing a gold mining company from operating along a river in Khentii aimag. The NGO had asked for the assistance of a scientist to explain an EIA report. The environmental scientist, a native of that area, agreed to help explain the content of the EIA and how its recommendations had been ignored in 
the actual mining operations. Using the scientist's conclusions, the NGO requested the Ministry to terminate the company's mining licence after the mining company had changed the river flow for mining use, resulting in environmental degradation and a dry river (Interview F5). Other NGOs also cooperated with a Japanese researcher, who concluded that poor mining was the main contributor of dry rivers in local regions (Interview F2, F3). Such examples demonstrate that there is ad hoc engagement of experts by NGOs in order to support the involvement of non-experts in EIAs. Although NGOs have not deliberately intended to participate in EIAs, they occasionally use them to make arguments opposing mining companies. However, NGOs acknowledged that they had not paid close attention or understood the importance of EIAs until 2008. Thus, in terms of Brown's (2009) framework, NGOs have begun to serve as bordercrossers among EIA constituents, using varying degrees of expertise and promoting non-expert engagement.

\section{b. Quality assurance}

Quality assurance of EIAs is problematic in Mongolia. Interviews and documents suggest a confidence that the quality of EIAs is inherently assured by EIA procedures and external monitoring by the SSIA. Figure 6 illustrates EIA procedures and outlines the quality assurance processes of the existing EIA framework. 
Figure 6. Quality assurance of the EIA

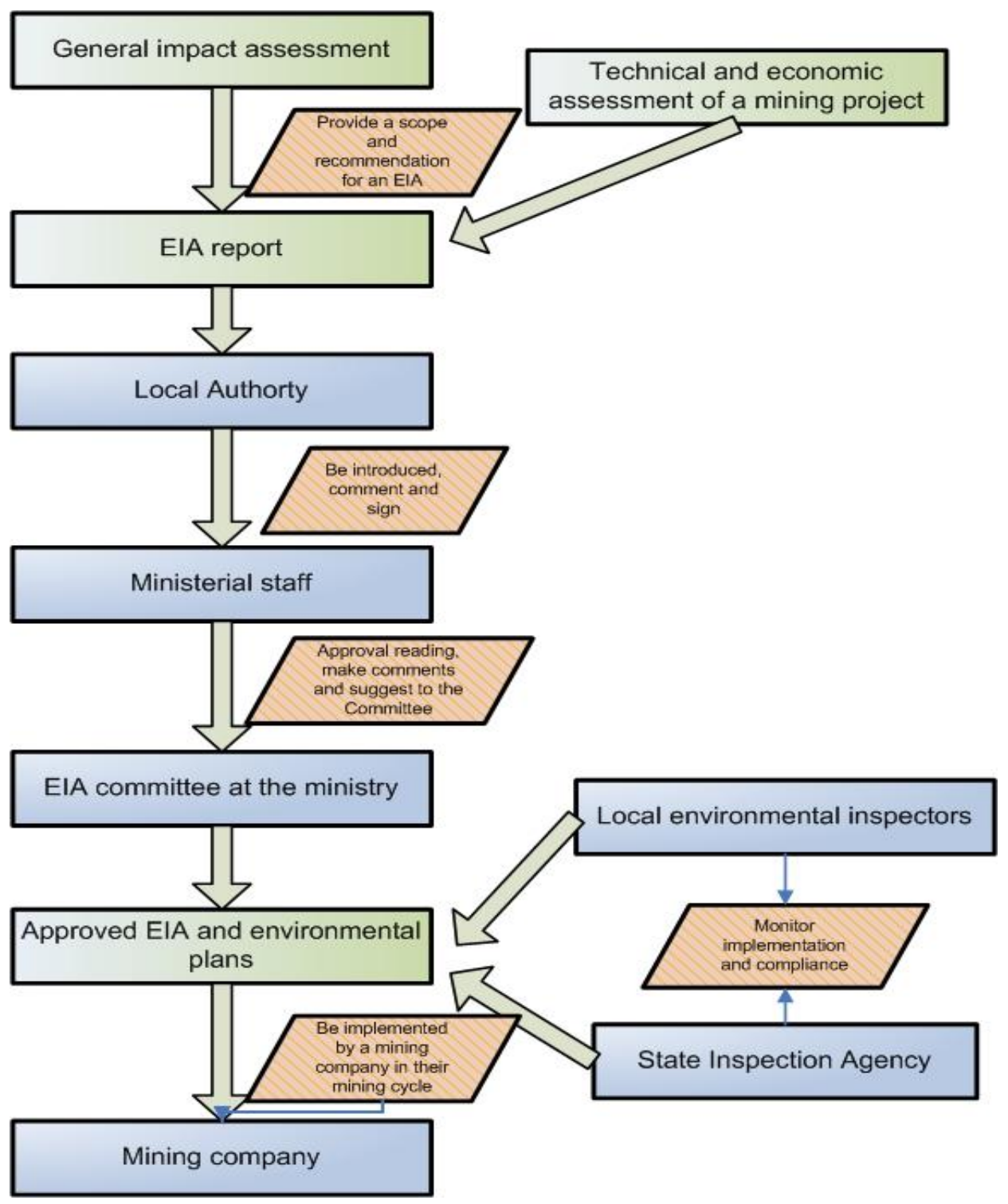

The MNET and SSIA are in charge of the legislative quality assurance mechanism. General assessors from the MNET conduct general assessments that define the scope of the EIA and provide recommendations for it. The EIA should be consistent with the general assessment, and this ensures that "EIA companies are not able to conduct an incorrect assessment" (Interview B1, 00:32:30-7). As Figure 6 shows, local authorities also engage in quality assurance by receiving EIA reports and making comments on them when signing. Once an EIA report is received by the MNET, EIA experts from the Ministry make comments on it, and then submit them to the EIA committee of the Ministry (MNET, 2006b). After this quality assurance process, the committee, consisting of EIA experts, 189 
academics and high-ranking ministerial officials makes approval or rejection decisions. On approval of EIAs, mining companies can commence their operations (The State Great Khural of Mongolia, 1997, Article 37). Environmental inspectors of local administrative bodies and inspectors of the SSIA monitor the implementation of EIAs (Interview B6). As indicated in Figure 6, mining companies are obliged to comply with the approved EIA and accompanied environmental plans (The State Great Khural of Mongolia 1995, Article 9). In the case of complaints and requests for independent reassessment, a special expert group appointed by the Ministry may conduct reassessment of an EIA and penalise a guilty EIA company if a report is found to be incorrect, resulting in environmental degradation (The State Great Khural of Mongolia, 1998, Article 12). As a public servant interviewee noted, there have in fact been no cases of reassessment or severe penalties for guilty EIA companies (Interview B3).

Although public officials, EIA companies, and mining interviewees were satisfied with this quality assurance mechanism, all interviewees agreed that the quality of EIAs is poor for various reasons. One NGO interviewee argued that the current environmental degradation is testimony to weak EIAs and their poor implementation (Interview F13).

At the ministerial level, it is possible that overworked EIA specialists approve poor quality reports. A public servant interviewee provided an example of the conflicts between EIAs and actual mining operations. The 40 mining projects along Selenge River ${ }^{89}$ had EIA reports that were conducted by well-known researchers of EIA companies. The EIA recommendations of the EIAs stated the area should be rehabilitated to the original state before mining. However, no rehabilitation has been carried out as stipulated in the EIAs. This was an example of how "some reports are approved even if they were wrong" (Interview B6, 00:15:25-0).

In terms of the inspection process, inspectors paid scant attention to EIAs until 2006 (Interview B5). Some interviewees were critical that inspectors did not

\footnotetext{
${ }^{89}$ Selenge is one of the three largest rivers in Mongolia.
} 
understand EIAs or their importance, and that inspectors were not sufficiently knowledgeable or competent at exercising their rights to penalise and close guilty EIA and mining companies (Interview A5). The lack of professional inspectors was also exacerbated by the constant changes of inspectors in local and central inspection organisations (Interview B5). Consequently, non-professional people, particularly in local areas, were often employed as inspectors (Interview A5) and were prone to corruption, which detracted from the reputation and credibility of inspectors (Interview F5).

The quality of EIAs relates directly to EIA companies. Most interviewees stated there are many EIA companies and instances where EIA reports have been copied from previous reports or from the reports of other EIA companies. An NGO interviewee claimed she saw a photocopied EIA of another mining company that still showed the name of the previous mining company (Interview F4). Another interviewee related a similar case:

We discovered an incorrect EIA report of a mining company that operates in the Gobi. The EIA was clearly copied as it suggested a rehabilitation plan prepared for a forestry area in the north. Of course, the EIA did not fit the circumstances of the mining company. It showed that the EIA was simply a copy of the previous EIA report conducted for a different mining project (Interview F2).

These cases indicate that expertise in conducting, approving and monitoring EIAs is deficient at all levels (Interview A4).

Besides EIA companies being non-professional, interviewees also criticised the preference of EIA companies for employing temporary or contractual specialists in order to reduce expenses. This negatively affected the quality of work. A mining interviewee complained that most EIA companies had a director and one or two experts (Interview C2). She said "they [EIA companies] are eager to have orders for EIAs and promise nice things to get a contract. But, they do not keep their promises regarding timeframe and quality of the EIAs" (Interview C2).

The location of EIA companies also attracted criticism. As all EIA companies are based in the capital city, they often do not conduct field-studies to gather evidence and local knowledge (Interview F4). An EIA interviewee stated that: 
To cut costs companies do not send their experts to local areas of proposed projects. Instead, they use similar cases or refer to books when preparing EIA reports. Therefore, it is not always a valid assessment ... and the quality of EIAs is poor' (Interview A1).

In terms of implementation, most mining companies were criticised for paying only scant attention to EIAs, regarding them, rather, as a document for a project's approval. Mining companies did not fully implement EIAs and kept them ready only for inspection by the SSIA (Interview A5). Some NGO interviewees commented that local people and NGOs required mining companies to show their EIAs, but were told that EIAs were either held in the capital city office or "locked in the boss's desk" (Interview F2, F4). According to the law, mining companies must keep EIAs on mining sites and implement them during the mining life cycle (The State Great Khural of Mongolia, 1998). With increased state inspection since 2006, mining companies have begun to understand the importance of EIAs (Interview C1).

In summary, the quality of EIAs is poor, and clearly needs improvements to all stages. Interviewees suggested it was crucial to have effective mechanisms for monitoring and that there was a need for greater penalties and accountability on the part of responsible parties (Interview A2, A5, F5). In short, there is a need for thorough investigation and improvement in how and by whom EIAs are conducted, approved, implemented and monitored.

\section{Recognise multiple ideological orientations:}

Similar to the lack of recognition of subjectivity, the existing EIA framework does not recognise the possibility of multiple ideological orientations among EIA constituents. Although the EIA is said to be "an outcome of collaboration" by ministerial experts, academics, and researchers of EIA companies (Interview B1), differences in perspectives are not considered or acknowledged.

The EIA is viewed as a technical assessment that provides technical or scientific "truths" of a given project (Interview A5): on one hand, a compulsory tool that should be undertaken at the outset of mining operations (Interview A1, A6, B2, 
B3); on the other hand, a process that must comply with the EIA methodology and related standards developed by the Ministry (Interview A1, B2). The underpinning ideologies and perspectives of EIA constituents are not recognised or questioned. Even if some NGO members criticise EIAs, their critiques are not considered valid, as local NGOs are often labelled as noise-makers, lacking scientific evidence. Thus, assessments and decisions by experts are considered as objective truths.

This may be a 'backlash' relating to a traditional Mongolian outlook. For Mongolians, to recognise different ideological orientations is a 'strange' matter. Two hundred years of colonialism under the Qing Dynasty and 70 years of communism, closely supervised by the USSR at every level of Mongolian society, have promoted a culture of state-worship, characterised by being "tolerant" (UNDP \& Government of Mongolia, 2006). This passivity has not changed radically during the democratic transition, with some interviewees emphasising that more time is required, possibly several generations, for change to occur (Interview D4, G1).

One difficulty of such "tolerance" is that it creates a widely held belief that difference and/or contestation is not a positive thing (Interview F8). The dominant ideology has penetrated every aspect of society and has promoted a technocratic approach by government organisations as the 'only, correct way' to deal with issues. The quality and subjectivity of EIAs conducted by experts are therefore not questioned, and are perceived as correct. This was evident from interviewees' responses as well as during various public debates in the press and on television programmes. Although the introduction of democracy and rapid development of information technology has opened people's minds and provided unprecedented information, people are still wary of new perspectives and views on alternative development agenda and proposals. As an NGO interviewee expressed matters: "The Mongolian attitude towards new things tends to be slow and negative" (Interview B1). It is not easy for people to recognise and accept different perspectives and views. However, all constituents can "learn by doing" (Interview F9). 


\section{Ensure effective participatory processes:}

This section examines public participation in the EIA and investigates whether existing participation is effective and meaningful. Four aspects will be discussed: participation practice, accessibility, the understandability of EIAs, and the inclusion of public comments.

\section{a. Effectiveness of public participation}

Due to the lack of previous research and statistics, information concerning public participation practice derives principally from interviews. As the EIA law amendment in 2001 mandated public participation, all interviewees said that local people should participate in the EIA preparation process. At the beginning of EIA preparation, an EIA company must introduce a mining project and its benefits to local people who live in proximity to the licensed area (Interview A3). Experts often use a survey and questionnaire to collect comments from local people (Interview A1, A3). A public 'town hall' meeting is also recommended by the regulation (MNET, 2006). Depending on the size of mining areas and mineral deposits, most EIA companies tend not to organise public meetings as they are costly and it is difficult to coordinate bringing local communities together.

However, since 2008 there have been some initiatives, particularly from international donor organisations and large mining companies. As South Gobi mining development is hugely important for the development of Mongolia, international organisations such as the World Bank have also introduced a benchmark impact assessment for the infrastructure strategy and have organised public meetings and training for local communities (World Bank, 2009). EIA companies conducting assessments for large mining projects, such as Oyu Tolgoi and Energy Resources, have organised public meetings among local communities of surrounding soums, so as to introduce mining projects and gather public comments on mining projects, local social development, cultural heritage management and other factors (Energy Resources LLC, 2011; Ivanhoe Mines Mongolia Inc., 2006). Thus, the public meeting, as a method of participation, has begun to be recognised by EIA companies. 
Once an EIA report is prepared, the EIA company presents it to the LRK, which consists of local representatives of the soum or aimag. Given there are only two scheduled meetings of LRK per year, most EIA companies are not able to have signatures from LRKs. Thus, EIAs are often introduced to and signed by the governor of a soum (Interview A3). The signature indicates a governor has read, commented, and approved the EIA (Interview B3). A number of interviewees, however, criticised this as being problematic and symbolic. They argued that governors are typically not capable of providing reasonable comment on EIA reports, given their poor understanding of mining and EIAs (Interview D6). They are also prone to being lobbied by mining interests and EIA companies for signature approval (Interview F2).

Interviewees offered different views on participation practice. Some viewed it as being relatively good and adequate, while others were critical. Most interviewees of government organisations, EIA and mining companies stated that participation is satisfactory as it meets the legislation and approval requirements of the EIA Committee. In 2006, the MNET established the EIA Committee in charge of the approval process for all EIA reports (MNET, 2006). Public participation is seen as one prerequisite of EIAs and the Committee requires that all EIAs should provide public ${ }^{90}$ meeting notes, signatures of participants, and the governor's approval signature as evidence (Interview B1). According to the law, mining companies have to pay costs of organising the public meeting (The State Great Khural of Mongolia, 1998, Article 7.4). An EIA company is also able to organise a public meeting to introduce the final EIA (The State Great Khural of Mongolia, 1998, Article 5.4.8); however, in practice, only a few reports have been presented to local communities, using a public meeting (Interview B3, 00:28:50-0).

Four interviewees from EIA companies suggested that public participation is currently adequate, as local people can comment through surveys and questionnaires developed by EIA companies (Interview A3). As an LRK is the highest legal representative organisation for a local administrative unit (The State

\footnotetext{
${ }^{90}$ Public refers to citizens who might be affected by the project (The State Great Khural of Mongolia, 1998).
} 
Great Khural of Mongolia, 1992), its meeting note and approval is regarded as satisfactory evidence of public participation (Interview B2, 00:11:51-5). All interviewees from mining companies also stated that the law was well implemented in terms of public participation. A mining manager said, "it is up to EIA companies on how to get public comments and organise participation" (Interview C2).

However, all interviewees of NGOs, international organisations, and researchers criticised participation practice as symbolic and almost non-existent in Mongolia. NGO interviewees and herders claimed that public comments were collected from those who favoured a mining project (Interview F2, 00:36:40-9). An interviewee of an NGO argued that there were many cases similar to Khongor soum, where a local governor gathered his relatives and then used their signatures as local meeting participants (Interview F8). Even the meeting of the LRK can be problematic, as some soum representatives are relatives of the governor, elected in corrupt local elections (Interview F8). This type of public meeting is not usually intended for a gathering of all affected people (Interview E1) that would include local NGOs with controversial views on mining (Interview A2, F2, 00:18:42-0).

Consistent with such an argument, a frequent criticism related to the representative power of participants. Many NGOs and herder interviewees argued that the people who are really affected are excluded from participation, and that those who participate in meetings are often not elected representatives. A herder reported that some people, close to the governor, had participated in meetings supposedly as representatives of mining affected herders (Interview E1, 00:29:144), and such people were unlikely to understand the situation of affected local people as they did not live in mining areas (Interview F13, 00:36:43-9). Such participants were not capable of representing the views of affected people, but their comments favoured the mining project (Interview F4). Such participation is "window-dressing with no benefits" or as the Mongolian proverb says: "Нүглийн нүдийг гурилаар хуурах” (Interview E1, 00:29:14-4). 
Even when meetings among affected people are held, they can be problematic, given the misinformation and bribery. Some interviewees reported that EIA companies often presented only positive facts about a mining project (Interview F7, 00:43:31-9); as most local areas had no experience of mining operations, local people were not aware of the possible environmental impacts, and they then say: 'no objection' (Interview D6, 00:26:43-7). In addition, mining companies can easily lobby local people, as most projects operate in remote areas, sparsely populated by herder families (Interview A4). In the case of a well-known Russian gold mining company, vodka and small gifts were given to local herders to gain their approval (Interview F10, 00:46:31-2). Such arguments show that even if public participation exists, it may only be symbolic (Interview D6).

Herders interviewed from two different regions affected by mining reported that they had not been informed of or invited to participate in EIAs. Mining and EIA companies had not informed them of the mining projects that would operate in their localities (Interview E2, 00:10:04-6). Herders only came to know about the mining after licences had been issued and projects begun (Interview F2). As EIAs are conducted "at the higher level", no one had listened to the views of ordinary herders (Interview E1, 00:06:38-3). They had no opportunity to see the EIAs (Interview E1, 00:04:34-1). Thus, herders are powerless in the face of mining companies, and some mining companies said shamelessly that "herders do not matter" (Interview E2, 00:02:59-3).

From the interview analysis, it became evident that various reasons for poor public participation exist. In terms of legislation, a number of interviewees criticised the lack of a legislative mechanism that would guarantee structured and productive public engagement in EIAs (Interview A2, D4). Some suspected this lack might reflect a lack of willingness to have public participation, as it might attract more controversy regarding projects (Interview F9, 00:33:25). As "there is no incentive or penalty for having or not having participation", certain public servants and EIA companies can determine whether to allow local communities to participate in EIAs (Interview F7, 00:14:53-7). 
Moreover, the existing EIA framework cannot ensure meaningful participation. An interviewee of an international organisation, seemingly 'amazed' at strange mining and EIA legislative systems in Mongolia, stated:

In most countries EIAs are done before the licence is issued. But in Mongolia the system is 'back-to-front'; mining companies can obtain mining licences before being required to carry out EIAs. As licences have already been granted, the system is counter-productive and EIA decisions have been pre-empted (Interview D1, 00:15:51-7).

As a consequence, public participation in EIAs is perceived as having no meaning or impact on poor mining practice (Interview B3, B5). The current EIA framework and system of issuing licences effectively discourage meaningful participation.

In terms of monitoring, no mechanism clearly defines the qualification of participation. The EIA approval committee is satisfied with meeting notes and signatures (Interview B1). Inspectors have no means or right to monitor it as they only do so after mining projects have already begun (Interview B6). Moreover, if companies have submitted all documents required by the law, inspectors cannot penalise them (Interview B5, 00:17:37-8 P2). Therefore, participation is dependent on EIA companies and the approval committee.

Interviewees mentioned other difficulties of participation, ranging from geographic isolation factors of Mongolia through to local people themselves. Mongolia has a large land area that is sparsely populated. In most instances, there might only be three to five families or no herders in proximity to licensed mining areas (Interview A5). Thus, it is easy for mining companies to make minor payments to local people, given the poor economic conditions of herders or to offer help for herders to move away from mining areas (Interview D5). Besides, herders are not usually resistant to mining projects in the steppes, as mining would probably occupy only five to ten percent of their pasture land (Interview A4). The situation is viewed differently if mining occurs near water resources, as water is the essential resource for the livelihood of herders (Interview A4, 00:11:35-1 P2). 
One of the greatest barriers to participation is local people, themselves. All interviewees agreed that local people should be better informed and knowledgeable so as to express their views and comments on mining projects and the associated social and environmental impacts. An unofficial public survey by an international donor NGO, conducted among 700 local people of six different soums, revealed that local people were not aware of the impacts of mining (Interview D6). Although local people supported public participation as "a right thing to have", they did not know "what participation is or how to participate" (Interview D6).

Given poor understanding about mining, local people are mostly either supportive or sometimes opposed to mining projects without being able to provide convincing arguments. People will often support a project and inquire mainly about the mining benefits for them and their local areas, through employment and investment in local hospitals and schools (Interview A1). However, local people will oppose mining projects if they are likely to affect their pasture, water resources and local heritage sites (Interview A4, A6, F4). Given uninformed licence issuing, local communities can become annoyed and protest against mining companies when they ultimately learn of mining licences after mining companies have asked them to leave their areas (Interview E1, F2, F4).

Poor participation is also related to a sense of powerlessness and lack of hope by local people. In many local areas, people are "powerless in the face of the state, as it is mainly outsiders who take local resources such as gold, timber, or whatever" (Interview D2). This is the consequence of endemic corruption and poor implementation of laws (Interview F3). Within the existing vertical decisionmaking system, local authorities are also powerless to influence decisions and licences made by central government organisations (Interview D2, F2, F3).

The combination of state-worship culture and selfish behaviour of Mongolians (UNDP \& Government of Mongolia, 2006) also contributes to poor participation. As an interviewee of an international organisation commented, "people have an attitude of being told and then acting" (Interview D3). Herders are indifferent 
about mining even if it occurs in their areas of pasture (Interview A4); they assume the local authority will take responsibility for their problems, so they do not make their views known (Interview E1). As Mongolians are accustomed to living individually, in separate places, they often do not have a chance to meet and discuss matters (Interview E1). Even if some herders discuss and oppose mining companies, and then seek compensation for the environmental impacts, others will suspect their motives if they have worked for or cooperated with local authorities to obtain benefits for their own interests (Interview E1). This may also be fuelled by a greedy, NIMBY (not in my backyard) attitude of people which "causes losses for all" (Interview F8, 00:52:23-5).

Interviewees of some mining and EIA companies contended that some herders resisted mining projects because of individual interests, and required mining companies to pay compensation for tuition fees for their children, etc., (Interview C2). But mining companies are not philanthropic organisations and cannot listen or take care of individual herders with diverse interests (Interview C3). An interviewee from a government organisation acknowledged that it was understandable "herders are more concerned with individual interests", given that most mining revenue and benefits went to the central government budget (Interview B7, 00:08:00-5 P5).

Another important factor in poor participation is the lack of knowledge about participation rights by local communities. As one EIA interviewee explained: "although public participation is a good thing from the classical democratic approach, participation practice is not so good, given our people's lack of knowledge" (Interview A1, 00:21:54-5). Many interviewees agreed that local people were not aware of their rights to express their views and participate in EIAs. As an interviewee of an international organisation said, "People don't know their rights to participate. Even if they know their rights, they don't know how to execute their rights" (Interview D3, 00:30:27-8). Low participation rates are also related to the court system. An NGO interviewee was critical that "according to the law, citizens do not have a right to sue guilty companies that conducted flawed EIAs; only the governor does' (Interview F8, 00:33:59-7). To overcome such 
problems, a number of interviewees suggested that local people needed to be better informed and educated about public participation, and that governance be improved (Interview A1, B4, D4, D5). Moreover, locals needed to become knowledgeable about mining, its technology, potential impacts and consequences (Interview D5, 00:23:31).

\section{b. Accessible EIA reports}

Accessibility of EIA reports is another major factor contributing to poor participation. Although laws on Environmental Protection and EIA have separate articles requiring a database, including EIAs (The State Great Khural of Mongolia 1995, Article 39), access to information is not implemented in practice (Interview A4). The Ministry has a project funded by the World Bank to create a website that enables the public to see most parts of EIA reports and environmental protection plans (Interview B1). The EIA database was launched at the end of 2010. It includes 1987 general assessments since July 2005, and 629 detailed EIAs of mining projects since 1998. However, it is designed to see only outlines of general assessment recommendations and environmental protection and monitoring plans (MNET, 2010). One cannot see detailed EIA reports of individual projects.

Interviewees had conflicting views on the accessibility of EIAs. Some from government organisations and EIA companies commented that EIAs were available for interested parties (Interview B2, 00:13:14-7), but most NGO interviewees argued that EIA reports were not accessible for anyone, especially the public (Interview F2, 00:36:19-2).

One reason for the non-accessibility is the assumption of secrecy at the ministerial level and by mining companies. Poor accessibility is fuelled by the state-secrecy mindset that remains from the old communist regime, which results in a lack of willingness by power-holders to make information available to the public (Interview D1, 00:33:35-8). In government organisations, almost every document is considered secret, and public servants are not willing to show interested parties even although the law stipulates access to information. It is a classic 'old habits 
die hard' situation in many post-communist countries (Toth, 2010, p.198), and can be evidenced in the arguments of various interviewees.

Government servants and EIA companies see EIAs as secret documents, as they contain some business information (Interview A1, B1). Ministerial officials are not keen to open up EIAs (Interview B2). One NGO interviewee claimed that ordinary people and NGOs could not see reports and might only have the chance to see EIAs on receipt of an official written request by a legal entity (Interview F2). Another reported they had found the English version of an EIA report and attempted to translate it into Mongolian, as they could not find the report in Mongolian (Interview F12, 00:12:49-9 P2). A third NGO interviewee argued that even some government officials could not see EIAs, as many powerful elites had their own mining companies, and therefore had no interest in disclosing information (Interview F8). As mentioned in Chapter 6, I personally experienced difficulty in accessing EIAs and failed to see them, even when I had followed the official procedure.

Mining companies also contribute to the secrecy of EIAs. They keep reports under their desk as secret documents, showing them to inspectors only when required (Interview A5). Some local inspectors claimed that even they could not see EIAs, as mining companies did not provide reports to them (Interview F7, 00:44:43-7). Therefore, it is understandable that it is even more difficult for local people to see EIAs. In fact, local people are rarely interested in EIAs (Interview E1) as they have little understanding and no expert knowledge about mining and EIAs (Interview A4); they assume that EIAs are only for the use of professional people (Interview F3).

\section{c. Understandable EIA reports}

Interviewees expressed contradictory views on the understandability of EIAs. Some interviewees of mining companies and government organisations did not assign much importance on this issue. They considered that EIA reports were understandable. As an interviewee from the Ministry explained: "as EIAs are written in Mongolian mother language they should be understandable for the 
public; and they [ministerial staff] approve EIAs because they think EIA reports are understandable" (Interview B2, 00:13:37-1).

However, most interviewees of NGOs, international organisations and herders agreed that EIAs are neither accessible nor understandable to local people. An NGO member shared her experience of finding an EIA report after lobbying a higher-ranking Ministry official and secretly viewing the report. She said the EIA was "a thick document full of numbers, and would have been barely understandable for ordinary people" (Interview F8, 01:01:40-5). Another interviewee supported this, commenting that EIAs include a lot of professional jargon and "the language is so professional that ordinary herders are too uneducated to understand it" (Interview F3, 00:54:28-6).

\section{d. Consideration of public comments in EIAs}

Interviewees were critical that it is unclear how EIA companies decide on which public comments to include in EIAs. Two controversial statements were made: on the one hand, interviewees of NGOs, international organisations, researchers, and some public servants argued there is neither a mechanism for ensuring inclusive EIA reports (Interview F9, 00:35:28), nor are comments necessarily included in the final EIAs (Interview F2). On the other hand, some EIA specialists, public servants, and mining interviewees said that as the EIA is a professional assessment, there was no need to engage people without expertise (Interview C2). Another argument opposing the inclusion of non-experts in EIAs concerned local people: an interviewee of a mining company claimed that local people sometimes provided positive comments (supporting a project), then later made complaints (Interview C3), which suggested they either made comments without understanding a mining project or they had a conflict of interest once the project began (Interview B7, 00:05:58-0 P4).

In summary, public participation in EIAs is symbolic because of various issues, relating not only to EIA constituents, institutional capacity, and legislation, but also to constraints on access to information, the language of EIAs, and inclusion of public comments in final EIAs. Thus, symbolic participation contributes to 
poor quality EIAs and mining, resulting sometimes in debates and demonstrations by unheard local voices and misinformation.

\section{Be attentive to power relations:}

Power relations and imbalance also contribute to poor public participation. Based on interviews, documents, and field notes, Figure 7 illustrates the complexity of power relations in the EIA. However, it should be acknowledged that these relationships are not as simplistic as depicted; rather, they are deeply interrelated among various EIA constituents.

Figure 7. Power relations and issues among EIA constituents

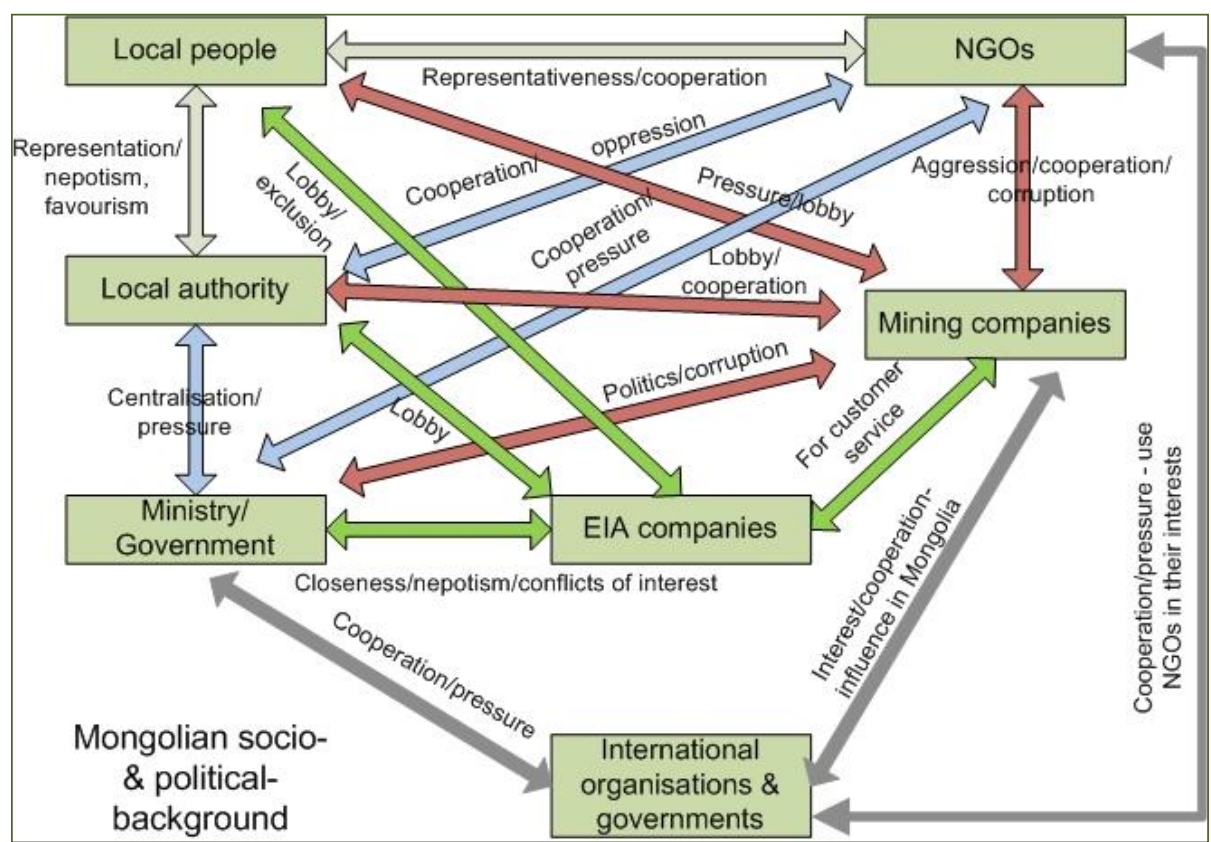

For local people, public participation is limited due to power imbalances within and between local people themselves, local authorities, and EIA and mining companies. People with different values, interests and backgrounds behave differently when it comes to issues such as mining development and environmental issues. They also have varying degrees of 'political' acumen, experience, and skills with which to engage in EIAs. For herders who are unaware of mining and its associated environmental issues, they have difficulties understanding the issues of mining and the need to protect their constitutional rights to live in safe and healthy environments (Interview A1, D3). 
On the one hand, local people are often not sufficiently vocal during meetings so as to express their views regarding mining and environmental issues (Interview D6); on the other hand, even if some herders particularly affected by mining operations express views, they can later encounter problems from their communities, local authorities, and mining companies. As noted in discussion of the problems of participation, herders are suspected of having conflicts of interest and are regarded as opportunists who can accept benefits from mining companies (Interview E1). Or they can be punished, like the herder who demonstrated against mining and later claimed he was sent to a local jail for 10 days (interview, E1). Local authorities and mining companies tend to ignore herders (Interview E1, E2).

Thus, Figure 7 illustrates that local people are under much pressure. As well as problems within local communities, some issues for herders are generated by other EIA constituents, ranging from being lobbied by mining and EIA companies to being excluded from decisions without being informed and excluded from participation and compensation even when decisions impact on their lives. Therefore, local people are often powerless in the face of other EIA constituents (Interview D2, E1, E3, F2).

For local authorities, their limited roles in decision-making and the distribution of mining benefits may contribute to weak public participation. As Mongolia still has a vertical decision-making system, as in the previous regime (Interview F3), all licences and EIA related decisions are made by central government organisations (Interview F2). For example, Article 19.4 of the Mineral Law allows local authorities to comment on the approval or rejection of mining licences. However, the legal requirement of 30 days (The State Great Khural of Mongolia, 1997, Article 19.4) is not long enough, given poor postal services and transportation in local regions, to enable feed-back to the Mineral Authority, which is located in the capital city (Interview F2). "No comment within 30 days" is automatically considered a sign of approval for mining licences (Interview A5). Moreover, local authorities are also legally limited to rejecting mining licences except if they can register certain areas for special local use (The State Great Khural of Mongolia, 1997, Article 17) that is restricted to reserve grass for the winter preparation of 
herding animals. Thus, local authorities have only limited powers for influencing the issue of licences (Suzuki, 2008).

In spite of a lack of financial and human capacity, local governors are expected to perform various functions regarding EIAs. They are often in charge of presenting final EIAs, organising public meetings with EIA companies where necessary, and providing their comments and signature for approval. As an interviewee stated:

They [local governors] are also under great pressure from mining companies for approval, from their MPs, and from communities for the jobs. But governors need to perform as they are supposed to know about mining when there are no local experts, information, or educational assistance from the government (Interview D6, 00:43:37-1).

Moreover, low salary, poor economic conditions and the lack of an adequate accountability mechanism might influence local governors to choose an easy option: to accept 'offers' from mining and EIA companies, and to sign EIAs without thorough consideration (Interview A1, D2).

Budget centralisation is another sign of the lack of power by local authorities. According to the Minerals Law, 10 percent of royalties and 25 percent of licence fee revenue go to the soum budget, 20 percent of royalties and 25 percent of licence fees to the aimag budget, and 70 percent of royalties and 50 percent of licence fees goes to the central government budget (The State Great Khural of Mongolia, 1997, Article 58). As most tax revenue go to the central government budget, local regions receive few economic benefits from mining in their areas (Interview B7). This also creates incentives for local communities and governors to be vulnerable to bribery and to prefer 'in kind' contributions from mining companies (Interview C1). It would be better to give authority to local government to use a portion of the tax revenue, so they would have more incentive to care for the natural environment (Interview F10, 00:12:38-9). However, this argument caused some controversy among interviewees.

A number of interviewees criticised the representative powers of local governors and LRKs, and the possibilities of their being lobbied and of being corrupt. Although the EIA law states that local people can express their views through their 
representatives in EIAs, practice shows it is not always the case, as some local administrative bodies are elected through corrupt elections, and they have "privatised" LRKs and soum governors for their interests (Interview F8, F10). One NGO interviewee provided an example of Khongor soum's local representatives, who were the parents, relatives, and son of the governor (Interview F8, 00:41:444). This kind of evidence is provided to argue that local elections are problematic and corrupt (Interview F2).

As well, local governors have conflicts of interest in mining matters. A mining interviewee said that local governors see mining companies as philanthropic organisations and require them to donate money for soum anniversaries etc. (Interview C3, 00:12:00-3). Another mining interviewee claimed that:

When governors introduce EIAs and other reports they ask to meet directors of the mining companies, saying they need to discuss issues. Directors then lobby or bribe them (Interview C1, 00:27:58-7).

In most cases, it is not clear how much mining companies pay local governors in the name of local development, as this kind of information is not disclosed to central government, local communities and other mining constituents. Therefore, some initiatives, such as the Extractive Industry Transparency Initiative, encourage mining companies to "declare what they pay" to local authorities and government organisations (Consortium of Hart Nurse Ltd and Ulaanbaatar Audit Corporations Ltd, 2010).

In terms of the Ministry in Charge of the Natural Environment, there are various issues relating to its main functions and capacity. A number of interviewees were critical that the MNET has no monitoring function. An interviewee of a government organisation argued that "unlike some other ministries with a producing function, the MNET has a protective function" (Interview B2, 00:09:27-7). Transferring the monitoring function from the Ministry to the SSIA has resulted in a lack of ministerial power to monitor environmental matters (Interview B1, B2, B5). If the MNET were allowed to monitor EIAs, it could improve implementation of the law (Interview B1). 
Although the intention of separating decision-making and monitoring functions might be desirable, the cooperation between MNET and SSIA is lacking (Interview D7). In fact, government organisations tend to "reject" each other (Interview A1). Poor coordination and cooperation is evident from information they provide. An NGO interviewee said that the MNET, the Ministry of Mining and Petroleum, and the SSIA provided three different statistics for rehabilitated land (Interview F12, 00:19:56-8). If central government organisations had proper liaison, there would be no issue concerning "poor coordination and information flows between the central government organisations and local authorities" that cause misunderstandings, conflict and bureaucracy for mining companies (Interview C3).

Another common problem for all government organisations is that after each election there are constant changes to their human resources. As the Mongolian corruption assessment reports:

Unofficial estimates maintain that as many as 60 percent of all government staff, including civil service employees, were terminated and replaced after the parliamentary elections of 1996 and 2000, when the party in power changed (USAID, 2005, p. 12).

In spite of gradual improvement, the situation still exists in current government organisations and this is supported by interviewees. Due to the deep penetration of political parties and MPs in executive functions (Interview B7, 00:10:30-5 P4), "ministerial staff could not be retained, and were fired/hired after each new minister depending on their political parties" (Interview A1, 00:11:22-8). Moreover, appointments of higher-ranking officials are not based on merit (Interview A5) but, rather, on their political contribution or closeness to leading political parties and leaders. Politicisation leads to political patronage, political appointments and nepotism in the public sector (Interview D1). Thus, the public service has become "a political game" (Interview D8, 00:03:43-9 P3). This system leverages "officials to make symbolic decisions in favour of their own interests, rather than leveraging them to make good decisions for the public" (Interview F9, 00:30:50). 
Some interviewees claimed that the Ministry has become the "ministry of environmental destruction", rather than "environmental protection" (Interview F2). Two NGO interviewees argued that Mongolian "ecology is a victim of politics" (Interview F4, F8). Even in parliament, MPs, particularly business-MPs whose interests are not "always in the best interests of the public" (Interview D1) have a lack of political will to form and pass effective legislation and regulations on environmental matters, such as the environmental destruction assessment, EIA amendments and compensation for mining affected people and regions (Interview A5). A project manager interviewee contended that legislation on the ecological destruction assessment has taken a decade to be passed by the parliament because of this lack of political will (Interview D5). These arguments indicate that environmental issues are politically sensitive and that there is "too much politicisation" (Interview A5). The Ministry is under great pressure from mining companies, business and political power groups, international governments and donor organisations. These groups lobby or put pressure on ministerial officials in various ways, as evidenced by media coverage, public debates on television and in newspapers, parliamentary debates among MPs, and public rumour on the street.

Moreover, accountability was a critical issue addressed by twelve interviewees. Being one of the principal players in environmental issues, the government and its organisations should be accountable to society. As an international organisation interviewee explained:

The law is not just about holding somebody else accountable. It is about setting a framework which applies to everybody including the government. Until that is really understood and implemented, you will continue to see strange decisions coming out of these ministries (Interview D1, 00:43:04-8).

However, at the moment there is no accountability mechanism, particularly for higher level officials and politicians. An NGO interviewee was critical that there is "no value is placed on honesty or a mechanism that guarantees accountability". She considered that "politicisation, corruption and nepotism... allow officials to protect each other from being accountable" (Interview F4, 00:26:50-4 P2). Thus, no one is responsible in Mongolia (Interview A4, Part 6). Responsibility is passed to another, without acknowledging their responsibilities (Interview F2, 00:12:58). 
One EIA interviewee asserted:

As a result, the EIA report has become a 'symbolic document', as all parties lack accountability and a proper system of penalties. EIA companies do not know how to conduct an EIA. Mining companies pay only scant attention to implement EIA recommendations. Ministerial staff and inspectors do not know how to ensure the quality of EIAs (Interview A5, 00:21:52-3).

Arguably, accountability for environmental matters is important and everyone needs to understand that "harming the natural environment means harming the future of our children" (Interview D5, 00:08:11-1).

The close connection of ministerial officials and EIA companies is a further issue that creates power imbalances among EIA constituents. According to the law, an EIA company should be an independent business entity (The State Great Khural of Mongolia, 1998). However, most interviewees argued that nepotism and corruption is widespread among EIA companies due to their close connections with ministerial officials (Interview A6, 00:01:22-4 P3). As an interviewee of a government organisation commented, the EIA has been regarded as a moneymaking activity for ministerial officials, particularly until 2006 (Interview A2, 00:37:45-3.).

Public officials and their friends or relatives established many EIA companies 83 licensed companies in total (Interview F9, 00:30:50). Some EIA interviewees complained that "in most cases, large EIA reports are conducted by their [ministerial officials] own EIA companies and accepted by their own people in the MNET" (Interview A1, 00:37:53-5). An NGO interviewee supported this and argued that "ministerial EIA experts receive EIAs carried out by their companies. So, it is clear that decisions will be made in favour of their interests" (Interview F9, 00:32:08). Another interviewee gave an example of a case where "a son has a mining company and his father owns an EIA company" (Interview F8, 00:36:03$\underline{6})$. 
Closeness to the Ministry results in easy approvals, weak monitoring and poor accountability for guilty EIA companies (Interview A2). As an EIA interviewee noted:

Some EIA companies produce 157 EIA reports per year. As it usually takes at least two months to prepare one report, this example shows that EIAs have been low quality or copied from previous reports (Interview A1, 00:06:41-6).

This situation undermines the reputation of EIA companies as professional, independent entities. It also contributes to further conflicts of interest among public servants and leverages them to use their positions and networks for individual gain.

In terms of EIA companies, some interviewees of EIA companies complained about the lack of ministerial support. The Ministry sees them as business entities and claims that "it is the duty and issue of EIA companies to improve their own capacity building, either through their association or in other ways" (Interview B2, 00:07:27-2 P2). Alternatively, an EIA interviewee argued that EIA companies are research institutions as well, but do not receive government support in this respect (Interview A1, 00:30:13-7).

Weak EIA companies, in turn, have produced poor quality EIA reports and work in favour of their customers - mining companies (Interview B3, 00:20:23-9). Thus, professional ethics, reputation and quality of EIA experts are at stake. In this environment, it is very difficult for EIA companies to balance being both a business entity and a professional research institution (Interview A1) without being lobbied (Interview A2, 00:32:54-4). Most interviewees, even ministerial staff, acknowledged that many EIA companies tended to favour mining companies by promising to approve EIAs (Interview B7, 00:04:25-5 P4). An interviewee of a mining company explained: "as mining companies pay money, EIA companies usually conduct EIAs in favour of mining companies" (Interview C2, 00:06:23-0 P2). And it is an "understandable logic" (Interview C1, 01:01:067). An NGO interviewee gave an example of one mining-biased EIA report that did not make mention of endangered plants in the local area where the mining project would operate (Interview F7, 00:43:31-9). This type of "customer-service 
focus" produces poor quality EIAs that have been prepared for monetary gain (Interview A4, 00:06 P5).

Regarding mining companies, there are problems, such as mining becoming a political issue, prone to public debate, and that it is becoming difficult to operate honestly when government organisations and local governors are corrupt (USAID, 2005; World Bank, 2007). However, mining companies usually have more power compared with other EIA constituents. Large foreign and domestic mining companies in particular can influence policies and decisions through business and political leaders, their professional interest groups ${ }^{91}$, international governments, and donor organisations. Mining companies lobby MPs, the government, and ministerial officials, and place pressure on them to have officials make favourable decisions. This has often been criticised among NGOs, activists, the public and media since the late $1990 \mathrm{~s}$.

Due to endemic corruption, mining companies have become both contributors and victims of public-sector corruption. On the one hand, NGO interviewees argued that mining companies bribe policy makers and public servants either to gain approval or to accelerate approval processes for mining projects (Interview F1, F2). On the other hand, mining interviewees claimed it was difficult for mining companies to operate in a corrupt country "as everyone sees mining companies as 'rich', and therefore wants more" either by bribery or philanthropy (Interview C1, C3).

Figure 7.3 also shows that international donor organisations have great influence on most EIA constituents. Interviewees, particularly NGO members, were critical of large international interests in Mongolian mining and the pressure of international organisations on the government and civil society. They asserted that the World Bank, IMF, and other international donor organisations forced the government to build an infrastructure for transnational companies (Interview F1). These organisations usually claimed they were helping LDCs to develop the right structure for development, which is generally interpreted as helping to attract

\footnotetext{
${ }^{91}$ Such as mining related associations and lobby groups
} 
more foreign investment to contribute to economic growth (Interview F10). Large international mining companies and governments also have interests in large coal, copper, and uranium deposits, and thus place pressure on or endeavour to lobby the main political parties, public officials, and the Mongolian government (Interview F8, F10). Some also argued that international donor organisations use $\mathrm{NGOs}^{92}$ to deeply implant their ideas in society (Interview F1).

Based on interviewees' arguments and document analysis, the following figure has been developed to illustrate the dangers of social and political issues that create increased power imbalances among EIA constituents.

Figure 8. Mongolian social and political context

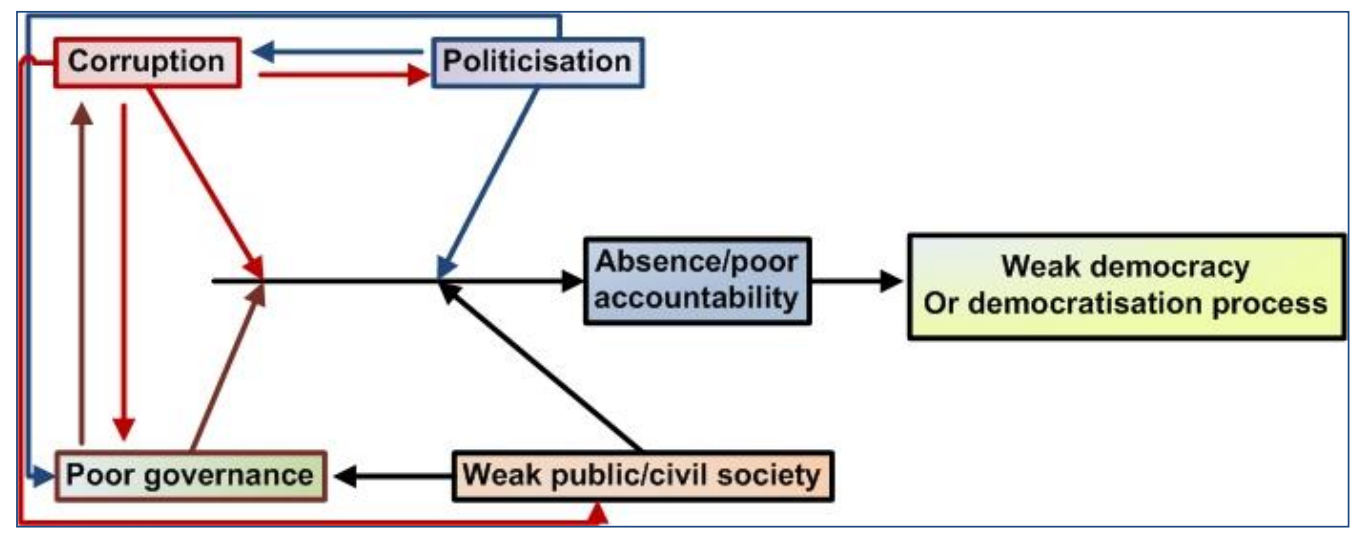

Figure 8 shows that poor governance, politicisation, corruption and weak public/civil society are both causes and consequences of each other. More seriously, they lead to poor accountability and weak democracy that have become serious barriers to the Mongolian social and political pursuit of democracy (UNDP \& Government of Mongolia, 2006).

Poor governance, ineffective institutions, legislation, and a politicised public sector provide a 'fertile' environment for corruption. Endemic corruption in the public sector can be seen by the comparison of the average salaries of public servants and their personal expenses ${ }^{93}$ (Interview F10). According to the corruption assessment, the most corrupt government organisations are customs,

${ }_{93}^{92}$ NGO related arguments will be discussed in Chapter 8 in more detail.

93 An average salary in the public sector ranges from NZ\$300 to NZ\$600 per month (approximately). But anecdotal evidence suggests many public servants have luxurious apartments, cars and expensive personal assets that cost thousands of dollars. 
tax, and inspection offices (USAID, 2005, p.20), all considered the most desirable organisations in which to be employed. An NGO interviewee complained that society accepts this situation without much questioning (Interview F10, 00:38:039). Social tolerance of corruption is very dangerous and makes democracy fragile "in the face of powerful internal and external challenges and shocks, in particular those associated with the current resource boom" (Fritz, 2008, p. 786). It also worsens power imbalances in society and results in the hopeless situation of EIAs, in which local communities feel powerless about decisions that have a profound impact on their lives. This was evident from interviews with herders, NGO members, and the voices of ordinary people on the street.

Corruption, politicisation, and poor governance go hand-in-hand, making their causes and consequences difficult to distinguish. However, the clear outcomes are the absence of accountability, widespread mistrust, opportunism, and nepotism at all levels of society. They ultimately affect EIA constituents and prevent meaningful participation and effective EIAs.

6. Recognise the transformative potential of dialogic accounting and resist new forms of monologism:

Based on data analysis outlined in previous principles, it can be asserted that existing EIAs are not dialogic. The EIA is a decision-making process carried out by the Ministry, EIA companies, and mining companies. It is a vertical decisionmaking system without the interaction of all interested parties. Thus, the EIA is seen as a compliance process of the environmental protection policy (Interview B2). In spite of some degree of participation by local people, EIAs are neither open to interested parties nor able to prevent mining-related negative impacts on the natural environment and society.

However, there are some initiatives that encourage dialogue among different stakeholders. Multi-stakeholder engagement in mining and environmental issues has been increasingly welcomed by policy-makers, from civil society and private sectors, with varying degrees of supervision from international donor organisations, such as the World Bank, UNDP, and the Asia Foundation. 
One example of such initiatives is the Asia Foundation (TAF) - a donor organisation which aims to address poverty, mining development, and corruption in Mongolia (Darling, 2009). It has organised a number of forums and meetings among mining constituents to promote dialogue for information-sharing and knowledge generation concerning mining. Dialogue among different mining constituents with conflicting views can be "quite adversarial and argumentative" as "a lot of aggression and fear" is caused by a lack of knowledge and information about mining (Interview D6). Through seminars and training in local areas, TAF noticed that the old monologue style of meetings has begun to change, as people gradually learn to engage in dialogue by talking and listening to each other (Interview D6, 00:54:22-5).

In this process it is challenging to overcome the long-standing mistrust among mining constituents and the lack of any tradition of active public engagement in decision-making. Through numerous forums and public debates in the press and media, all parties have gradually understood the importance and benefit of engagement in major developmental projects and environmental issues. This can be evidenced by the last five years of social debates and forums on developing large mining projects, such as Oyu Tolgoi copper mining and Tavan Tolgoi coal mining.

As current EIAs are not dialogic, the principle of "resist[ing] new forms of monologism" is not necessarily relevant at the moment. However, if the EIA framework and its progress to date are investigated, this principle can be related to the status quo. After its trial introduction by the ADB in 1992, the EIA framework became the main environmental management tool after the EIA law (1998). The law established a solid basis for the EIA, and its amendments in 2001 promoted public participation in EIAs. However, interviewees argued that the EIA law does not provide a clear mechanism for public participation (Interview A2, A5, D4, F9). As the importance of participation is not recognised, participation in EIAs has become a 'symbolic' prerequisite of the EIA Committee for the approval process. For the last three years the government has proposed a new amendment bill, which has been discussed among EIA constituents, including environmental and 
human-rights NGOs (Interview F2, F7). The bill attempts to improve existing participatory practice by defining a participatory mechanism (Interview A5). It proposes two separate articles on informing the public and for receiving public comments, and requires the MNET to provide accessible, full EIAs, and to consider public comments in final EIAs (The State Great Khural of Mongolia, 2008).

In summary, existing EIAs are monologic - they are expert-oriented, technocratic, environmental management tools that provide compulsory documents for mining project approval. EIAs are heavily dependent on vertical decision-making that lacks free information flows and open, fair interactions among EIA constituents.

\subsection{The potential of dialogic EIAs}

\subsubsection{Deficiencies of monologic EIAs}

In spite of initial goals for proposing changes in developmental decisions that could consider environmental and social consequences, EIAs have not produced the necessary 'revolutionary transition' in decision-making. From both the EIA literature review in Chapter 3 and Mongolian practice explored above, it is evident that EIAs have become a formal assessment process for project approval. As has happened in other LDCs, Mongolia uncritically imported its EIA legislation (Kolhoff, et al., 2009). There is a lack of awareness and capacity among EIA constituents and the lack of a clear implementation mechanism that could ensure realisation of the potential benefits of EIAs. Mongolian EIA practice for mining projects supports the criticism of Jay et al. (2007) that EIAs have become a "decision-aiding tool" rather than a "decision-making tool" as initially proposed (p. 293).

A monologic EIA falls short of addressing realities and of being value-neutral and apolitical, as proponents claim. As in monologic accounting (Brown, 2009), monologic EIAs do not have the ability to reflect and address social and environmental realities or the complexities of proposed mining projects. Arguably, the EIA needs to confront subjectivity and explicit value judgements if it is to be a 
management tool that can protect against the adverse environmental impacts of development projects (Cashmore, 2004; Jay, et al., 2007). Environmental damage respects "no political boundaries", negative impacts may take many years to manifest, and such damage is prohibitively expensive to rectify in either economic or social terms (Toth, 2010).

The monologic EIA is technocratic and claims to be value-neutral and apolitical. However, advocates of technocracy argue that depoliticisation of decision-making can ensure value-neutrality and objective assessment (Wilson, 2006, p. 53). The basic assumption is that decision-makers make decisions when pursuing the public good, even in the absence of broad based participation (O'Faircheallaigh, 2010).

However, Curran and Hollander (2008) argue that the arguments of technocrats for value neutrality and the apolitical natures of EIAs are not valid as they "can be dominated by project proponents, consultants on their payroll, government agencies that are subject to 'capture' by proponents, and politicians intent on promoting short-term economic growth to boost their electoral prospects" (Curran \& Hollander, 2008). This situation is particularly relevant to LDCs with weak governance and accountability, a lack of institutional and human capacities, and endemic corruption (Cherp, 2001; Kakonge, 1998).

The analyses of interviews and documents suggest that Mongolian EIAs are neither value-neutral nor apolitical. EIAs are political and often favour project proponents' interests (Interview A4, F2). Moreover, decision-makers act within their political arena. They are often under pressure from the government, politicians, international donor organisations and international investors (Interview A4, A6, B3, D2, D5, F1, F7). They make decisions in the name of development, where development projects may "conflict with environmental and public health concerns", and "reward elected politicians for short-term results" (Toth, 2010, p. 297).

Technocratic EIAs supported by the existing framework and institutions result in expert-oriented reports. These reports provide decision-makers with a 'protective 
shell' from interested parties, including the more critical voices of NGOs and local people. By being privileged with scientifically 'objective' evidence, technocracy forces EIA constituents to reduce a wide range of political, economic, and social demands and discontent into arguments that can be evaluated based on their "scientific validity" (Lockie, et al., 2008). This is supported by Mongolian EIA practice and shows that the validity requirements of EIAs monologise decision-making, with the exclusion of 'others' as non-valid. This was obvious from some interviews with public servants, EIA and mining companies, and donor organisations; they were critical of having other voices from environmental NGOs and activist locals in EIAs, calling them noise-makers, and criticising them as unprofessional and lacking scientific evidence, and also having conflicts of interest (Interview A6, C2, D1, D6).

Thus, the technocratic EIA is non-democratic, given its monologism, excludes 'others' and is privileged with experts as the dominant group in decision-making. There is little room in EIAs for democracy or the pluralism of different perspectives with consideration of local knowledge. In terms of providing meaningful participation, monologic EIAs are deficient.

Although public participation is possible in the existing legislative framework (Interviewees A1, A5, B2), practice shows that it is symbolic. In practice, affected communities are excluded from EIAs due to non-accessible reports written in "professional language" for only expert use (Interview A5, E1, F3), which effectively alienates non-experts from EIAs, and "keep[s] out any critical voice in the decision-making process" (Menon \& Kohli, 2008, p. 17). Some NGO interviewees acknowledged this, arguing that mining and EIA companies exclude affected local people and only include people who are in favour of mining projects (Interview F1, F2, F4, A4). In addition, these companies misinform local people for the purpose of obtaining positive comments or they lobby or threaten environmental NGOs and local people so as to silence critical views on mining (Interview F4, F8, E1). Thus public participation in Mongolia is primarily "symbolic" (Interview F8). 
Contradictory statements on participation confirm that symbolic participation is not effective or meaningful. Interviewees from NGOs, international organisations, some EIA companies and government organisations acknowledged that current participation is inadequate for addressing the ever increasing mining-related environmental and social issues in Mongolia. Conducting the EIA after the mining licence is issued has resulted in the EIA becoming a "check-and-tick" activity for approval of a mining project. Thus the EIA system itself is "counter-productive" for promoting participation (Interview D1). This supports Wilson's (2006) argument that EIA participation is "co-opted for the purposes of technocratic management", and "domesticated away from its radical roots" by "focusing on getting the techniques right while avoiding consideration of power and politics as divisive and obstructive" (Wilson, 2006, pp. 507-508). Mongolian EIA practice shows that participation is minimal and has become a bare prerequisite for the necessary evidence that is incorporated in EIAs to obtain approval from the EIA Committee.

This symbolic participation has become regarded as a "useless" process for local people to influence the outcomes of mining projects (Interview B5). Lack of hope can only result in further non-participation in EIAs, as evidenced in countries such as Peru, where affected local people began to refuse to participate, as their participation served only to "legitimise" the legal process for mining approval ( $\mathrm{Li}$, 2009). However, with minimal public input, the EIA has been "pushed towards a predictive, or technical, paradigm" which cannot provide social learning for EIA constituents (Lockie, et al., 2008, p. 186).

To summarise, monologic EIAs are deficient for the purposes of promoting sustainable and participatory mining in Mongolia. Their technocracy undermines the democratic intention of public participation. Monologic EIAs are incapable of addressing sustainable development for mining, as they are closed to alternative opinions and perspectives that would identify and assess social and environmental impacts and propose mitigation methods. 
As sustainability is "a contested concept", with various interpretations among different actors (Söderbaum, 2011), it is important to promote pluralism to recognise different political and ideological orientations of actors and to have dialogue about such differences, and to propose or act to revise the EIA framework so it can become a meaningful decision-making tool for the promotion of sustainable and participatory mining. Pluralism would also enable social learning for all EIA constituents absent from current EIA practices. In this respect, change towards a dialogic EIA could be promising as a means of overcoming the deficiencies of the existing monologic EIAs.

\subsubsection{Potential of dialogic EIAs}

Given its pluralistic roots and capacity for participatory decision-making, the dialogic approach is open to subjectivity and is sufficiently flexible for contestation. As Molisa et al. (forthcoming) explained:

A dialogic approach is explicitly concerned with the inclusiveness of all actors in accountability processes, identification of unequal power relations, and expansion of ethics to include issues previously excluded by identifying marginalised voices and including them in exposing social conflicts and tensions as ways of beginning to work toward their resolution (p. 17).

As noted in Chapter 5, one of the goals of the EIA is power re-distribution and change in decision-making structures through public participation. O'Faircheallaigh (2010) argues that an EIA can be used as a space for marginalised or affected people to "change the social order, and in so doing alter in basic ways the distribution [of] costs and benefits from development" (p. 22). The dialogic EIA has the potential to address mining-related environmental and social impacts by providing an arena where contestation and differences can be revealed through dialogue and openly discussed by both experts and non-experts.

Particularly in the Mongolian context, dialogic EIAs have the potential "to construct more empowering and enabling forms" of EIAs "in ways that are just, democratic, sustainable and, most of all, of benefit to their peoples and communities" (Molisa, et al., forthcoming, p. 17). In recent years, socially 
beneficial mining has become a crucial issue. This is supported by interviewees' views and current parliamentary and public debates in Mongolia. A dialogic approach could not only contribute to discussion on how to effectively distribute the benefits from mining to the public (Interview D3), but could also allow engagement of affected people in issues that affect their lives (Interview F2). As an interviewee argued, it was important to have everyone's involvement in environmental issues as "neither empty criticism, nor 'blind eyes' to problems can be helpful for the status quo" (Interview D5, 00:10:11-6).

In spite of the symbolic participation of monologic EIAs, nine interviewees emphasised the importance of good participation. In their view, good participation could be enabled by well-informed, knowledgeable, and active citizens, whose comments are considered in decision-making and who are granted access to the jurisdiction system on EIA matters (Interview A5, B3, D5, F3, F7, G1, G2). Interviewees believed that participation could make positive contributions to existing mining and enable "information sharing and community development" that would build trust among EIA constituents and would help reduce future conflict (Interview B1, D2, D6). Moreover, early engagement of affected people could assist mining companies to discover the major issues before projects commence (Interview B1) and could assist in promoting realistic EIAs (Interview D2, 00:18:43-5). The quality of EIAs would also be improved as participants could be involved in all processes from the impact assessment through to monitoring, which would change the attitude of all parties towards mining (Interview A1, 00:54:11-1). In this respect, dialogic EIAs could provide opportunities for participants to go "beyond any one individual's understanding... in dialogue, people become observers of their own thinking” (Wilson, 2006, p. 515), which could have wider consequences for the empowerment of citizens (Lockie, et al., 2008; Wilson, 2006).

\subsubsection{EIA as a space/tool/process}

In spite of its symbolism, the Mongolian EIA legislation has promoted participation (Interview F8, F9). In the absence of other participatory mechanisms, 
dialogic EIAs could be an important tool of local democracy as they would "encompass [the] empowerment of local people; and enhance the position of ... disadvantaged or marginalised members of society" (O'Faircheallaigh (2010) by creating a space "where local people can frame and articulate their needs, values and priorities" (Li, 2008). Most interviewees agreed that public participation could help to improve the existing poor mining practice (Interview A5, D1, F2, B1). Unlike monologic EIAs, dialogic EIAs would include affected local people and allow them to have dialogue with other EIA constituents. With dialogic engagement, EIA decisions would be better informed and have a "multidirectional feedback mechanism" among the government, private sector, public and civil society organisations (Toth, 2010).

Dialogic EIAs could also open "a learning space" that recognises differences between experts and non-experts (Sinclair, et al., 2008). However, it is "a unique space where learning cannot be prescribed" and is:

... neither strategic learning for 'normalisation' nor learning for transformation. Nor are different kinds mutually exclusive; one can have elements of both strategic and transformatory learning within the same space and one might move from one to the other and back again over time (Wilson, 2006, p. 512).

This learning process could enable the "transformative potential" of EIAs to direct EIA constituents towards social-value change that would be inspired by sustainable development (Söderbaum, 2004; Wilkins, 2003). As Sinclair et al. (2008) explained, through dialogue, participation could also lead to "the perspective transformation necessary for changing unsustainable resource use patterns", and address the need for "a change in response to the sustainability imperative" (pp. 416-425).

As a dialogic learning tool, the EIA could also contribute to democratisation in newly democratic countries such as Mongolia. As discussed in Chapter 3, the Aarhus Convention (1998) legitimised and accelerated this process, as most governments have voluntarily signed to enforce it. It could also challenge the state-secrecy culture in post-communist countries and “... represent a compromise 
or intermediate step to broader actions toward transparency" by allowing accessibility of environmental information (Toth, 2010, p. 328).

The Mongolian government has voluntarily adopted the Aarhus Convention since the early 2000s (MNET, 2009b). Although current monologic EIAs do not apply to many recommendations of the convention, dialogic EIAs would better suit the ethos of the Aarhus framework of participatory environmental decision-making. The transformation to dialogic EIAs, with the promotion of pluralism and dialogue, could be regarded as a democratisation process in the environmental decision-making framework and EIA related institutions.

As EIA and participation processes create "an image of consensus, cooperation with local communities and state avowal" (Li, 2009, p. 232), the benefits of the dialogic approach in EIAs could be enormous. Through pluralist dialogue, EIA constituents with conflicting views on mining may better understand their differences and commonalities; be enabled to make more inclusive decisions; and learn from each other as no one party would be explicitly 'privileged'. Some interviewees expressed their agreement with this, based on their past experience of multi-stakeholder dialogue in which multi-stakeholders with conflicting views and knowledge had been able to share information with each other and discuss common goals for mining development (Interview D6, F9).

Arguably, "shared responsibility" set by the existing EIA framework (Szablowski, 2007) could lead EIA constituents to pay more attention to mining and environmental issues as participants become part of a proposed project and become beneficiaries of mining-related benefits and costs. Perhaps this engagement of shared responsibility could change the NIMBY attitude of some people, referred to by some NGO and herder interviewees.

To summarise, the dialogic EIA, as a legitimate space for participation and dialogue, could serve as a dialogic tool and process that would enable EIA constituents to achieve shared common goals, such as sustainable and participatory mining. 


\subsection{How to transition from monologic to dialogic}

To enable transformation from monologic to dialogic EIAs, a number of issues must be addressed, which can be framed by the following three questions:

1. What must be changed to facilitate this transformation?

2. Who can carry out the necessary changes?

3. How can this change happen?

The following sections will discuss these in detail.

\subsubsection{What to change, and by whom?}

It is important to understand that the monologic EIA is both a tool and process. Thus, any transformation must address the 'dual nature' of monologic EIAs. In this respect, EIA related institutions and constituents would need to take various actions: forming a participatory mechanism/framework that would enable meaningful dialogue and social learning; organising dialogue among EIA constituents to discuss the opportunities and challenges of the transformation process; ensuring information accessibility; and having broader participation that would include affected local communities. However, it might prove challenging for LDCs such as Mongolia, which as a young democracy has weak governance and endemic corruption.

Regarding the second question as to who can carry out the necessary changes, all EIA constituents would need to contribute to the change towards dialogic EIAs. A number of interviewees acknowledged the importance of mutual understanding among EIA constituents. They suggested that all parties, including government officials, inspectors, EIA specialists, mining companies and local people, would need to be trained and be cooperative, to enable better participation (Interview A1, 00:50:13-3) and provide opportunities for each other to participate in EIAs (Interview B7, 00:10:31-5 P5). An interviewee of an EIA company emphasised the importance of engagement by the most active people - NGO leaders or other interest groups - to facilitate this process through the education and mobilisation of affected local communities (Interview A5, 00:35:05-1). The potential engagement of NGOs will be discussed in the next chapter. 
For mining companies, more participatory dialogic EIAs would also be beneficial. As mining projects operate for decades, public perception of mining is crucial for mining companies (Interview C3, D2). Poor engagement and misunderstanding increases the risks for mining companies, which can be evidenced by numerous demonstrations, debates and hunger strikes against mining companies in Mongolia (Interview D2, F2, F4). As one interviewee described it, public participation should be seen "as in their [mining companies] self-interests to have engagement of communities around mine sites" (Interview D2, 00:20:20-5). Participation could improve public perception and trust among mining constituents and could help reduce future conflict (Interview B1, D6). In addition, increased participation would contribute to economically sustainable mining development (Interview D3, $\underline{00: 13: 33-6}$.

In terms of when to participate, some interviewees suggested that affected communities ought to participate from the outset of the planning process of an EIA (Interview D5, 00:23:31) and be able to "express their views, determine how the project will affect them and their surrounding natural environment, and discuss whether these impacts are acceptable or not" (Interview F13, 00:35:05-6). While others proposed that participation should begin from the issue of the mining licence, as this could enable more meaningful participation for those who will be impacted by poor mining (Interview D1, D8, B5). However, it is better to have an effective mechanism and economic incentives to ensure that affected local communities can engage in EIAs and receive benefits from mining operations, rather than have empty slogans and only minor penalties for companies after adverse environmental impacts occur (Interview D5, 00:10:11-6).

Public participation that is limited to ad hoc questionnaires and surveys would need to be changed to multi-stakeholder dialogue that could enable dialogic EIAs that foster sustainable and participatory mining.

\subsubsection{How to transition from monologism towards dialogic EIAs?}

There could be two forms of dialogic EIAs: formal and informal. Although their boundaries may become blurred, both forms would contribute to the 
transformation process. Formal EIAs would be deliberative, in terms of having a legislative framework for public participation and having organised dialogue among EIA constituents. Alternatively, informal EIAs would provide a more agonistic type of participatory democracy. Participation in informal EIAs would be flexible and temporary. Participants could have their own pro- and counterEIA assessments, arguments and perspectives on EIA related issues. This will be discussed further in Chapter 8, with consideration of the potential engagement of NGOs for promoting dialogic EIAs.

In terms of dialogue, the Western style town-hall meeting for public participation in EIAs may not be appropriate and effective in the Mongolian context, given sparsely populated herders and their nomadic life style. Some interviewees suggested the need for a different 'model' of participation that would recognise the specific characteristics of the nomadic culture of herders (Interview D4). In this respect an interviewee of an international organisation suggested that:

You've got to think about a new model for doing it. You cannot use European, North American or South-East Asian models. I'm not sure where you would find a model because it requires participation at an individual 'ger' ${ }^{\prime 4}$ level - I don't see how you can avoid that. You need to understand the movement of people. Because in the area where most of the mining happens, it's the herding environment where people move throughout the year and over the years. So, you are going to have to find a model that is appropriate for Mongolia (Interview D2, 00:15:47-8).

Thus it is important to carefully consider time, space and structural issues when proposing the development of dialogic EIAs. There may need to be at least two levels of dialogic participation in formal EIAs: one at the herder family level and another at the EIA constituent level. The reason for having different levels of dialogue is to have greater input from all affected local communities and to enable broader social learning among EIA constituents. Given geographical distances, time differences for the workloads of each EIA constituent and the costs involved

\footnotetext{
94 'Ger' or 'yurt' is a traditional Mongolian living place or tent. It is a portable, felt-covered, wood lattice-framed dwelling structure traditionally used by Turkic and Mongolian nomads in the steppes of Central Asia. A 'ger' is more home-like than a tent in shape and build, with thicker walls (http://en.wikipedia.org/wiki/Yurt).
} 
in organising and participating in dialogue, not all affected people may be able to participate in formal multi-stakeholder dialogue. Thus, it would be better to have two different levels of dialogue, each having different benefits and inputs to dialogic EIAs.

The herder family level dialogue would enable discussion among herder families and EIA experts about a mining project and its potential impacts on local society, the economy, and natural environment. Herders would not only be information receivers, but also act as discussants and information providers for EIA experts. Their inputs to an EIA could be concerned with the impacts the mining project might have, how to define, measure, and mitigate such impacts, the local knowledge herders may have to address these issues, and how they could engage during the preparation, implementation and monitoring of an EIA report. From this process, both herders and experts would gain understanding and local knowledge. This could provide a social learning process for herders on how to express their views and knowledge, how to present arguments and engage in dialogue. In turn, EIA experts could learn to appreciate non-experts, become familiar with local knowledge, and become accustomed to preparing more inclusive EIAs.

Through the herder family level of dialogue, herders could discuss their formal engagement in EIA processes and the best way to execute their engagement. Due to family commitments and limited time availability, herders might agree to become an organised, identifiable group for further EIA participation, or could select herders to represent their interests at the next level of multi-stakeholder dialogue.

Regarding timing and distance factors, this type of dialogue would be better organised during summer and autumn, as the workload of herders and travelling to each other would be easier than in spring and winter. This dialogue could be organised on either the 'bag' level or 'khot ail' level, depending on distances and population density. 
The second level of dialogue would be the EIA constituent dialogue or multistakeholder dialogue. This could be organised during the preparation and after the issue of final EIA reports. To be inclusive and have effective impact on mining, it would better to stage such dialogue both during and after EIAs. Multi-stakeholder dialogue would provide an arena for all EIA constituents, including affected communities (or their representatives if it is organised far from the mining area), EIA and mining companies, local authority, experts from relevant government organisations, and interested environmental/other NGOs and academics.

The dialogue would, in deliberative terms, initiate discussion and monitor the timing of meetings. However, it should maintain a flexible structure and procedures that would ensure a pluralistic, dialogic approach. This would mean dialogue must encourage the contestation of different actors, expressing their views of affected communities, and avoidance of trying to find immediately any single consensus. Thus, this dialogue would be more akin to the expression of views and methods, rather than seeking a 'right' decision.

The benefits of having such dialogue during the EIA preparation period would be to open up different views of EIA constituents on defining, measuring, determining social, economic and environmental impacts of a mining project and their mitigation methods. Through discussion, these views may be proposed, argued, accepted or rejected by constituents. EIA experts would appreciate a broader picture of their impact assessments, be able to find methods that best suit certain local areas, and learn from non-experts. All participants would also benefit from dialogue as they began to recognise the differences and similarities of each other, acknowledge subjectivity of EIAs, open up their ideological differences, learn to have dialogue, express views and gain more understanding of mining, social development, and EIAs. Organising multi-stakeholder dialogue after the final EIA report would also benefit multi-stakeholder engagement in the implementation of EIA recommendations in a project life cycle and monitoring that process. 
In terms of having an effective dialogue, an international organisation interviewee said that it was important to be "focused on what is important" for all constituents and that "they need to have goals which they are working towards" even if "not everybody necessarily agrees on those goals" (Interview D1). He continued that once the government became part of the dialogue and agreed with common goals, it would be very difficult for the government to turn around and say "no, we are not going to do it" (Interview D1, 00:36:43-8).

Moreover, information and knowledge sharing is crucial for encouraging effective multi-stakeholder engagement. As an interviewee said, "aggression and fear comes from a lack of knowledge", so the more informed and knowledgeable stakeholders can be, the more likely they will be to engage productively in dialogue (Interview D6). Thus, it is important that affected local communities be informed before a mining project and has time to comment on EIAs (Interview D2, 00:16:59-3). The amendment bill of the EIA law proposed 30 days to provide public comments on an EIA (The State Great Khural of Mongolia, 2008).

In terms of the accessibility of EIA reports, some interviewees suggested it was crucial to have accessible EIAs for the public and to have public engagement both before and after final reports (Interview D5, F9). If access to EIAs were granted and became available to interested parties, this could promote more effective participation. In addition, EIAs would need to be open to the public at least one to three months before final reports are issued in order to provide the necessary time to gather public comments and include them in final EIAs (Interview F9, 00:41:37). As understandable EIAs are another prerequisite for meaningful participation, EIA companies should provide at least an executive summary of an EIA to local people (Interview F7, 00:44:43-7), so they can more easily understand reports.

As well as dialogue, participation in monitoring the implementation of the EIA is important, and was raised by twelve interviewees. Participation in the monitoring process, particularly during and after rehabilitation, is essential. As an NGO interviewee said, even up to five years after rehabilitation has been undertaken, local communities should monitor whether the natural environment has returned 
to the original condition prior to mining, as recommended in the EIA (Interview F2, 00:30:16-9).

Under the Environmental Protection Law, environmental inspectors at local and central government levels are responsible for environmental monitoring (The State Great Khural of Mongolia 1995, Section 3). However, this area of management is problematic due to limited human and financial capacities (Interview B3, 00:33:55-1). Regular monitoring by local people could be more effective than the 'sole' monitoring undertaken by a few inspectors (Interview B5, 00:03:05-3 P4). Because local herders have more time, capacity and knowledge about their surrounding natural environment and biodiversity, they could be more effective environmental guardians for checking mining operations and later rehabilitation programmes (Interview B3, 00:33:55-1). Herders naturally perform a monitoring role of their surrounding environments (Interview C3, 00:25:07-3) as their nomadic life requires close observation of their environmental surroundings. An interviewee suggested, given that monitoring plans have their basis in EIAs, that environmental protection and the monitoring of plans were potential areas of involvement for local people, (Interview D5). She also argued it would be more beneficial if local people were allowed to participate from the planning process stage onwards (Interview D5).

In practice, there are already initiatives that promote the participation of local people in monitoring. Some large and medium mining companies have a representative group of local people, consisting of three herders who are paid to monitor mining activities according to the environmental protection and local social development plans proposed by companies (Interview B1, 00:42:14-8). Environmental law also has a separate article on partnership with local people or 'nukhurlul', which encourages local people to organise local environmental partnerships to protect the natural environment, implement environmental protection projects, and to perform public monitoring (The State Great Khural of Mongolia 1995, Article 31). Although such partnership practice is in its infancy, it has the potential to promote public engagement in environmental protection and EIAs. 


\subsection{Limitations of dialogic EIAs and barriers to transformation}

\subsubsection{Barriers for EIA constituents}

To enable dialogic EIAs, each EIA constituent, including EIA companies, decision-makers, mining companies, affected communities and NGOs, needs to accept the concept of dialogic EIAs and make an effort, individually and collectively.

Through legislation, experts of EIA companies would act as facilitators of public participation (The State Great Khural of Mongolia, 1998). However, they could also be technocrats with a lack of awareness and appreciation for effective dialogue among EIA constituents. Thus, a legislative framework for participation at the initial stage of the EIA process would be necessary to provide guidelines on methods and processes for organising multi-stakeholder engagement, and how to ensure effective dialogue among EIA constituents. In such a deliberative process, the role of government organisations and initiatives by international donors and professional NGOs, such as the EIA association, would be substantial. For instance, government organisations would need to ensure that EIA companies comply with high quality regulations, whereas donors and professional associations could apply international best practices and benchmarks in mining and EIAs, and develop professional training programmes and codes of conduct for regulating the professional ethics of EIA experts.

For decision-makers, a range of difficulties would exist in institutions for the development of dialogic EIAs. The tension of decision-makers in participation would be problematic, as they often have participation "within tiny circumscribed limits" so as to maintain "centralised control" (Lawrence, 2003). However, increased international initiatives, following an appraisal of participatory decisionmaking (Toth, 2010) and "pressure" from international quasi-legal institutions and national NGOs, has forced national governments to manage the dilemma between "their propensity towards centralised control" and the "decentralising tendencies of public involvement" (Lawrence, 2003, p. 273). Finding the political will to open EIAs to public participation would be challenging, particularly in those 
LDCs with a politicised, corrupt public service. Some interviewees, including public servants, considered that Mongolia lacked the political will to have more participatory EIAs (Interview B3, F8).

Opportunistic behaviour of public officials would pose another threat for the promotion of dialogic EIAs. Due to the highly politicised public service and the four-year election period in Mongolia, public officials tend to make decisions that favour their individual interests. This phenomenon supports Wilkins' (2003) argument that decision-makers "overemphasise short-term individualism over the long-term community goals" (p. 410). This could worsen, given that the EIA committee is "often headed by the current and ex-bureaucrats" (Menon \& Kohli, 2008), who may be un-aware or unwilling to recognise the benefits of a dialogic approach and therefore be unavailable to foster change towards dialogic EIAs. Thus, it would be necessary to have independent watchdogs over state organisations to hold them accountable and to act in accordance with public expectations (Interview D2). This function is already partially performed by current NGOs in Mongolia and will be examined in Chapter 8 in the case of environmental and mining NGOs.

For mining companies, most interviewees, including those from mining pointed out the importance of state involvement in setting regulations and mechanisms that would ensure mining companies have more effective compliance with EIAs and also be self-monitoring (Interview C3, F9, D5). Again, professional NGOs such as the Mining Association could facilitate this process by introducing benchmarks, organising training and multi-stakeholder dialogue, and establishing self-monitoring systems, such as codes of conduct that would ensure better EIA enforcement and community engagement of mining companies. As mining companies tend to comply with only minimum standards (Interview F1, F3, A4), the public and NGOs would need to actively express their views on mining, cooperate with mining companies to promote social development, and act as watchdogs to ensure that mining operates in socially and environmentally friendly ways. 
For affected local communities, earlier discussion in section 7.3 on public participation demonstrates the issues and impediments for local communities to engage in EIAs. The principal problems relate to a lack of power and knowledge to participate effectively in an EIA, and its monitoring. Arguably, the ability to express views, protect Constitutional rights and to have time, have the financial capacity and willingness to engage in EIAs are the chief barriers that would restrict the participation of affected communities. Thus, environmental and social NGOs, which aim to protect human rights and the natural environment, could help local communities to increase their awareness of mining, EIAs, and participation, and encourage them to exercise their legislative rights. Such potential roles of NGOs will be discussed in Chapter 8 .

In summary, Mongolian socio-political issues, such as corruption, weak governance, power imbalances and poor accountability in both public and private sectors could limit EIA constituents from developing dialogic EIAs and having meaningful participation. Moreover, the promotion of dialogic EIAs, without consideration of the possible manipulation by experts and power-holders, may risk the creation of a new type of monologism.

\subsubsection{Dangers of a new type of monologism}

Dialogic EIAs are promising, as they could create more inclusive, qualified and effective EIAs without marginalising affected local communities and local knowledge. However, there would be barriers and possible risks of manipulation (similar to those recognised in the "tyranny of participation" literature - see Cooke and Kothari, 2001).

An overemphasis on cooperative participation could create a new form of monologism. Critics argue that such an emphasis could in fact restrict "public critique and disqualify opposition to mining activity" (Li, 2009, p. 224). Li (2009) claims that EIA participation could be used by project proponents to 'map' the relations of various individuals and groups vis-à-vis the corporation: their attendance at meetings, concerns, and willingness to cooperate, as a basis for surveillance and establishing "friendly alliances" (p.231). By making pro- and 
anti-mining "alliances visible", corporate could reinforce the polarisation between "constructive" stakeholders and "trouble-makers" (ibid.). In the process, "the role of corporations and the state fades to the background" while local people "take it upon themselves to monitor the activities of their fellow citizens and discipline them accordingly" (ibid.).

In addition, the public and NGOs that refuse to engage in EIAs could argue that the formal EIA participation was symbolic and contrary to democracy, as their attendance in EIAs already would legitimate public hearings that were biased in favour of project proponents ( $\mathrm{Li}, 2009$, pp. 230-231). In spite of enthusiasm for participation on the basis that it may empower citizens by including marginalised or affected people, EIA participation does not always allow such engagement. O'Faircheallaigh (2010), for example, observes that disempowered groups are less likely to participate in EIAs, given their lack of resources and possible intimidation. Within the existing system of symbolic participation, EIAs are not distributing power among the public as hoped initially (Wilkins, 2003). Rather, EIAs are being used "to reinforce marginalisation or marginalise social groups even further" (O'Faircheallaigh, 2010, p. 23). This has given rise to a loss of credibility for the idea of EIA participation (Jay, et al., 2007; Wilkins, 2003). Too often participation in EIAs has been used by technocrats in ways that create new forms of monologism.

Accordingly, researchers and practitioners argue for the need to foster a "dynamic and political environment", where participation occurs, based on a flexible framework of participation rather than on "hard-and-fast rules" (O'Faircheallaigh, 2010, p. 25). Practitioners would also need to recognise the dangers of power manipulation - closing down debate, ignoring uncertainties and excluding human/nonhuman actors (Chilvers, 2008). At the same time it is recognised that even monologic EIA processes could provide some small "opportunity for public control of decisions", and "for acquisition of skills, such as communication strategies and methods of social mobilisation" (Diduck \& Mitchell, 2003, 358$359)$. 
Power inequalities among participants and political influences are serious issues which need to be addressed in developing participatory democracy and the practice of dialogue. Power inequality exists not only among EIA constituents, but also between LDC governments and international donor organisations. International donor organisations are criticised for favouring the governments of developed countries and multinational corporations at the expense of LDCs (Cooke \& Kothari, 2001). Some NGO interviewees argued that an initiative for responsible mining would amount to the importation of a new form of Western capitalism (Interview F1, F8). They alleged that international donors use such initiatives to embed their infrastructure and to promote the interests of large multinational mining companies (Interview F8, F12).

Dialogue has the potential to empower citizens through both formal deliberation and informal discussion. Especially in newly democratic countries, a democracy built on participation and dialogue helps to address "a fundamental disconnection between the public and their governments" (Toth, 2010). Dialogue also helps to build a relationship between experts and non-experts and provides opportunities for mutual learning (Wilson, 2006). In this respect, this thesis argues that a transformation to dialogic EIAs, through participation and dialogue, has the potential to enable democratisation in environmental decision-making. However, time and resources would be required for the development of meaningful dialogue, and a number of obstacles would need to be addressed, some specific to LDC contexts.

Dialogue in Mongolia could possibly continue to marginalise some local people, as the current system has effectively already excluded them. Kapoor (2008) argues that the assumption of deliberative democracy that marginalised people can be heard by elites is not often realised, as the system "filter[s] out, den[ies], or suppress[es] subaltern voices" (Kapoor, 2008, p. 115). Such power imbalances may generate obstacles for dialogic EIAs to develop an accountability process and to institutionalise a democratic approach. Kapoor (2008) further highlights that in LDCs with extreme socio-economic inequalities it is easy for elites to divert resources to their own ends, and the risks that they will "manipulate and impose 
consensus are heavier and more difficult to minimise" (Molisa, et al., forthcoming, p. 19). Furthermore, there are discursive barriers between elites (Kapoor, 2008, p. 113) and ordinary people, and experts and non-experts that are not easily overcome. Some interviewees were critical of the monologue style of discussion by local people and their lack of ability to express their views, and recognised that they would be major barriers for effective, inclusive dialogue (Interview D6, F2).

Interviewees also reported the lack of trust among EIA constituents as a further constraint. Distrust among the public persists from the communist period, while cynicism about mining stems from a lack of understanding about mining and the poor social and environmental performance of mining companies (Interview D4, F9). Distrust and cynicism about mining would work against honest and open discussion among EIA constituents (Interview D1, D6, F2). As trust is "a basis for genuine dialogue" its absence means people are "less prepared to expose themselves and explore differences", thus inhibiting "transformatory dialogue" (Wilson, 2006). Any consensus that could be drawn from this kind of dialogue would be arguably "little more than ideological fantasy" (Kapoor, 2008, p. 115).

To conclude, efforts to have meaningful participation and dialogue among EIA constituents could be obstructed and manipulated by power-holders who conduct EIAs, dominate dialogue, make EIA decisions, and monitor their implementation. This could diminish hope in, and the credibility of, dialogic EIAs and waste the efforts made by active participants. With a danger of co-option or manipulation by EIA companies, government organisations, and mining companies, overemphasis on participation could also create a new form of monologism. Thus, it is crucial to consider power issues carefully and to improve the awareness and capacity of all constituents, rather than to proceed with a naive faith in the 'transformative possibilities' of dialogic EIAs.

\subsubsection{Benefits of transformation}

Notwithstanding important caveats that dialogic EIAs could be manipulated or result in a new form of monologism, there would be many potential benefits. Dialogic EIAs could be both a tool and process for environmental decision- 
making and public participation and dialogue among EIA constituents, potentially affecting each participant and institution in numerous ways.

Even with a 'minimal' dialogic approach, the most important benefit would be social learning for all EIA constituents. As the dialogic approach would encourage "dialectic learning in pluralistic environments" (Brown, 2009, p. 327), transformation to dialogic EIAs could provide opportunities "to expose oneself before others, push the boundaries of what one knows, explore radical ideas together, and embrace disagreement where necessary" (Wilson, 2006, p. 518). The learning process could help actors go beyond "the purpose of reinforcing and tweaking existing practice ... towards transformation of ideas, knowledge and practice" (Wilson, 2006, pp. 518-519). Thus, it is crucial for Mongolians to address new challenges, such as enabling participatory environmental decisionmaking and promoting sustainable and participatory mining.

Even if dialogue among constituents does not occur as expected, the public particularly affected local communities - could gradually learn about participatory rights and ways to engage in dialogue. Some interviewees claimed that dialogue was a passive form of engagement in environmental issues that would not have straightforward, direct outcomes that could be created by radical activism, such as hunger strike and protests (Interview F1, F10). In spite of its unnoticeable shortterm effects, dialogue could have long-term positive effects through the transformation of perspectives held by EIA constituents, increases in the quality of EIAs, and the development of EIA institutionalisation.

Arguably, dialogic EIAs would free up information on the EIA, mining, and other issues and would challenge the long-standing state-secrecy culture of the public sector. EIA decisions would probably become more accessible to the public, which would enable improved accountability in both public and private sectors. Dialogic EIAs would also provide an opportunity to incorporate both scientific and local knowledge into EIAs, which is an important aspect for Mongolia, as the local knowledge of nomadic culture could benefit existing scientific know ledge of the EIA, which has been imported from Western countries. Thus dialogic EIAs 
would have the potential to incorporate local knowledge in the scientific understanding of experts and to create a country-specific EIA framework and learning process.

With more open engagement and information, EIA constituents would be more likely to identify and address environmental and social impacts "before a crisis point is reached" (Toth, 2010, p. 297). This is crucial for Mongolia, where global warming and desertification has already begun to threaten people's lives and the biodiversity. As well, dialogic EIAs would have the potential to promote the engagement of local people and NGOs in environmental monitoring, which is currently poorly performed due to a lack of financial and human capacity of government organisations and a lack of political will (Interview A5, B3, F13).

In summary, the pluralist environment provided by dialogic EIAs would encourage the dynamic engagement of EIA constituents in identifying impacts, discussion of mitigation methods, and mutual learning among experts and nonexperts. Moreover, it would enable much broader social learning of democratisation in environmental management by opening up the differences of EIA constituents and by initiating dialogue on an agenda for social change towards sustainable and participatory mining.

\subsection{Conclusion}

This chapter has argued that existing EIAs in Mongolia are monologic with only symbolic public participation. It is important to challenge monologic EIAs to address effectively the current poor mining practices and to foster sustainable development. Transformation from monologic EIAs to dialogic EIAs could be executed using two forms of dialogue; formal dialogue of EIAs would be deliberative, whereas informal dialogue would be more likely to be agonistic so as to include actors with conflicting views, different voices and perspectives. However, the boundaries between EIA forms would not be clearly divided, making them more pluralistic and inclusive, so as to enable dialogic EIAs. Although not everyone would choose to engage in deliberative dialogue of formal EIAs, dialogic EIAs would provide a space for informal/outside engagement. 
The next chapter will discuss the potential engagement of NGOs for promoting dialogic EIAs, and will outline the different roles and strategies for NGOs to participate in both formal and informal forms of dialogic EIAs. 


\section{Chapter 8: MONGOLIAN ENVIRONMENTAL NGOs}

\subsection{Introduction}

This chapter introduces the empirical findings from two studies of environmental and mining related NGOs. As noted in Chapter 7, NGOs have the potential, as constituents of the formal EIA process, to promote dialogic EIAs. Compared with other constituents, NGOs could have greater impact in terms of the transformation process if they were to consider engaging in environmental and mining issues in various ways. Accordingly, this chapter discusses the roles and participation of NGOs in mining and EIA matters and explores their potential engagement in dialogic EIAs. The chapter is structured as follows: first, the roles of NGOs are discussed, based on interviews and document analysis; second, case-studies of two NGOs are introduced to illustrate the diverse ways NGOs in Mongolia are engaging in mining and environmental issues; third, critiques of NGOs are discussed to provide insight into the challenges Mongolian NGOs face and the constraints on their activities; and finally, the current involvement of NGOs in EIAs is briefly discussed, followed by discussion of the potential for NGOs to promote dialogic EIAs.

\subsection{Mongolian NGO practice}

\subsubsection{Roles of environmental NGOs}

Because of booming mining development in Mongolia, the negative impacts of mining on the local society and environment are becoming more obvious. Growing numbers of NGOs have been established by local communities and citizens who are concerned about human rights and environmental protection. As noted in Chapter 4 there are currently approximately 550 environmental NGOs that focus on environmental protection, environmental education, and mining issues (Gansukh, 2010). However, these NGOs account for only ten percent of total registered NGOs, some of which also address human rights and social issues arising from poor mining practices. 
Similar to NGOs in other countries, Mongolian environmental NGOs have played important roles in increasing social awareness of mining-related environmental and social issues (Interview F8). In response, mining constituents have begun to acknowledge the rights of people to live in safe and healthy environments (Interview F7), and environmental issues have become one of the hottest topics in public debates. The roles of Mongolian NGOs can be categorised as follows:

Provide critical voices: NGOs provide critical voices in society when the government cannot (or will not) act in the public interest (Interview F8). Some mining interviewees acknowledged that "there is a need for NGOs to address environmental protection" (Interview C1, C3). For example, interviewees felt NGOs should watch over the government to ensure public monitoring (Interview D6) and to investigate the wrongdoings of government and the public (Interview F3). NGOs are regarded as important as they can monitor and exert pressure on the government "to improve the quality of things done in the country" (Interview D1, 00:27:52-1).

Provide information: NGOs are also seen as important contributors in that they are able to inform the government about developments in local areas, as the government appears unable to manage everything without assistance (Interview B3). Environmental NGOs have played an important role by informing local authorities and MPs about poor mining practices in local areas (Interview F4).

Engage in monitoring functions: Some interviewees argued that NGOs should exist in society to perform some government functions, such as monitoring and providing professional consultation (Interview A5, F5). Environmental NGOs were seen as having the potential to enable public monitoring in mining affected areas, given that the government is unable to reach all areas (Interview B3, D6). Professional NGOs, such as the EIA Association, could for example encourage cooperation between EIA companies and government organisations, develop EIA methodologies, and organise training for EIA companies on how to use EIA methodologies (Interview A6). 
Public educators: Environmental NGOs were also seen as educators, informing the public, increasing awareness of mining and environmental issues, improving knowledge of legal rights and responsibilities, and educating people about environmental protection (Interview B7, F3, F4).

Influence decision-making: NGOs undertake various activities to lobby and influence decision-making and policy-making (Interview F7). One NGO interviewee reported:

Because of the vertical decision-making system, local environmental NGOs realised it was useless acting in local areas already affected by decisions that had been made in the capital city. Rather, it was better to have an office and representative in the capital city and ... cooperate with other NGOs with similar goals to influence government policies (Interview F2).

NGOs have chosen both peaceful, cooperative strategies and more activist types of engagement to influence public debate and government policies. As NGOs began to realise 'the power of numbers', they sought cooperation with similar NGOs to influence government policies and improve the legislative environment in terms of environmental protection (Interview F2, F3, F78 F10).

Activism: NGOS have more contentiously organised petitions, demonstrations, protests and hunger strikes to exert pressure on the parliament and government to urgently address mining-related social and environmental issues (Shinebayar, 2011; Snow, 2010). Such NGO activism attracts both criticisms and support.

Some interviewees complained that NGOs politicise issues and criticise mining companies without credible evidence to support their claims (Interview B7). Instead of addressing issues in advance to prevent them, NGOs criticise after the event, which has "little effect" (Interview D5). Some interviewees labelled environmental activist NGOs as "grandstanders" or "noise-makers" (Interview D1, F8).

Other interviewees argued that NGOs have contributed to increasing public awareness of mining-related issues. They might not always be "right", but NGOs such as the Onggi River Movement make a lot of noise (Interview D2) and in 
doing so attract attention to issues, about which people had previously been unaware (Interview F12). Interviewees provided examples of several successes resulting from NGO activism, including opposition to the government 'Gold Programme' (Interview F10) and cyanide contamination in Khongor soum (Interview F8), where NGO activism, together with media releases, raised social awareness and public anger against poor mining practices.

The various roles outlined above are not mutually exclusive; NGOs may perform various roles individually and collectively. Some choose different strategies to address issues they care most about. To illustrate differences in approach, the following section introduces case-studies of two NGOs: the Onggi River Movement and the Responsible Mining Initiative. These particular NGOs have been chosen because of their popularity in Mongolia, the relevance of their activities to the promotion of sustainable and participatory mining, and the frequency with which they were mentioned by interviewees.

\subsubsection{Two case-studies of environmental and mining NGOs}

\subsubsection{A challenger NGO - Onggi River Movement}

Onggi River Movement (ORM) ${ }^{95}$ is an example of a local NGO. It is a wellknown pioneering environmental NGO whose activities have been widely publicised.

The primary reason for the formation of this NGO was the drying up of the Onggi River and Lake Ulaan, which sustained the lives of many people in the central and southern regions of Mongolia. Since the government 'Gold Programme' in 1993, economic interests in gold mining have prevailed, exploiting gold deposits at river heads. The Onggi River flows for 430 kilometres through mountains, steppes and the Gobi region, and discharges its water into Lake Ulaan, which covers an area of 175 kilometres $^{2}$. Historically, the river has sustained the lives of more than 100,000 people and more than one million livestock (UMMRL, 2009). Currently,

\footnotetext{
${ }^{95}$ Nine interviewees mentioned this NGO when addressing environmental NGOs and their roles in society.
} 
it flows only 100 kilometres, and Lake Ulaan ${ }^{96}$, one of the ten largest lakes in Mongolia, has been dry ${ }^{97}$ since the late 1990s. As Mongolia depends largely on surface water, which comprises 70 percent of its water reserves, depletion of this river system has serious implications for local communities (Lovgren, 2008). Land degradation around the Onggi River basin is serious, due to poor mining practices that include diverting river water flow for mining use, and because appropriate technical and biological rehabilitation has not been undertaken (Tsolmon, Tungalag, Miller, \& Sloan, 2009; UMMRL, 2009).

This visible decline in water resources and pasture land spurred local communities to act. The ORM NGO was founded in 2001. The chair of the soum's LRK at that time, Mr Munkhbayar, was the main driving force. He brought together residents of eight soums from three neighbouring aimags, through which the Onggi River flows, and established the NGO with a stated mission to reverse the drying up of the Onggi River system and to restore Lake Ulaan (UMMRL, 2009). The local residents recognised the importance of an organised NGO to protect their vital community interests in a more influential way (Munkhbayar, 2005).

The NGO has 1200 regional members and a Leadership Council of nine members who are representatives of soums, a Supervising Council of three members, and a sub-council in each soum. Since its formation, Mr Munkhbayar has been continuously elected as chair. The NGO has three other paid staff positions: an executive director, legal adviser, and a driver. It also has an office in the capital city, Ulaanbaatar (UMMRL, 2009).

The NGO has undertaken various activities to accomplish its objectives, which are to raise public awareness of mining impacts in local areas, to educate local people about environmental protection, to prevent desertification along the river, and to demonstrate against poor mining and the lack of accountability by government.

\footnotetext{
${ }^{96}$ Lake Ulaan used to reach 40 kilometres in diameter during wet periods, playing an important part in balancing the climate of Mongolian Gobi Desert.

${ }^{97}$ According to the report of the Independent Review Group (formed by the MNET), the Onggi River and Lake Ulaan dried up due to the direct impacts of exploitation of gold deposits at the river catchment areas. Furthermore, the study released that 28 rivers in the eight aimags were in danger of drying up (Independent Review Working Group, 2002).
} 
The NGO has organised meetings with local authorities, local communities, and mining companies to raise awareness of local environmental issues and to seek possible solutions. It has also organised training for local communities to inform them of their legal rights and environmental issues, and to gather their opinions. With the cooperation of local school teachers, the ORM has also prepared and published textbooks on environmental protection for primary and secondary schools. Some local schools have introduced new subjects into their curriculum in order to increase student awareness of the region's natural environment (UMMRL, 2009).

In 2004, the ORM began a long-term reforestation project, planting seabuckthorn ${ }^{98}$ trees on the banks of the Onggi River. The plan was to replant the entire river banks over several years, for the purposes of preventing soil erosion and to mitigate desertification. Sea-buckthorns are indigenous to Mongolia. Their extensive root systems have a positive impact on water balance and help to prevent erosion and desertification. Fruit can be harvested after three years and are rich in vitamins. The NGO has collected donations from the public and has been awarded international projects for tree planting. It has also organised numerous workshops and training for local communities, showing them how to plant and benefit from their trees (Global Nature, 2011).

Between 2002 and 2003, the ORM NGO appealed to all 76 members of parliament, the Prime Minister, and the President to take immediate action to avert an ecological disaster in the region which seriously threatened to violate the constitutional rights ${ }^{99}$ of citizens. In spite of repeated requests to the state, no radical measures were introduced. Another strategy used by the ORM for raising the awareness and support of public officials and citizens was a 478 kilometre 'Ecology protest march', organised between May and June 2004. The march traced the entire span of the river with over 2000 participants, including

\footnotetext{
${ }^{98}$ Sea-buckthorns are planted for soil and water conservation purposes. They are tolerant of salt in the air and soil, and grow typically in dry and sandy areas (Wikipedia).

${ }^{99}$ Article 16 states that Mongolian citizens shall have the rights to live in a healthy and safe environment, and be protected against environmental pollution and ecological imbalance (The State Great Khural of Mongolia, 1992).
} 
representatives from eight soums, some MPs, other NGOs, and journalists (Munkhbayar, 2005). Since then the NGO has organised and taken part in a number of demonstrations opposing poor mining. It has used media coverage and other options to publicise activities and to raise public awareness of the misconduct of mining companies and government organisations. The NGO has worked closely with newspapers and television channels, set up its own website, and produced documentaries in collaboration other environmental NGOs in a television programme, "Calls from the Rivers" (Interview F3, 00:04:42-0).

The positive outcomes from these demonstrations include: increased public awareness of mining impacts and the stimulus given to environmental NGOs to consider different strategies and activities for addressing poor mining practices; government research that confirmed the NGO's claims concerning the adverse impacts of mining activities; and joint physical inspection of the river basin with the Mineral Resource and Petroleum Authority that led to agreement on the need to conduct a scientific study (UMMRL, 2009).

Financial and technical support was crucial for development of projects and training by the NGO, as such social activism was new for rural Mongolians for both socio-political and cultural reasons. The NGO has received a variety of funding and support from international donor organisations, given its limited local resources and the impoverishment of rural regions (Snow, 2010; UMMRL, 2009).

To achieve its goals, the ORM has cooperated with other NGOs, and is "learning by doing". Between 2006 and 2008 it was a member of the Mongolian Nature Protection Civil Movement Coalition (MNPCMC) that was established and supported by an international donor NGO. As a donor organisation the ORM realised the importance of "power of numbers" in addressing environmental issues effectively, and changed its strategy by encouraging greater cooperation among NGOs (Interview D6). As an interviewee said:

Rather than giving out a lot of small grants, [we] have larger grants to the coalition, who could then use part of them for core funding, professional development, capacity building, and for coming a force and presence in Ulaanbaatar and throughout the country (Interview D6). 
The idea was not only to promote the cooperative skills of NGOs, but also to sustain their operations by improving their institutional and human capacities (Interview F9). The ORM actively engaged in activities of the coalition along with thirteen local environmental NGOs. However, the donor NGO announced it would end its cooperation when the ORM issued a media release expressing its willingness to organise violent protest, if necessary, against poor mining in some local regions (Interview D6). The ORM, for its part, refused to work with the donor NGO and coalition as it wished to maintain its independence and be free from international influences. As the ORM leader described:

The cooperation with NGOs enabled us to make progress only on matters that were wanted by the donor NGO. If the donor did not want them, then matters could not be carried out by NGOs. Therefore, cooperation was limited by the preferences of the donor. ... When NGOs made a contract of cooperation, they were told not to criticise government policies, and not to protest against mining companies. It appeared the donor's main goal was to silence NGOs and condone mining practices, as that was the main income and growth generator (Interview F1, 00:14:43).

Following ORM, some other coalition member NGOs also refused to cooperate, and the coalition disbanded. After the donor's refusal to cooperate, the ORM had been excluded as a board member of the Responsible Mining Initiative NGO, which was supported by the same donor (Interview F1, 00:12:46).

ORM then began new cooperative initiatives with some local environmental NGOs, forming a new NGO coalition called 'United Movements of Mongolian Rivers and Lakes' (UMMRL). The coalition consists of six local environmental movements, representing five different regions that have significant mining development. These NGOs are the ORM, Salhin Sandag, Huder Gol, Toson Zaamar, Anggir Nuden Munduuhei, and the Local Environmental Protection Movement. All are registered environmental NGOs.

The common goal is to protect rivers and lakes from environmentally and socially harmful legal and illegal mining. Through various activities, principally protests in their local areas, the NGOs realised their weakness as 'solo' players at the local 
level because of little impacts that individual NGOs can have to influence mining related government decisions (Interview F3). Local NGOs recognised the need for cooperation to become more influential and realised the importance of having representatives based in the capital city to influence decision-making. Accordingly, in early 2009 they united and established the UMMRL NGO (Interview F12).

An interesting feature of the UMMRL is its management principles. All member NGOs have equal rights in decision-making processes and equal opportunities to manage, in turn, the UMMRL (Interview F12). Leaders of member NGOs meet once a month ${ }^{100}$ in the city and select a leader as the monthly head. The selected leader will introduce his/her plan for the month, ensuring it is consistent with activities of previous months. At the end of the managing period, the head will report to other NGOs about his/her achievements, the financial situation (monthly member fees, donations or project monies, and costs), and matters for action in the next month. Two permanent staff of the UMMRL are in charge of administrative activities and assist the monthly head. Among other NGOs, the ORM NGO plays an inspiring, 'informal' leadership role, as it has more experience and knowledge of organising various activities and addressing mining-related social and environmental issues ${ }^{101}$.

In spite of united activities in the city, each NGO retains autonomy in its own region (Interview F6); each NGO has its own activities and voice. This was clear at monthly meetings as members presented different views and proposed their own solutions. At the same time, NGOs had a united view on certain strategic issues, such as when undertaking a wide range of activities to accelerate the formation and implementation of a new law.

\footnotetext{
${ }^{100}$ To update, NGOs now select a head on a quarterly basis, due to the cost of travel, and to allow the leader more time to work independently and achieve desired outcomes.

${ }^{101}$ The leader of ORM was elected as chair of the board of the Citizens Representative Committee during the first NGO conference held in November 2008. However, after a few months, he resigned from the position.
} 
The first goal of the UMMRL was to form a new law prohibiting the exploration and mining at river headwaters and in forest reservations ${ }^{102}$. Since 2006, six NGOs have cooperated and undertaken various activities, such as organising local meetings, lobbying and sending letters to MPs written by 6000 local people from five regions, collecting signatures of support in petitions in the city, cooperating with other environmental NGOs to organise protests near the parliament building, and declaring a hunger strike in front of the parliament building to pressure MPs into passing the law.

The following photographs were taken during the hunger strike when five NGO leaders went without food for four days, and three local people sat with them in peaceful protest.
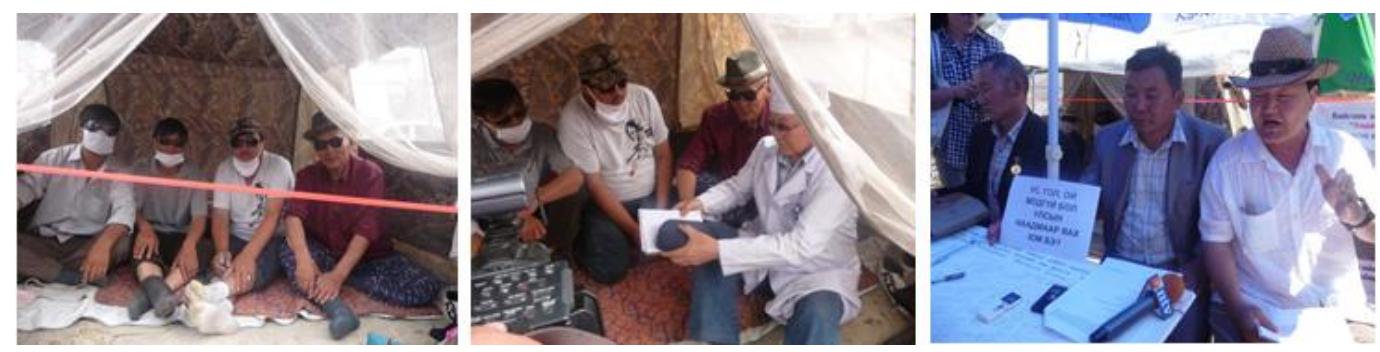

The left photograph shows the hunger strikers, and the middle photograph, a doctor from the government hospital, checking the health of the strikers to confirm whether they were well enough to participate. The blood pressure of the oldest striker (approximately 65 years old) was high, and the doctor advised him not to continue participating. The coalition replaced him with a younger man that afternoon. In the right photograph, the NGO leaders, including the UMMRL, were giving television and newspaper interviews. The poster reads 'No need for the Naadam ${ }^{103}$ if we have no rivers and forests'.

\footnotetext{
${ }^{102}$ Mongolia is a landlocked country with scarce water and forestry resources. Forestry counts for only 7\% (Dorjgotov \& Purevsuren, 2006). As the country is located in one of the world's arid and semi-arid regions, there is more likelihood of water scarcity (UN, 2007, p. 4).

${ }^{103}$ The Naadam Festival is the biggest three-day national holiday in Mongolia between 11-13 July. It is also called "The three games of men", and has existed for centuries. The games are wrestling, horse racing and archery. The hunger strike began on $3^{\text {rd }}$ July - close to the Naadam Festival and just before the official closure of the spring session of the Mongolian Parliament.
} 

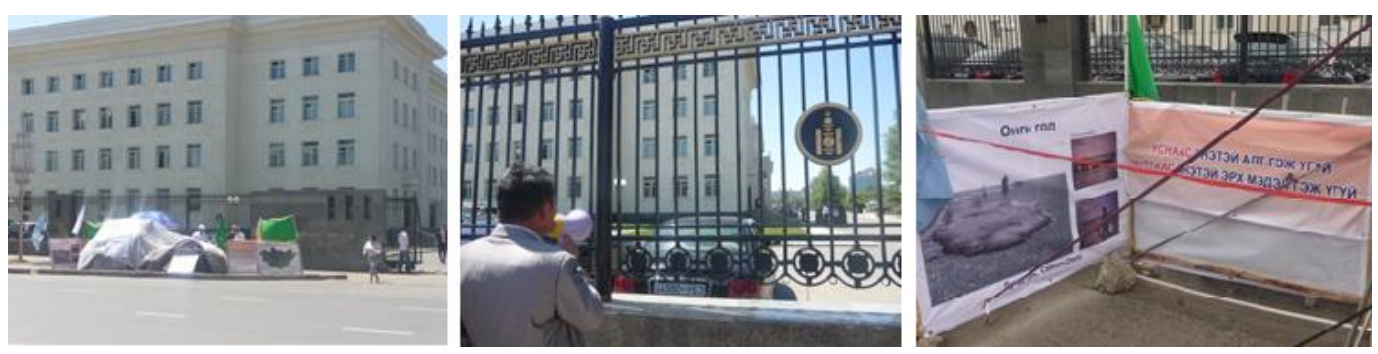

The above photographs show the proximity of the hunger strike to the parliament building. In the right photo, the posters read 'Onggi River' and 'there is no gold more precious than water, and no legal authority is more important than the interests of our country'.
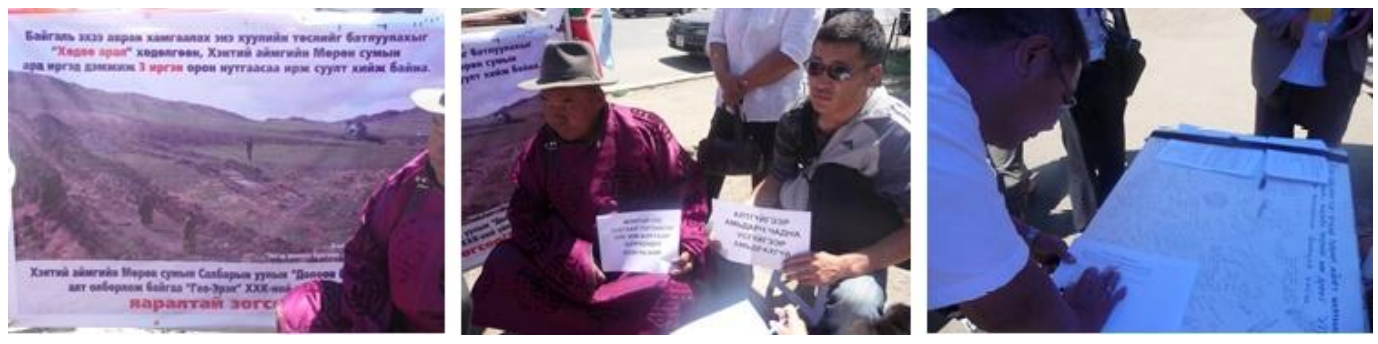

The poster in the left photo reads 'We, Khuduu Aral NGO, support the new law to protect our environment'. Three local residents of Khentii aimag are taking part in a sitting protest, calling for an immediate end to the mining operations of 'GeoErel' (a mining company in Murun soum of Khentii aimag). The middle photograph shows two sitting protesters holding posters, stating 'If Mongolia is an independent country, we should be owners of our territory', and 'We can live without gold but not without water'. The right photograph shows a citizen signing a petition to express his support for the new law.

Besides the six NGOs of the UMMRL, 25 other local environmental NGOs cooperated in this protest. As a result of their efforts, the law was passed on 9 July 2009. This law illustrated a new phenomenon in Mongolia - it was the outcome of local environmental NGO pressure and lobbying of some MPs. It has subsequently led to numerous public and parliamentary debates on how to define the borders of river basins and forestry reservations, which mining operations should cease, who will implement and monitor procedures for closing and prohibiting mining, the environmental measurements that need to be taken, and 
the compensation that ought to be paid by mining companies. The UMMRL, including the ORM NGO, has worked to help enforce the law, and has been part of the Committee that defined the borders of river basins and forestry areas. The law clearly requires government organisations to be accountable, and has affected 1700 mining licences, which are now under review (Shenbayar, 2010). This consequence has created huge controversy among MPs, government organisations, mining companies and NGOs. Although the government passed a regulation to terminate 254 mining licences, based on the new law (Shenbayar, 2010), the companies are still operating, and the regulation has not yet been enforced due to political and economic factors and the lack of effective accountability mechanisms.

Interviewees mentioned the ORM NGO as an exemplar of both an active NGO for environmental protection, and as an NGO that had been silenced by power influences. Four interviewees noted that the ORM has acted as a leading NGO that consistently focused on environmental protection and poor mining practices (Interview A4, C1, D4, F12). However, some argued the NGO was in danger of losing its independence and of being "absorbed by the government", given that the government provides funding and an office:

Although the ORM is an activist NGO with its own voice, and has been listened to, even if its claims were not always right, that is okay; but the NGO has been more like an advocacy NGO in Mongolia. However, it is now silent, having lost its independence, which is probably a shame (Interview D2, 00:09:47-2).

Another interviewee complained that the ORM was lobbied by foreigners when the international donor organisation nominated its leader for a prestigious international award ${ }^{104}$ (Interview A4). In spite of these differing views, the ORM is acknowledged as a legitimate well-known environmental NGO in Mongolia. This is evidenced by interviewees' arguments and various domestic and international publications.

\footnotetext{
${ }^{104}$ Mr Munkhbayar, the leader of the ORM, was awarded one of six 2007 Goldman Environmental Prizes. This prize is awarded annually to grassroots environmental activists, one from each of the world's six geographic regions (Nijhuis, 2007).
} 
In October 2010, the ORM and UMMRL NGOs appealed to the Court against the government of Mongolia's mismanagement of the mining sector, alleging that it had caused environmental degradation and water scarcity in many local regions. The NGOs also sued the government for its "alleged failure to enforce the law prohibiting mineral resource exploration and exploitation in river and forest basins" (Niislel Times, 2011). However, the Sukhbaatar District Court rejected the lawsuit in March 2011 on the grounds that "there is no law stating that the government should be responsible for damage to environment caused by mining companies and to compensate local communities for such damage" (Shinebayar, 2011).

In early September 2010, a small group of citizens, including the ORM leader and members of the UMMRL, "armed with hunting rifles, opened fire on gold mining equipment owned by two foreign mining firms operating illegally in northern Mongolia" (Snow, 2010). This action raised numerous criticisms in both domestic and international media, but once again focused social attention on poor mining practices. In company with other environmental and social NGOs, the leader of the ORM became a co-founder of the Gal Undesten Movement, regarded as a strong activist NGO aiming to forcefully address environmental and mining issues. The leader of the ORM co-organised demonstrations against mining companies and the government, but was arrested.

On 19 June 2011, forty activists of the Gal Undesten Movement were threatened and shot twice at the gold mining equipment of the Ermuun Bosgo Company in Uvurkhangai province. Before the shots, activists had sent a written request to the director of the company to stop mining operations in the prohibited area (Lkhagjav, 2011). However, the company did not reply, and the movement organised demonstrations followed by the shootings. Seven activists were arrested and investigated, according to the criminal code of Mongolia, under the article of offences against property (Oyundari, 2011).

In summary, ORM has challenged mining constituents to address poor mining practices, and has improved the accountability of both the government and mining companies. It has adopted various activist strategies both individually and 
collectively with other environmental NGOs. As well as demonstrations, ORM has undertaken a diverse range of activities to protect the environment and to educate local communities. Notwithstanding criticisms of its activities, ORM has become a widely acknowledged exemplar NGO.

\subsubsection{A cooperative NGO - the Responsible Mining Initiative}

Another influential NGO, which has sought to raise awareness and influence political and policy discourses to develop socially and environmentally responsible mining, is the Responsible Mining Initiative for Sustainable Development (RMI). The RMI was registered as an NGO in December 2007, and was the initiative of several multi-stakeholder forums, set up to address responsible mining. As a non-membership public NGO, it operates primarily in the capital city. The RMI seeks to promote responsible mining by aligning itself with the concept of sustainable development. The aim of the NGO, as outlined in its mission statement, is:

To build a common framework of understanding of responsible mining in Mongolia among the public, government, industry, and investors; to provide open and transparent information; and to secure equal participation of the multistakeholders in these activities (RMI, 2009).

The emergence of the RMI reflects the diversity of Mongolian civil society. The first 'Multi-stakeholder Forum' was held in 2006, facilitated by an international donor NGO, the Asia Foundation (TAF); it attracted a wide range of interest, including from the government, civil society, mining industry and academia. Participants developed a definition of responsible mining and its eight guiding principles. As Molisa et al. (forthcoming) argued, the way the RMI defined mining, however, "was clearly normative in the sense that it said more about how mining ought to be rather than about how it currently is" (p. 6). Its definition of responsible mining is:

A comprehensive and transparent minerals activity respecting the rights of all stakeholders, especially of local people, environmentally friendly and free of human health impacts, embracing the best international practices and upholding 
rule of law while generating a sustainable stream of benefits for Mongolia (RMI, 2007). ${ }^{105}$

Thus, the idea of responsible mining was fully 'imported' from the best mining practice of developed countries.

The second forum was organised in April 2007, where participants agreed to establish the RMI NGO. They developed and signed a 'Declaration on Responsible Mining', which was signed by different mining constituents. Later that year, the RMI was registered as an NGO. The declaration set out fundamental principles to guide the NGO: which assisted in defining its purpose, providing general guidance for its activities, and identifying principles of cooperation for its constituents. The declaration acknowledges the harmful impacts of existing mining on the environment, society and economy, and recognises the importance of responsible mining that "will benefit all Mongolians now and in the future" (Darling, 2009). Multi-stakeholder engagement, based on mutual respect and information sharing, is recognised as a key principle of the NGO, and its members have equal rights and responsibilities to participate in making collective decisions (RMI, 2007). Approximately 60 organisations have signed the declaration to date, agreeing to develop responsible mining and follow its guiding principles (RMI, 2009).

Since 2008, the RMI has undertaken various activities: engagement in policy and standard development, knowledge building and information sharing, and development of performance indicators. The NGO successfully cooperated with MPs to include responsible mining-related clauses in the mining and environmental policy sections of 'The 2008 - 2012 Government of Mongolia Action Plan'. The NGO also co-organised thirteen multi-stakeholder forums with TAF and organised a series of panel discussions at the National University to

\footnotetext{
${ }^{105}$ The eight guiding principles are as follows:

- Secure multi-stakeholder participation

- Transparent and open

- Law-abiding and enforcing

- Responsible for environment and human security

- Investing in the future

- Efficient

- Humane and ethical

- Technologically advanced (RMI, 2009).
} 
build knowledge and share information with the public and other stakeholders (RMI, 2009). Facilitated and funded by the MNET, the RMI participated in the development of standards aimed at regulating mining rehabilitation. The NGO has also begun to develop criteria for mining companies to measure their compliance with principles, and to inform the public about successes (Interview F9).

The RMI represents an interesting case in the Mongolian NGO sector as it illustrates the new phenomenon of a tri-sector partnership approach. For the last two decades, mining has attracted huge interest and controversy. As discussed in Chapter 7, there are differing views and debates about mining development, and its role and contribution to Mongolia's development. Mining constituents have worked separately and not listened to each other. Through these engagements, stakeholders have begun to recognise a need for listening and cooperating with each other in an endeavour to address mining issues and to change the mining sector so it can be "beneficial to Mongolia" (Interview D3).

The 2006 and 2007 forums, facilitated by TAF, have provided the opportunity for mining constituents to come together and collectively discuss mining issues; they had agreed on the need for more regular and consistent engagement to address issues they all care about (Interview D1). Although constituents have different backgrounds, understanding and views, they realised they need a place or organisation that can facilitate potential interaction and cooperation among different constituents (Interview D6).

For forum participants, NGOs have been recognised as a space for participation, dialogue and collective action for promoting responsible mining initiatives. As an interviewee said:

Participants of the forum chose to establish a non-political, non-governmental and non-profit organisation that could enable stakeholders with contested interests to come together, and talk and act with equal rights: no one stakeholder has more privilege than another, and all have equal rights and responsibilities to express their voices, to provide information, and to participate in activities (Interview F9). 
To enable this interaction, dialogue among stakeholders has been promoted as the foundation of RMI operations, and the principal form of activity (RMI, 2007). To have effective dialogue is challenging for Mongolians as they have little experience of the concept of dialogue. In practice they often have "monologue type meetings, where one talks and others listen without much interaction" (Interview D6). However, they are gradually learning to talk, listen, and debate with each other by participating in various meetings and public debates supported by NGOs, international organisations and the media. Thus, the RMI is becoming a 'space' where mining constituents try to listen, talk, share their views, and reach mutual understanding and decisions for the promotion of responsible mining principles.

The RMI's organisational structure comprises board members, supervisory board members, and staff. The board is composed of fifteen different organisations, including:

- two MPs from the most powerful opposition political parties, which have led the parliament and government interchangeably since 1990

- the deputy director of the Water Agency of the MNET

- two academics, including a former MP and the vice president of the University of Agriculture; and a lecturer and head of Young Researcher Innovation of the University of Science and Technology

- the vice president of the Corporate Affairs and Social Responsibility Division of Ivanhoe Mines Inc. ${ }^{106}$

- an expert of an EIA company

- a leader of a local environmental NGO

- representatives of two social NGOs, including the national social responsibility NGO and the human rights NGO

- representatives of five other civil society organisations including: the Mining Association, the Mining Sector Youth Confederation, the Mongolian Labour

\footnotetext{
${ }^{106}$ Ivanhoe Mines is a Canadian mining company that has signed a stability agreement with the government in September 2009 to begin its operation of the Oyu Tolgoi copper deposit in the Gobi. 
Union, the ecology department of the National Chamber of Commerce and Industry, and the Incubation Centre of Business Development (RMI, 2009). The director of TAF serves as a supervisory board member. The RMI has two permanent staff, including a senior advisor and project manager.

Each board member of the RMI has contributed in different ways. TAF has played an important role in operationalising the RMI through its support during the establishment phase. It facilitated multi-stakeholder forums, and mediated between mining constituents with contested viewpoints. TAF helped different constituents come together and interact with each other. Once the RMI was established, TAF began to fund operational costs, such as the office rent and staff salaries (Interview F9).

Although the advantages of having support from the donor organisation have been many, difficulties can also be created, such as the donor influence on the RMI's policies, decision-making processes and the board structure ${ }^{107}$. One NGO interviewee, who criticised the relationship between RMI and the donor NGO, observed:

The RMI was at the mercy of the donor's orders. On first appearances the RMI looks a good initiative that enables tri-sector partnership, and generates dialogue. In reality, however, the RMI is the opposite of the public's intentions. It pretends to be multi-stakeholder oriented but is heavily dependent on the donor NGO. The donor NGO dictates what and how to carry out matters. If you do not listen to it, then it will not work with you. Through various discussions and forums, only those who are willing to accept the donor's requirements and who have same interests remain (Interview F1, 00:12:46).

In terms of state representatives of the RMI, there are two members of parliament from the two major opposition parties. This could be viewed as a good beginning, as these MPs will become aware of multi-stakeholder comments and views, and

\footnotetext{
${ }^{107}$ The donor could influence who should or should not be a board member. For example, ORM resigned from the board of the RMI. According to the ORM leader, this was related to the fact that the donor NGO called the ORM a 'terrorist', and ceased cooperation after the ORM declared its willingness to participate in activism against mining companies to stop irresponsible mining operations.
} 
can consider those views in relevant legislation and policies, thus hopefully legislation can be more inclusive and effective. Similarly, a government agency representative could inform the RMI members about government policies and decisions, and be persuaded to improve policies by recognising the views of other RMI members.

In terms of NGOs, the RMI has a relatively good mix representing environmental, social, and mining specialised NGOs, comprising eight out of fifteen board members. Two board members are from the Mining Association and the Mining Youth Association, while another three are from business-related organisations. Nevertheless, including more NGOs is an achievement as it suggests that NGOs are beginning to be regarded as 'legitimate' actors, and their views and comments are being heard among mining constituents.

The RMI provides an opportunity for domestic NGOs to engage in discussion and to influence the decisions and actions of other mining constituents. This cooperation among NGOs offers a way to address criticisms that NGOs are simply critics and activists, rather than being part of any "practical solution". Some interviewees supported this argument and expressed their views that NGOs needed to engage in activities that can have real benefits for mining issues (Interview B7, D5).

However, NGOs in the RMI structure could also be criticised on the basis of their representation. The environmental NGO is a member of an NGO coalition established by the same donor $\mathrm{NGO}$, and some social and business-oriented NGOs are new to this field. It is not clear whether these NGOs can ideally represent the NGO sector, given that some influential NGOs in mining and environmental issues are not included in the RMI. This might be either because more activist NGOs do not wish to cooperate with other mining constituents (namely, mining companies and the state), or that they are excluded from the RMI as it does not wish to include more controversial and critical voices, which might make it difficult for RMI members to cooperate and reach shared understandings. 
The Canadian mining company occupies a prominent place on the RMI board as a mining representative. Compared to other mining companies, it refers more often to CSR and sustainable development (Ivanhoe Mines Mongolia LLC, 2008). It has been one of the most high-profile companies in the media due to its deposits and stability agreement negotiations with the government ${ }^{108}$. Having this company as part of the RMI board provides other members with access and influence during the process of persuading mining companies to adopt best mining practices. However, there is considerable concern that Ivanhoe Mines might merely engage with the RMI to improve its public image through favourable publicity, or more disturbingly for some, to influence the RMI and its polices for its own benefit.

The RMI case-study illustrates that an NGO can focuses on cooperation and dialogue to promote sustainable and participatory mining. Through the tri-sector partnership, controversy among mining constituents has begun to be openly discussed and problematised, and more importantly, conflicting parties are learning to collectively engage in decision-making. However, this cooperation might also create a degree of compromise, exclusion, manipulation and politics due to the power dynamics among constituents.

\subsubsection{Challenges for Mongolian NGOs}

In spite of their achievements, environmental NGOs face various challenges that prevent them from achieving their common goals - environmental protection and the well-being of Mongolians. Based on interviews and document analysis, it can be argued that the NGO sector is still in its infancy, at a fragile stage of development "where it could easily change in any direction" (Interview D3). Some interviewees were critical and described such a developmental stage as a "wrong formation", given that most NGOs have been established to improve the personal reputation and careers of their leaders, and to make money from environmental funding (Interview F1). This opportunistic behaviour can be

\footnotetext{
${ }^{108}$ The company discovered world class copper/gold deposits in the Gobi, and has spent five years since 2004 negotiating a stability agreement with the Mongolian government. The agreement was the hottest topic of public debate, and the company organised various meetings, training sessions, and press conferences to stimulate dialogue on this subject.
} 
evidenced in statistics that indicate that approximately only 20 out of 500 environmental NGOs are active (Interview F8, F12), with 80 percent located in the capital city (Open Society Forum, 2005). On the other hand, this could also relate to the fact that Mongolian NGOs have not had enough time to develop their core skills and capacities (Interview C2, D6).

Table 5 lists the principal challenges for NGOs, which can be categorised as internal and external, although these are deeply interrelated.

Table 5. Challenges of Mongolian NGOs

\begin{tabular}{|l|l|l|}
\hline & \multicolumn{1}{|c|}{ Internal issues } & \multicolumn{1}{c|}{ External issues } \\
\hline $\mathbf{1}$ & Financial capacity & Cooperation \\
\hline $\mathbf{2}$ & Human resources & Political pressure \\
\hline $\mathbf{3}$ & Consistency & $\begin{array}{l}\text { Government support and } \\
\text { bureaucracy }\end{array}$ \\
\hline $\mathbf{4}$ & Conflict of interest & Corruption \\
\hline $\mathbf{5}$ & Leadership & Pressure on NGOs \\
\hline $\mathbf{6}$ & Representativeness & \\
\hline
\end{tabular}

\section{a. Internal issues:}

1. Financial capacity: NGOs, particularly local NGOs, struggle with their financial and basic operating capacities (UNDP, 2006). Most NGOs are financially dependent on foreign projects (Interview D3, D4), which creates a difficult dilemma for NGOs. As an NGO interviewee observed, the situation is so mixed that it is difficult to distinguish whether NGOs are "finding funding for funding" or "finding funding for an operation" (Interview F9).

Although other financial resources exist, such as a share of income tax revenue and donations from organisations and the public, these resources are not fundamental resources as in other countries (The National Network of Mongolian Women's NGO, 2004). The legal environment does not encourage NGO development, as only one percent of personal tax income is used for NGO funding, and provisions that previously allowed tax exemption for organisational donations to NGOs have been discontinued (Interview F1). Due to poor economic 
conditions, people are not able to support NGOs, thus public donations are not "a reliable financing method" (Interview F13).

2. Human resources: Working in NGOs is often a voluntary job. NGO staff face difficulties balancing personal life with NGO work (Interview F8). Even for paid positions, it is a challenge to find people who are willing to work hard and passionately for only modest salary (Interview F7). The lack of human resources restricts the ability of NGOs to engage continuously in activities (Interview D3). NGOs were criticised for their lack of knowledge and specialisation. Some argued that the public and NGOs still do not fully understand "what is an NGO?" (Interview F9). An interviewee claimed that 70 to 80 percent of NGOs do not understand their roles and "what they can and cannot do" (Interview A2). Sometimes, NGOs sought to conduct EIAs, which according to the EIA law should be only carried out by licensed professional experts (Interview A2, A6). Mining interviewees argued that NGOs merely criticised mining in a poorly informed manner (Interview C2, C3); and NGOs were blamed for being critics of environmental destruction and pollution after the event, and for causing public discontent and needless demonstrations (Interview F13). Rather than developing strategies and methods on how to engage in decision-making (Interview D5), misinformed NGOs were seen as making great deal of noise, but without scientific evidence to support claims (Interview D1, D6). This detracts from the credibility and reputation of NGOs in society, and creates social misunderstanding about NGOs as "activists" (Interview D5).

Due to their different stages of development, some NGOs are more skilled, conduct research, and have input into a law drafting process, whereas others merely struggle to begin their operations (Interview F13). Although many NGOs are funded by international donor organisations, they have weaknesses in the areas of language and communication skills, and need more interaction with donors (Interview D6). They also lack the capacity to use scientific evidence (Interview D1, F9). NGO interviewees, themselves, acknowledged such criticisms, and agreed that NGOs shied away from engaging in environmental decision-making and monitoring because of a lack of knowledge, experience, and ability to engage 
(Interview F3, F7). Thus, interviewees suggested that NGOs needed to be better informed and educated, and to improve their capacity building in order to gain public trust (Interview D1, F12).

3. Consistency: NGOs were also criticised for competing for financial resources without attending to the environmental issues they were supposed to address (Interview F3). An NGO interviewee argued that 'NGOs have an 'opposite logic' - of fighting for government provided projects - rather than providing voices when the government does not act in the public interest" (Interview F8). They are deficient in terms of their vision and of acting consistently in relation to goals, and tend to "jump from project to project" (Interview D3, F9). Such arguments are supported by reports that criticise NGOs for acting inconsistently with respect to their goals (Open Society Forum, 2005; UNDP, 2006). This creates public scepticism of NGOs, and affects their credibility.

4. Conflict of interest: Many interviewees raised the issue of conflict of interest among NGOs, which can be identified at an individual or organisational level, such as personal ambition, and the 'money-making' sector.

NGOs were regarded as operating with an overly short-term view or as being unduly influenced by individual interests, such as a desire to improve their organisation's reputation, or to gain a personal career improvement (Interview F1, F14). Moreover, claims were made that some NGOs favoured particular individuals or groups, and focused on foreign mining companies to enhance their political careers (Interview C3). Such criticism is interesting as it supports arguments that environmental and mining issues are political, thus NGOs have become politicised.

On an organisational level, most NGOs viewed civil society as the 'moneymaking arena' (Interview F8). Many opportunistic NGOs have been formed to receive donor funding. An interviewee described: "I have met people who conduct three different businesses, funded by three different NGOs, but they are all operated by the same person. That is unfortunate" (Interview D6, 00:24:50-9). 
The increased donor funding for environmental protection has led to opportunism and corruption. There are approximately 15 to 20 million dollars (US) of funding for environmental projects annually (Interview F1). As the Ministry distributes funding, government officials establish their own NGOs under the names of relatives and friends, and receive project money (Interview F12). Anecdotal evidence suggests that the mother of a previous president has eleven NGOs (not all environmental), and an ex-minister of the MNET has many NGOs (Interview F8).

Because of this opportunism, there is a lack of interest in reporting on the use of foreign funding. Statistics of environmental funding for the last two decades do not exist due to the lack of political will to report (Interview D5). An interviewee stated that when he personally asked the current minister ${ }^{109}$ to show a report on the Environmental Protection Fund, "he [the minister] shamelessly told me "you guys don't need to see [the report of Environmental Fund], I'll tell you when I'm not afraid to see it" (Interview F1, 00:39:51). These arguments illustrate that foreign funding for environmental protection is poorly managed, and contributes to conflicts of interest among government organisations and NGOs.

Another criticism of opportunistic NGOs came from interviewees of mining companies. They argued that some local NGOs were more like 'ninja-miners', and asked mining companies to allow them or local people mining in their licensed areas to contribute to local development (Interview C1, C2). Another mining interviewee claimed that some people and NGOs have realised an opportunity to make money by threatening mining companies, and use NGOs to pursue their own interests (Interview C3). A ministry official also experienced a similar case, where a local NGO negotiated with the Ministry to rehabilitate an abandoned mining area, but later found that the NGO was washing gold from gold-bearing ore tailings (Interview B1). Thus, interviewees complained that claims of NGOs and their actual interests are often contradictory (Interview C2), and require thorough investigation.

${ }^{109}$ During that time, he had been in the position for a year. 
5. Leadership: Leadership is another valid issue. NGO success is very dependent on the leader's personality, his/her passion, discipline, bravery and hard work (Interview A4). Many NGO leaders have conflicts of interest, thus the consistency and sustained activity of an NGO is often related directly to the leader (Interview F9). Although there are approximately 500 environmental NGOs, there is a lack of leadership (Interview D2). This gives rise to passive NGOs that struggle for funding to survive. Most leaders work on an intuitive basis and passion, rather than formal education and management, to address and influence effectively poor mining practices.

6. Representativeness: Most NGOs cannot act as public voices and representatives (Interview F8). There are two kinds of NGOs: the first is formed at the local level in response to poor mining practices, whereas the second type is established in the capital city mostly by middle-class, educated people (Interview A4). Thus many NGOs cannot actually represent the affected local people, as NGOs are mostly organised and managed by city people who are often not aware of the actual situation of local people (Interview B3). However, a counter argument was that some NGOs do not need to represent specific people, as NGOs can be social and member-oriented. Social-oriented NGOs work for the general well-being of people, thus do not need to directly represent local communities (Interview F13). This raises the question of NGO accountability to members and society at large. The accountability of NGOs is poor (Open Society Forum, 2005; UNDP \& Government of Mongolia, 2006), yet none of the interviewees raised or addressed this issue.

b. External issues:

1. Cooperation: Cooperation of environmental NGOs has gradually developed. The main advantage of cooperation is "power of numbers" (Interview D2). Through cooperation, NGOs can collectively impact decision- and policy-making in ways that cannot be achieved by individual NGOs (Interview F1). However, the unity of NGOs is weak for a number of reasons.

Failures to cooperate are usually caused by conflicts of interest, individual ambition, aims of NGOs and their leaders (Interview F1, F5). Once cooperation or 
coalition shows signs of success, members wish to form their own NGO so as to have independent leadership. This results in the formation of more NGOs that need "grants to survive" (Interview D2). Similarly, the distribution of limited financial resources among coalition member NGOs causes problems (Interview F1) as members compete to receive bigger portions for their NGOs. Thus, cooperation fails due to selfish and opportunistic NGO leaders.

Regarding the development of cooperation, an interviewee shared her experience. During efforts to form a coalition of NGOs, an international donor NGO recognised that they needed to develop trust and cooperative skills as in civil society organisations of developed countries (Interview D6). These skills are lacking in Mongolia at the moment, but NGOs are gradually learning from their mistakes (Interview F9, F13).

2. Political pressure: Although NGOs are supposed to be non-governmental and apolitical, practice shows they are often political. However, there are differences: some NGOs use NGOs for political purposes, while others became silent because of political pressures.

On the one hand the NGO sector is criticised for being a 'joke', consisting of 'unreal' NGOs. An interviewee argued that political leaders and government officials established their own NGOs so Mongolia could be "looked on as a democratic country" (Interview F8), or to use environmental funding for themselves (Interview F1). Other interviewees were critical that NGOs are mixed, and that some are influenced by political interests (Interview D6) or under pressure from political groups (Interview A4). Politicisation of NGOs becomes more evident nearer to elections (Interview C1, C2), as some NGOs "serve their political networks" (Interview F8).

'Political' NGOs not only threaten the credibility of the NGO sector in society, but also cause trouble for mining companies. A mining interviewee related his company's attempt to mine gold along the Taaz River. The company faced arguments, demonstrations, and physical conflict from local people and NGOs, in spite of the fact it had the necessary licences and documents required by law. It 
attempted to negotiate with demonstrators, but had no success and eventually left the area (Interview C1). Another mining interviewee shared a similar story, complaining that politicisation of NGOs had resulted in a large loss for the company, as it had already invested and moved equipment to that area (Interview C2).

On the other hand, there are also many NGOs that become silent, due to political pressures. As raising mining issues usually involves taking "a stand against someone", NGOs often engage in activism in the capital city rather than working in local regions (Interview F1, F7). Once NGO members and local people become intimidated by power groups and mining companies, some become careful and prefer not to complain so often (Interview D2, F12). Two women interviewees of NGOs shared their experiences of the dangers of lobbying rich and powerful people and companies. One was threatened during the Khongor soum cyanide contamination case; her car was shot at as she drove alone, returning to the city after organising a demonstration in Khongor soum (Interview F8); but the police refused, with no explanation, to register her case (Interview F8). More generally, various threats from government, political groups, and companies can cause NGOs to stop operating, even after many years of activism (Interview A4).

3. Government support and bureaucracy: Another issue raised by interviewees, not only by NGOs, was the lack of government support. Government support for training and informing NGOs is critical (Interview A5). Unfortunately, NGOs have little power to operate as the government provides only a limited budget (Interview D4, F13).

Poor governance and bureaucracy of the public sector is a widely criticised problem in Mongolia, and also causes problems for many NGOs (UNDP, 2006; World Bank, 2007a). Due to centralised governance, all decisions are made in the city (Interview F3). Thus NGOs need to have representatives and offices in the city, and this leads to financial and human resource difficulties (Interview F2, F8).

NGOs also find it difficult to express their voices because of bureaucracy and politicisation. When they try to organise marches or demonstrations in the main 
squares, the Police Department can reject or introduce bureaucratic procedures that obstruct the permission process ${ }^{110}$ (Interview F1, F10). Such barriers from government organisations limit the activities of NGOs.

4. Corruption: Corruption affects NGOs in a number of ways. On the one hand, corruption limits and can result in failures of NGOs. NGO members complained they were powerless to stop mining operations, claiming that even if mining licences were revoked they could easily be renewed by corrupt senior officials (Interview F3). An interviewee said that she and other cooperating NGOs sent requests to government organisations, collected hundreds of protest letters from local people, organised demonstrations, and finally had government authorities stop irresponsible mining operations in their region. But within 24 hours, mining companies had obtained approvals from senior officials, even from the Prime Minister (Interview F2). Even relatively active NGOs can become silent when the impossibility of operating in a corrupt society is recognised (Interview A4), or when threatened by corrupt bureaucrats (Interview F8).

On the other hand, corruption among NGOs attracted criticism. Interviewees argued that corrupt NGOs threatened the reputation of all NGOs (Interview A1, F3). An interviewee argued:

There is a lot of corruption among NGOs, which is unfortunate. Without funding, they cannot do what they aim to do. So they are paid by mining companies to be silent... It is very difficult for these NGOs to be transparent and to operate $\ldots$ in corruption-free ways (Interview D6, 00:24:50-9).

Corruption not only limits and silences NGOs, but also attracts opportunistic people to use NGOs for pursuing their individual interests. Thus, it is very difficult for NGOs to operate in a society with endemic corruption.

5. Pressure on NGOs: There are various pressures on environmental NGOs, and these can be classified as expectations of NGOs and government 'pressure' on NGOs.

\footnotetext{
${ }^{110}$ According to regulations, organisers need to obtain permission from the related district Police Department to organise public events in the main squares of the capital city (The State Great Khural of Mongolia, 1994).
} 
In spite of a great many expectations of NGOs, the public do not actively engage and support NGOs (Interview D6). Although people may personally support the goals and activities of NGOs, they do not know how to influence, organise and support them (Interview F8). This is related to the lack of awareness and knowledge about the roles and characteristics of NGOs (Interview F9). In the absence of a philanthropic mindset, as in Western countries (Interview D6), there is little financial support for NGOs (Interview F13).

Similarly, donor organisations expect much from Mongolian NGOs without recognising they are not as developed or as institutionalised as in Western countries (Interview D2, D6). Corruption among NGOs and their misuse of environmental funding causes donor cynicism of NGOs (Interview, D5). This results in an "uncomfortable relationship" among donors and NGOs, and donors focus on short-term projects rather having long-term positive influences on the sustainability of NGOs (Interview D6).

There are criticisms of donors as well. Some NGO members were critical of the influence and intentions of donors. The ORM leader related his experience of cooperation with a donor organisation, criticising donors for having silencing tactics, and for using NGOs to plant their capitalist ideas in Mongolia (Interview F1). Another NGO interviewee argued that through funding, some international NGOs and power groups had joined the boards of NGOs, and then silenced or divided strong NGOs from within (Interview F10). A third interviewee complained that international donor organisations had played crucial roles in importing their capitalist infrastructures, and had used some NGOs as informants (Interview F8).

As well as expectations from the public and donor organisations, there is a tension among government organisations to 'filter' NGOs into 'good' and 'bad'. Many government officials and EIA interviewees saw NGOs as a substitute for government functions, such as monitoring (Interview A5, B1, B2, B5, D5). They saw activist NGOs as "noise-makers" and destructive, while NGOs that cooperated with the government and implemented its projects were seen as "good" 
(Interview F14). This attitude was evident from the statements of some interviewees, such as "the government needs to clean up this situation" that is having activists and other types of NGOs (Interview B1), "the SSIA tries to work with the right ones [right NGOs refer to non-activist cooperative NGOs]" (Interview D6), and "it might need to have an organisation that distinguishes the good NGOs from the bad" (Interview B7). It is argued that the government needed a filtering mechanism to rid civil society of "bad" or activist NGOs.

Pressures through expectations and classification of "good" and "bad" NGOs affect the formation and development of NGOs. They not only restrict the activities of NGOs, but also influence what type of NGOs form. This is arguably dangerous as this situation could damage the diversity of NGOs and democratic processes.

Given the internal and external problems facing NGOs, the current NGO sector can be summarised as struggling to gain credibility and authority in existing social and political spaces. Although various issues make it difficult for them to have influential and active engagement in mining and environmental issues, NGOs still arguably have the potential to promote dialogic EIAs and economically sustainable mining.

\subsection{The potential of NGOs to promote dialogic EIAs}

\subsubsection{Current NGO engagement in EIAs}

Currently, environmental and social NGOs do not participate in EIAs. This is mainly related to the monologism and technocracy of existing EIAs as discussed in

Chapter 7.

From the NGO perspective, they were not aware of EIAs until 2007, and lacked understanding of them (Interview F3, F12). There have since been some 'ad hoc' NGO engagements in monitoring the enforcement of EIAs. As found in the debate in literature on EIAs, in LDCs, some NGOs have attempted to use EIAs to make 'scientifically valid' counter-arguments to oppose poor mining practices. As EIAs 
are conducted by experts and based on scientific assessments, NGOs occasionally point to EIAs and claim that either mining companies have not complied with EIA recommendations or that EIAs have been incorrectly carried out. For example the "Khuduu Aral" NGO of Khentii aimag sent an official written request to the MNET, claiming that a mining company had not complied with an EIA and had polluted the river. The MNET agreed to send a re-assessment expert group to the mining site for investigation. Interviewees shared other cases where they undertook similar tactics of using the EIAs to bolster their arguments and to call for mining companies to cease operations (Interview F3, F7).

The principal difficulty for NGOs to use EIAs as a basis for their activism is the lack of access to EIAs. All NGO interviewees complained that EIAs are not accessible in terms of either the information itself or the language used. To monitor environmental compliance, the ORM NGO leader requested on several occasions that the MNET keep him informed of EIAs and monitoring plans. Notwithstanding the legal requirement for access to EIAs, he noted such requests are almost impossible as:

Ministry officials prevaricated on these requests, and in some cases gave implausible excuses for not releasing the documents. Some claimed the documents were confidential, while in a few incidents ORM leaders were prevented from seeing the appropriate ministry officials. For the ORM, this reinforced the urgent need for a freedom of information law that would guarantee access to such information, require officials to respond, thus rendering the government to be more transparent and accountable' (UMMRL, 2009).

Interviewees stated that they made various efforts to find EIAs: for example, they sent official requests to the MNET, used their personal connections with senior officials to see EIAs, and found an English version of an EIA through their international networks (Interview F1, F3, F7, F8, F12). These statements also supported claims of the inaccessibility of EIAs as discussed in Chapter 7.

In spite of the lack of awareness, experience, and access to EIAs, NGOs reported that they have become more aware of the importance of EIAs, public participation, 
and enforcement of EIAs. An interviewee of the Centre for Human Rights and Development reported the experience of working on an environmental case, caused by poor mining practices; after two years of hard work, the NGO lost the case due to the lack of an assessment methodology on environmental damage. The Court rejected the case because there was no scientific assessment of environmental damage and compensation. The NGO informed the MNET about the lack of an assessment methodology on ecological destruction; it later developed and proposed a methodology, which was trialled between 2008 and 2009 (Interview F7).

With increased pressure by NGOs, the media, and local communities, the situation is gradually improving. Previously, mining companies held their EIAs as confidential documents, but some mining companies, particularly high-profile ones, are now voluntarily placing EIAs on their websites, and NGOs have been able to request companies to make their EIAs available (Interview A1, A3, C3). Although there is a lack of NGO engagement in the public participation of EIAs, NGOs have begun to recognise the roles they could play in promoting such participation.

Some NGOs have worked with the drafting team on the EIA law amendment Bill, and have proposed separate law articles on participation by collecting comments from various environmental and social NGOs (Interview A5, F2, F3, F7). Most interviewees agree that the roles of NGOs for promoting participatory EIAs are crucial, and that NGOs have the ability to act as informers, educators, organisers, and participants.

In summary, there is a lack of effective NGO engagement at the moment. However, through years of activities and demonstrations, some NGOs have 'discovered' the importance of EIAs in addressing poor mining practices. They have come to understand that they have the potential to play important roles in promoting public participation in EIAs, and some are actively working to realise this potential. 


\subsubsection{Potential roles of NGOs among EIA constituents}

Chapters 4 and 5 discussed the potential of NGOs to promote participatory dialogic EIAs, which is further supported by the analysis of Mongolian EIA practice in Chapter 7. Given the ability of NGOs to bring lawsuits directly, to lobby MPs to draft legislation, Toth (2010) argues that NGOs could act as the "fifth estate", as their relationship to power is "often more direct than that of the press" (Toth, 2010, p. 163). Mongolian NGOs can demonstrate that they have actively addressed mining issues, along with the press, and are gradually learning how to influence and lobby decision-makers.

The role of the ORM and UMMRL NGOs in the development of the new law, and the formation of the RMI NGO, illustrates there have been varying degrees of success. Such cases also show that the development of NGOs and their relationship with other mining constituents have stepped up to the next level, where NGOs can have more strategic influence. Discussions on mining have moved from pure criticism, aimed at stopping or revoking mining licences, to developing responsible mining with the cooperation of all mining constituents, and to drafting law with the support of MPs to prevent mining at river headwaters and in forestry reserves.

In spite of various internal and external challenges, the roles of NGOs in addressing politically sensitive issues of mining and its impacts are essential. As stated in Chapter 7, poor mining, weak governance and a lack of awareness of mining-related issues are closely interrelated to the Mongolian socio-political context. Although NGOs contribute to politicisation of the mining sector, this helps to open up mining issues in society. These can otherwise be neglected by powerful mining constituents, and the public can often remain unaware and incapable of tackling mining-related social and environmental issues. Besides their occasional engagements, NGOs have the potential to strengthen EIAs through improved public participation and non-expert involvement.

In the absence of effective public and private sector accountability, NGOs can help to activate 'sleeping', 'ignorant' EIA constituents; 'sleeping' refers to the 
public, particularly affected local communities, whereas 'ignorant' refers to EIA experts and mining companies that often exclude local communities from preparation, enforcement, and monitoring of EIAs. Figure 9 illustrates how relationships among EIA constituents, and the related power dynamics, can be improved through the engagement of NGOs.

Figure 9. Engagement of NGOs with other EIA constituents

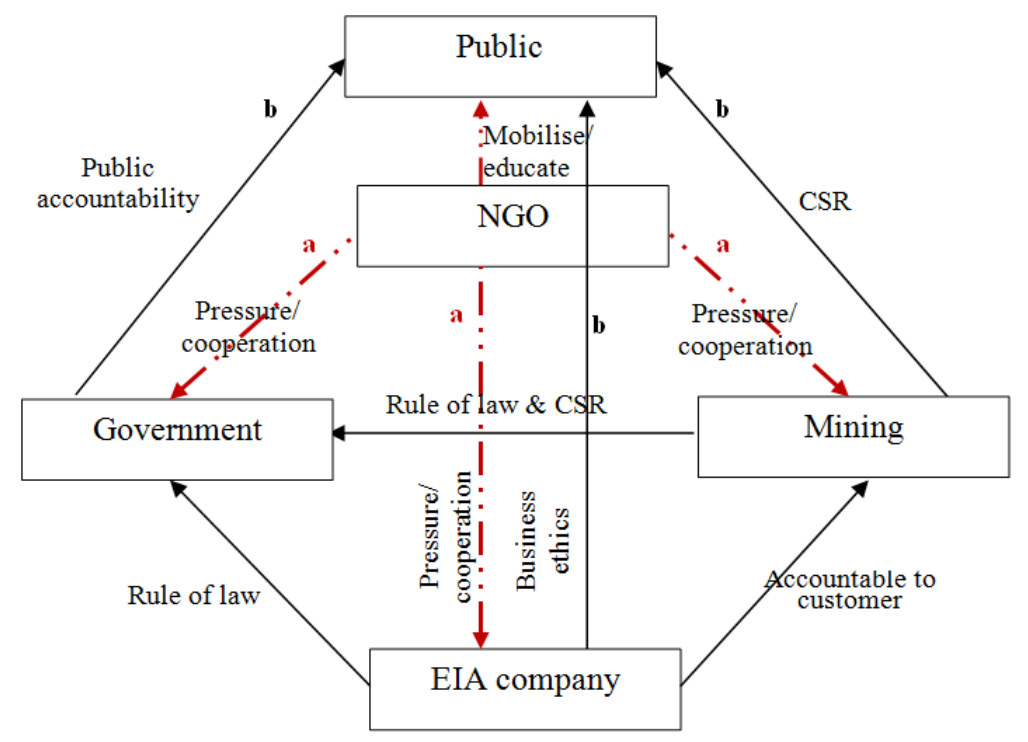

Through the red dotted-lines, NGOs interact with each constituent differently depending on the roles and responsibilities of EIA constituents. NGOs mobilise and educate affected communities showing them how to participate in the preparation, enforcement, and monitoring of EIAs. Some NGOs put pressure on the government and its officials, EIA companies, and mining to act in responsible ways. Other NGOs cooperate with these constituents to improve the quality of EIAs, develop professional ethics, and engage with government organisations to monitor EIAs. The potential benefits of these differing engagements include improvements in EIA quality and inclusiveness, enhancement of accountability of constituents, and enabled social learning for all.

As argued in Chapters 4 and 5, the diversity of NGOs should be recognised, and the NGO sector should not be regarded as a unitary whole. The issue then becomes how NGOs, given their plurality, can promote dialogic EIAs. 


\subsubsection{Plurality of NGOs and promotion of the dialogic EIA}

As discussed in Chapter 7, existing EIA practice in Mongolia, as elsewhere, is monologic and public participation is only symbolic. However, this can be challenged because "even quite closed and technocratic processes can be broken open if the public becomes aware of the project and begins to mobilise against it" (Devlin \& Yap, 2008, p. 19). In this respect, it is argued that NGOs have the potential to mobilise the public for the purposes of promoting dialogic EIAs.

The power of NGOs lies in their potential to be 'border-crossers' among EIA constituents. Depending on their own perspectives and values, NGOs are diverse in their interests and flexible in their strategies. For example, the EIA Association, as a professional NGO, could work with EIA companies, and local and central government organisations to form and facilitate a dialogic EIA framework; while, the Mining Association, as a mining interest group NGO, might facilitate and introduce a benchmark for dialogic multi-stakeholder engagement among mining companies; and local environmental NGOs could mobilise affected local communities to participate in dialogic EIAs.

NGOs could engage in the promotion of dialogic EIAs from different perspectives and with different strategies. The two case-studies of the ORM and RMI NGOs illustrated the complexity for NGOs in addressing mining issues. The ORM has chosen to act as a challenger NGO, aiming to increase social awareness through activism, and to urge the government and mining companies to be accountable for their actions. However, the RMI prefers to cooperate with mining constituents to raise social awareness of responsible mining, and to embed its principles in mining practice. This cooperative strategy also relates to its formation, associated with multi-stakeholder and tri-sector partnership initiatives.

Throughout their development these two NGOs have had similar but different challenges to achieve their goals. Both have faced financial and human capacity issues. The ORM has addressed its problems through international funding and donations from supporters. Diversification of its activities, such as developing a secondary school environmental teaching curriculum, planting sea-buckthorn trees, 
organising local seminars to raise public awareness of mining-related environmental issues, has provided the ORM with the opportunity to apply for international donor funding and to receive public donations. It has also shown consistent leadership among NGOs by mobilising people and similar NGOs to demonstrate against poor mining practices and water pollution. With its strong voice since 2000 , environmental and social consequences of poor gold mining practices in local regions have been widely publicised. This has led to social dissatisfaction with mining, which were previously praised without question as the key to economic development. In spite of criticism levied against the ORM, today its name is synonymous with the mining-related environmental impacts on the Onggi river system, and its actions opposing poor mining practices.

The RMI has resolved its financial difficulties with the help of an international donor NGO. It is a donor 'nurtured' NGO, as the donor NGO has supervised every stage of development and financed all administrative costs. Board members of the RMI are representatives from the mining constituents. The inclusion of powerful groups allows the RMI to cooperate with and lobby large mining players and decision-makers. Dialogue among RMI members is encouraged, making the RMI a unique exemplar, which seeks to overcome distrust and to create mutual understanding and cooperation among Mongolian mining constituents with conflicting views.

In spite of their lack of engagement in EIAs, the strategies of challenger and cooperative NGOs demonstrate that the plurality of NGOs have the potential to promote participatory dialogic EIAs. In Chapter 7, the case was made for having two forms to develop fully dialogic EIAs that could promote economically sustainable mining, and enable meaningful participation, democratisation, and social learning for EIA constituents. Based on the plurality of NGO strategies, the following table (a modified version of Table 3 in Chapter 5) proposes the potential engagement of NGOs in the promotion of dialogic EIAs. 
Table 6. Participatory democracies and the potential of NGOs to promote and facilitate dialogic EIAs

\begin{tabular}{|c|c|c|}
\hline $\begin{array}{c}\text { Types of participatory } \\
\text { democracy }\end{array}$ & Deliberative democracy & Agonistic democracy \\
\hline Position of NGO & Inside mainstream institutions & Outside mainstream institutions \\
\hline NGO strategies & Cooperative/collaborative & Challenger \\
\hline $\begin{array}{l}\text { Engagement in } \\
\text { dialogue }\end{array}$ & $\begin{array}{l}\text { Initiate and facilitate dialogue in } \\
\text { a deliberative sense }\end{array}$ & $\begin{array}{l}\text { Initiate and facilitate dialogue } \\
\text { Or oppose the formal dialogue }\end{array}$ \\
\hline Danger & Being co-opted & $\begin{array}{l}\text { Being excluded from the } \\
\text { mainstream institutions }\end{array}$ \\
\hline $\begin{array}{l}\text { Advantages of co- } \\
\text { existence }\end{array}$ & $\begin{array}{l}\text { Prevent challenger NGOs from } \\
\text { being excluded from } \\
\text { mainstream institutions (by } \\
\text { including their arguments and } \\
\text { proposals to the mainstream } \\
\text { agenda and developmental } \\
\text { discourses) } \\
\text { Perform a connection function } \\
\text { between inside and outside } \\
\text { parts } \\
\text { Facilitate dialogue in a } \\
\text { deliberative sense }\end{array}$ & $\begin{array}{l}\text { Prevent cooperative NGOs } \\
\text { from being co-opted by } \\
\text { mainstream institutions (by } \\
\text { criticising cooperative NGOs, } \\
\text { putting pressure on them) } \\
\text { Perform a monitoring function } \\
\text { over cooperative NGOs and } \\
\text { formal ElA institutions } \\
\text { Participate in dialogic EIAs to } \\
\text { express their views and } \\
\text { propose their agenda } \\
\text { Produce their own counter- } \\
\text { assessment and arguments }\end{array}$ \\
\hline Main objectives & $\begin{array}{l}\text { Effective public participation in El } \\
\text { sustainable mining }\end{array}$ & s, to promote dialogic EIAs and \\
\hline An EIA as a space & $\begin{array}{l}\text { A formal dialogic ElA provides a } \\
\text { legal space for stakeholders to } \\
\text { engage in dialogue }\end{array}$ & $\begin{array}{l}\text { An informal dialogic EIA - } \\
\text { NGOs may produce their own } \\
\text { counter-EIAs and arguments }\end{array}$ \\
\hline \multicolumn{3}{|c|}{$\begin{array}{l}\text { Although NGOs might ignore or reject each other, they are inherently learning from each } \\
\text { other }\end{array}$} \\
\hline \multicolumn{3}{|c|}{$\begin{array}{l}\text { As a result of this co-existence and contestation, these NGOs can contribute to } \\
\text { transformation processes towards: } \\
\text { a. democratisation of ElAs and environmental management } \\
\text { b. sustainable and participatory mining }\end{array}$} \\
\hline
\end{tabular}

As discussed in Chapter 5, both deliberative and agonistic democracies have the potential to address the shortcomings of monologic EIAs. NGOs with cooperative strategies can initiate and facilitate dialogue among EIAs constituents in a deliberative sense. They would be more capable of engaging in the formal form of dialogic EIAs proposed in Chapter 7. Their relations and legitimate positions among EIA constituents may provide advantages for cooperative NGOs. Through cooperation/collaboration from inside the mainstream institutions, these NGOs might bring the stronger voices of challenger NGOs into discussions with EIA experts, decision-makers and mining companies. They could also educate participants on how to effectively engage in dialogue, raise awareness of mining, 
facilitate dialogue in a way that constituents could respect and listen to each other, and ensure inclusive EIAs. However, cooperative NGOs bring the risks of cooption to powerful EIA constituents, and the favouring of mining interests. Thus, the promotion of dialogic EIAs needs NGOs that can also challenge cooperative NGOs and powerful EIA constituents to act in the best interests of the public.

Challenger NGOs, such as the ORM, could act from outside mainstream institutions, given their preference for being watchdogs over the government and mining companies. Based on agonistic participatory democracy, challenger NGOs may act differently, depending on their own perspectives and chosen strategies. Some may cooperate with other EIA constituents and cooperative NGOs to initiate and facilitate the formal dialogic EIAs, and to ensure participation of local affected communities. Others may prefer to remain outside the formal process and to propose counter-EIAs and arguments, if they consider formal dialogic EIAs cannot satisfactorily address mining challenges. They may criticise cooperative NGOs they consider have been co-opted by powerful groups. Although not all EIA constituents may be comfortable with activism and criticism, challenger NGOs would preserve the contestation of dialogic EIAs, and help prevent any new type of monologism.

In spite of their different strategies, both cooperative and challenger NGOs would aim to have meaningful public participation in EIAs for the promotion of dialogic EIAs. Their co-existence would enable mutual learning, contribute to transformation of EIA democratisation, and would promote sustainable and participatory mining. Perhaps this combination could assist in identifying and "unpack[ing] tensions between such issues as consensus and difference, pluralism and justice, or universalism and particularity" (Kapoor, 2008, p. 111) that lie at the core of agonistic democracy.

\subsection{Conclusion}

This chapter has introduced the roles of Mongolian environmental NGOs in addressing poor mining practices. Through case-studies of two NGOs, it has 
illustrated how NGOs act differently to promote more socially and environmentally responsible mining. The chapter has also discussed NGO engagements in existing EIAs, and proposed ways for NGOs to develop dialogic EIAs. The role of NGOs, as 'border-crossers' among constituents, highlights the potential for NGOs to initiate and facilitate dialogic EIAs. Contrary to those who promote a singular approach, the plurality of NGOs is not viewed as a disadvantage. Rather, it means NGOs could encourage both deliberative and agonistic engagements in dialogic EIAs; some would seek to build cooperative relationships, while others would act as challenger NGOs. In short, the contention is that the co-existence of both challenger and cooperative NGOs could help to transform monologic EIAs to dialogic ones, and ultimately promote sustainable and participatory mining practices. 


\section{Chapter 9: CONCLUSIONS}

\subsection{Research overview}

This study examines sustainable development in practice, particularly in the context of mining and environmental management in an LDC. Sustainable development for mining can be defined as economically profitable activities that include consideration of social and environmental issues (MMSD, 2002). The mining sector has been enthusiastically supported in mineral-rich LDCs, in the belief that mining can alleviate poverty and lead to economic prosperity because of increased employment and GDP growth (MMSD, 2001; Ross, 2008). However, mining is under increasing scrutiny because of its social and environmental impacts. Less developed countries are particularly vulnerable to social and environmental issues due, inter alia, to their weak governance and poor economic circumstances (Molisa, et al., forthcoming).

It is increasingly argued that the participation of affected communities in social and environmental decisions regarding mining projects is crucial if sustainability concepts are to be embedded and conflict managed (Hilson, 2000; Toth, 2010). The EIA, an environmental management tool, provides a mechanism whereby mining constituents can assess and discuss ways of mitigating the social and environmental impacts of mining. It is a well-institutionalised tool used around the world, for which public participation is mandated in most countries (Glasson, et al., 2005).

This study aims to address global and local calls for sustainable and participatory mining. It problematises the symbolic participation practices associated with existing EIAs, and investigates whether more inclusive and meaningful EIAs are possible. To this end, Brown's (2009) critical dialogic accounting framework is applied to evaluate existing EIA practices and to suggest the possibilities for reform. The EIA is explored as a potential dialogic tool for promoting sustainable mining practices. This study also explores the potential roles of NGOs to promote 
dialogic EIAs in an attempt to 'democratise' environmental management and foster more socially responsible mining practices.

Chapters 2, 3 and 4 introduced key literature on mining, SEA, EIA, and NGOs. Drawing on this literature, research questions and analytical frameworks were formulated in Chapters 5 and 6. The key research question was: Can the EIA provide a dialogic accounting tool to promote sustainable and participatory mining. Chapters 7 and 8 addressed this question by examining the EIA and Mongolian mining practices, and the roles of NGOs in contesting certain practices.

Mongolians have begun to question existing mining practices because of mismanagement, and the negative social and environmental impacts. On the one hand, mining proponents point to the potential to bring economic prosperity to 2.6 million Mongolians (World Bank, 2004; World Growth, 2008). On the other hand, environmental and social NGOs and others are cynical about mining, and are concerned that the country will be left with polluted land and water resources and depleted mineral deposits for future generations (Munkhbayar, 2005). With increased public awareness and scrutiny, there is a trend among mining constituents to promote the idea of sustainable and participatory mining through various initiatives: large mining companies have made their annual reports and EIAs publicly available and developed CSR agendas; mining NGOs have introduced best practice guidelines and codes of conduct for mining; and donors and the government have begun to encourage multi-stakeholder engagement.

Environmental protection laws have authorised the EIA as a legitimate environmental management tool. However, practice shows that EIAs have been implemented in a monologic fashion. EIAs are approached as a technical tool for experts to apply before a mining project begins. Public participation is minimal and symbolic. NGOs have not yet been actively engaged in EIA processes. With growing conflict among mining constituents and demonstrations against poor mining, EIA constituents have begun to question the quality of existing EIAs, while at the same time acknowledging the importance of EIAs for developing sustainable and participatory mining. Some experts and NGOs have developed an 
Amendment Bill for parliamentary debate on the need to establish more participatory procedures in EIAs.

NGOs have played crucial roles in raising social awareness of poor mining and environmental issues. As discussed in Chapter 8, Mongolian NGOs are still in their infancy and have experienced a number of internal and external challenges. Some NGOs have addressed operational and other challenges, while others have been silenced or have disappeared. Two case-studies of environmental and mining related NGOs illustrate this struggle for development, but also demonstrate how NGOs have challenged existing mining practices by different strategies of engagement. Both NGOs aim to address poor mining practices, and to promote sustainable and participatory mining. However, the ORM has acted as a challenger NGO with a strong critical voice and activism, whereas the RMI has focused on cooperation and dialogue among mining constituents. Through exploration of their similarities and differences, it is clear that NGOs cannot be regarded as a unitary whole. Rather, they need to be examined in all their sociopolitical complexity, including their power relations vis-à-vis other mining constituents.

Based on my findings, this thesis argues that the promotion of inclusive and dialogic EIAs is important if sustainable and participatory mining practices are to be developed. However, this requires careful consideration of how to change and the role(s) that can be played by different EIA constituencies. Along with other players, this thesis argues that NGOs would have important roles to play in any transformation process. The combination of both challenger and cooperative strategies could enable development of more democratic, participatory, and meaningful EIAs that could challenge existing poor mining practices, nonparticipatory decision-making, and the lack of accountability among government organisations, EIA companies, and mining companies.

\subsection{Implications for theory}

This thesis contributes to literature on SEA, particularly dialogic accounting and environmental management. As discussed in Chapters 3 and 5, dialogic 
accounting is an emerging field in SEA that proposes dialogic engagement and pluralism could foster sustainability and accountability. This study applies Brown's (2009) dialogic accounting framework to explore and evaluate existing environmental management practices. By taking Mongolian EIA practice for illustrative purposes, it seeks to contribute to the debate in EIA and SEA literature, and to support calls for more participatory EIAs that can be embedded in the practice of sustainable development.

\subsubsection{Dialogic accounting}

This study contributes to the emergent body of literature on dialogic accounting. Given its relatively short history, much work remains to be done on both the theoretical and empirical fronts (Brown, 2009). Much of the prior research has focused on the development and application of a sustainability assessment model developed in the United Kingdom and New Zealand (Bebbington, Brown, Frame, et al., 2007; Brown, 2009; Frame \& Brown, 2008). As in SEA more generally, little attention has yet been paid to LDCs (Molisa, et al., forthcoming).

This study contributes to dialogic accounting literature by exploring it in an LDC context and linking dialogic accounting with the literature of other disciplines. It draws ideas from literature on environmental management, mining, and civil society to help flesh out discussion in an LDC context. It also examines Mongolian EIA practices relating to mining projects for illustrative purposes, arguing that the EIA is a potential tool for the application of dialogic accounting.

Given the wider economic, social, and environmental impacts of mining, it is not surprising that mining development in Mongolia has proved controversial. This study argues that there are initial signs of dialogic engagement in discussion of mining development and of encouraging economically sustainable and participatory approaches; it claims these approaches can be extended to the EIA as a tool to address the sustainability challenges of mining (Jay, et al., 2007; Nooteboom, 2007). However, existing monologic EIAs need to be transformed to dialogic EIAs if this potential can be realised. As public participation in EIA is mandated, the social and environmental impacts of mining projects should be 
openly discussed among constituents with differing views. This dialogic process should be seen as a social learning process where "engager and engaged mutually learn" (Bebbington, Brown, Frame, et al., 2007), and reflections from dialogue are subject to further discussion and contestation among EIA constituents.

This thesis brings NGOs into the transformation process. The accountability of business can be addressed not only from the "shareholders' side" (Mathews, 1997; Milne \& Gray, 2007). Stakeholders, including local communities and NGOs, have the potential to promote dialogic EIAs from different perspectives. This study supports the idea of insider and outsider engagements of civil society actors (Bebbington, Brown, Frame, et al., 2007; Brown, 2009), and argues that transformation to dialogic EIAs could be activated and facilitated by a combination of different NGOs. Two case-studies of NGO engagements, concerning responsible mining in Mongolia, suggest that both cooperative and challenger strategies of NGOs can encourage pluralistic engagements within formal and informal arenas of the EIA. A cooperative NGO could mobilise EIA participants and facilitate dialogic EIAs in a deliberative sense. Whereas a challenger NGO could work from outside formal dialogic EIAs by acting as an independent watchdog, making 'counter-EIAs' that could challenge formal EIAs, highlighting power imbalances among EIA constituents, and preventing the formation of new types of monologism. Although cooperative NGOs face risks of being co-opted, and challenger NGOs of being excluded from the EIA arena, the co-existence of these NGOs could be beneficial. While each group might be sceptical of the other's approach, a combined approach would allow dual strategies and the potential for NGOs to learn from each other.

\subsubsection{Environmental impact assessment}

It is also hoped this thesis can contribute to current debate in EIA literature. The EIA is criticised as a technocratic, expert-oriented, 'decision-aiding' tool which overemphasises the instrumentality of natural science, and falls short of providing meaningful public participation (Jay, et al., 2007; Sinclair, et al., 2008). Such a monologic EIA must be censured for its inability to foster sustainability. It is 
argued that existing EIAs do not consider ideological differences and power dynamics among constituents, are incapable of acknowledging the subjective and political nature of EIAs, and do not foster social learning (Cashmore, et al., 2010; Sinclair, et al., 2008; Söderbaum, 2004; Wilkins, 2003).

Based on my data analysis, this study supports the above-mentioned critiques of the EIA. It applies the dialogic accounting framework to assess whether existing Mongolian EIA practices are monologic or dialogic, arguing that they are monologic and incapable of addressing the sustainability challenges of mining raised by local communities and environmental NGOs. At the same time, it is proposed that application of ideas from dialogic accounting might assist in transforming monologic EIAs into sustainability-oriented participatory EIAs.

To this end, the thesis suggests there could be formal and informal EIA arenas to allow greater multi-stakeholder engagement and social learning. Based on EIA legislation, the formal arena would be well-institutionalised and facilitated by experts. In contrast, informal EIAs could provide flexibility and space for EIA constituents, particularly local communities and NGOs, to have informal gatherings, discussion and dialogue to open up the contested nature of EIAs and mining projects. Moreover, formal dialogic EIAs could provide a legal space for stakeholders to engage in dialogue, whereas informal EIAs could offer more room for challenger NGOs and others to produce counter-EIAs and arguments, and to act as watchdogs. Through this plurality and contestation, EIA constituents could recognise their similarities and differences, become attentive to issues of social power dynamics, including the impacts on EIA practices (Cashmore, 2004; Cashmore, et al., 2010), and learn from each other (Saarikoski, 2000; Sinclair, et al., 2008). Moreover, EIA quality and accountability should improve as more participants would have 'a close watch' on EIAs and, with enhanced public participation, practice would become more inclusive. Both formal and informal arenas would be equally important.

In terms of public participation, two stages of engagement may be useful to ensure effective participation of affected communities, and to provide meaningful social 
learning for all EIA constituents. Given sparsely populated local areas and the lack of awareness by some local communities about EIAs, these two stages could be particularly important for a country such as Mongolia. The initial stage would involve local communities, NGOs, mining companies, EIA companies, and local authorities sharing information about a proposed mining project and the EIA, and to begin dialogic engagement among the constituents. As this stage would need to fit in with the nomadic lifestyle of local communities and their engagement preferences, this participation would most likely be informal, and its venues, times and style would be suitable for herders so as to ensure maximum participation of all affected people. Comments and views of local herders regarding a mining project and its potential negative impacts could be heard, and their local knowledge could be acknowledged by experts. This process could also provide an opportunity for experts to learn from local communities.

The second stage of participation could be a formal dialogic process among EIA constituents, including local communities or their representatives if meeting venues and times are inconvenient for affected communities to participate directly. During dialogue, EIA constituents could discuss the mining project and EIA in more detail, including consideration of comments and local knowledge obtained from the initial participation.

These different stages of participation could help address critiques in EIA literature regarding existing approaches to public participation. They might foster changes in practice, so that formality and the exclusion of affected communities is minimised (O'Faircheallaigh, 2010), wider social learning on mining and EIAs among EIA constituents is enabled (Sinclair, et al., 2008), and that ideas about sustainable and participatory mining are actually applied. Organising multistakeholder dialogue after the final EIA report would also allow discussion of the stakeholders' engagement in implementing EIA recommendations. This could be built into the life cycle of a mining project, including defining stakeholder roles in ongoing monitoring processes. 
In short, this study seeks to contribute to mining related debate on the transformation process to sustainable and participatory mining. It argues that such mining could be realised through the greater participation and dialogic engagement of mining constituents from the beginning of mining projects (MMSD, 2002; O'Faircheallaigh, 2010). The EIA could be used in LDCs as a potential transformatory tool that could embed sustainability and participatory concepts into the DNA of mining projects. EIAs and related environmental plans could help transform the current poor mining practices in Mongolia.

\subsection{Implications for Mongolian EIA practice}

In addition to its contributions to academic discussion, this study has suggested practical recommendations on how to improve the Mongolian EIA framework, and has identified roles for different EIA constituents in this process. Due to the relatively short history of the EIA framework, mining, and NGOs, there is a lack of comprehensive research in Mongolia that examines the use of the EIA in mining development and its potential to address mining challenges. Furthermore, no prior research has been conducted to investigate the roles of NGOs in addressing issues of mining and environmental management. This study provides schools of thought and discussion by which EIA constituents could foster sustainable and participatory mining, and develop public participation in EIAs. Suggestions for each EIA constituent are discussed below.

\subsubsection{Government organisations}

As the EIA can be regarded as a tool and process of environmental decisionmaking, policy and decision makers of government organisations would need to consider several issues in order to develop dialogic EIAs.

It would be crucial to establish comprehensive legislation or amendments to existing EIA law and regulations. Most interviewees agreed that the current law needs to be improved to facilitate better public participation. Policy-makers would need to set the 'rules of the game' to clarify what mechanisms and processes are required to enable meaningful dialogic engagement of all EIA constituents, 
particularly affected communities. Amendments in legislation should be attentive to power imbalances among EIA constituents, recognise the subjective and contestable nature of EIAs, aim to minimise bureaucracy, and attend to the potential conflicts of interest of public officials. They would also need to ensure the inclusion of both monetary and non-monetary data in EIAs, and give consideration to the social and environmental impacts of a proposed mining project.

The implementation and monitoring of this legislation would be equally important for the promotion of dialogic EIAs. Information should be accessible to all interested parties, and EIA reports would need to be discussed among EIA constituents both before and after finalisation. Dialogue before final EIAs would be crucial to ensure all constituents could include their concerns, views and local knowledge. Discussion after final EIAs would allow them to express their views on, and share responsibilities for, enforcing EIA recommendations over the life cycle of mining projects (for example, discussing who and how to monitor this enforcement).

Government organisations would need to view the EIA as a dialogic process that requires the active engagement of all constituents, acknowledges inputs from nonexperts, and openly and reflectively discusses alternatives. The EIA would need to be perceived not only as a decision-making process, but also as a social learning process for all EIA constituents. Through dialogic EIAs, participants would obtain knowledge about the EIA, its importance, inclusion, exclusion and its potential to prevent adverse impacts (Sinclair, et al., 2008). They could also discuss their different roles and potential for improving existing EIA processes and for addressing local mining challenges.

This whole process would endeavour to strive for continuous improvement in the quality of EIAs through the inclusion of comments, gathered from a two-stage dialogue among EIA participants. Reflections and lessons from dialogue could also assist the preparation of further EIAs. With inclusion of local knowledge, this process as a whole could localise the Western imported formal EIA, and help 
policy-makers to create a country-specific EIA framework and style of participation.

\subsubsection{EIA companies}

EIA companies would play an important role in promoting dialogic EIAs. Unlike existing monologic EIAs, where EIA companies are the main actors, experts in dialogic EIAs would act as organisers and facilitators of dialogue among EIA constituents, and as experts in preparing and finalising EIAs. They would need to recognise their status in EIA processes as being an equal member of EIA participation, rather than as privileged experts of monologic EIAs. Although such change might be regarded by EIA companies as a loss of their privilege, dialogic EIAs could help them to establish legitimacy in society and, more importantly, to improve the quality of EIAs.

In this transformation, EIA companies would need to recognise the engagement of non-experts as being equally important for the development of EIAs. Comments, views and alternatives proposed by non-experts, during a two-stage dialogue in formal and informal EIA arenas, would need to be considered in final EIAs to obtain the full benefit of dialogic engagements. Thus, experts of EIA companies would need to be attentive to local knowledge and alternative proposals raised by non-experts.

Most importantly, EIA companies would need to ensure the engagement of affected communities in the EIA preparation process, and to have internal mechanisms for enabling the inclusion of affected communities and related NGOs in the implementation and monitoring of EIAs. By doing so, the existing disengagement of EIA companies in EIA enforcement could be corrected.

\subsubsection{Mining companies}

Mining companies would need to recognise their responsibility to incorporate EIA recommendations in their mining operations, and to have participatory mining in order to keep their "social licence to operate". Improved public awareness on mining and EIAs has the potential to benefit mining companies themselves - 
engagement with local communities can foster a two-way understanding of mining issues as well as discussion of ways of fostering sustainable mining practices.

Rather than making ad hoc monetary 'contributions' to local authorities, it would be preferable for mining companies to establish a comprehensive framework and plan for contributing to local social and economic development. In such a process, mining companies would need to ensure that local communities participate fully in planning, discussion, and monitoring of their strategies and plans.

\subsubsection{Environmental NGOs}

The roles of NGOs are crucial in developing dialogic EIAs. Given their plurality of perspectives and strategies, different kinds of NGOs could adopt different approaches. Cooperative NGOs, such as professional associations and NGOs, could take the initiative in organising dialogue among EIA constituents to discuss ideas about improving EIA quality, engagement of non-experts in EIAs, development of social and environmental assessment methodologies and methods, and enforcement mechanisms. More importantly, these NGOs could act as facilitators of the two-stage dialogue in the formal EIA arena because they are part of a tri-sector partnership and are regarded as professional NGOs among the public and EIA companies. They could also be educators and mediators among EIA constituents, given their reputation and cooperative status.

Challenger NGOs, such as environmental and human rights activists, could also contribute to the transformation to dialogic EIAs. Their roles in organising and educating affected communities to participate in two-stage dialogue would be crucial. As these NGOs, particularly local ones, are often formed by local people themselves, they are closer to local communities, and have greater local knowledge on how to organise and involve local communities in dialogue. Thus, they could be facilitators of the first stage of dialogue, organised at the local community level. Moreover, through initial dialogue local people might develop strategies to participate in the second stage of formal dialogue to express their views and influence final EIA reports. Challenger NGOs might prefer to 
cooperate with local communities in executing their strategies, increasing their awareness of legal rights and responsibilities, and giving advice on how to participate effectively in multi-stakeholder dialogue.

Challenger NGOs could also participate in formal dialogic EIAs, acting on behalf of the general public, given their long-standing activism in relation to environmental protection and participatory decision-making. Environmental challenger NGOs may become the strongest counter-voice among EIA constituents. Compared with individuals in local communities, these NGOs have more capacity and skills to develop strong arguments and propose alternative assessments and mitigation methods for potential social and environmental negative impacts. They could produce their own counter-EIAs and arguments, and warn other EIA constituents to be attentive to issues of subjectivity and power dynamics in relation to EIAs. Such NGOs might even refuse to participate in formal EIAs, and form their own informal dialogic EIAs, and undertake activities to challenge formal EIAs.

\subsubsection{Affected communities}

Although local communities would be essential players in the promotion of dialogic EIAs, they would need to become more active members of society to perform this role. Instead of having the current NIMBY attitude, they would need to behave as co-owners of local areas, engaging actively in EIAs, and sharing their views and local knowledge with other EIA constituents. Local communities should have an understanding of their legal rights and responsibilities, and know when and how to execute their rights and take responsibility. Environmental NGOs could facilitate this.

As dialogic EIAs put more emphasis on affected communities and their engagement in different stages of dialogue, local communities could benefit greatly from participation in dialogue and the monitoring of EIA enforcement: they could learn how to engage in dialogue, how to express their views in a credible manner, how to organise effectively to influence final decisions, and how to ensure effective monitoring of EIA enforcement. All these processes might 
challenge existing power dynamics among EIA constituents, and lead to public empowerment (Brown, 2009; Dillard \& Roslender, 2011).

\subsubsection{International donor organisations}

Although there would be no direct engagement of international donor organisations in dialogic EIAs, these organisations might have indirect impacts on the formation of and transformation to dialogic EIAs. Given their active involvement in supervision to improve the capacity building of environmental governance and responsible mining, international donor organisations could act as supervisors and mentors for such a transformation. They could introduce international best practices and in successful cases, where they have overcome poor participation and irresponsible mining, they could help government organisations and EIA companies to implement effective participatory mechanisms in EIA legislation and methodology, and help provide financial support to improve their capacity building. However, they would need to be attentive to their roles as mentors, and not put pressure on EIA constituents to import uncritically Western democracy, capitalism and associated infrastructures.

\subsection{Challenges of implementing dialogic EIAs}

There are issues that would need careful consideration to enable a transformation from monologic to dialogic EIAs. As greater public participation would lead to a redistribution of power from experts to the public (Arnstein, 1969), experts and government officials might fear heightened stakeholder demand and control (Brown, 2009), and they might be reluctant to fully support and facilitate dialogic EIAs. Depending on their educational background and perspectives, they might approach public participation instrumentally as one of the EIA requirements (Doberstein, 2003). Thus, experts and decision-making government officials might not appreciate different stages of dialogue, and could regard it as too timeconsuming and costly (Biller, 2003; Brown, 2009). Some activist NGOs interviewees might also complain that dialogic engagement would not produce immediate outcomes that could solve mining-related environmental issues (Interview F1, F10). 
The proposed forms of dialogic EIAs and dialogue in different stages could not be developed without appropriate legislation, regulatory mechanisms and institutions. However, given the lack of political will among Mongolian politicians and their close connections with business, they could delay passing the Amendment Bill of the EIA law. Mining companies could also obstruct dialogic EIA related legislation, and attempt to keep dialogue as only a voluntary initiative (Fitzpatricka, et al., 2011; Scottish Executive, 2006). Not all affected local people might be willing to participate due to their lack of knowledge, limited ability to express themselves, and lack of power to influence EIAs. As in other LDCs, the majority of Mongolians, particularly women, are traditionally shy, and expressing their views in front of older people and authority and opposing them is regarded as inappropriate. Although people are learning to participate in dialogue and to voice concerns to government, this cultural aspect could take time and effort to change.

In short, the promotion of dialogic EIAs in LDCs could encounter a lack of willingness from EIA constituents. Given this background it is difficult to rely fully on experts and decision-makers in the belief that they will initiate and develop dialogic EIAs; because they have more power to influence other EIA constituents, they might effectively exclude "subaltern voices" (Kapoor, 2008), and this could influence the preparation, engagement and results of dialogic engagement. Some of their power needs to be intentionally redistributed to the public and NGOs through EIA legislation and the participatory framework of dialogic EIAs.

In spite of its oppressive negative side, power also has a positive side, being "the basis of all forms of behaviour in which people resist, struggle and fight for their image of a better world" (Freire, 1985). Therefore, power might have both positive and negative impacts on dialogic EIAs. As discussed in Chapter 7, power imbalances among EIA constituents could restrict effective dialogue and limit potential outcomes. However, attempts at dialogic engagement among participants might also lead to more contestation that could promote discontent and a desire to 
fight for public empowerment and to challenge existing taken-for-granted monologic EIAs.

Approaches to dialogic accounting, based on agonistic democracy, acknowledge the impossibility of eliminating power (Bebbington, Brown, Frame, et al., 2007; Brown, 2009). Rather, the main challenge is "how to constitute forms of power which are compatible with democratic values" (Mouffe, 1995, p. 1536). Therefore, the dialogic approach recognises a need for counter-narratives or "oppositional" forms of talk to have dialogue with the powerful (Brown, 2009, p. 370). This might be intentionally and unintentionally promoted by various NGOs, affected local people, and even by some experts, as experts could become the strongest legitimate actor cooperating with NGOs in developing NGO counter arguments (Li, 2009; Suzuki, 2008).

Considering the lack of political will and appreciation of the need for more dialogic engagement, participation, and facilitation of NGOs could be a potential way to foster power issues in the promotion of dialogic EIAs, and to help people "to see themselves as active constructors of reality" (Brown, 2009, p. 368). As discussed in Chapter 8, this could be realised through different NGO engagement strategies. However, it should be emphasised that NGOs are not yet fully advantaged players in terms of power. Some, challenger NGOs in particular, are considered "noise-makers". This indicates a tendency among all EIA constituents to exclude NGOs, if they have a more critical voice, from important discussion and policy making. This also relates to the contested nature of NGOs and existing politics and opportunism among them. Thus, the NGO sector has also experienced great power struggles among NGOs to establish their legitimacy in Mongolian society.

All these situations cannot be easily overturned within a short period. Rather, there is a need for cooperation among EIA constituents for their common good sustainable and participatory mining. In spite of the above-mentioned difficulties, all constituents have begun to recognise that there is growing social pressure from the general public, media, NGOs and international communities to change 
existing bureaucracy, mining mismanagement and the lack of participation. This study argues that different types of NGOs might challenge power issues, in spite of power imbalances among participants, and the current limited ability of affected people to participate in dialogue. Thus, the contestation and coexistence of various NGOs could positively influence the transformation to dialogic EIAs.

\subsection{Limitations of the study}

This study has limitations, given its exploratory nature and the availability of data sources. The study focuses on Mongolian EIA practices, and its findings and lessons might not apply to other LDCs. Because it is multi-disciplinary and focuses on Mongolia, comprehensive literature and previous research that combines all relevant issues do not exist. For this reason, a longitudinal study could not be conducted.

Due to time and funding restrictions, the fieldwork was carried out over a limited period, and it was not possible to observe events unfolding that a longer casestudy would have allowed. These limitations also influenced the choice of the two NGO case-studies. Thus the findings and discussion on NGOs might not provide a full picture of the Mongolian NGO sector. In spite of these difficulties, I tried to obtain as much information on Mongolian EIAs, NGOs, and public participation as possible by interviewing existing and potential stakeholder groups of EIA and mining. Interviewees were selected, given their direct work experience in mining and EIAs, and their interest in mining and environmental protection.

Various data resources and research methods were used in data collection. Contacts with interviewees and data resources were made by telephone calls and personal meetings. After interviews, some interviewees were contacted when clarification of particular points was needed. The ethical issues arising from the research were handled according to the Human Ethics Committee requirements of VUW, and by my careful conduct. The identity of most interviewees was kept anonymous except for some interviewees and organisations that expressed their willingness to be identified. 
In terms of data analysis and the writing-up, common themes in the interviews were extracted, and related to those in existing literature. Interview data was triangulated against document analysis and personal observation, where possible. Where there were inconsistencies, clarifications from interviewees were sought. Given the controversial nature of mining and its impacts, however, it is not surprising that interviewees sometimes contradicted each other. In those cases, divergent views were discussed.

Data was checked through triangulation of data sources, where possible. My application of the dialogic accounting framework for Mongolian EIA and NGO cases was an exploration, and in many instances I have provided interpretations and discussion from my own standpoint. Other researchers or respondent groups may have different interpretations depending on their perspectives.

\subsection{Future research}

This study opens up various avenues for future research on dialogic accounting and SEA, particularly in LDC contexts.

My thesis addresses calls in SEA for more empirical studies and interdisciplinary research, linking SEA with other social and natural science disciplines (Bebbington, Brown, Frame, et al., 2007). It attempts to foster greater accountability by the mining sector from the "stakeholders' side", and brings EIA into SEA discussion. More detailed SEA research is needed to explore the dialogic potential of the EIA as an environmental management tool that can explicitly address the environmental and social impacts of development projects.

The study contributes to dialogic accounting literature by exploring its application in an LDC context. This field of SEA calls for pluralistic and democratic accounting to promote sustainable development (Bebbington, Brown, Frame, et al., 2007; Gray, 2006a; Unerman, et al., 2007). Future researchers could extend research findings and reflections in this study to continue discussion on how to develop and apply dialogic accounting, particularly in LDCs where Western style democracies and dialogic engagement might be emerging, or to develop more 
LDC-specific alternatives. There is a need for more research examining dialogic engagement among stakeholders, evaluating its effectiveness, and exploring the potential and challenges of this new approach to accounting.

This study brought NGOs into the dialogic accounting discussion and argued that they could be potential promoters and facilitators of the dialogic process. However, future in-depth research is needed to explore their roles and engagement strategies in different contexts. Moreover, the roles of other stakeholders, particularly local communities, could be investigated through a participatory action research study that would need a longer research period.

This study raises accountability issues of NGOs, particularly in the LDC context. Although not explored in detail, my findings support the argument of Gray et al. (2006) that the accountability of NGOs in LDCs requires more attention from SEA researchers. Further research into NGO accountability is necessary, as NGOs might have different accountability challenges, depending on their accountholders, such as donor organisations, NGO members, and beneficiaries. The latter account-holder is often excluded from NGO accountability (Bebbington, 2005; McIlwaine, 2009) due to lack of awareness of their rights, responsibilities, and power to hold NGOs accountable.

In sum, researchers could extend the findings of this study and further investigate synergies between the EIA and SEA. The EIA provides a potential way to foster sustainability, accountability, and accounting in environmental management and SEA, and to address calls for operationalising SEA ideas in practice. In addition, the potential and challenges of critical dialogic accounting could be further explored, discussed, and addressed among researchers and practitioners from various disciplines.

\subsection{Concluding comments}

This study explores the potential application of the dialogic accounting framework in the mining and environmental management of an LDC. It seeks to contribute to the ongoing development of SEA theory and practice, and to foster responsible 
mining practices in Mongolia and elsewhere. Instead of proposing the "correct" solution for Mongolian mining practice, I have endeavoured to open up avenues for various EIA constituents, and SEA researchers to begin/continue discussion of the potential of dialogic accounting, and of ways to change current practices that could address the challenges of sustainable development. 


\section{References}

Adams, C. A., \& McNicholas, P. (2007). Making a difference: Sustainability reporting, accountability and organisational change. Accounting, Auditing \& Accountability Journal, 20(3), 382-402.

ADB (2005). Mongolia: Country environmental analysis. Philippines.

ADB (2008). Mongolia: Governance reform program (first phase).

Akol, D. (2001). Assessing the utility of environmental impact assessment as a strategy for global sustainable development. McGill University, Montreal

Amnesty International (2009). 'Where should I go from here?' The legacy of the I July 2008 riot in Mongolia. London.

Annandale, D., \& Taplin, R. (2003). Is environmental impact assessment regulation a 'burden' to private firms? Environmental Impact Assessment Review, 23, 383-397.

Arnstein, S. (1969). A ladder of citizen participation. Journal of American Institute of Planners, 35, 216-224.

Australian Government: Corporate and Markets Advisory Committee (2006). The social responsibility of corporations: Report and summary of submissions: Corporate and Markets Advisory Committee.

Auty, R. (2007). Natural resources, capital accumulation and the resource curse. Ecological Economics, 61(2007), 627-634.

Bakei, A. (2010). The status quo of the natural environment: Roles of NGOs. Paper presented at the Mongolian 2nd NGO conference, Ulaanbaatar, Mongolia.

Bano, M. (2008). Dangerous correlations: Aid's impact on NGOs' performance and ability to mobilise members in Pakistan. World Development, 36(11), 2297-2313.

Barrow, C. J. (1997). Environmental and social impact assessment: An introduction. London: Arnold Publishing.

Barton, B. D. (2005). A global/local approach to conflict resolution in the mining sector: The case of the Tintaya dialogue table. Unpublished Diplomacy thesis, Tufts University.

Batbayar, Z. (2009). Water use in mining and legislation. Paper presented at the 4th Mining and Rehabilitation Seminar, Ulaanbaatar, 2009.10.01-02.

Batmonkh, S. (03.01.2008). "Black spot" protest in Khongor. The UB Post, from http://ubpost.mongolnews.mn/index.php?option=com_content\&task=view \&id $=1108 \&$ Itemid $=36$

Bebbington, A. (2005). Donor - NGO relations and representation of livelihood in nongovernmental aid chains. World Development, 33(6), 937-950.

Bebbington, J., Brown, J., \& Frame, B. (2007). Accounting technologies and sustainability assessment models. Ecological Economics, 61, 224-236.

Bebbington, J., Brown, J., Frame, B., \& Thomson, I. (2007). Theorising engagement: The potential of a critical dialogic approach. Accounting, Auditing \& Accountability Journal, 20(3), 356-381. 
Bebbington, J., Gray, R., Hibbit, C., \& Kirk, E. (2001). Full cost accounting: An agenda for action. London: Association of Chartered Certified Accountants.

Belal, A. R. (2007). Absence of corporate social reporting (CSR) in Bangladesh: A research note. Paper presented at the APIRA 2007.

Bessire, D., \& Onnée (2010). Assessing corporate social performance: Strategies of legitimation and conflicting ideologies. Critical Perspectives on Accounting, 21(6), 445-467.

Betsill, M. M., \& Corell, E. (Eds.). (2008). NGO diplomacy: The influence of nongovernmental organizations in international environmental negotiations. Massachusetts: The MIT Press.

BHP Billiton (2007). Full sustainability report Melbourne, Australia.

Biller, D. (2003). Environmental impact assessment. In D. E. Ervin, J. R. Kahn \& M. L. Livingston (Eds.), Does environmental policy work?: The theory and practice of outcomes assessment. Cheltenham: Edward Elgar Publishing Limited.

Boeije, H. (2010). Analysis in qualitative research London: Sage.

Booth, A. L., \& Skelton, N. W. (in press). Industry and government perspectives on First Nations' participation in the British Columbia environmental assessment process. Environmental Impact Assessment Review.

Boyce, G. (2000). Public discourse and decision making: Exploring possibilities for financial, social and environmental accounting Accounting, Auditing \& Accountability Journal, 13(1), 27-64.

Boyle, J. (1998). Cultural influences on implementing environmental impact assessment: Insights from Thailand, Indonesia and Malaysia. Environmental Impact Assessment Review, 18, 95-116.

Branis, M., \& Christopoulos, S. (2005). Mandated monitoring of post-project impacts in the Czech EIA. Environmental Impact Assessment Review, 25, 227-238.

Brooke, J. L. (1998). Reason and passion in the public sphere: Habermas and the cultural historians. Journal of Interdisciplinary History, 29(1), 43-67.

Brown, J. (2009). Democracy, sustainability and dialogic accounting technologies: Taking pluralism seriously. Critical Perspectives on Accounting, 20(3), 313-342.

Brown, L. D., Khagram, S., Moore, M. H., \& Frumkin, P. (2000). Globalization, NGOs and multisectoral relations. In J. S. Nye \& J. D. Donahue (Eds.), Governance in a globalizing world (pp. 271-286). Washington, DC: Brookings Institution Press.

Bulag, U. E. (2010). Mongolia in 2009: From landlocked to land-linked cosmopolitan. Asian survey, 50(1), 97-103.

Bury, J. (2005). Mining mountains: Neoliberalism, land tenure, livelihoods, and the new Peruvian mining industry in Cajamarca. Environment and Planning A, 37(2005), 221-239.

Caldwell, L. K. (1993). Achieving the NEPA intent: New directions in politics, science, and law. In S. G. Hildebrand \& J. B. Cannon (Eds.), Environmental analysis: The NEPA experience. London: Lewis Publishers. Canadian Standards Association (1994). Life cycle assessment. Rexdale (Toronto). 
Carson, R. (1962). Silent spring. New York: Houghton Mifflin Company.

Cashmore, M. (2004). The role of science in environmental impact assessment: Process and procedure versus purpose in the development theory. Environmental Impact Assessment Review, 24, 403-426.

Cashmore, M., Richardson, T., Hilding-Ryedvik, T., \& Emmelin, L. (2010). Evaluating the effectiveness of impact assessment instruments: Theorising the nature and implications of their political constitution. Environmental Impact Assessment Review, 30(2010), 371-379.

Centre for Civil Society (2004, 1 March 2004). What is civil society? Retrieved 25.07.2008,

from http://www.lse.ac.uk/collections/CCS/what_is_civil_society.htm

Cherp, A. (2001). EA legislation and practice in Central and Eastern Europe and the former USSR: A comparative analysis. Environmental Impact Assessment Review, 21, 3335-3361.

Chilvers, J. (2008). Deliberating competence: Theoretical and practitioner perspectives on effective participatory appraisal practice. Science, Technology and Human Values, 33(2), 155-185.

CIA (1997). The World Factbook 1996.

CIA (2010). The World Factbook 2010.

Cleary, S. (1995). Enhancing people's participation. In K. Griffin (Ed.), Poverty and the transition to a market economy in Mongolia. London: St.Martin's Press.

Coenen, F. H. J. M. (Ed.). (2008). Public participation and better environmental decisions: The promise and limits of participatory processes for the quality of environmentally related decision-making: Springer

Collins, D. (2009). The failure of a socially responsive gold mining MNC in El Salvador: Ramifications of NGO mistrust. Journal of Business Ethics, 88(2009), 245-268.

Consortium of Hart Nurse Ltd and Ulaanbaatar Audit Corporations Ltd (2010). Mongolia third EITI reconciliation report 2008. Ulaanbaatar.

Cooke, B., \& Kothari, U. (Eds.). (2001). Participation: The new tyranny? London: Zed Books.

Cooper, C. (1992). The non and nom of accounting for (m)other nature? Accounting, Auditing \& Accountability Journal, 5(3), 16-39.

Cooper, C. (2005). Accounting for the public interest: Public ineffectuals or public intellectuals? . Accounting, Auditing \& Accountability Journal, 18(5), 592-607.

Cooper, D., \& Sherer, M. J. (1984). The value of corporate accounting reports: Arguments for a political economy of accounting. Accounting, Organisations and Society, 9(3/4), 207-232.

Cornejo, N., Kells, C., Zuniga, T. O., Roen, S., \& Thompson, B. (2010). Promoting social dialogue in the mining sector in the state of Para, Brazil. Consilience: The Journal of Sustainable Development, 3(1), 1-67.

Crane White \& Accosiates (2007). Extractive industry transparency initiatives: Report on the first Mongolian reconciliation Ulaanbaatar.

Crotty, M. (1998). The foundations of social research: Meaning and perspective in the research process. St Leonards NSW, Australia: Sage Publications 
Crowson, P. (2009). The resource curse: A modern myth? In J. Richards (Ed.), Mining, society, and a sustainable world (pp. 3-36). Berlin.

$\mathrm{CSP}^{2}$ and WRI (2005). Framework for responsible mining: A guide to evolving standards Sydney: Centre for Science in Public Participation, World Resources Institute.

Curran, G., \& Hollander, R. (2008). A tale of two pulp mills: Realising ecologically sustainable development in Australia. Australian Journal of Public Administration, 67(4), 483-497.

Daly, H. E., \& Farley, J. (2004). Ecological economics: Principles and applications. Washington: Island Press.

Danielson, L. (2006). Architecture for change: An account of the mining, minerals and sustainable development project: History. Berlin: Global Public Policy Institute.

Darling, R. (2009). From Mongolia: A new paradigm in responsible mining is taking shape. Retrieved from http://asiafoundation.org/inasia/2009/04/15/from-mongolia-a-new-paradigm-in-responsible-miningis-taking-shape/

David, S. (2010). Political mobilisation and the construction of collective identity in Mongolia. Central Asian Survey, 29(3), 251-267.

Deegan, C., \& Rankin, M. (1996). Do Australian companies report environmental news objectively? An analysis of environmental disclosures by firms prosecuted successfully by the Environmental Protection Authority. Accounting, Auditing \& Accountability Journal, 9(2), 50.

Deegan, C., \& Rankin, M. (1997). The materiality of environmental information to users of annual reports. Accounting, Auditing \& Accountability Journal, $10(4), 562-583$.

Denzin, N. K., \& Lincoln, Y. S. (Eds.). (2005). The Sage handbook of qualitative research (3 ed.). California: Sage Publications.

Devlin, J. F., \& Yap, N. (2008). Contentious politics in environmental assessment: Blocked projects and winning coalitions. Impact Assessment and Project Appraisal, 26(1), 17-27.

Diamond, J. (2005). Collapse: How societies choose to fail or succeed. New York: Viking.

Diduck, A., \& Mitchell, B. (2003). Learning, public involvement and environmental assessment: A Canadian case study. Journal of Environmental Assessment Policy and Management, 5(3), 339-364.

Diduck, A., \& Sinclair, A. J. (2002). Public involvement in environmental assessment: The case of the nonparticipant. Environmental Management, 29(4), 578-588.

Diduck, A., Sinclair, J., Pratar, D., \& Hostetler, G. (2007). Achieving meaningful public participation in the environmental assessment of hydro development: Case studies from Chamoli District, Uttarakhand, India. Impact Assessment and Project Appraisal, 25(3), 219-231.

Dierkes, J., \& Khushrushahi, N. (2006). Mining in Mongolia: Some recommendations for long-term investment agreements in the Mongolian mining sector. Vancouver: Institute of Asian Research. 
Dillard, J., \& Roslender, R. (2011). Taking pluralism seriously: Embedded moralities in management accounting and control systems. Critical Perspectives on Accounting, 22(2), 135-147.

Doberstein, B. (2003). Environmental capacity-building in a transitional economy: The emergence of EIA capacity in Viet Nam. Impact Assessment and Project Appraisal, 21(1), 25-42.

Dorjgotov, D., \& Purevsuren, C. (2006). Ecological situation in dry land of Mongolia. Paper presented at the Dry Land Processes Studies Workshop.

Edelman, R. (2005). Edelman trust barometer 2005: The sixth global opinion leaders study. Brussels: Edelman Public Relations.

Edwards, M., \& Sen, G. (2000). NGOs, social change and the transformation of human relationships: A 21st-century civic agenda. Third World Quarterly, 21(4), 605-616.

EIA Centre (1995a). Consultation and public participation within EIA. Manchester: EIA Leaflet Series, No. 10, EIA Centre, University of Manchester.

EIA Centre (1995b). EIA in developing countries. Manchester: EIA Leaflet Series, No. 15, EIA Centre, University of Manchester.

Energy Resources LLC (2011). Cultural heritage management, from http://www.energyresources.mn/responsibility?id=6

Escobar, A. (2006). Difference and conflict in the struggle over natural resources: A political ecology framework Development, 49(3), 6-13.

Essex Planning Officers Association (1995). Environmental assessment: The way forward. Chelmsford.

European Bank for Reconstruction and Development (1996). Environmental procedures. London: EBRD.

Everett, J., \& Neu, D. (2000). Ecological modernization and the limits of environmental accounting? Accounting Forum, 24(1), 5-29.

Feher, M., Krikorian, G., \& McKee, Y. (Eds.). (2007). Nongovernmental politics. New York: Zone books.

Fischer, T. B. (2003). Strategic environmental assessment in post-modern times. Environmental Impact Assessment Review, 23(2), 155-170.

Fitzpatricka, P., Fonsecab, A., \& McAllisterb, M. L. (2011). From the Whitehorse Mining Initiative towards sustainable mining: Lessons learned. Journal of Cleaner Production, 19(4), 376-384.

Fontana, A., \& Frey, J. H. (2005). The interview: From neutral stance to political involvement. In N. K. Denzin \& Y. S. Lincoln (Eds.), The Sage handbook of qualitative research (3 ed.). California: Sage Publications.

Frame, B., \& Brown, J. (2008). Developing post-normal technologies for sustainability. Ecological Economics, 65(2), 225-241.

Fraser Insititute (2007). Annual survey of mining companies 2006/2007. Vancouver.

Freire, P. (1985). The politics of education: Culture, power and liberation. London: Macmillan.

Fritz, V. (2007). Democratisation and corruption in Mongolia. Public Administration and Development, 27, 191-203. 
Fritz, V. (2008). Mongolia: The rise and travails of a deviant democracy. Democratisation, 15(4), 766-788.

Furia, L. D., \& Wallace-Jones, J. (2000). The effectiveness of provisions and quality of practices concerning public participation in EIA in Italy. Environmental Impact Assessment Review, 20(457-78).

Gansukh, L. (2010). Multi-stakeholder engagement in environmental protection. Paper presented at the Mongolian 2nd NGO conference, Ulaanbaatar, Mongolia.

Garb, Y., Manon, M., \& Peters, D. (2007). Environmental impact assessment: Between bureaucratic process and social learning. In F. Fischer, G. J. Miller \& M. S. Sidney (Eds.), Handbook of public policy analysis. Boa Ration, FL: CC Press.

Garvin, T., McGee, T. K., Smoyer-Tomic, K. E., \& Aubynn, E. A. (2009). Community - company relations in gold mining in Ghana. Journal of Environmental Management, 90(2009), 571-586.

Glasson, J., Therivel, R., \& Chadwick, A. (2005). Introduction to environmental impact assessment (3 ed.). New York: Routledge.

Global Nature (2011). Reforestation of sea-buckthorn trees on the banks of Onggi River in Mongolia.

Global Witness (2005). Extracting transparency: The need for an international financial reporting standard for the extractive industry. London.

Goddard, A., \& Assad, M. J. (2006). Accounting and navigating legitimacy in Tanzanian NGOs. Accounting, Auditing \& Accountability Journal, 19(3), 377-404.

Gold, R. (1969). Roles in sociological field observation. In G. McCall \& J. Simmons (Eds.), Issues in participant observation: A text and reader. London: Addison Wesley.

Gray, R. (1992). Accounting and environmentalism: An exploration of the challenge of gently accounting for accountability, transparency and sustainability. Accounting, Organisations and Society, 17(5), 399-425.

Gray, R. (2002). The social accounting project and Accounting, Organisations and Society: Privileging engagement, imaginings, new accountings and pragmatism over critique? . Accounting, Organisations and Society, 27(687-709).

Gray, R. (2006a). Does sustainability reporting improve corporate behaviour?: Wrong question? Right time? Paper presented at the ICAEW conference, 'Information for Better Markets'.

Gray, R. (2006b). Social, environmental and sustainability reporting and organisational value creation?: Whose value? Whose creation? Accounting, Auditing \& Accountability Journal, 19(6), 793-819.

Gray, R., Bebbington, J., \& Collison, D. (2006). NGOs, civil society and accountability: Making the people accountable to capital. Accounting, Auditing \& Accountability Journal, 19(3), 319-348.

Gray, R., Dey, C., Owen, D., Evans, R., \& Zadek, S. (1997). Struggling with the praxis of social accounting: Stakeholders, accountability, audits and procedures Accounting, Auditing \& Accountability Journal, 10, 325-365. 
Gray, R., Owen, D., \& Adams (1996). Accounting and accountability: Prentice Hall Europe.

Gray, R., Owen, D., \& Mauders, K. (1987). Corporate social reporting: Accounting and accountability. London: Prentice-Hall International.

Gray, R., Walters, Bebbington, J., \& Thompson, I. (1995). The greening of enterprise: An exploration of the (non) role of environmental accounting and environmental accountants in organisational change. Critical Perspectives on Accounting, 6, 211-239.

Gray, R. A. (1994). Ecology and ethics: Is there a duty to nature? Reference Services Review, Spring(1994), 57-74.

Grayson, R., \& Baatar, C. (2009). Worst and best avaliable techniques. Paper presented at the 4th Mining and Rehabilitation Seminar, Ulaanbaatar, 2009.10.01-02.

GRI (2006). Sustainability reporting guidelines.

Griffin, K. (Ed.). (1995). Poverty and the transition to a market economy in Mongolia. London: St. Martin's Press.

Guerin, T. F. (2009). Applications of stakeholder engagement and eco-efficiency as enablers of corporate social responsibility in the Australian mining and minerals processing industry. In J. Richards (Ed.), Mining, society, and a sustainable world. Berlin: Springer.

Gunter, M. M. (2004). Building the next ark: How NGOs work to protect biodiversity. Hanover, New Hamsphire: University Press of New England.

Guthrie, J., \& Parker, L. D. (1990). Corporate social disclosure practice: A comparative international analysis. Advances in Public Interest Accounting $3,159-176$.

Hall, J. A., \& Trentmann, F. (Eds.). (2005). Civil society: A reader in history, theory and global politics. New York: Palgrave Macmillan.

Harper, D. (2007). On the authority of the image: Visual methods at the crossroads. In N. K. Denzin \& Y. S. Lincoln (Eds.), Collecting and interpreting qualitative materials (3 ed., pp. 130-149). Thousand Oaks, CA: Sage.

Haselip, J., \& Hilson, G. (2005). Winners and losers from industry reform in the developing countries: Experiences from the electricity and mining sectors. Resource Policy 30(2005), 87-100.

Heller, P. (2001). Moving the state: The politics of democratic decentralisation in Kerala, South Africa, and Porto Alegre. Politics and Society, 29(1), 131163.

Hickey, S., \& Mohan, G. (Eds.). (2004). Participation: From tyranny to transformation? Exploring new approaches to participate in development. London: Zed Books Ltd.

Hilson, G. (2000). Sustainable development policies in Canada's mining sector: An overview of government and industry efforts. Environmental Science \& Policy, 3, 201-211.

Hilson, G. (2003). Devising indicators of sustainable development for the mining and minerals industry: An analysis of critical background issues. International Journal of Sustainable Development and World Ecology, 10(4), 319-331. 
Hilson, G., \& Maconachie, R. (2009). The Extractive Industry Transparency Initiative: Panacea or white elephant for Sub-Saharan Africa? In J. Richards (Ed.), Mining, society, and a sustainable world. Berlin: Springer.

Hines, R. (1991). On valuing nature. Accounting, Auditing \& Accountability Journal, 4(3), 27-29.

Holling, C. S. (1978). Adaptive environmental assessment and management. New York: John Wiley and Sons Ltd

Holstein, J. A., \& Gubrium, J. F. (2004). The active interview. In D. Silverman (Ed.), Qualitative research: Theory, method and practice. London: Sage Publications Ltd.

Hopper, T., Tsamanyi, M., Uddin, S., \& Wickramasinghe, D. (2007). Management accounting in less developed countries: What we know and need to know

Howell, J., \& Pearce, J. (2001). Civil society and development: A critical exploration. Colorado: Lynne Rienner Publishers, Inc.

Humphreys, D. (2006). Industry consolidation and integration: Implications for the base metals sector. Paper presented at the GFMS's precious and base metals seminar.

Humphreys, M. (2005). Natural resources, conflict, and conflict resolution: Uncovering the mechanisms. The Journal of Conflict Resolution, 49(4), 508-537.

Hutchinson, A. C. (1989). Taking the good life: From free speech to democratic dialogue. Yale journal of Law and Liberty, 1, 17-30.

ICMM (2005). Community development tools: ESMAP, the World Bank and ICMM. Paper presented at the Women and Mining II.

IIED, \& WBCSD (2002). Mining, minerals and sustainable development.

Imbun, B. Y. (2007). Cannot manage without the 'significant other': Mining, corporate social responsibility and local communities in Papua New Guinea. Journal of Business Ethics, 73, 177-192.

Independent Review Working Group (2002). The final report of the independent review working group. Ulaanbaatar.

Ingelson, A., Holden, W., \& Bravante, M. (2009). Philippine environmental impact assessment, mining and genuine development. Law, Environment and Development, 5(1), 1-17.

International Association for Impact Assessment (1999). Principle of environmental impact assessment best practice.

International Monetary Fund (2011). World economic outlook database. Data for the year 2010

IPPC (2007). Climate change 2007: Synthesis report. Valencia, Spain.

ISO (2005). ISO 14000 essentials, 10 May 2011, from http://www.iso.org/iso/iso_14000_essentials

IUCN, \& URM NGO (2010). Mining in Mongolia: Engaging local communities to help reduce the impacts of mining. Switzerland.

Ivanhoe Mines Mongolia Inc (2005). Oyu Tolgoi project, Mongolia: Integrated development plan.

Ivanhoe Mines Mongolia Inc. (2006). Oyu Tolgoi project: Annual report. Ulaanbaatar. 
Ivanhoe Mines Mongolia LLC (2008). Our corporate citizenship: Statement of values and responsibilities. Ulaanbaatar.

Jachid, S., \& Hyer, P. (1979). Mongolia's culture and society Boulder: Westview Press.

Jacobson, A. J. (1990). Environmental accountability beyond compliance: Externalities and accounting. Cardozo Law Review, 1990-1991, 13331343.

Jay, S., Jones, C., Slinn, P., \& Wood, C. (2007). Environmental impact assessment: Retrospect and prospect. Environmental Impact Assessment Review, 27, 287-300.

Johnova, E. (2004). An introduction into the environmental performance of sustainable development in Mongolia. In C. M. Teaf, B. K. Yessekin \& M. K. Khankhasayev (Eds.), Risk assessment as a tool for water resources decision-making in Central Asia. The Netherlands: Kluwer Academic Publishers.

Jones, E. G. (1997). Risky assessments: Uncertainties in science and the human dimensions of environmental decisionmaking. Environmental Law and Policy Review, 22, 1-69.

Jordan, L., \& van Tuijl, P. (Eds.). (2006). NGO accountability: Politics, principles and innovations. London: Earthscan.

Kakonge, J. O. (1998). EIA and good governance: Issues and lesson form Africa. Environmental Impact Assessment Review, 18(289-305).

Kapoor, I. (2001). Towards participatory environmental management. Journal of Environmental Management, 63, 269-279.

Kapoor, I. (2004). The power of participation. Current Issues in Comparative Education, 6(2), 125-129.

Kapoor, I. (2008). The postcolonial politics of development. New York: Routledge.

Kolhoff, A. J., Runhaar, H. A., \& Driessen, P. P. (2009). The contribution of capacities and context to EIA system performance and effectiveness in developing countries: Towards a better understanding. Impact Assessment and Project Appraisal, 27(4), 271-282.

Korten, D. C. (1990). Getting to the 21st century voluntary action and the global agenda. Kansas City, MO: Bookmark Press.

Kravchenko, S. (2002). New laws on public participation in the newly independent states. In D. N. Zillman, A. R. Lucas \& G. R. Pring (Eds.), Human rights in natural resource development: Public participation in the sustainable development of mining and energy resources. Oxford: Oxford University Press.

Kwiatkowski, R. E., \& Ooi, M. (2003). Integrated environmental impact assessment: A Canadian example. Bulletin of the World Health Organisation, 81(6), 434-438.

LaFree, G., \& Morris, N. (2004). Corruption as a global social problem In G. Ritzer (Ed.), Handbook of social problems: A comparative international perspective: Sage Publication:Thousand Oakes.

Lahiridutt, K. (2006). May god give us chaos, so that we can plunder: A critique of 'resource curse' and conflict theories. Development, 49(3), 14-21. 
Lambsdorff, J. G. (2006). Causes and consequences of corruption: What do we know from a cross-section of countries? In S. Rose-Ackerman (Ed.), International handbook on the economics of corruption. Cheltenham: Edward Elgar Publishing Limited.

Lawrence, D. (2003). Environmental impact assessment: Political solutions to recurrent problems. New Jersey: John Wiley and Sons.

LeBlanc, P., \& Fisher, K. (1994). Application of EA to policies and programs: The federal experience in Canada. Paper presented at the The Policy EA Workshop.

Lehman, C. R. (2005). Accounting and the public interest. Accounting, Auditing \& Accountability Journal, 18(5), 675-689.

Lehman, G. (1995). A legitimate concern for environmental accounting. Critical Perspectives on Accounting, 6, 393-412.

Lehman, G. (1996). Environmental accounting: Pollution permits or selling the environment. Critical Perspectives on Accounting, 7(6), 667-676.

Lehman, G. (1999). Disclosing new worlds: A role for social and environmental accounting and auditing. Accounting, Organisations and Society, 24, 217241.

Lehman, G. (2001). Reclaiming the public sphere: Problems and prospects for corporate social and environmental accounting. Critical Perspectives on Accounting, 12, 713-733.

Lehman, G. (2007). The accountability of NGOs in civil society and its public spheres. Critical Perspectives on Accounting, 18(2007), 645-669.

Li, F. (2009). Documenting accountability: Environmental impact assessment in a Peruvian mining project. PoLAR, 32(2), 218-236.

Li, J. (2008). Environmental impact assessments in developing countries: An opportunity for greater environmental security? USAID and FESS.

Lipset, S. M. (1995). The encyclopaedia of democracy (Vol. 3). Washington, DC: Congressional Quarterly.

Lkhagjav, A. (2011). Activists of Gal Undesten Movement declared hunger strike. Niigmiin Toli,

Lockie, S., Franetovich, M., Sharma, S., \& Rolfe, J. (2008). Democratisation versus engagement? Social and economic impact assessment and community participation in the coal mining industry of the Bowen Basin, Australia. Impact Assessment and Project Appraisal, 26(3), 177-187.

Lovgren, S. (2008). Mongolia gold rush destroying rivers, nomadic lives. National Geographic News. Retrieved from http://news.nationalgeographic.com/news/2008/10/081017-mongoliamining-missions.html

Margerum, R. D. (1999). Integrated environmental management: The foundations for successful practice. Environmental Management, 24(2), 151-166.

Marsden, S. (1998). Why is legislative EA in Canada ineffective, and how can it be enchanted? Environmental Impact Assessment Review, 18, 241-265.

Martin, J. P. (2006). Royal Dutch Shell: How deep the changes? In G. Andreopoulos, Z. K. Arat \& P. Juviler (Eds.), Non-state actors in the human rights universe. Bloomfield Kumarian Press, Inc.

Mason, J. (2002). Qualitative researching (2 ed.). London: Sage. 
Mathews, M. R. (1997). Twenty-five years of social and environmental accounting research: Is there a silver jubilee to celebrate? Accounting, Auditing \& Accountability Journal, 10(4), 481-531.

May, T. (2001). Social research: Issues, methods and process (3 ed.). Buckingham: Open University Press.

Mbaku, J. M. (1992). Bureaucratic corruption as rent seeking behavior Konjunkturpolitik, 38(4), 247-265.

McIlwaine, C. (2009). Civil society. In R. Kitchin \& N. Thrift (Eds.), International encyclopedia of human geography (1 ed.): Elsevier Science.

McLean, I., \& McMillan, A. (2003). The concise Oxford dictionary of politics, The concise Oxford dictionary of politics. London: Oxford University Press.

Meadows, D., Randers, J., \& Meadows, D. (2004). Limits to growth: The 30 year update. London: Earthscan.

Meadows, D. H., Meadows, D. L., Randers, J., \& Behrens III, W. W. (1972). The limits to growth. New York: Universe Books.

Menon, M., \& Kohli, K. (2008). Re-engineering the legal and policy regimes on environment. Economic \& Political Weekly, June 7.

Mercer, C. (2002). NGOs, civil society and democratisation: A critical review of the literature. Progress in Development Studies, 2(1), 5-22.

Millon, D. (1993). New directions in corporate law: Communitarians, contractarians, and the crisis in corporate law. Washington and Lee Law Review, 50(4), 1373-1393.

Milne, M. J., \& Gray, R. (2007). Future prospects for corporate sustainability reporting. In J. Unerman, J. Bebbington \& B. O'Dwyer (Eds.), Sustainability accounting and accountability. New York: Routledge.

Milne, M. J., \& Patten, D. M. (2002). Securing organisational legitimacy: An experimental decision case examining the impact of environmental disclosures. Accounting, Auditing \& Accountability Journal, 15(3), 372405.

Ministry of Finance (2007). The millennium development goals implementation: Second national report. Ulaanbaatar, Mongolia.

Ministry of Nature and Environment (2008). The current state of EIA and rehabilitation Ulaanbaatar.

Mitchell, B. (2001). Resource and environmental management (2nd ed.). New York: Pearson Education.

MMSD (2001). Mining and economic sustainability: National economies and local communities. England: International Institute for Environment and Development, World Business Council for Sustainable Development.

MMSD (2002). Breaking new ground. England: International Institute for Environment and Development, and the World Business Council for Sustainable Development.

Regulation on general and detailed environmental impact assessments (2006).

MNET (2008). Report on the state of the environment of Mongolia. Ulaanbaatar: MNET.

MNET (2009a). Environmental impact assessment companies. MNET. 
MNET (2009b). Ministry of Nature, Environment and Tourism, 10 July, 2011, from http://www.mne.mn

MNET (2010). EIA database. from MNET: http://geodata.mne-ngic.mn/eia/

MNPC (2008). Mongolian nature and environmental assessment. Ulaanbaatar.

Mohan, G. (2002). The disappointments of civil society: The politics of NGO intervention in Northern Ghana. Political Geography, 21(2002), 125-154.

Molisa, P., Vandangombo, D., \& Brown, J. (Eds.). (forthcoming). Social and environmental accounting in developing countries: Challenges, conflicts and contradictions Routledge

Mongolia-Web (2009). At 12.06pm on 18th of June 2009, the new president swears in, from http://www.mongolia-web.com/government/2508-at-1206pm-on-18th-of-june-2009-the-new-president-swears-in

Mongolian National Statistical Office (2009). Statistical yearbook. Ulaanbaatar.

Mongolian National Statistical Office (2010). Population survey. Ulaanbaatar.

Mongolian National Statistical Office (2011). Statistical yearbook 2010. Ulaanbaatar.

Mongolian River Resources (2007a). Artisanal Mining Retrieved 20.01.2008, from

http://www.mongolianriverresources.mn/index.php?option=com_content\& task=blogcategory\&id=35\&pid=139

Mongolian River Resources (2007b). Responsible Mining Initiative Retrieved 10.12.2009, from http://www.mongolianriverresources.mn/index.php?option=com content\& task=view\&id=15\&pid=105

Morgan (1988). Accounting as reality construction: Toward a new epistemology for accounting practice. Accounting, Organisations and Society, 13(5), 477-485.

Morgan, R. K. (1998). Environmental impact assessment: A methodological perspective. Dordrecht, The Netherlands: Kluwer Academic Publishers.

Mouffe, C. (1995). Democracy, pluralism: A critique of the rationalist approach. Cardozo Law Review, 16, 1533-1545.

Mouffe, C. (2000). Deliberative democracy and agonistic pluralism. Vienna: Institute of Advanced Studies.

Mouffe, C. (2002). Which democracy in a post-political age? Paper presented at the Dark Markets: Infopolitics, electronic media and democracy in times of crisis.

MRPAM (2008). Mining sector overview. Retrieved from http://mrpam.gov.mn/index.php?option=com_content\&task=blogcategory $\underline{\text { \&id }=55 \& \text { Itemid }=83}$

Munck, R. (2006). Global civil society: Royal road or slippery path? Voluntas, 17, 325-332.

Munkhbayar, T. (2005). Safe environment is a fundamental right that never can be given up Retrieved 30.06.2008, from http://www.onggiriver.org/index.php?mid=2

Myagmarsuren, D. (2006). Current state of the natural environment in Mongolia. Ulaanbaatar. 
Nelimarkka, M. (2010, The evolution of internet services used by nongovernmental

organisations. http://humanisti.fixme.fi/ matnel/temp/civicsociety.pdf.

Netherlands Commission for Environmental Impact Assessment (2002). Advice on the assessment of the EIA system in Mongolia. Ulaanbaatar.

Niislel Times (2011). The lawsuit postponed. Niislel Times,

Nijhuis, M. (2007). He does not dig gold: Ts. Munkhbayar fights destructive mining in Mongolia. Retrieved from http://www.grist.org/article/nijhuismunkhbayar

Nooteboom, S. (2007). Impact assessment procedures for sustainable development: A complexity theory perspective. Environmental Impact Assessment Review, 27, 645-665.

O'Dwyer, B. (2007). The nature of NGO accountability: Motives, mechanisms and practice. In J. Unerman, J. Bebbington \& B. O'Dwyer (Eds.), Sustainability accounting and accountability. New York: Routledge.

O'Dwyer, B., \& Unerman, J. (2008). The paradox of greater NGO accountability: A case study of Amnesty Ireland. Accounting, Organisations and Society, 33(2008), 801-824.

O'Faircheallaigh, C. (2010). Public participation and environmental impact assessment: Purposes, implications, and lessons for public policy making. Environmental Impact Assessment Review 30(2010), 19-27.

O'Neill, J. (1998). The market: Ethics, knowledge and politics London: Routledge.

O'Sullivan, N., \& O'Dwyer, B. (2009). Stakeholder perspectives on a financial sector legitimation process: The case of NGOs and the Equator Principles. Accounting, Auditing and Accountability Journal, 22(4), 553-587.

Odgerel, T., \& Battsetseg, G. (2006). The Mongolian legal system and laws: A brief overview. Retrieved from http://www.nyulawglobal.org/globalex/Mongolia.htm\# The Modern Syst em_of\%20Mongolian\%20Law

Olloo.mn (Producer). (2007, 30.06.2008) The emergency situation in Khongor soum. Podcast retrieved from http://www.olloo.mn/modules.php?name=News\&file=article \&sid=67463 \&catid $=2188$.

Open Society Forum (2005). NGOs in Mongolia: Survey report. Ulaanbaatar.

Otto, J. (2009). Global trends in mine reclamation and closure regulation. In J. Richards (Ed.), Mining, society, and a sustainable world. Berlin: Springer.

Oyundari, E. (2011). Seven members of Gal Vndesten Movement arrested. The UB Post,

Patton, M. Q. (2002). Qualitative research and evaluation methods (3 ed.). Thousand Oaks, California: Sage Publications, Inc.

Petts, J. (2003). Barriers to deliberative participation in EIA: Learning from waste policies, plans and projects. Journal of Environmental Assessment Policy and Management, 5(3), 269-293.

Petts, J. (2004). Barriers to participation and deliberation in risk decisions: Evidence from waste management. Journal of Risk Research, 7(2), 115133. 
Petts, J. (2007). Learning about learning: Lessons from public engagement and deliberation on urban river restoration The Geographical Journal, 173(4), 300-311.

Petts, J., \& Brooks, C. (2006). Expert conceptualisations of the roles of lay knowledge in environmental decionmaking: Challenges for deliberative democracy. Environment and Planning A, 38, 1045-1059.

Portfolio Media Inc. (2007). Mongolian mining: A golden opportunity? Energy Law 360,

Power, M. (1992). After calculation? Reflections on critique of economic reason by Andre Gorz. Accounting, Organisations and Society, 17(5), 477-499.

Power, M., \& Laughlin, R. C. (1996). Habermas, Law and Accounting. Accounting, Organisations and Society, 21(5), 441-465.

Putnam, R. (Ed.). (2002). Democracies in flux: The evolution of social capital in contemporary society. New York: Oxford University Press.

Puxty, A. G. (1991). Social accounting and universal pragmatics. Advances in Public Interest Accounting, 4(1991), 35-47.

Radnaasumberel, V., Baatartogtokh, T., Purev, T., \& Namkhai, D. (2006). Ethics of public servants: Analysis and discussion Ulaanbaatar, Mongolia: Academy of Management.

Reed, D. (2002). Resource extraction industries in developing countries. Journal of Business Ethics, 39(3), 199-226.

Research team (2006). Motives of public servants. Ulaanbaatar, Mongolia: Academy of Management.

Richards, J. (Ed.). (2009). Mining, society, and a sustainable world Berlin: Springer.

Richardson, T. (2005). Environmental assessment and planning theory: Four short stories about power, multiple rationality, and ethics. Environmental Impact Assessment Review, 25, 341-365.

RMI (2007). Declaration of responsible mining. Ulaanbaatar.

RMI (2009). Responsible mining initiative for sustainable development. Ulaanbaatar, Mongolia.

Robertson, D. (1986). Dictionary of politics. London: Penguin.

Rockloff, S. E., \& Lockie, S. (2006). Democratisation of coastal zone decision making for indigenous Australians: Insights from stakeholder analysis. Coastal Management, 34, 251-266.

Ross, M. (1997). Review essay: The political economy of the resource curse. Wold Politics, 51(2), 297-322.

Ross, M. (2004). Mineral wealth and equitable dependence. In World Bank (Ed.), Background paper for the 2004 World Development Report. Washington, DC.

Ross, M. (2008). Mineral wealth, conflict, and equitable development. In M. Walton, A. J. Bebbington, A. A. Dani \& A. D. Haan (Eds.), Institutional pathways to equity: Addressing inequality traps (New frontiers of social policy). Washington DC: World Bank Publications

Saarikoski, H. (2000). EIA as collaborative learning process. Environmental Impact Assessment Review, 20(681-700). 
Salamon, L. M. (1994). The rise of the nonprofit sector: A global 'associational revolution'. Foreign Affairs, 73(4), 109-122.

Saran, B. (2009). The current rehabilitation practice of the mining sector. Paper presented at the 4th Mining and Rehabilitation Seminar, Ulaanbaatar, 2009.10.01-02.

Saravanamuthu, K. (2004). What is measured counts: Harmonised corporate reporting and sustainable economic development. Critical Perspectives on Accounting, 15(3), 295-302.

Sawabe, N. (2005). Accounting for the public interest: A Japanese perspective. Accounting, Auditing \& Accountability Journal, 18(5), 631-647.

Schlosberg, D. (2007). Defining environmental justice: Theories, movements, and nature. Oxford: Oxford University Press.

Schwartz, F. J., \& Pharr, S. J. (2003). The state of civil society in Japan. Cambridge, UK: Cambridge University Press.

Scottish Executive (2006). Public participation in environmental impact assessment: Consultation report. Edinburgh.

Sethi, S. P. (2005). The effectiveness of industry-based codes in serving public interest: The case of the International Council on Mining and Minerals. Transnational Corporations, 14(3), 55-99.

Shell (2007). Responsible energy: Shell sustainability report 2007.

Shenbayar, P. (2010). 1,700 mining licenses under review The UB Post,

Shiirevdamba, T. (2009). The legislative framework of the Mongolian mining sector. Paper presented at the Fourth Mining Rehabilitation Seminar, Ulaanbaatar.

Shinebayar, P. (2011). Court rejects NGOs case against Government. The UB Post,

Sinclair, Diduck, A., \& Fitzpatrick, P. (2002). Public hearings in environmental assessment: Towards a civics approach. Environments, 30(1), 17-35.

Sinclair, \& Diduck, A. P. (1995). Public education: An undervalued component of the environmental assessment public involvement process Environmental Impact Assessment Review, 15, 21-240.

Sinclair, \& Diduck, A. P. (2001). Public involvement in EA in Canada: A transformative learning perspective. Environmental Impact Assessment Review, 21, 113-136.

Sinclair, A. J., Diduck, A., \& Fitzpatrick, P. (2008). Conceptualising learning for sustainability through environmental assessment: Critical reflections on 15 years of research Environmental Impact Assessment Review, 28(7), 415426.

Slack, K. (2009). The role of mining in the economies of developing countries: Time for a new approach. In J. Richards (Ed.), Mining, society, and a sustainable world. Berlin: Springer.

Smith, D. J. (2010). Corruption, NGOs, and development in Nigeria. Third World Quaterly, 31(2), 243-258.

Snow, K. H. (2010). The naked face of capitalism: Goldman prizewinner shoots up foreign mining firms in Mongolia. Retrieved from http://www.consciousbeingalliance.com/2010/12/post-2/ 
Söderbaum, P. (1994). Actors, ideology, markets, neoclassical and institutional perspectives on environmental policy. Ecological Economics, 10(1), 47-60.

Söderbaum, P. (2004). Decision processes and decision-making in relation to sustainable development and democracy: Where do we stand? Journal of Interdisciplinary Economics, 14, 41-60.

Söderbaum, P. (2006). Democracy and sustainable development: What is the alternative to cost benefit analysis? Integrated Environmental Assessment Management, 2(2), 182-190.

Söderbaum, P. (2007). Issues of paradigm, ideology and democracy in sustainability assessment. Ecological Economics, 60(3), 613-626.

Söderbaum, P. (2011). Commentary: Sustainability economics as a contested concept. Ecological Economics, 70(2011), 1019-1020.

Söderbaum, P., \& Brown, J. (2010). Democratising economics: Pluralism as a path towards sustainability. Annals of the New York Academy of Sciences, 1185(1), 179-195.

Spence, C. (2009). Social accounting's emancipatory potential: A Gramscian critique. Critical Perspectives on Accounting, 20(2), 205-227.

Stevens, P. (2003). Resource impact: Curse or blessing?: Literature survey Dundee: IPIECA.

Stewart, J. M., \& Sinclair, A. J. (2007a). Meaningful public participation in environmental assessment: Perspectives from Canadian participants. Environmental Assessment Policy and Management, 9(2), 161-183.

Stewart, J. M., \& Sinclair, A. J. (2007b). Meaningful public participation in environmental assessment: Perspectives from Canadian participants, proponents and government Environmental Assessment Policy and Management, 9(2), 161-183.

Stiglitz, J. (2006). Making globalisation work. London: Penguin Books.

Sumyabazar, C. (13.03.2008). Khongor pollution levels acceptable: WHO, from http://ubpost.mongolnews.mn/index.php?option=com_content\&task=view $\underline{\text { \&id}=1528 \& \text { Itemid }=1}$

Supreme Court. Mongolian political parties Retrieved May 2011, from http://www.pmis.gov.mn/pmis_eng/index.php

Suzuki, Y. (2008). Mining development and environmnetal problems in Mongolia. Ulaanbaatar.

Szablowski, D. (2007). Transnational law and local struggles: Mining communities and the World Bank. Oxford: Hart Publishing.

Tarras-Wahlberg, N. (2002). Environmental management of small-scale artisanal mining: The Portovelo-Zaruma goldmining area, Southern Ecuador Journal of Environmental Management, 65(2002), 165-179.

Tarras-Wahlberg, N., \& Nguyen, L. T. (2008). Environmental regulatory failure and metal contamination at the Giap Lai Pyrite mine, Northern Vietnam Journal of Environmental Management, 86(2008), 712-720.

Teegan, H., Doh, J., \& Vachani, S. (2004). The importance of nongovernmental organizations (NGOs) in global governance and values creation: An business research agenda. Journal of International Business Studies, 35(6), 463-483. 
The HUB (2007). Khongor village. Retrieved 10.12.2009: http://hub.witness.org/en/node/2878

The National Network of Mongolian Women's NGO (2004). Mongolian NGO report Paper presented at the Asia-Pacific NGO Forum on Beijing+10.

The constitution law of Mongolia(1992).

Regulation on demonstration and assembly procedures (1994).

Environmental protection law of Mongolia(1995).

Minerals law of Mongolia(1997).

Law on environmental impact assessments(1998).

Law of Mongolia on land(2002a).

Public sector management and finance law (2002b).

Anti-corruption law of Mongolia(2006a).

Tax on windfall profits(2006b).

Bill of EIA law amendment(2008).

Thomas, A., \& Mohan, G. (Eds.). (2007). Research skills for policy and development. London: The Open University and Sage Publications.

Thomson, I., \& Bebbington, J. (2005). Social and environmental reporting in the UK: A pedagogic evaluation. Critical Perspectives on Accounting, 16, 507-533.

Tinker, T., Lehman, C., \& Neimark, M. (1991). Falling down the hole in the middle of the road: Political quietism in corporate social reporting. Accounting, Auditing \& Accountability Journal, 4(2), 28-54.

Tinker, T., \& Neimark, M. (1987). The role of annual reports in gender and class contradictions at General Motors:1917-1976. Accounting , Organizations and Society, 12(1), 71-88.

Tinker, T., \& Neimark, M. (1988). The struggle over meaning in accounting and corporate research: A comparative evaluation of conservative and critical histography. Accounting, Auditing \& Accountability Journal, 1(1), 55-74.

Toth, B. (2010). Public participation and democracy in practice - Aarhus convention principles as democratic institution building in the developing world. Journal of Land Resources and Environmental Law, 30(2), 295-330.

Transparency International (2010). Corruption perceptions index 2010. Berlin.

Tsogtbaatar, C. (2009). The current state of mining. Paper presented at the Forth Mining Rehabilitation Seminar, Ulaanbaatar.

Tsolmon, R., Tungalag, A., Miller, D. A., \& Sloan, J. L. (2009, March 9-13, 2009). Land use change analysis in Uvurkhangai province. Paper presented at the ASPRS 2009 Annual Conference, Baltimore, Maryland.

UMMRL (2009). Introduction of Onggi River Movement NGO.

UN (2007). Coping with water scarcity: Challenge of the twenty-first century.

UNDP (2005). Mongolia: Common country assessment (First MDG report). Ulaanbaatar.

UNDP (2006). State of civil society in Mongolia: Final draft country report. Ulaanbaatar.

UNDP (2007). Mongolian human development report 2007: Employment and poverty in Mongolia.

UNDP, \& Government of Mongolia (2006). Democratic governance indicators: Assessing the state of governance in Mongolia. Ulaanbaatar. 
UNECE (1991). Convention on environmental impact assessment in a transboundary context.

UNECE (1998). Convention on access to information, public participation in decision-making and access to justice in environmental matters. Aarhus, Denmark: United Nations Economic Commission for Europe (UNECE).

Unen sonin (Producer). (24.12.2007) Minister of Petrolium and Energy: "Mineral sector is considered to be an advantage for our development". Podcast retrieved from http://www.olloo.mn/modules.php?name=News \&file=article \&catid=2157 $\&$ sid $=81367$.

UNEP (2000). Dissection of an accident: Lessons learned and follow-up actions from Baia Mare. Mining and Susutainable Development II, Challenges and Perspectives

UNEP (2003). Environmental impact assessment: Training resource manual: United Nations Environment Programme.

UNEP GEMS/Water Programmes (2006). Water quality: For ecosystem and human health. Ontario.

Unerman, J. (2007). Stakeholder engagement and dialogue. In J. Unerman, J. Bebbington \& B. O'Dwyer (Eds.), Sustainability accounting and accountability. New York: Routledge.

Unerman, J., Bebbington, J., \& O'Dwyer, B. (Eds.). (2007). Sustainability accounting and accountability. New York: Routledge.

Unerman, J., \& Bennett, M. (2004). Increased stakeholder dialogue and the internet: Towards greater corporate accountability or reinforcing capitalist hegemony? . Accounting , Organizations and Society, 29(7), 685-707.

Unerman, J., \& O'Dwyer, B. (2006). Theorising accountability for NGO advocacy. Accounting, Auditing \& Accountability Journal, 19(3), 349-376.

United Nations (1992). Earth summit, Agenda 21. New York.

Unknown (1228). The secret history of the Mongols.

UNWCED (1987). Our common future, the Brundtland report. Oxford: Oxford University Press.

Urkidi, L. (2010). A glocal environmental movement against gold mining: Pascua-Lama in Chile. Ecological Economics, 70(2), 219-227.

USAID (2005). Assessment of corruption in Mongolia. Alexandria, VA: USAID and The Asia Foundation.

Vakil, A. (1997). Confronting the classification problem: Towards a taxonomy of NGOs. World Development, 25(12), 2057-2070.

Wackernagel, M., \& Rees, W. (1996). Our ecological footprint: Reducing human impact on the earth. Gabriola Island, BC: New Society Publishers.

Warner, M., \& Sullivan, R. (Eds.). (2004). Putting Partnership to Work: Strategic Alliances for Development between Government, the private Sector and Civil Society: Greenleaf Publications.

Waye, A., Young, D., Richards, J., \& Doucet, J. A. (2009). Sustainable development and mining: An exploratory examination of the roles of government and industry. In J. Richards (Ed.), Mining, Society, and a Sustainable World. Berlin: Springer. 
Webler, T., Kastenholz, H., \& Renn, O. (1995). Public participation in impact assessment: A social learning perspective. EIA Review, 15, 443-463.

Webler, T., \& Tuler, S. (2006). Four perspectives on public participation process in environmental assessment and decision-making: Combined results from ten case studies. Policy Studies Journal, 34(4), 699-722.

Whiteman, G., \& Mamen, K. (2002). Meaningful Consultation and Participation in the Mining Sector? A Review of the Consultation and Participation of Indigenous Peoples within the International Mining Sector Ottawa: The North-South Institute.

Wikipedia $\quad$ Sea-buckthorn. $\quad$ Retrieved 31.12.2010: http://en.wikipedia.org/wiki/Sea-buckthorn

Wikipedia (2008). Mongolian legislative election, 2008. Retrieved 10.12.2009: http://en.wikipedia.org/wiki/Mongolian_legislative_election,_2008\#cite_n ote-reuters-10

Wilkins, H. (2003). The need for subjectivity in EIA: Discourse as a tool for sustainable development. Environmental Impact Assessment Review, 23, 401-414.

Willis, J. (2007). Foundations of qualitative research: Interpretive and critical approaches. Thousand Oaks, California: Sage Publications, Inc.

Wilson, G. (2006). Beyond the technocrat? The professional expert in development practice. Development and Change 37 (3), 501-523

Wood, G. (2008). Thresholds and criteria for evaluating and communicating impact significance in environmental statements: 'See no evil, hear no evil, speak no evil'? Environmental Impact Assessment Review, 28(2008), 2238.

World Bank (1992). Strategy for African mining: Executive summary. Washington.

World Bank (1997). Helping countries combat corruption: The role of the World Bank. Washington, DC: World Bank.

World Bank (1999). Operational manual. Bank procedures 4.01. Environmental assessment. Washington, DC: World Bank.

World Bank (2004). Mongolia: Mining sector sources of growth study.

World Bank (2006). A review of environmental and social impacts in the mining sector. Washington.

World Bank (2007a). The enabling environment for social accountability in Mongolia.

World Bank (2007b). Mongolia: Sources of growth. Washington, DC.

World Bank (2009). Southern Mongolia: Infrastructure strategy. Ulaanbaatar.

World Bank, \& International Finance Corporation (2002). An asset for competitiveness: Sound environmental management in mining countries. Washington.

World Bank, \& International Finance Corporation (2003). Mining reform and the World Bank: Providing an policy framework for development. Washington.

World Commission on Environment and Development (1987). Our common future. Oxford: Oxford University Press.

World Growth (2008). Averting the resource curse: Path to prosperity, project Mongolia. Arlington. 
WWF (2002). To dig or not to dig? . Switzerland: WWF.

Ziegler, C. E. (1991). Environmental politics and policy under perestroika. In J. B. Sedaitis \& J. Butterfield (Eds.), Perestroika from below: Social movements in the Soviet Union (pp. 85-109). Boulder (CO): Westview Press.

Zillman, D. N., Lukas, A. R., \& Pring, G. R. (Eds.). (2002). Human rights in natural resource development: Public participation in the sustainable development of mining and energy resources. Oxford: Oxford University Press.

Zimmermann, E. (1933). World resources and industries New York Harper \& Brothers. 


\section{Appendix:}

Coding of interviewees

\begin{tabular}{|c|c|c|}
\hline & EIA constituent groups & Code \\
\hline & \multicolumn{2}{|l|}{ a. Experts } \\
\hline & 1. EIA companies & A \\
\hline 1 & EIA company A & A1 \\
\hline 2 & EIA company B & A2 \\
\hline 3 & EIA company $\mathrm{C}$ & A3 \\
\hline 4 & EIA company $\mathrm{D}$ & A4 \\
\hline 5 & EIA company E & A5 \\
\hline \multirow[t]{2}{*}{6} & EIA company $\mathrm{F}$ & A6 \\
\hline & 2. Government organisations & B \\
\hline 7 & Government organisation A - senior official 1 & B1 \\
\hline 8 & Government organisation A - senior official 2 & $\mathrm{~B} 2$ \\
\hline 9 & Government organisation A - senior specialist & B3 \\
\hline 10 & Government organisation A - officer & B4 \\
\hline 11 & Government organisation B - senior inspector 1 & B5 \\
\hline 12 & Government organisation B - senior inspector 2 & B6 \\
\hline \multirow[t]{3}{*}{13} & Government organisation $\mathrm{C}-$ officer & B7 \\
\hline & b. Non-experts & \\
\hline & 3. Mining companies & $\mathrm{C}$ \\
\hline 14 & Mongolian mining company A & $\mathrm{C} 1$ \\
\hline 15 & Mongolian mining company B & $\mathrm{C} 2$ \\
\hline \multirow[t]{2}{*}{16} & Foreign mining company A & $\mathrm{C} 3$ \\
\hline & 4. International organisations and projects & D \\
\hline 17 & International donor organisation $\mathrm{A}-$ consultant 1 & D1 \\
\hline 18 & International donor organisation $\mathrm{A}-$ consultant 2 & D2 \\
\hline 19 & International donor organisation A - officer & D3 \\
\hline 20 & International donor organisation B - consultant & D4 \\
\hline 21 & International project A - manager & D5 \\
\hline 22 & Donor NGO - manager & D6 \\
\hline 23 & International project B - manager & D7 \\
\hline 24 & Government project - manager & D8 \\
\hline & 5. Local herders & $\mathbf{E}$ \\
\hline
\end{tabular}




\begin{tabular}{|c|c|c|}
\hline 25 & A herder of Zaamar soum, Tuv aimag & E1 \\
\hline 26 & A Herder of Uyanga soum, Uvurkhangai aimag & E2 \\
\hline \multirow[t]{3}{*}{27} & A herder of Khentii aimag & E3 \\
\hline & 6. NGOs & $\mathbf{F}$ \\
\hline & a. Local people initiated environmental NGOs & \\
\hline 28 & Local environmental NGO A & $\mathrm{F} 1$ \\
\hline 29 & Local environmental NGO B & $\mathrm{F} 2$ \\
\hline 30 & Local environmental NGO C & $\mathrm{F} 3$ \\
\hline 31 & Local environmental NGO D & $\mathrm{F} 4$ \\
\hline 32 & Local environmental NGO E & F5 \\
\hline \multirow[t]{2}{*}{33} & Local environmental NGO F & F6 \\
\hline & $\begin{array}{l}\text { b. Domestic NGOs (responsible mining, human right and other } \\
\text { social issues) }\end{array}$ & \\
\hline 34 & Domestic NGO A & F7 \\
\hline 35 & Domestic NGO B & F8 \\
\hline 36 & Domestic NGO C & F9 \\
\hline 37 & Domestic NGO D & F10 \\
\hline \multirow[t]{2}{*}{38} & Domestic NGO F & F11 \\
\hline & c. $\quad$ NGO coalitions & \\
\hline 39 & NGO coalition A & F12 \\
\hline \multirow[t]{2}{*}{40} & NGO coalition B & F13 \\
\hline & d. Business interest-oriented NGO & \\
\hline \multirow[t]{2}{*}{41} & Professional NGO A & F14 \\
\hline & 7. Researchers & $\mathbf{G}$ \\
\hline 42 & Researcher A & G1 \\
\hline \multirow[t]{2}{*}{43} & Researcher B & $\mathrm{G} 2$ \\
\hline & Total number of interviews & 43 \\
\hline
\end{tabular}

